Cochrane Database of Systematic Reviews

\title{
Interventions to improve hearing aid use in adult auditory rehabilitation (Review)
}

Barker F, Mackenzie E, Elliott L, Jones S, de Lusignan S

Barker F, Mackenzie E, Elliott L, Jones S, de Lusignan S.

Interventions to improve hearing aid use in adult auditory rehabilitation.

Cochrane Database of Systematic Reviews 2016, Issue 8. Art. No.: CD010342.

DOI: 10.1002/14651858.CD010342.pub3.

www.cochranelibrary.com 
TABLE OF CONTENTS

ABSTRAC

PLAIN LANGUAGE SUMMARY

SUMMARY OF FINDINGS

BACKGROUND

OBJECTIVES

METHODS

RESULTS

Figure 1.

Figure 2.

Figure 3.

DISCUSSION

AUTHORS' CONCLUSIONS

ACKNOWLEDGEMENTS

REFERENCES

CHARACTERISTICS OF STUDIES

DATA AND ANALYSES

Analysis 1.1. Comparison 1 Self-management support interventions versus control, Outcome 1 Quality of life - short/mediumterm.

Analysis 1.2. Comparison 1 Self-management support interventions versus control, Outcome 2 Self-reported hearing handicap - short/medium-term.

Analysis 1.3. Comparison 1 Self-management support interventions versus control, Outcome 3 Use of verbal communication strategy - short-term.

Analysis 2.1. Comparison 2 Delivery system design interventions versus control, Outcome 1 Adherence - short/medium-term.

Analysis 2.2. Comparison 2 Delivery system design interventions versus control, Outcome 2 Daily hours of hearing aid use short/medium-term.

Analysis 2.3. Comparison 2 Delivery system design interventions versus control, Outcome 3 Adverse effects - long-term. ........ Analysis 2.4. Comparison 2 Delivery system design interventions versus control, Outcome 4 Self-reported hearing handicap short/medium-term.

Analysis 2.5. Comparison 2 Delivery system design interventions versus control, Outcome 5 Hearing aid benefit - short/mediumterm.

Analysis 2.6. Comparison 2 Delivery system design interventions versus control, Outcome 6 Use of verbal communication strategy.

Analysis 3.1. Comparison 3 Combined SMS/DSD interventions versus control, Outcome 1 Adherence - short/medium-term. ... Analysis 3.2. Comparison 3 Combined SMS/DSD interventions versus control, Outcome 2 Daily hours of hearing aid use - longterm.

Analysis 3.3. Comparison 3 Combined SMS/DSD interventions versus control, Outcome 3 Daily hours of hearing aid use - short/ medium-term - SMS content.

Analysis 3.4. Comparison 3 Combined SMS/DSD interventions versus control, Outcome 4 Daily hours of hearing aid use - short/ medium-term - DSD format.

Analysis 3.5. Comparison 3 Combined SMS/DSD interventions versus control, Outcome 5 Daily hours of hearing aid use - short/ medium-term - DSD intensity.

Analysis 3.6. Comparison 3 Combined SMS/DSD interventions versus control, Outcome 6 Quality of life - long-term. Analysis 3.7. Comparison 3 Combined SMS/DSD interventions versus control, Outcome 7 Quality of life - short/medium-term - SMS content.

Analysis 3.8. Comparison 3 Combined SMS/DSD interventions versus control, Outcome 8 Quality of life - short/medium-term - DSD format.

Analysis 3.9. Comparison 3 Combined SMS/DSD interventions versus control, Outcome 9 Quality of life - short/medium-term - DSD intensity.

Analysis 3.10. Comparison 3 Combined SMS/DSD interventions versus control, Outcome 10 Self-reported hearing handicap long-term.

Analysis 3.11. Comparison 3 Combined SMS/DSD interventions versus control, Outcome 11 Self-reported hearing handicap short/medium-term - SMS content.

Analysis 3.12. Comparison 3 Combined SMS/DSD interventions versus control, Outcome 12 Self-reported hearing handicap short/medium-term - DSD format. 
Analysis 3.13. Comparison 3 Combined SMS/DSD interventions versus control, Outcome 13 Self-reported hearing handicap short/medium-term - DSD intensity.

Analysis 3.14. Comparison 3 Combined SMS/DSD interventions versus control, Outcome 14 Hearing aid benefit - long-term. ..

Analysis 3.15. Comparison 3 Combined SMS/DSD interventions versus control, Outcome 15 Hearing aid benefit - short/mediumterm - SMS content.

Analysis 3.16. Comparison 3 Combined SMS/DSD interventions versus control, Outcome 16 Hearing aid benefit - short/mediumterm - DSD format.

Analysis 3.17. Comparison 3 Combined SMS/DSD interventions versus control, Outcome 17 Hearing aid benefit - short/mediumterm - DSD intensity.

Analysis 3.18. Comparison 3 Combined SMS/DSD interventions versus control, Outcome 18 Use of verbal communication strategy - long-term.

Analysis 3.19. Comparison 3 Combined SMS/DSD interventions versus control, Outcome 19 Use of verbal communication strategy - short/medium-term - SMS content.

Analysis 3.20. Comparison 3 Combined SMS/DSD interventions versus control, Outcome 20 Use of verbal communication strategy - short/medium-term - DSD intensity.

ADDITIONAL TABLES

APPENDICES

FEEDBACK

WHAT'S NEW

HISTORY

CONTRIBUTIONS OF AUTHORS 
[Intervention Review]

\section{Interventions to improve hearing aid use in adult auditory rehabilitation}

Fiona Barker ${ }^{1}$, Emma Mackenzie ${ }^{2}$, Lynette Elliott ${ }^{3}$, Simon Jones ${ }^{4}$, Simon de Lusignan4

1Department of Clinical and Experimental Medicine, University of Surrey, Guildford, UK. ${ }^{2}$ Hearing and Balance Centre, Institute of Sound and Vibration Research, University of Southampton, Southampton, UK. ${ }^{3}$ Audiology, Princess Margaret Hospital, Windsor, UK. 4Department of Healthcare Management and Policy, University of Surrey, Guildford, UK

Contact: Fiona Barker, Department of Clinical and Experimental Medicine, University of Surrey, Guildford, UK. f.barker@surrey.ac.uk.

Editorial group: Cochrane ENT Group.

Publication status and date: Edited (no change to conclusions), published in Issue 11, 2017.

Citation: Barker F, Mackenzie E, Elliott L, Jones S, de Lusignan S. Interventions to improve hearing aid use in adult auditory rehabilitation. Cochrane Database of Systematic Reviews 2016, Issue 8. Art. No.: CD010342. DOI: 10.1002/14651858.CD010342.pub3.

Copyright $\odot 2017$ The Cochrane Collaboration. Published by John Wiley \& Sons, Ltd.

\section{A B S T R A C T}

\section{Background}

Acquired adult-onset hearing loss is a common long-term condition for which the most common intervention is hearing aid fitting. However, up to $40 \%$ of people fitted with a hearing aid either fail to use it or may not gain optimal benefit from it. This is an update of a review first published in The Cochrane Library in 2014.

\section{Objectives}

To assess the long-term effectiveness of interventions to promote the use of hearing aids in adults with acquired hearing loss fitted with at least one hearing aid.

\section{Search methods}

The Cochrane ENT Information Specialist searched the Cochrane ENT Trials Register; Central Register of Controlled Trials (CENTRAL 2016, Issue 5); PubMed; EMBASE; CINAHL; Web of Science; ClinicalTrials.gov; ICTRP and additional sources for published and unpublished trials. The date of the search was 13 June 2016.

\section{Selection criteria}

We included randomised controlled trials (RCTs) of interventions designed to improve or promote hearing aid use in adults with acquired hearing loss compared with usual care or another intervention. We excluded interventions that compared hearing aid technology. We classified interventions according to the 'chronic care model' (CCM). The primary outcomes were hearing aid use (measured as adherence or daily hours of use) and adverse effects (inappropriate advice or clinical practice, or patient complaints). Secondary patient-reported outcomes included quality of life, hearing handicap, hearing aid benefit and communication. Outcomes were measured over the short $(</$ $=12$ weeks), medium ( $>12$ to $<52$ weeks) and long term (one year plus).

\section{Data collection and analysis}

We used the standard methodological procedures expected by Cochrane.

\section{Main results}

We included 37 studies involving a total of 4129 participants. Risk of bias across the included studies was variable. We judged the GRADE quality of evidence to be very low or low for the primary outcomes where data were available.

The majority of participants were over 65 years of age with mild to moderate adult-onset hearing loss. There was a mix of new and experienced hearing aid users. Six of the studies (287 participants) assessed long-term outcomes. 
All 37 studies tested interventions that could be classified using the CCM as self-management support (ways to help someone to manage their hearing loss and hearing aid(s) better by giving information, practice and experience at listening/communicating or by asking people to practise tasks at home) and/or delivery system design interventions (just changing how the service was delivered).

\section{Self-management support interventions}

We found no studies that investigated the effect of these interventions on adherence, adverse effects or hearing aid benefit. Two studies reported daily hours of hearing aid use but we were unable to combine these in a meta-analysis. There was no evidence of a statistically significant effect on quality of life over the medium term. Self-management support reduced short- to medium-term hearing handicap (two studies, 87 participants; mean difference (MD) -12.80, 95\% confidence interval (Cl) -23.11 to -2.48 (0 to 100 scale)) and increased the use of verbal communication strategies in the short to medium term (one study, 52 participants; MD $0.72,95 \% \mathrm{Cl} 0.21$ to 1.23 ( 0 to 5 scale)). The clinical significance of these statistical findings is uncertain. It is likely that the outcomes were clinically significant for some, but not all, participants. Our confidence in the quality of this evidence was very low. No self-management support studies reported long-term outcomes.

\section{Delivery system design interventions}

These interventions did not significantly affect adherence or daily hours of hearing aid use in the short to medium term, or adverse effects in the long term. We found no studies that investigated the effect of these interventions on quality of life. There was no evidence of a statistically or clinically significant effect on hearing handicap, hearing aid benefit or the use of verbal communication strategies in the short to medium term. Our confidence in the quality of this evidence was low or very low. Long-term outcome measurement was rare.

\section{Combined self-management support/delivery system design interventions}

One combined intervention showed evidence of a statistically significant effect on adherence in the short term (one study, 167 participants, risk ratio (RR) $1.06,95 \% \mathrm{Cl} 1.00$ to 1.12 ). However, there was no evidence of a statistically or clinically significant effect on daily hours of hearing aid use over the long term, or the short to medium term. No studies of this type investigated adverse effects. There was no evidence of an effect on quality of life over the long term, or short to medium term. These combined interventions reduced hearing handicap in the short to medium term (14 studies, 681 participants; standardised mean difference (SMD) $-0.26,95 \% \mathrm{Cl}-0.50$ to -0.02 ). This represents a small-moderate effect size but there is no evidence of a statistically significant effect over the long term. There was evidence of a statistically, but not clinically, significant effect on long-term hearing aid benefit (two studies, 69 participants, $\mathrm{MD} 0.30,95 \% \mathrm{Cl} 0.02$ to 0.58 ( 1 to 5 scale)), but no evidence of an effect over the short to medium term. There was evidence of a statistically, but not clinically, significant effect on the use of verbal communication strategies in the short term (four studies, 223 participants, $\mathrm{MD} 0.45,95 \% \mathrm{Cl} 0.15$ to 0.74 ( 0 to 5 scale)), but not the long term. Our confidence in the quality of this evidence was low or very low.

We found no studies that assessed the effect of other CCM interventions (decision support, the clinical information system, community resources or health system changes).

\section{Authors' conclusions}

There is some low to very low quality evidence to support the use of self-management support and complex interventions combining self-management support and delivery system design in adult auditory rehabilitation. However, effect sizes are small. The range of interventions that have been tested is relatively limited. Future research should prioritise: long-term outcome assessment; development of a core outcome set for adult auditory rehabilitation; and study designs and outcome measures that are powered to detect incremental effects of rehabilitative healthcare system changes.

\section{PLAIN LANGUAGE SUMMARY}

\section{Interventions to improve hearing aid use in adult auditory rehabilitation}

\section{Review question}

We wanted to know if any interventions help people to wear their hearing aids more. We measured effects over the short term (less than 12 weeks), medium term (from 12 to 52 weeks) and long term (one year plus). This is an update of a review first published in The Cochrane Library in 2014.

\section{Background}

Hearing loss is very common. People who get hearing loss as adults are often offered a hearing aid(s). However, up to $40 \%$ of people fitted with a hearing aid choose not to use it.

\section{Study characteristics}

The evidence is up to date as of June 2016. We found 37 studies involving a total of 4129 people. Most of the people in the studies were aged over 65. There was a mix of new and experienced hearing aid users. Seven studies funded by the United States Veterans Association 
dominate the evidence. The 1297 people in these studies were serving in the military or military veterans. All but two of the other studies included fewer than 100 people in each study.

\section{Results}

Thirty-three of the 37 studies looked at ways to help someone to manage their hearing loss and hearing aid(s) better by giving information, practice and experience at listening/communicating or by asking people to practise tasks at home. These are forms of self-management support. Most of these studies also changed how the self-management support was provided, for example by changing the number of appointment sessions or using telephone or email follow-up.

Six studies looked at the effect of just changing how the service was delivered. No studies looked at the effect of using guidelines or standards, computerised medical record systems, community resources or changing the health system.

We found no evidence that the interventions helped people to wear their hearing aids for more hours per day over the short, medium or long term. One study that used interactive videos to give information after hearing aid fitting encouraged more people to wear their hearing aids.

We found no evidence of adverse effects of any of the interventions, but it was rare for studies to look for adverse effects.

Giving self-management support meant that people reported less hearing handicap and improved verbal communication over the short term. When this was combined with changing how the support was delivered people also reported slightly more hearing aid benefit over the long term.

Only six studies (287 people) looked at how people were doing after a year or more.

\section{Conclusions}

Complex interventions that deliver self-management support in different ways improve some outcomes for some people with hearing loss who use hearing aids. We found no interventions that increased self-reported daily hours of hearing aid use. Few studies measured how many people use hearing aids compared to how many are fitted (adherence). Many things that might increase daily hours of hearing aid use or encourage more people to wear the hearing aids they have been fitted with have not been tested. It was difficult to combine data across different studies because many outcome measures were used and results were not always fully reported. In future it would be helpful if researchers:

- used existing guidelines for presenting their results;

- agreed a set of outcome measures for use in this type of study; and

- focused on long-term outcomes where people are followed up for at least a year.

\section{Quality of the evidence}

We judged the evidence to be of very low or low quality. There was risk of bias in the way many of the studies were carried out or reported. The largest studies included only military veterans. We do not know whether studies would find the same results in more mixed populations. Most of the other studies had small sample sizes. Very few studies measured long-term outcomes. 
SUMMARY OF FINDINGS

Summary of findings for the main comparison. Self-management support interventions for adults with hearing loss who use hearing aids

Self-management support interventions for adults with hearing loss who use hearing aids

Patient or population: adults with hearing loss who use hearing aids

Settings: outpatient clinic

Intervention: self-management support interventions

\begin{tabular}{|c|c|c|c|c|c|c|}
\hline \multirow[t]{3}{*}{ Outcomes } & \multicolumn{2}{|c|}{ Illustrative comparative risks* $(95 \% \mathrm{Cl})$} & \multirow{3}{*}{$\begin{array}{l}\text { Relative effect } \\
(95 \% \mathrm{CI})\end{array}$} & \multirow{3}{*}{$\begin{array}{l}\text { No of partici- } \\
\text { pants } \\
\text { (studies) }\end{array}$} & \multirow{3}{*}{$\begin{array}{l}\text { Quality of the } \\
\text { evidence } \\
\text { (GRADE) }\end{array}$} & \multirow[t]{3}{*}{ Comments } \\
\hline & Assumed risk & Corresponding risk & & & & \\
\hline & Control & $\begin{array}{l}\text { Self-management sup- } \\
\text { port interventions }\end{array}$ & & & & \\
\hline Adherence & \multicolumn{6}{|c|}{ No studies identified } \\
\hline Daily hours of hearing aid use & \multicolumn{6}{|c|}{ Two studies reported daily hours of hearing aid use but we were unable to combine these in a meta-analysis } \\
\hline Adverse effects & \multicolumn{6}{|c|}{ No studies identified } \\
\hline $\begin{array}{l}\text { Quality of life } \\
\text { Validated self-report measures. } \\
\text { WHODAS } 2.0 \text { scale from: } 0 \text { to } \\
100 \\
\text { Follow-up: } 0 \text { to } 12 \text { months }\end{array}$ & \multicolumn{2}{|c|}{$\begin{array}{l}\text { The mean quality of life in the intervention group } \\
\text { was } 9.1 \text { lower ( } 21.33 \text { lower to } 3.13 \text { higher) than in } \\
\text { the control group (on this generic health-related } \\
\text { quality of life scale (WHODAS } 2.0 \text { ) a lower score indi- } \\
\text { cates better quality of life) }\end{array}$} & - & $\begin{array}{l}35 \\
\text { (1 study) }\end{array}$ & $\begin{array}{l}\oplus \ominus \ominus \ominus \\
\text { very low } 1\end{array}$ & $\begin{array}{l}\text { The minimal impor- } \\
\text { tant difference on this } \\
\text { scale has not been es- } \\
\text { tablished for hearing } \\
\text { health care. }\end{array}$ \\
\hline $\begin{array}{l}\text { Self-reported hearing handi- } \\
\text { cap } \\
\text { Validated self-report measure: } \\
\text { HHIE (Ventry 1982) scale from } 0 \\
\text { to } 100 \\
\text { Follow-up: } 0 \text { to } 12 \text { months }\end{array}$ & \multicolumn{2}{|c|}{$\begin{array}{l}\text { The mean self-reported hearing handicap in the in- } \\
\text { tervention groups was } \mathbf{1 2 . 8 0} \text { lower ( } 23.11 \text { lower to } \\
2.48 \text { lower) than in the control groups (lower score } \\
\text { indicates less handicap) }\end{array}$} & - & $\begin{array}{l}87 \\
\text { (2 studies) }\end{array}$ & $\begin{array}{l}\oplus \ominus \ominus \ominus \\
\text { very low } 2\end{array}$ & $\begin{array}{l}\text { The minimal impor- } \\
\text { tant difference on this } \\
\text { scale is reported to be } \\
18.7 \text { for face-to face } \\
\text { administration and } 36 \\
\text { for pencil and paper } \\
\text { (Weinstein 1986). }\end{array}$ \\
\hline Hearing aid benefit & \multicolumn{6}{|c|}{ No studies identified } \\
\hline $\begin{array}{l}\text { Communication } \\
\text { Validated self-report measure: } \\
\text { verbal subscale of the CPHI (De- } \\
\text { morest 1987) scale from } 0 \text { to } 5\end{array}$ & \multicolumn{2}{|c|}{$\begin{array}{l}\text { The mean reported use of verbal communication } \\
\text { strategy in the intervention group was } \mathbf{0 . 7 2} \text { higher } \\
\text { ( } 0.21 \text { higher to } 1.23 \text { higher) than in the control group } \\
\text { (higher score indicates increased use of verbal com- } \\
\text { munication strategy) }\end{array}$} & - & 52 & $\begin{array}{l}\oplus \ominus \ominus \ominus \\
\text { very low } 3\end{array}$ & $\begin{array}{l}\text { The minimal impor- } \\
\text { tant difference for this } \\
\text { subscale of the CPHI } \\
\text { is } 0.93 \text { at the } 0.05 \text { level } \\
\text { (Demorest 1988). }\end{array}$ \\
\hline
\end{tabular}

munication strategy)

(Demorest 1988). 
*The basis for the assumed risk (e.g. the median control group risk across studies) is provided in footnotes. The corresponding risk (and its $95 \%$ confidence interval) is based on the assumed risk in the comparison group and the relative effect of the intervention (and its $95 \% \mathrm{Cl}$ ).

CI: confidence interval; CPHI: Communication Profile for the Hearing Impaired; RR: risk ratio; WHODAS 2.0: World Health Organization Disability Assessment Schedule 2.0

GRADE Working Group grades of evidence

High quality: Further research is very unlikely to change our confidence in the estimate of effect.

Moderate quality: Further research is likely to have an important impact on our confidence in the estimate of effect and may change the estimate.

Low quality: Further research is very likely to have an important impact on our confidence in the estimate of effect and is likely to change the estimate.

Very low quality: We are very uncertain about the estimate.

1Downgraded due to very serious concerns regarding limitations in study design (risk of bias), indirectness (participants were military veterans and only short- to medium-term outcomes were available) and serious concerns regarding imprecision (single study with small sample size).

2Downgraded due to very serious concerns regarding limitations in study design (risk of bias) and serious concerns due to indirectness (only short- to medium-term outcomes available) and imprecision (two small studies with a high risk of skewed data).

3Downgraded due to very serious concerns regarding limitations in study design (risk of bias) and serious concerns due to indirectness (only short- to medium-term outcomes available) and imprecision (single study with small sample size).

\section{Summary of findings 2. Delivery system design interventions for adults with hearing loss who use hearing aids}

Delivery system design interventions for adults with hearing loss who use hearing aids

Patient or population: adults with hearing loss who use hearing aids

Settings: outpatient clinic

Intervention: delivery system design interventions

\begin{tabular}{|c|c|c|c|c|c|c|}
\hline \multirow[t]{3}{*}{ Outcomes } & \multicolumn{2}{|c|}{ Illustrative comparative risks ${ }^{\star}(95 \% \mathrm{Cl})$} & \multirow{3}{*}{$\begin{array}{l}\text { Relative effect } \\
(95 \% \mathrm{CI})\end{array}$} & \multirow{3}{*}{$\begin{array}{l}\text { No of partici- } \\
\text { pants } \\
\text { (studies) }\end{array}$} & \multirow{3}{*}{$\begin{array}{l}\text { Quality of the } \\
\text { evidence } \\
\text { (GRADE) }\end{array}$} & \multirow[t]{3}{*}{ Comment } \\
\hline & Assumed risk & Corresponding risk & & & & \\
\hline & Control & $\begin{array}{l}\text { Delivery system design } \\
\text { interventions }\end{array}$ & & & & \\
\hline $\begin{array}{l}\text { Adherence } \\
\text { Number of people fitted with } \\
\text { hearing aid/number of people } \\
\text { who use the aids } \\
\text { Follow-up: } 0 \text { to } 12 \text { months }\end{array}$ & 948 per 1000 & $\begin{array}{l}967 \text { per } 1000 \\
\text { (938 to } 995)\end{array}$ & $\begin{array}{l}\text { RR } 1.02 \\
(0.99 \text { to } 1.05)\end{array}$ & $\begin{array}{l}686 \\
\text { (2 studies) }\end{array}$ & $\begin{array}{l}\oplus \oplus \ominus \ominus \\
\text { low } 1\end{array}$ & - \\
\hline $\begin{array}{l}\text { Daily hours of hearing aid } \\
\text { use }\end{array}$ & \multicolumn{2}{|c|}{$\begin{array}{l}\text { The mean daily hours of hearing aid use in the in- } \\
\text { tervention groups was } 0.06 \text { lower }\end{array}$} & - & $\begin{array}{l}700 \\
\text { (4 studies) }\end{array}$ & $\begin{array}{l}\oplus \odot \odot \ominus \\
\text { very low } 2\end{array}$ & $\begin{array}{l}\text { Participant } \\
\text { vention gro } \\
\text { hearing aid }\end{array}$ \\
\hline
\end{tabular}


Average self-reported or data-logged hours of use per day. Scale from: 0 to 12 hours Follow-up: 0 to 12 month
(1.06 lower to 0.95 higher) than in the control groups. On average the intervention groups used their hearing aids for under a minute per day less than the control groups utes less each day on average than those in the control group. This is not a clinically significant difference

$\begin{array}{lllllll}\begin{array}{l}\text { Adverse effects } \\ \text { Number of outstanding com- }\end{array} & \mathbf{5 7 1} \text { per } \mathbf{1 0 0 0} & \begin{array}{l}\mathbf{4 2 9} \text { per } \mathbf{1 0 0 0} \\ (286 \text { to } 640)\end{array} & \begin{array}{l}\text { RR } \mathbf{0 . 7 5} \\ (0.5 \text { to } 1.12)\end{array} & \begin{array}{l}98 \\ (1 \text { study) }\end{array} & \begin{array}{l}\oplus \odot \odot \odot \\ \text { very low } 3\end{array}\end{array}$

plaints

Follow-up: 1+ years

\section{Quality of life}

No studies identified

Self-reported hearing hand-

icap

Validated self-report mea-

sure HHIE scale from: 0 to 100

(Ventry 1982)

Follow-up: 0 to 12 months

\section{Hearing aid benefit}

Validated self-report mea-

sure. Outer EAR scale from:

to 100

Follow-up: mean 6 months

The mean self-reported hearing handicap in the intervention groups was $\mathbf{0 . 7}$ lower $\mathbf{5 . 2 2}$ lower to 3.81 higher) than in the control groups (on this scale from 0 to 100 , a lower score indicates less hearing handicap)

0.5 to 1.12

(1 study)

very low

$-$

$\oplus \odot \ominus \ominus$ very low 4

The minimal important difference on this scale is reported to be 18.7 for face-to-face administration and 36 for pencil and paper (Weinstein 1986)

\begin{tabular}{|c|c|c|c|c|}
\hline $\begin{array}{l}\text { The mean hearing aid benefit in the intervention } \\
\text { group was } 1.8 \text { higher ( } 3.1 \text { lower to } 6.7 \text { higher) than } \\
\text { in the control group (on this scale from } 0 \text { to } 100 \text {, a } \\
\text { higher score indicates more hearing aid benefit) }\end{array}$ & - & $\begin{array}{l}582 \\
\text { (1 study) }\end{array}$ & $\begin{array}{l}\oplus \odot \odot \ominus \\
\text { very low } 4\end{array}$ & $\begin{array}{l}\text { While we were unable to } \\
\text { reference a minimal im- } \\
\text { portant difference for this } \\
\text { scale, a mean difference } \\
\text { of } 1.8 \text { on a scale from } 0 \text { to } \\
100 \text { is unlikely to be a clin- } \\
\text { ically significant change }\end{array}$ \\
\hline $\begin{array}{l}\text { The mean reported use of verbal communication } \\
\text { strategy in the intervention group was } \mathbf{0 . 1 0} \text { high- } \\
\text { er ( } 0.40 \text { lower to } 0.20 \text { higher) than in the control } \\
\text { group (higher score indicates increased use of ver- } \\
\text { bal communication strategy) }\end{array}$ & - & $\begin{array}{l}588 \\
\text { (1 study) }\end{array}$ & $\begin{array}{l}\oplus \odot \odot \ominus \\
\text { very low } 5\end{array}$ & $\begin{array}{l}\text { The minimal important } \\
\text { difference for this sub- } \\
\text { scale of the CPHI is } 0.93 \text { at } \\
\text { the } 0.05 \text { level (Demorest } \\
\text { 1988) }\end{array}$ \\
\hline
\end{tabular}
sure: verbal subscale of the $\mathrm{CPHI}$ scale from 0 to 5 (Demorest 1987)

bal communication strategy)

Follow-up: 0 to 12 months

*The basis for the assumed risk (e.g. the median control group risk across studies) is provided in footnotes. The corresponding risk (and its $95 \%$ confidence interval) is based on the assumed risk in the comparison group and the relative effect of the intervention (and its $95 \% \mathrm{Cl}$ ).

CI: confidence interval; CPHI: Communication Profile for the Hearing Impaired; HHIE: Hearing Handicap Inventory for the Elderly; RR: risk ratio

GRADE Working Group grades of evidence

High quality: Further research is very unlikely to change our confidence in the estimate of effect.

Moderate quality: Further research is likely to have an important impact on our confidence in the estimate of effect and may change the estimate.

Low quality: Further research is very likely to have an important impact on our confidence in the estimate of effect and is likely to change the estimate.

Very low quality: We are very uncertain about the estimate. 
1Downgraded due to very serious concerns regarding indirectness of the evidence (only short- to medium-term evidence and the majority of the participants were military veterans).

2Downgraded due to very serious concerns regarding indirectness (short- to medium-term data and military veteran participants) and serious concerns about limitations in study design (unclear risk of bias) and imprecision (standard deviations imputed in the largest study).

${ }^{3}$ Downgraded due to very serious concerns regarding indirectness (short- to medium-term data and military veteran participants) and serious concerns regarding limitations in study design (unclear risk of bias) and imprecision (small sample size, wide Cls).

${ }^{4}$ Downgraded due to very serious concerns regarding indirectness (short- to medium-term data and military veteran participants) and serious concerns about imprecision (standard deviations imputed).

${ }^{5}$ Downgraded due to very serious concerns regarding indirectness (short- to medium-term outcomes, military veteran participants and the lack of a global communication outcome measure) and serious concerns about imprecision (standard deviations imputed).

Summary of findings 3. Combined self-management support/delivery system design interventions for adults with hearing loss who use hearing aids

Combined self-management support/delivery system design interventions for adults with hearing loss who use hearing aids

Patient or population: adults with hearing loss who use hearing aids

Settings: outpatient clinic

Intervention: combined self-management support/delivery system design interventions

\begin{tabular}{|c|c|c|c|c|c|c|}
\hline \multirow[t]{3}{*}{ Outcomes } & \multicolumn{2}{|c|}{ Illustrative comparative risks* $(95 \% \mathrm{Cl})$} & \multirow{3}{*}{$\begin{array}{l}\text { Relative effect } \\
(95 \% \mathrm{CI})\end{array}$} & \multirow{3}{*}{$\begin{array}{l}\text { No of partici- } \\
\text { pants } \\
\text { (studies) }\end{array}$} & \multirow{3}{*}{$\begin{array}{l}\text { Quality of the } \\
\text { evidence } \\
\text { (GRADE) }\end{array}$} & \multirow[t]{3}{*}{ Comments } \\
\hline & Assumed risk & Corresponding risk & & & & \\
\hline & Control & $\begin{array}{l}\text { Combined SMS/DSD } \\
\text { interventions }\end{array}$ & & & & \\
\hline $\begin{array}{l}\text { Adherence } \\
\text { Number of people fitted } \\
\text { with hearing aid/number of } \\
\text { people who use the aids } \\
\text { Follow-up: } 5 \text { to } 8 \text { weeks }\end{array}$ & 943 per 1000 & $\begin{array}{l}\mathbf{1 0 0 0} \text { per } 1000 \\
(943 \text { to } 1000)\end{array}$ & $\begin{array}{l}\text { RR } 1.06 \\
\text { (1 to } 1.12)\end{array}$ & $\begin{array}{l}162 \\
\text { (1 study) }\end{array}$ & $\begin{array}{l}\oplus \oplus \odot \ominus \\
\text { low } 1\end{array}$ & - \\
\hline $\begin{array}{l}\text { Daily hours of hearing aid } \\
\text { use } \\
\text { Self-reported or da- } \\
\text { ta-logged average hours of } \\
\text { use per day. Scale from: } 0 \text { to } \\
12 \text { hours } \\
\text { Follow-up: } 1+\text { years }\end{array}$ & \multicolumn{2}{|c|}{$\begin{array}{l}\text { The mean daily hours of hearing aid use in } \\
\text { the intervention groups was } \mathbf{0 . 0 4} \text { higher } \\
\text { ( } 0.64 \text { lower to } 0.73 \text { higher) than in the con- } \\
\text { trol groups }\end{array}$} & - & $\begin{array}{l}69 \\
\text { ( } 2 \text { studies) }\end{array}$ & $\begin{array}{l}\oplus \ominus \ominus \ominus \\
\text { very low } 2\end{array}$ & $\begin{array}{l}\text { Participants in the intervention } \\
\text { groups wore their hearing aids for } \\
2 \text { to } 3 \text { minutes more per day than } \\
\text { those in the control group. This is } \\
\text { not a clinically significant differ- } \\
\text { ence. }\end{array}$ \\
\hline Adverse effects & \multicolumn{6}{|c|}{ No studies identified } \\
\hline
\end{tabular}




\begin{tabular}{|c|c|c|c|c|c|}
\hline $\begin{array}{l}\text { Quality of life } \\
\text { Validated self-report mea- } \\
\text { sures. IOI-HA item } 7 \text { scale } \\
\text { from: } 1 \text { to } 5 \\
\text { Follow-up: } 1 \text { + years }\end{array}$ & $\begin{array}{l}\text { The mean quality of life in the intervention } \\
\text { groups was } \\
\mathbf{0 . 3 2} \text { higher ( } 0.17 \text { lower to } 0.8 \text { higher) than } \\
\text { in the control groups, measured on item } 7 \\
\text { of the IOI-HA (Cox 2002) }\end{array}$ & - & $\begin{array}{l}69 \\
\text { (2 studies) }\end{array}$ & $\begin{array}{l}\oplus \oplus \ominus \ominus \\
\text { low } 3\end{array}$ & $\begin{array}{l}\text { The minimally important differ- } \\
\text { ence for this subscale of the IOI-HA } \\
\text { is } 0.32 \text { for those with mild-moder- } \\
\text { ate hearing loss and } 0.28 \text { for those } \\
\text { with moderate-severe hearing loss } \\
\text { (Smith 2009). }\end{array}$ \\
\hline $\begin{array}{l}\text { Self-reported hearing } \\
\text { handicap } \\
\text { Validated self-report mea- } \\
\text { sures } \\
\text { Follow-up: } 1+\text { years }\end{array}$ & $\begin{array}{l}\text { The mean self-reported hearing handicap in } \\
\text { the intervention groups was } \mathbf{0 . 3 1} \text { standard } \\
\text { deviations lower (1.06 lower to } 0.44 \text { higher) } \\
\text { than in the control groups }\end{array}$ & - & $\begin{array}{l}88 \\
\text { (3 studies) }\end{array}$ & $\begin{array}{l}\oplus \odot \odot \ominus \\
\text { very low } 4\end{array}$ & $\begin{array}{l}\text { Using the classification suggested } \\
\text { by Cohen } 1988 \text { a SMD of } 0.31 \text { repre- } \\
\text { sents a moderate effect size. }\end{array}$ \\
\hline $\begin{array}{l}\text { Hearing aid benefit } \\
\text { Validated self-report mea- } \\
\text { sures (IOI-HA item 4). Scale } \\
\text { from: } 1 \text { to } 5 \\
\text { Follow-up: } 1+\text { years }\end{array}$ & $\begin{array}{l}\text { The mean hearing aid benefit in the inter- } \\
\text { vention groups was } 0.3 \text { higher ( } 0.02 \text { to } 0.58 \\
\text { higher) than in the control groups, mea- } \\
\text { sured on item } 4 \text { of the IOI-HA (Cox 2002) }\end{array}$ & - & $\begin{array}{l}69 \\
\text { (2 studies) }\end{array}$ & $\begin{array}{l}\oplus \oplus \ominus \ominus \\
\text { low } 3\end{array}$ & $\begin{array}{l}\text { This is a statistically significant dif- } \\
\text { ference. However, the minimal- } \\
\text { ly important difference for this } \\
\text { subscale of the IOI-HA is } 0.39 \text { for } \\
\text { those with mild-moderate hearing } \\
\text { loss and } 0.32 \text { for those with mod- } \\
\text { erate-severe hearing loss (Smith } \\
\text { 2009), so this does not represent a } \\
\text { clinically important difference. }\end{array}$ \\
\hline $\begin{array}{l}\text { Use of verbal communica- } \\
\text { tion strategy } \\
\text { Validated self-report mea- } \\
\text { sures (verbal subscale of } \\
\text { the CPHI (Demorest 1987)). } \\
\text { Scale from: } 0 \text { to } 5 \\
\text { Follow-up: } 1+\text { years }\end{array}$ & $\begin{array}{l}\text { The mean use of verbal communication } \\
\text { strategy in the intervention groups was } 0.3 \\
\text { higher ( } 0.2 \text { lower to } 0.8 \text { higher) than in the } \\
\text { control groups }\end{array}$ & - & $\begin{array}{l}34 \\
\text { (1 study) }\end{array}$ & $\begin{array}{l}\oplus \ominus \ominus \ominus \\
\text { very low } 5\end{array}$ & $\begin{array}{l}\text { The minimal important difference } \\
\text { for this subscale of the CPHI is } 0.93 \\
\text { at the } 0.05 \text { level (Demorest 1988). }\end{array}$ \\
\hline
\end{tabular}

*The basis for the assumed risk (e.g. the median control group risk across studies) is provided in footnotes. The corresponding risk (and its $95 \%$ confidence interval) is based on the assumed risk in the comparison group and the relative effect of the intervention (and its $95 \% \mathrm{Cl}$ ).

Cl: confidence interval; CPHI: Communication Profile for the Hearing Impaired; DSD: delivery system design; IOI-HA: International Outcome Inventory for Hearing Aids; RR: risk ratio; SMD: standardised mean difference; SMS: self-management support

GRADE Working Group grades of evidence

High quality: Further research is very unlikely to change our confidence in the estimate of effect.

Moderate quality: Further research is likely to have an important impact on our confidence in the estimate of effect and may change the estimate.

Low quality: Further research is very likely to have an important impact on our confidence in the estimate of effect and is likely to change the estimate.

Very low quality: We are very uncertain about the estimate.

1Downgraded due to concerns regarding consistency (single study) and indirectness of the evidence (short-term evidence only).

2Downgraded due to very serious concerns regarding imprecision (small sample size) and serious concerns regarding inconsistency (heterogeneity). 
Draded due to very serious concerns regarding imprecision (small sample size).

4Downgraded due to very serious concerns regarding imprecision (small sample size, risk of skewed data in two of the studies) and serious concerns regarding limitations in study design (high risk of bias in one study) and inconsistency (heterogeneity).

5Downgraded due to very serious concerns regarding imprecision (small sample size) and indirectness (lack of a global measure of communication, participants were all firsttime hearing aid users, we do not know whether equivalent benefit could be gained in people already fitted with hearing aids). 


\section{B A C K G R O U N D}

This is an update of a review first published in The Cochrane Library in 2014.

\section{Description of the condition}

Adult acquired hearing loss is a common long-term condition, which in the majority of cases is not remediable by surgical or medical intervention. It ranks 15th amongst the leading causes of global burden of disease and is the second leading cause of 'years lived with a disability' (WHO 2012). The prevalence of hearing loss increases with age, which has serious implications in a global population in which the proportion of elderly people is rising at unprecedented rates according to the World Health Organization (WHO 2011). The standard intervention for hearing loss, at least in the developed world, usually involves the provision of monaural or binaural hearing aids within an audiology clinic (Cox 2014). Despite the evidence of the negative consequences of hearing loss (Brooks 2001; Hallberg 1993; Lin 2011; Saito 2010), and the benefits of hearing aids (Bainbridge 2014; Chisolm 2007; Mulrow 1992; National Council on Aging 2000; Swan 2012), uptake of fitting is relatively low, even in countries where the provision of hearing aids is free at the point of use. In addition, results from studies on use and non-use of hearing aids support the finding that a proportion of those being prescribed a hearing aid do not use it. Estimates of non-use vary from 5\% to $40 \%$ (Gimsing 2008; Lupsakko 2005; Smeeth 2002; Sorri 1984; Vuorialho 2006), and this is supported by commercial survey data from hearing aid dispensers (Hougaard 2011; Kochkin 2009). Some studies have highlighted poor sound quality or lack of perceived benefit as one of the reasons for nonuse (Brooks 1985; Lupsakko 2005; Smeeth 2002), and it is likely that developments in sound processing technology have had an effect over time, such as the move from analogue to digital sound processing. The more recent studies tend to show higher levels of use but there is still room for improvement. Recent evidence suggests that increased cost does not necessarily improve outcome over and above that gained from more cost-effective options (Cox 2014). In addition, there is a reliable placebo effect when assessing different hearing aid technologies, which may have an impact on the results of unblinded studies (Dawes 2013). There are no data on rates of use in developing countries where access to hearing aid technology presents more of a challenge, although reasons for non-use are starting to be investigated in less well-resourced populations (Borg 2015).

\section{Description of the intervention}

This review considered any healthcare interventions aimed at improving or promoting the use of hearing aids in the context of acquired adult hearing loss. To provide a structure for this analysis we chose to classify interventions based on the chronic care model (CCM) (Bodenheimer 2002). This is a framework used to develop and describe initiatives in the care of long-term conditions. Adult acquired hearing loss fits the World Health Organization definition of a long-term condition in that it is a health problem that requires ongoing management over a period of years or decades (WHO 2002). We chose the CCM because it is widely cited, has been used in a variety of healthcare settings and its implementation has been associated with improved outcomes (DH 2007; NHS 2006; Tsai 2005). It has also been used as a framework in previous reviews looking at the effects of interventions in the context of long-term conditions (Kreindler 2009; Tsai 2005).
We therefore hoped that this review would provide information on interventions and outcomes in the context of hearing loss as a longterm condition.

We classified potential interventions according to the six elements of the CCM as follows:

\section{Self-management support interventions}

Self-management support is at the heart of the CCM and other frameworks used in the context of long-term conditions. For chronic conditions such as hearing loss, patients themselves take on the primary responsibility for managing their condition. These are interventions that seek to empower and prepare patients to manage their own health and health care. They emphasise the patient's central role in managing their health. Self-management support involves collaborating with patients and their families to help them develop the skills and confidence they need to do this effectively. In their review of self-management approaches for people with long-term conditions, Barlow and colleagues state that "self-management refers to the individual's ability to manage the symptoms, treatment, physical and psychosocial consequences and life-style changes inherent in living with a chronic condition" (Barlow 2002). Self-management is a complex task.

The provision of self-management support might therefore include:

- self-management assessment - assessment of the impact of hearing loss, the difficulties it is causing and facilitators and barriers to potential solutions;

- patient education;

- patient activation - interventions that involve practice of the behaviour changes needed to develop practical, symptom and psychosocial management skills;

- self-management resources and tools - battery replacement services, provision of additional equipment to improve hearing aid benefit;

- collaborative decision-making (Tsai 2005).

These processes align to the Assess, Advise, Assist and Agree components of the 5As model of health behaviour change (Whitlock 2002). These have been applied previously in the context of longterm condition self-management (Glasgow 2003).

\section{Delivery system design interventions}

These interventions involve the introduction of systems to assure the delivery of efficient, effective care and self-management support. Kreindler 2009 and Tsai 2005 describe how this includes interventions that:

- reshape healthcare provider roles - for example, introducing the role of case manager or defining roles within a multi-disciplinary team;

- reorganise the scheduling or organisation of care - changes in care delivery, the provision of follow-up or planned visits, visit system change.

Delivery system design interventions involve changes in the mode (for example, group versus individual), format (face-to-face, online, booklet etc.), timing or follow-up pattern and location of delivery of self-management support rather than the content of the support 
itself. This category would include interventions such as group counselling and group rehabilitation, providing the same content is delivered in the same way to the intervention and control group. It will also include interventions where changes have been made to the post-fitting follow-up process in terms of timing, quantity, location, mode or format of delivery. The 'arrange followup' component of the $5 \mathrm{As}$ model would fit within this element.

In reality it is likely that many interventions will contain an element of self-management support and delivery system design because in order to provide self-management support some changes in delivery system design are likely to be needed (Tsai 2005).

\section{Decision support interventions}

Decision support interventions promote clinical care that is consistent with scientific evidence and patient preferences. They embed evidence-based guidelines into daily clinical practice and provide mechanisms to share evidence-based guidelines and information with patients to encourage their participation. They may involve the use of proven provider education methods or seek to integrate specialist expertise and primary care.

\section{Clinical information system interventions}

Interventions involving clinical information systems, generally computerised medical records systems, aim to organise patient and population data to facilitate care, provide timely reminders for providers and patients, identify relevant subpopulations for proactive care, facilitate individual care planning, share information with patients and providers to co-ordinate care, and monitor performance of the practice team and care system as a whole. For example, in audiology this might include the introduction of electronic patient records that facilitate the development of individual management plans or identify patients in need of routine review or follow-up.

\section{Community interventions}

Interventions falling into this category include those that mobilise community resources to meet the needs of patients, encourage patients to participate in community-based programmes or where partnerships have been formed with community organisations to support and develop interventions that fill gaps in services or advocate for policies to improve patient care. In audiology this might include partnerships with local deaf clubs or community volunteers who visit patients in their own homes.

\section{Health system interventions}

Health system interventions seek to create a culture, organisation and mechanisms to promote safe, high-quality care or visibly support improvement at all levels of the organisation, beginning with the senior leader. They may involve the introduction of policies that encourage open and systematic handling of quality problems or provide incentives based on quality of care. Health system interventions may also seek to develop agreements that facilitate care co-ordination within and across organisations. Examples from hearing health care would include the introduction of the Improving Quality in Physiological Diagnostic Services (IQIPS) programme.

See Column 1, Table 1.
We recognise that within each of these elements there will be clinical diversity in the type of intervention delivered and we therefore planned to investigate this diversity with subgroup analyses where appropriate. However, we felt it would of interest to policy-makers to know the relative effects of different interventions grouped by element so that they can make an informed judgement about whether it is more cost-effective to make changes in intervention content (e.g. self-management support), how that content is delivered (delivery system design) or in how delivery is supported (decision support, clinical information system).

\section{How the intervention might work}

\section{Self-management support interventions}

These interventions act directly to promote behaviour change on the part of the patient. The behaviour change of primary interest in this review is increased hearing aid use. This might be achieved through:

- improving knowledge (advice);

- practising new skills - practical, symptom management and psychosocial management skills (assist through activation/ engagement);

- providing self-management resources and tools (assist through resource provision);

- collaborating in decision-making (agree).

We recognised that these subtypes of self-management support may have an impact on behaviour to different extents and we explored this further with subgroup analyses (see Subgroup analysis and investigation of heterogeneity).

\section{Delivery system design interventions}

Delivery system design interventions work by making changes in the system to facilitate the delivery of self-management support through:

- reorganisation of staff roles;

- restructuring of care delivery.

In terms of clinical outcomes for patients, delivery system design interventions therefore have a less direct mode of action than selfmanagement support interventions. They do not act directly to change patient behaviour but facilitate the delivery of interventions that do.

\section{Decision support interventions}

Decision support interventions work by promoting behaviour change on the part of the clinician. Again these have an indirect impact on patient behaviour. They work by providing the clinician with the knowledge and skills they need to provide selfmanagement support as effectively as possible.

\section{Clinical information system interventions}

Again these have an indirect action on patient behaviour. These interventions work by using organising data to facilitate effective self-management support.

\section{Community interventions}

These interventions work by using resources within the wider community either by supporting the patient directly or by helping 
the health system function so that self-management support can be provided more effectively.

\section{Health system interventions}

How health system interventions work is complex, context-specific and less easy to quantify (Kreindler 2009). Tsai 2005 also noted that health system interventions are difficult to manipulate empirically and that evidence is hard to find across the spectrum of long-term conditions.

Since the action and implementation of community and health system interventions cross the boundary between the direct healthcare patient-provider environment into the wider healthcare system and policy environment, we did not plan to carry out a detailed meta-analysis of effects for these two elements. Instead we documented whether any studies tested this type of intervention.

\section{Why it is important to do this review}

Researchers have argued that the negative consequences of hearing loss make a strong argument for early, effective hearing aid fitting (Arlinger 2003). Interventions that improve rates of hearing aid use should have an impact on such negative psychosocial consequences, both on an individual level and across the population with hearing loss who have been fitted with hearing aids

In addition, if uptake of hearing aids is increased by the use of screening or education programmes (Davis 2007; Thodi 2013), then it is important that subsequent hearing aid fitting is as effective as possible. There are also economic implications of non-use, both for national funding bodies and on an individual level for those purchasing their own hearing aids.

This review does not aim to compare the effects of contextspecific interventions (e.g. auditory training, communication training) or modes of delivery (e.g. group versus individual interventions). However, adult hearing loss is an under-researched, under-theorised field. Hence we have employed a framework from the wider field of long-term conditions research and service development. We hope that this framework will provide information about high-level intervention types such as those that act directly to support patient behaviour change and those that seek to influence patient behaviour in less direct ways. However we also hope to provide another level of detail using subgroup analyses for those stakeholders interested in, for example, subtypes of self-management support. We hope that by structuring the review in this way we will be able to encourage new research directions and highlight gaps in the evidence base.

\section{O B J E C T IVES}

To assess the long-term effectiveness of interventions to promote the use of hearing aids in adults with acquired hearing loss fitted with at least one hearing aid.

\section{METHODS}

\section{Criteria for considering studies for this review}

\section{Types of studies}

We included randomised controlled trials (RCTs) that fulfilled the inclusion criteria. We included quasi-randomised trials such as those allocating by an arbitrary but not truly random process (e.g. day of the week) and cluster-randomised trials.

\section{Types of participants}

Adults with hearing loss greater than $25 \mathrm{~dB}$ hearing level $(\mathrm{HL})$ in the better ear averaged across four frequencies $(0.5 \mathrm{kHz}, 1 \mathrm{kHz}, 2 \mathrm{kHz}$ and $4 \mathrm{kHz}$ ) who were fitted with a hearing aid for at least one ear. This is consistent with World Health Organization criteria for the definition of hearing loss (WHO 2000), and includes those with mild, moderate, severe and profound losses. Studies on the acceptability and benefit of hearing screening sometimes set different criteria for what constitutes a significant hearing loss (e.g. Davis 2007). These are generally more conservative and so would be included under the definition given above. Where trials did not give details of hearing levels for participants we assumed that those fitted with a hearing aid would have met these criteria. For the purposes of this review we considered adults to be aged 18 years and over. Trials that included participants under the age of 18 were included if the data for adults could be accessed separately by contacting the authors where it was not obvious from the trial data. We included adults with sensorineural, conductive and mixed hearing losses. We excluded trials that included participants using implantable devices such as bone-anchored hearing aids or cochlear implants.

\section{Types of interventions}

This review considered any healthcare interventions, classified according to the chronic care model (CCM), intended to increase the use of hearing aids. We excluded studies that tested or compared developments in hearing aid technology (see Description of the intervention).

\section{Comparisons}

- Self-management support interventions versus alternative interventions that control for other elements delivery method/ pattern.

- Delivery system design interventions versus alternative interventions that control for content.

- Combined self-management support/delivery system design interventions versus standard care/control.

- Decision support interventions versus standard care.

- Clinical information system interventions versus standard care.

We planned to include subgroup analyses by self-management support content, delivery system design format and followup schedule (see Subgroup analysis and investigation of heterogeneity).

Interventions were compared against each other, against no intervention or against 'standard care'. This review considered interventions supplementary to the hearing aid fitting process itself. We defined standard care as being a face-to-face individual hearing aid fitting typically lasting 45 to 60 minutes. We would expect a standard fitting to include a basic level of advice regarding use and management of the hearing aid with some practice at physical management of the device itself.

\section{Types of outcome measures}

The purpose of this review was to look at interventions that promote use of hearing aids once they have been fitted either by increasing the proportion of those fitted who become successful 
users or by increasing the amount of use per person. We recognise that for an individual use does not always equate to benefit but it is certainly a necessary starting point. At the most basic level it is not possible to benefit from a hearing aid if it is not in use for at least a proportion of the time.

As hearing loss is a long-term condition and hearing aids are usually intended as a long-term intervention, we were interested in hearing aid use after a follow-up period of at least a year. We also included short-term $(</=12$ weeks $)$ and medium-term $(>12$ to $<52$ weeks $)$ follow-up, but we considered this lower quality evidence than if long-term data were available for the same outcome.

\section{Primary outcomes}

\section{Hearing aid use}

The purpose of this review was to assess the degree to which any of the interventions described above resulted in the increased usage of hearing aids by the patient. This may be measured in many different ways (Perez 2012). This review uses the following measures:

1.1. Adherence (i.e. the proportion of participants who continued to use their hearing aids after fitting relative to the total number fitted). The World Health Organization defines adherence as "the extent to which a person's behaviour - taking medication, following a diet, and/or executing lifestyle changes, corresponds with agreed recommendations from a health care provider" (WHO 2003). This definition differs from purely behavioural definitions of use (is the patient wearing their hearing aid?) and compliance (is the patient wearing their hearing aid as recommended?). For the purposes of this review we assumed that those being fitted with a hearing aid had agreed to this management option. We have therefore defined number of aids in use/number fitted as adherence. Participants were classified as users or non-users. Users were defined as those who used their hearing aids on at least a weekly basis. Non-users were those who did not use their hearing aids at all or those who had not used their hearing aid for at least a week prior to followup data collection. Where it was unclear how often participants were using their hearing aids and how they had been classified as users or non-users, we attempted to contact the study authors for clarification. If we were unable to get clarification the study was excluded.

1.2. Daily hours of hearing aid use. This may be assessed using validated self-report measures that record the daily hours of hearing aid use or data-logging by the hearing aid itself. Modern hearing aids have the capacity to capture and record when the hearing aid is switched on. It does not represent a true objective measure of use because it is only able to measure whether the hearing aid is switched on and the acoustic environment it is in, not whether it is switched on and in the patient's ear. However, we hoped to use it as a proxy measure of use. Both data collection methods yield continuous data either in terms of hours of use/time or proportion of the time the hearing aid(s) are worn. Since it is not the purpose of this review to compare methods of data collection, we combined data obtained using self-report and data-logging in our analyses of daily hours of hearing aid use.

\section{Adverse effects}

2.1 Inappropriate advice/clinical practice causing damage to patients' hearing.

\subsection{Patient complaints:}

- unresolved problems with physical management of the hearing aid;

- unresolved issues with symptom or psychosocial management;

- complaints relating to the nature of the intervention itself, such as having to make repeat visits to the clinic.

\section{Secondary outcomes}

For the purposes of this review we were interested in additional patient-reported outcomes that might be theoretically related to hearing aid use. Additional process-related outcomes such as utilisation, quality of care and resource use are outside the scope of this review.

\section{We included validated measures of:}

- quality of life - we included validated generic (e.g. SF-36, SF-12) and disease-specific measures of quality of life (e.g. IOI-HA item 7 Cox 2002);

- hearing handicap - validated measures of residual handicap or activity limitations (e.g. Hearing Handicap Inventory for the Elderly (HHIE) (Ventry 1982), Hearing Coping Assessment (HCA) (Andersson 1995a), Hearing Measurement Scale (HMS) (Noble 1970), Hearing Performance Inventory (HPI) (Giolas 1979), QDS (Alpiner 1978), IOI-HA item 3);

- hearing aid benefit - validated measures of hearing aid benefit (e.g. Abbreviated Profile of Hearing Aid Benefit (APHAB) (Cox 1995), Glasgow Hearing Aid Benefit Profile (GHABP) (Gatehouse 1999), IOI-HA item 2);

- communication - any validated measure of communication ability or strategy (e.g. Communication Profile for the Hearing Impaired (CPHI) (Demorest 1987)).

These measures might be completed by the patient, their communication partner(s) or both, with or without supervision from a clinician. We selected the outcomes we considered would be of most interest to patients, clinicians and policy-makers as recommended in the Cochrane Handbook for Systematic Reviews of Interventions (Higgins 2011). We reached the decision on which outcomes to include a priori following discussion between FB, EM and LE, who all have clinical experience in the context of hearing health care.

\section{Search methods for identification of studies}

The Cochrane ENT Information Specialist conducted systematic searches for randomised controlled trials and controlled clinical trials. There were no language, publication year or publication status restrictions. The date of the search was 13 June 2016.

\section{Electronic searches}

The Information Specialist searched:

- the Cochrane ENT Trials Register (searched 20 June 2016);

- the Cochrane Central Register of Controlled Trials (CENTRAL 2016, Issue 5);

- PubMed (1946 to 13 June 2016);

- Ovid EMBASE (1974 to 2016 June 10);

- Ovid CAB Abstracts (1910 to 2016 week 22);

- EBSCO CINAHL (1982 to 13 June 2016); 
- Ovid AMED (1985 to 13 June 2016);

- LILACS, lilacs.bvsalud.org (searched 13 June 2016);

- KoreaMed (searched via Google Scholar 13 June 2016);

- IndMed, www.indmed.nic.in (searched 13 June 2016);

- PakMediNet, www.pakmedinet.com (searched 13 June 2016);

- Web of Knowledge, Web of Science (1945 to 13 June 2016);

- CNKI, www.cnki.com.cn (searched via Google Scholar 13 June 2016);

- ClinicalTrials.gov (searched via the Cochrane Register of Studies 13 June 2016);

- World Health Organization (WHO) International Clinical Trials Registry Platform (ICTRP), www.who.int/ictrp (searched 13 June 2016);

- ISRCTN, www.isrctn.com (searched 13 June 2016);

- Google Scholar, scholar.google.co.uk (searched 17 June 2016);

- Google, www.google.com (searched 17 June 2016).

The Information Specialist modelled subject strategies for databases on the search strategy designed for CENTRAL. Where appropriate, they were combined with subject strategy adaptations of the highly sensitive search strategy designed by Cochrane for identifying randomised controlled trials and controlled clinical trials (as described in the Cochrane Handbook for Systematic Reviews of Interventions Version 5.1.0, Box 6.4.b. (Higgins 2011). Search strategies for major databases including CENTRAL are provided in Appendix 1.

\section{Searching other resources}

We scanned the reference lists of identified publications for additional trials. We searched PubMed, The Cochrane Library and Google to retrieve existing systematic reviews relevant to this systematic review, so that we could scan their reference lists for additional trials. We searched for conference abstracts using the Cochrane ENT Trials Register.

\section{Data collection and analysis}

\section{Selection of studies}

Material downloaded from electronic sources included details of author, institution or journal of publication and abstract. FB and EM inspected all reports independently in order to ensure reliable selection. We resolved any disagreement by discussion and, where there was still doubt, we acquired the full article for further inspection. Once the full articles were obtained, we decided whether the studies met the review criteria. If disagreement could not be resolved by discussion, we sought further information and added these trials to the list of those awaiting assessment.

\section{Data extraction and management}

\section{Data extraction}

Review authors FB and LE independently extracted data from all included studies. Again, we discussed any disagreement, documented decisions and, if necessary, contacted authors of studies for clarification. We extracted data presented only in graphs and figures whenever possible, but included them only if two review authors independently came to the same result. We attempted to contact authors through an open-ended request in order to obtain missing information or for clarification whenever necessary. If studies were multicentre, where possible, we extracted data relevant to each component centre separately.

\section{Data management}

Forms

We extracted data onto standard, simple forms, which are available on request from the corresponding author.

\section{Scale-derived data}

We included ordinal data from rating scales only if:

- the psychometric properties of the measuring instrument had been described in a peer-reviewed journal; and

- the measuring instrument had not been written or modified by one of the investigators for that particular trial.

We considered the ideal measuring instrument to be either i) selfreport or ii) completed by an independent rater or relative (not the clinician).

\section{Endpoint versus change data}

There are advantages of both endpoint and change data. Change data can remove a component of between-person variability from the analysis. On the other hand, calculation of change needs two assessments (baseline and endpoint), which increases the likelihood of missing data points. We primarily used endpoint data and only used change data if the former were not available. Where appropriate we used standardised mean differences to combine endpoint and change data in the analyses (Higgins 2011).

\section{Skewed data}

Continuous data on clinical and social outcomes are often not normally distributed. To avoid the pitfall of applying parametric tests to non-parametric data, we applied the following standards to all data before inclusion:

- standard deviations and means were reported in the paper or obtainable from the authors;

- when a scale started from zero, the mean should be more than twice the standard deviation (as otherwise the mean was unlikely to be an appropriate measure of the centre of the distribution (Altman 1996);

- if a scale started from a positive value we modified the calculation described above to take the scale starting point into account. In these cases skew was present if $2 \mathrm{SD}>(\mathrm{S}-\mathrm{S} \mathrm{min}$ ), where $\mathrm{S}$ is the mean score and $\mathrm{S}$ min is the minimum score.

Endpoint scores on scales often had a finite start and endpoint and these rules could be applied. We entered potentially skewed endpoint data from studies into our analyses but noted the high risk of skew, downgrading our judgement of the quality of the evidence for a particular outcome where the majority of studies were at high risk of bias.

When continuous data were presented on a scale that included a possibility of negative values (such as change data) and it was difficult to tell whether data were skewed or not, we entered change data but again noted where we considered it to be of potential significance when interpreting the evidence. 


\section{Common measure}

To facilitate comparison between trials, we converted variables that were reported in different metrics, such as hours of use (mean hours per day, per week or per month) to a common metric. We used mean hours per day. For conversion purposes we considered a full day to equal 12 hours since hearing aids are not normally worn at night.

\section{Direction of graphs}

For outcomes where a higher score was judged to be a positive outcome (such as daily hours of use or quality of life), we displayed the results so that the area to the left of the line of no effect indicated a favourable outcome for the control group. For outcomes where a higher score was judged to be a negative outcome (such as hearing handicap), we displayed the results so that the area to the left of the line of no effect indicated a favourable outcome for the intervention group.

\section{Assessment of risk of bias in included studies}

Authors FB and EM independently undertook an assessment of the risk of bias of the included trials as guided by theCochrane Handbook for Systematic Reviews of Interventions (Higgins 2011). This set of criteria is based on evidence of associations between overestimate of effect and high risk of bias of the article such as sequence generation, allocation concealment, blinding, incomplete outcome data and selective reporting.

We used the Cochrane 'Risk of bias' tool in RevMan 5.3 (RevMan 2014), which involves describing each of the domains as reported in the trial and then assigning a judgement about the adequacy of each entry: 'low', 'high' or 'unclear' risk of bias. We judged that any study that had a high risk of bias in three or more areas had an overall high risk of bias and we subjected those to a sensitivity analysis (see Sensitivity analysis).

Where the raters disagreed, we made the final rating by consensus, with the involvement of another member of the review group. Where inadequate details of randomisation and other characteristics of trials were provided, we attempted to contact authors of the studies in order to obtain further information. We recorded non-concurrence in quality assessment and, where there was disagreement as to which category a trial was to be allocated, again we resolved this by discussion.

We noted the level of risk of bias in both the text of the review and in the 'Summary of findings' tables.

\section{Measures of treatment effect}

\section{Binary data}

For binary outcomes we calculated a standard estimation of the risk ratio (RR) and its 95\% confidence interval ( $\mathrm{Cl}$ ). It has been shown that the RR is more intuitive than the odds ratio (Boissel 1999), and additionally that odds ratios tend to be interpreted as RR by clinicians (Deeks 2000). Where we identified heterogeneity we planned to used a random-effects model.

\section{Continuous data}

If continuous data, for example from hearing aid benefit questionnaires, were measured on the same scale, we used the mean difference to summarise the results between studies. For outcomes measured using different scales, we calculated the standardised mean difference (SMD) to combine the results.

\section{Unit of analysis issues}

\section{Cluster trials}

We anticipated that some studies might employ 'clusterrandomisation' (such as randomisation by clinician or practice) and we planned for how we would deal with this statistically to reduce the risk of 'unit of analysis' errors (Divine 1992). In the event no trials involving cluster-randomisation were included in this review.

\section{Cross-over trials}

A major concern of cross-over trials is the carry-over effect. It occurs if an effect (e.g. pharmacological, physiological or psychological) of the treatment in the first phase is carried over to the second phase. As a consequence, on entry to the second phase the participants can differ systematically from their initial state despite a wash-out phase. For the same reason cross-over trials are not appropriate if the condition of interest is unstable or progressive. As both these possibilities arise with hearing loss, we sought to use only data from the first phase of cross-over studies.

\section{Studies with multiple treatment groups}

Where a study involved more than two treatment arms, if relevant, we presented the additional treatment arms in comparisons. If data were binary we added and combined these within the two-by-two table. If data were continuous we combined data following the formula in section 7.7.3.8 ('Combining groups') of the Cochrane Handbook for Systematic Reviews of Interventions where appropriate (Higgins 2011). Where the additional treatment arms were not relevant, we did not use these data.

\section{Dealing with missing data}

\section{Overall loss of credibility}

At some degree of loss of follow-up data must lose credibility. We decided that, for any particular outcome, should more than $50 \%$ of data be unaccounted for, we would not present these data or use them within analyses. If, however, more than $50 \%$ of those in one arm of a study were lost, but the total loss was less than $50 \%$, we marked such data with $\left({ }^{*}\right)$ to indicate that such a result may well be prone to bias.

\section{Binary}

In the case where attrition for a binary outcome was between $0 \%$ and $50 \%$ and where these data were not clearly described, we presented data on a 'once randomised always analyse' basis (an intention-to-treat analysis). We assumed those leaving the study early to have the same rates of negative outcome as those who completed. We planned to undertake a sensitivity analysis to test how prone the primary outcomes are to change when data only from people who completed the study to that point were compared with the intention-to-treat analysis using the above assumption.

\section{Continuous}

\section{Attrition}

In the case where attrition for a continuous outcome was between $0 \%$ and $50 \%$ we reported data only from people who completed the study to that point. 


\section{Standard deviations}

If standard deviations were not reported, we first tried to obtain the missing values from the authors. If not available, where there were missing measures of variance for continuous data, but an exact standard error and confidence intervals were available for group means, and either $\mathrm{P}$ value or $\mathrm{t}$ value were available for differences in mean, we calculated them according to the rules described in the Cochrane Handbook for Systematic Reviews of Interventions (Higgins 2011). When only the standard error (SE) was reported, we attempted to calculate standard deviations (SDs) by the formula SD $=\mathrm{SE}{ }^{*}$ square root (n). Chapters 7.7.3 and 16.1.3 of the Cochrane Handbook for Systematic Reviews of Interventions present detailed formulae for estimating SDs from $P$ values, $t$ or $F$ values, confidence intervals, ranges or other statistics (Higgins 2011).

\section{Last observation carried forward}

We anticipated that in some studies the method of last observation carried forward (LOCF) might be employed within the study report. As with all methods of imputation to deal with missing data, LOCF introduces uncertainty about the reliability of the results. Therefore, where LOCF data were used in a trial, if less than $50 \%$ of the data was assumed, we presented and used these data and indicated that they are the product of LOCF assumptions.

\section{Assessment of heterogeneity}

\section{Clinical diversity}

We considered all included studies initially, without seeing comparison data, to look for variations in participants, interventions and outcomes (clinical diversity). We inspected all studies for clearly outlying people or situations that we had not predicted would arise. We planned theory-led subgroup analyses based on CCM element definitions and long-term conditions research (see Subgroup analysis and investigation of heterogeneity).

\section{Methodological diversity}

We considered all included studies initially, without seeing comparison data, to look for variability in study design and risk of bias (methodological diversity). We inspected all studies for clearly outlying methods that we had not predicted would arise.

\section{Statistical heterogeneity}

Heterogeneity may arise as a result of clinical or methodological diversity, or both. We assessed it in two ways.

\section{Visual inspection}

We visually inspected graphs to investigate the possibility of statistical heterogeneity by looking at the degree of overlap between confidence intervals.

\section{Employing the $I^{2}$ statistic}

We investigated heterogeneity between studies by considering the $\mathrm{I}^{2}$ statistic alongside the $\mathrm{Chi}^{2}$ test $\mathrm{P}$ value. The $\mathrm{I}^{2}$ statistic provides an estimate of the percentage of inconsistency thought to be due to chance. The importance of the observed value of 12 depends on i) the magnitude and direction of effects and ii) the strength of evidence for heterogeneity (e.g. P value from $\mathrm{Chi}^{2}$ test, or a confidence interval for 12 ). We have interpreted an 12 estimate greater than or equal to around $50 \%$ accompanied by a statistically significant $\mathrm{Chi}^{2}$ value as evidence of substantial levels of heterogeneity (Section 9.5.2 - Higgins 2011).

\section{Assessment of reporting biases}

Reporting biases arise when the dissemination of research findings is influenced by the nature and direction of results (Egger 1997). These are described in section 10.1 of the Cochrane Handbook for Systematic Reviews of Interventions (Higgins 2011).

\section{Protocol versus full study}

We attempted to locate protocols for included randomised trials. If the protocol was available, we compared outcomes in the protocol and in the published report. If the protocol was not available, we compared outcomes listed in the methods section of the trial report with the results actually reported.

\section{Funnel plot}

We are aware that funnel plots may be useful in investigating reporting biases but are of limited power to detect small study effects. We did not use funnel plots for outcomes where there were 10 or fewer studies, or where all studies were of similar sizes.

\section{Data synthesis}

Fixed-effect models hold that only within-study variation influences the uncertainty of an effect (as reflected in the confidence interval). Variation between the estimates of effect from each study (heterogeneity) does not influence the confidence interval in a fixed-effect model. Random-effects models incorporate an assumption that the different studies are estimating different (yet related) but not fixed intervention effects.

In a group of studies where there is low heterogeneity, fixed-effect and random-effects models will return the similar confidence intervals. However, where there is evidence of statistical heterogeneity this will be taken into account only by a randomeffects model analysis and the confidence intervals will be wider than they would be when analysing the same data using a fixedeffect model. In terms of identifying evidence of significant effects a random-effects model is therefore more conservative. However, it does put more weight on the smaller studies, which are often the most biased. Depending on the direction of effect these studies can either inflate or deflate effect size.

Since we anticipated a degree of clinical and methodological heterogeneity in these data, given the wide range of interventions included, we used a random-effects model for all analyses. To investigate heterogeneity further, where appropriate, we carried out a series of theory-led subgroup analyses based on the CCM element definitions and previous research carried out in other longterm conditions and we assessed risk of bias (see Subgroup analysis and investigation of heterogeneity).

\section{Subgroup analysis and investigation of heterogeneity Subgroup analyses}

In this review, we have grouped the results into comparisons within the CCM element. We anticipated that there would be diversity of intervention within a CCM element (see Description of the intervention) and so we planned to use the CCM element definitions and previous research analysing complex interventions in longterm conditions to perform subgroup analyses where appropriate. 
Due to the wide range of skills needed to live well with a long-term condition, self-management support interventions can be varied and complex. Based on the work of Lorig 2003, Pearson 2007 and Whitlock 2002 and previous reviews by Barlow 2002, Kreindler 2009 and Tsai 2005, results for comparisons that include a component of self-management support should be subject to a subgroup analysis as follows:

- Advise: interventions aiming to inform and educate the patient about any aspect of self-management.

- Activate - practical skills: interventions that include practice of practical skills in terms of hearing aid management.

- Activate - symptoms management skills: interventions that include practice addressing the direct symptoms associated with hearing loss, i.e. reduced sound/speech perception/ discrimination.

- Activate - psychosocial management skills: interventions that include practice addressing the psychosocial and emotional consequences of hearing loss, i.e. communication difficulties, acceptance of hearing loss etc.

- Assist: interventions that include the provision of additional practical tools to support self-management.

- Agree: collaborative decision-making.

We have assumed that an assessment of need has been incorporated into all the self-management support interventions and so have chosen not to include this as a discrete subgroup. We have augmented the 5As model with behavioural activation subgroups based on the work of Barlow 2002 and Pearson 2007.

This subdivision of self-management provision was supported by the results of a Delphi review involving a panel of 26 hearing healthcare stakeholders including patients, clinicians, researchers and commissioners. It involved a three-round online Delphi process to investigate whether consensus could be reached on what it means to live well with a hearing loss, how this might be measured and the clinical processes that might support it (Barker 2015). The relative effect of these subgroups of self-management support would be of interest to patients, clinicians and policy-makers. The division into 'informing' and 'involving' processes has also recently been suggested as a way to operationalise patient-centred care within hearing healthcare (Grenness 2014).

Results for comparisons that include a component of delivery system design were subject to subgroup analyses as follows:

Delivery system design format:

- Face-to-face

- Telephone

- Booklet

- Remote (online/PC-based/DVD/video)

- Other

Delivery system design intensity:

- Low-intensity - single session interventions

- Medium-intensity - up to four session interventions

- High-intensity - five or more session interventions

The cut off between medium- and high-intensity interventions was chosen based on clinical experience.
This was based on the clinical experience of FB, LE and EM and on the results of the Delphi review described above where there was consensus that follow-up scheduling may be an important factor in supporting someone to live well with their hearing loss. The effect of delivery format may be of interest to patients and healthcare professionals and policy-makers interested in system redesign.

We recognise the possibility of interaction in effect between content, follow-up pattern and format but it was not the intention of this review to carry out a full multiple regression analysis to investigate this. We review the relevance and usefulness of the use of these research-based subgroups in the Discussion.

\section{Investigation of heterogeneity}

We anticipated that there might be a high degree of heterogeneity across eligible studies due to variations in patient populations, characteristics of interventions, outcome measurement, study design and risk of bias. Where this was found to be the case for a particular outcome we first checked that all data had been entered correctly, including checking for unit of analysis errors. We then sought to investigate remaining clinical heterogeneity using subgroup analyses. Where this did not adequately reduce heterogeneity we then went back to the original papers and study designs looking for studies that shared common characteristics in terms of population, intervention, comparison and outcome. We assessed the impact of risk of bias using sensitivity analysis (see Sensitivity analysis).

\section{Sensitivity analysis}

We carried out sensitivity analyses based on the quality criteria reported in this review.

\section{Implication of randomisation}

We included trials when they were described in some way as to imply randomisation even when details were not given of the allocation process. For the primary outcome we included these studies and if there was no substantive difference when the implied randomised studies were added to those with a better description of randomisation, then we employed all data from these studies.

\section{Assumptions for lost binary data}

Where assumptions had to be made regarding people lost to followup, we planned to compare the findings of the primary outcomes when using our assumptions compared with completer data only. If there was a substantial difference, we planned to report the results and discuss them but continue to employ our assumptions. We had also planned to follow a similar protocol where assumptions were made regarding missing SD data.

\section{Risk of bias}

We analysed the effects of excluding trials that we judged to be at overall high risk of bias (see Assessment of risk of bias in included studies). Where the exclusion of trials at high risk of bias did not substantially alter the direction of effect or the precision of the effect estimates, then we included data from these trials in the analysis. If it did alter the direction or precision of effects we included the data but discussed the implications when presenting the results (see Effects of interventions; Summary of findings for the main comparison; Summary of findings 2; Summary of findings 3). 


\section{Imputed values}

We planned also to undertake a sensitivity analysis to assess the effects of including data from trials where we had to use imputed values for the intra-cluster correlation coefficient (ICC) in calculating the design effect in cluster-randomised trials.

\section{RES U L T S}

\section{Description of studies}

See: Characteristics of included studies; Characteristics of excluded studies; Table 1.

\section{Results of the search}

The search identified 2256 papers, reviews, book chapters and conference abstracts, of which 1308 remained once duplicates were removed. We discarded 1165 papers on the basis of the title and/or abstract leaving 143 remaining sources for which we searched the full text. We also searched their reference lists and this identified a further 14 papers and two reviews, which we also attempted to access in full text. Of these 159 sources, we discarded 73 on the basis that they did not meet the inclusion criteria, four could not be traced, 11 referred to study protocols for which results were not available and two were abstracts for oral presentations but the authors could not be traced. This left 69 papers that we analysed in detail. We subsequently excluded 18 of these for the reasons given in Excluded studies and two completed studies await classification (Henshaw 2013; Malmberg 2015). Three studies are ongoing (ISRCTN77340339; NCT02233361; NCT02264314).

Forty-six papers giving results from 37 original studies were eligible for inclusion in the review (Figure 1). Quantitative data for the primary outcome of hearing aid use were reported in 22 studies, but we were able to combine only 13 of these studies in quantitative meta-analyses. 
Figure 1. PRISMA diagram showing process for sifting search results and selecting studies for inclusion.

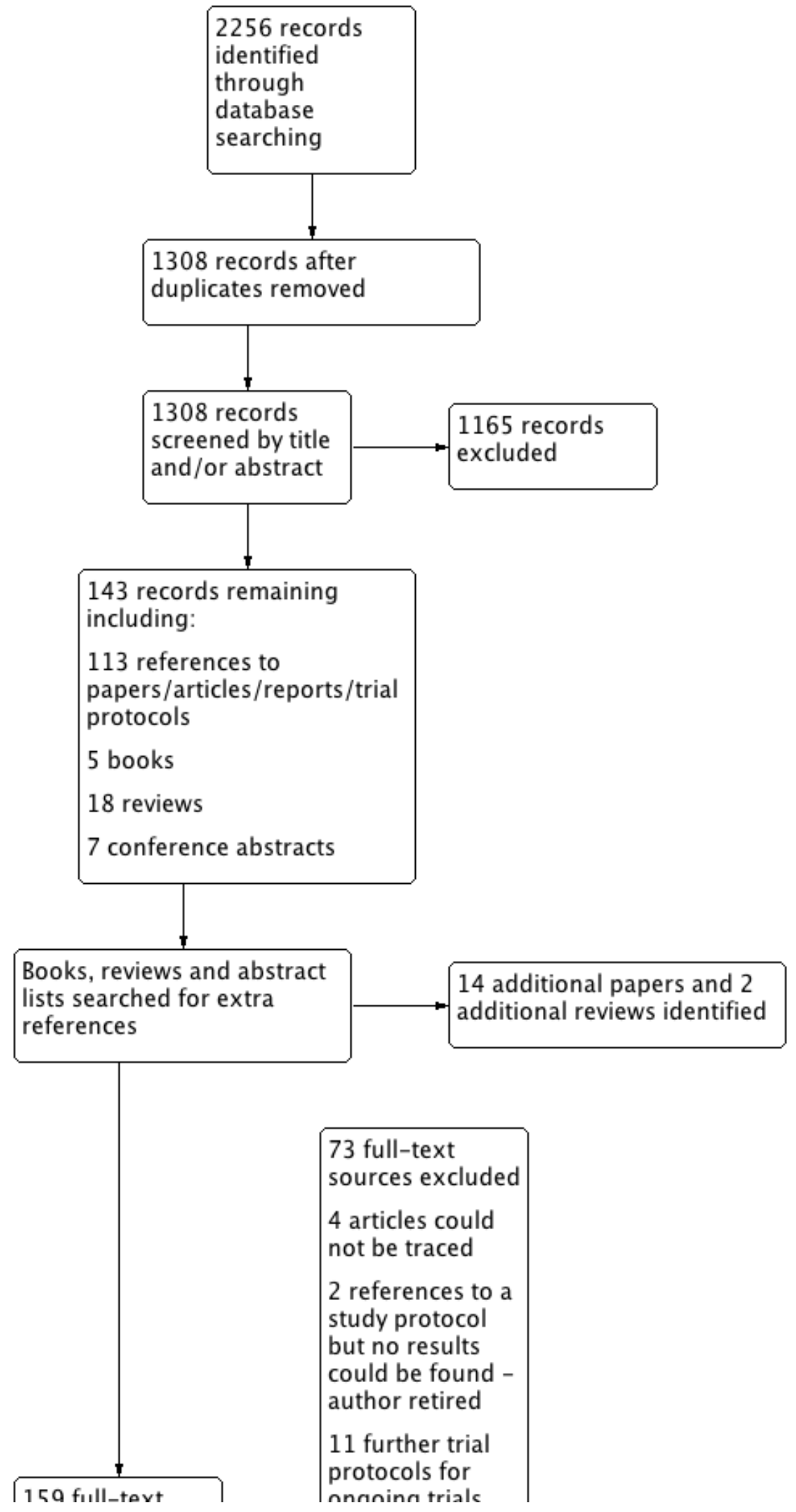


Figure 1. (Continued)

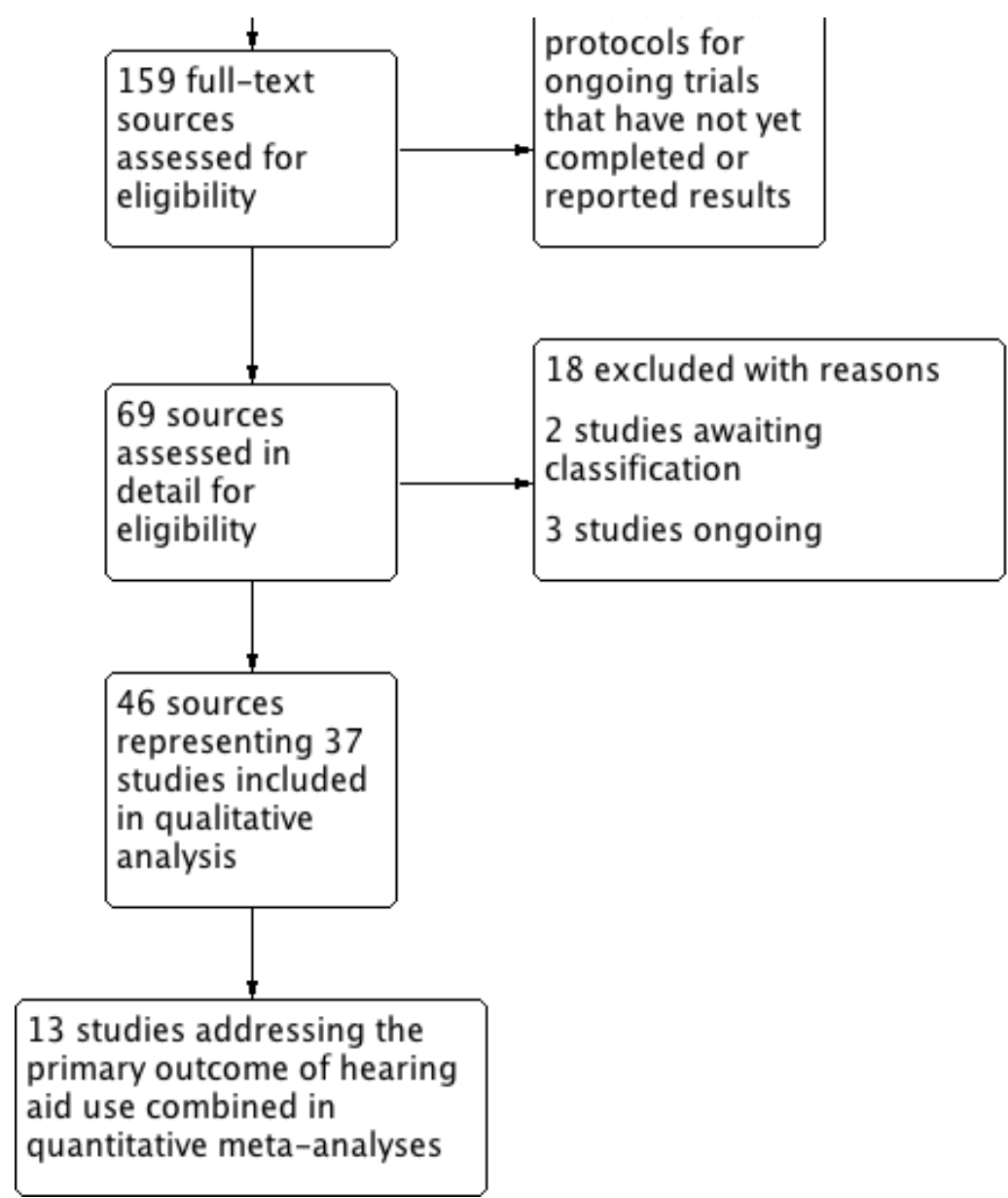

\section{Included studies}

\section{Participants}

In all the included studies participants were adults as defined in Types of participants. Some studies included participants aged in their 20s and upwards (e.g. Collins 2013; Smaldino 1988; Sweetow 2006; Thoren 2011), but the majority of the studies included participants aged 50 or above. Even in those studies that included younger participants the mean age was generally in the 60- to 70year age range. Other frequently applied inclusion criteria were that participants should have no evidence of additional cognitive or physical impairment that might have an impact on hearing aid use and that their hearing loss was sensorineural in nature.

Where information was reported we also looked at the gender of participants. Seven of the studies were carried out in a US military veteran population and hence included an overwhelmingly male population (Abrams 1992; Chisolm 2004; Collins 2013; Preminger 2010a; Saunders 2009; Saunders 2016; Turbin 2006).

\section{Interventions}

\section{Self-management support interventions}

Five studies reported comparisons that changed the content of self-management support in isolation (Fitzpatrick 2008; Kricos 1996; Preminger 2010a; Saunders 2009; Saunders 2016). Alternative interventions were compared to control for changes in delivery system design (see Table 1).

There were no studies that sought to investigate the effect of providing resources to support self-management (assist) or the role of collaborative decision-making, goal-setting or action-planning (agree).

\section{Delivery system design interventions}

Six studies reported comparisons that changed the delivery of self-management support and included comparison interventions that controlled for changes in self-management support content (Campos 2013; Cherry 1994; Collins 2013; Cunningham 2001; Lavie 2014; Ward 1981). Four studies changed the format of delivery (Campos 2013; Cherry 1994; Lavie 2014; Ward 1981), two changed the intensity (Cherry 1994; Cunningham 2001), and one changed the mode (Collins 2013).

There were no studies that sought to investigate staff roles and task distribution amongst team members on the usage of hearing aids. No studies specifically addressed participants' understanding of the care they received or investigated whether it fitted in with their cultural background.

Twenty-nine studies reported on comparisons of combined selfmanagement support/delivery system design interventions where the self-management support content and delivery were changed. 
Where interventions were compared against standard care or 'no intervention' we defined this as a standard individual hearing aid fitting comprising a single visit for the fitting itself and any routine follow-up session(s).

\section{Decision support interventions}

None found.

\section{Clinical information system interventions}

None found.

\section{Community resource interventions}

None found.

\section{Health system interventions}

None found.

Details of interventions are given in Characteristics of included studies and summarised in Table 1. All interventions in the included studies could be classified according to the chronic care model (CCM). The majority involved both self-management support and delivery system design changes.

\section{Outcomes}

This review aimed to look at long-term outcomes as hearing loss is a long-term condition requiring self-management on the part of the patient over many years. Only six of the studies we identified looked at outcome over one year or longer (Andersson 1994; Andersson 1995; Cherry 1994; Chisolm 2004; Oberg 2008; Oberg 2009), and only two of these addressed the primary outcome of hearing aid use (Oberg 2008; Oberg 2009) (see Summary of findings 3).

\section{Primary outcomes}

\section{Hearing aid use}

1.1. Collins 2013 and Campos 2013 reported data that could be interpreted as adherence as defined in this review, although only the Collins 2013 study actually specified adherence as an outcome.

1.2. Twenty-two studies measured daily hours of use or used a scale that could be converted to daily hours of use (Andersson 1995; Andersson 1997; Campos 2013; Cherry 1994; Collins 2013; Cunningham 2001; Eriksson-Mangold 1990; Ferguson 2016; Fitzpatrick 2008; Kemker 2004; Kramer 2005; Lavie 2014; Lundberg 2011; Oberg 2008; Oberg 2009; Olson 2013; Saunders 2009; Thoren 2011; Thoren 2014; Vreeken 2015; Ward 1978; Ward 1981). Campos 2013, Lavie 2014 and Ferguson 2016 used data-logging to measure hours of use per day in addition to or instead of self-reported hours of use.

\section{Adverse effects}

2.1 No studies reported on clinical adverse events.

2.2 Cherry 1994 looked at the number of outstanding complaints at one year after the provision of telephone follow-up.

\section{Secondary outcomes}

\section{Quality of life}

Twelve studies reported quality of life as an outcome measure (Ferguson 2016; Kramer 2005; Lundberg 2011; Oberg 2008; Oberg 2009; Olson 2013; Preminger 2008; Preminger 2010; Preminger 2010a; Thoren 2011; Thoren 2014; Vreeken 2015). Only Oberg 2008 and Oberg 2009 reported on long-term quality of life.

\section{Hearing handicap}

Twenty-seven studies reported hearing handicap as an outcome (Abrams 1992; Andersson 1994; Andersson 1995; Andersson 1997; Beynon 1997; Cherry 1994; Chisolm 2004; Collins 2013; Ferguson 2016; Kramer 2005; Kricos 1992; Kricos 1996; Lundberg 2011; Miranda 2008; Oberg 2008; Oberg 2009; Preminger 2008; Preminger 2010; Preminger 2010a; Saunders 2009; Saunders 2016; Smaldino 1988; Sweetow 2006; Thoren 2011; Thoren 2014; Ward 1978; Ward 1981). Only Andersson 1994; Andersson 1995; Oberg 2008 and Oberg 2009 reported long-term hearing handicap.

\section{Hearing aid benefit}

Fourteen studies reported hearing aid benefit as an outcome (Collins 2013; Cunningham 2001; Ferguson 2016; Gil 2010; Kemker 2004; Kramer 2005; Lundberg 2011; Oberg 2008; Oberg 2009; Olson 2013; Saunders 2009; Thoren 2011; Thoren 2014; Vreeken 2015), but only Oberg 2008 and Oberg 2009 did so over the long term.

\section{Communication}

Eight studies reported a measure of communication as an outcome (Andersson 1997; Chisolm 2004; Collins 2013; Kricos 1996; Oberg 2008; Preminger 2010; Sweetow 2006; Turbin 2006), but only Chisolm 2004 and Oberg 2008 did so over the long term.

Only two of the studies reported an overall single score measure of communication (Preminger 2010; Sweetow 2006). The remaining studies used the Communication Profile for the Hearing Impaired (CPHI) to measure communication ability (Demorest 1987), with some choosing to use only the communication strategies subscale of this measure. This measures whether people use verbal, non-verbal and maladaptive strategies for communication. We took the verbal strategy subscale of the $\mathrm{CPHI}$ as an example measure of communication. This subscale was chosen post hoc on the basis that a primary aim of hearing aid fitting and subsequent rehabilitation is to improve verbal communication. However, we recognise that this scale does not represent the range of communicative ability or potential improvement. Where appropriate this has been taken into consideration when grading the quality of the evidence.

\section{Excluded studies}

Details of the 18 studies that we excluded after careful study of their methods are given in Characteristics of excluded studies.

\section{Risk of bias in included studies}

In general the risk of bias was unclear or high in most studies. Please see Figure 2 for the 'Risk of bias' analysis for the individual included studies and Figure 3 showing the review authors' judgements about each 'Risk of bias' item presented as percentages across all included studies. Specific areas of concern are highlighted below. 
Figure 2. 'Risk of bias' summary: review authors' judgements about each risk of bias item for each included study.

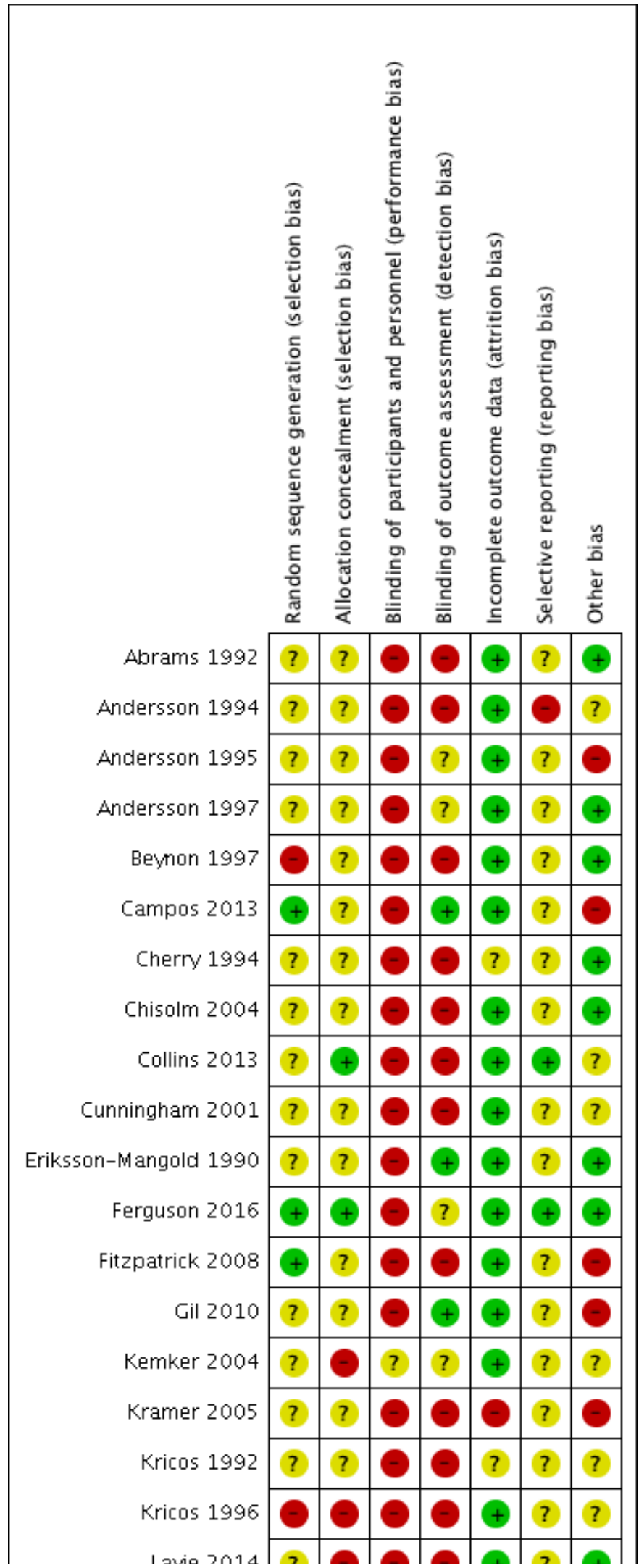


Figure 2. (Continued)

\begin{tabular}{|c|c|c|c|c|c|c|c|}
\hline WMUs & $\nabla$ & $\bullet$ & $\bullet$ & $\bullet$ & $T$ & 5 & 3 \\
\hline Lavie 2014 & $?$ & $\odot$ & $\odot$ & $\odot$ & 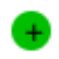 & $?$ & $\odot$ \\
\hline Lundberg 2011 & $?$ & $?$ & $\odot$ & $\odot$ & $?$ & $?$ & $\odot$ \\
\hline Miranda 2008 & $\hookrightarrow$ & $?$ & $\odot$ & 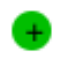 & $\odot$ & $?$ & - \\
\hline Oberg 2008 & † & † & $\odot$ & $?$ & $?$ & 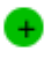 & $?$ \\
\hline Oberg 2009 & $\hookrightarrow$ & $\hookrightarrow$ & $\odot$ & $?$ & $\odot$ & 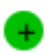 & $\odot$ \\
\hline Olson 2013 & 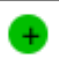 & $?$ & $\odot$ & $\odot$ & $?$ & $\odot$ & $\odot$ \\
\hline Preminger 2008 & $?$ & $?$ & $\odot$ & $\odot$ & $?$ & $?$ & $?$ \\
\hline Preminger 2010 & $\odot$ & $\odot$ & $\odot$ & $\odot$ & $\odot$ & $?$ & $?$ \\
\hline Preminger $2010 \mathrm{a}$ & $\odot$ & $\odot$ & $\odot$ & $\odot$ & 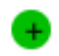 & $?$ & $\odot$ \\
\hline Saunders 2009 & $?$ & $?$ & $\odot$ & $\odot$ & 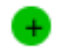 & $?$ & $?$ \\
\hline Saunders 2016 & 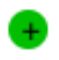 & $?$ & $\hookrightarrow$ & $\odot$ & $\odot$ & $?$ & $\odot$ \\
\hline Smaldino 1988 & $?$ & $?$ & $\odot$ & - & 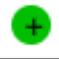 & $?$ & $?$ \\
\hline Sweetow 2006 & $?$ & $?$ & $\odot$ & $\odot$ & $\odot$ & $?$ & $\Theta$ \\
\hline Thoren 2011 & $?$ & 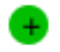 & $?$ & $?$ & 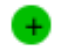 & $?$ & $\hookrightarrow$ \\
\hline Thoren 2014 & $?$ & 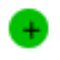 & $\odot$ & $\odot$ & $\odot$ & $?$ & $?$ \\
\hline Turbin 2006 & $?$ & $?$ & $\odot$ & - & O & $?$ & $?$ \\
\hline Vreeken 2015 & 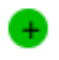 & 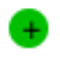 & $\odot$ & 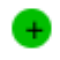 & 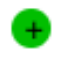 & $?$ & $?$ \\
\hline Ward 1978 & $\odot$ & $?$ & $\odot$ & 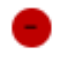 & $\odot$ & $?$ & $?$ \\
\hline Ward 1981 & $?$ & $?$ & - & $\odot$ & 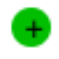 & $?$ & $\odot$ \\
\hline
\end{tabular}

Figure 3. 'Risk of bias' graph: review authors' judgements about each risk of bias item presented as percentages across all included studies.

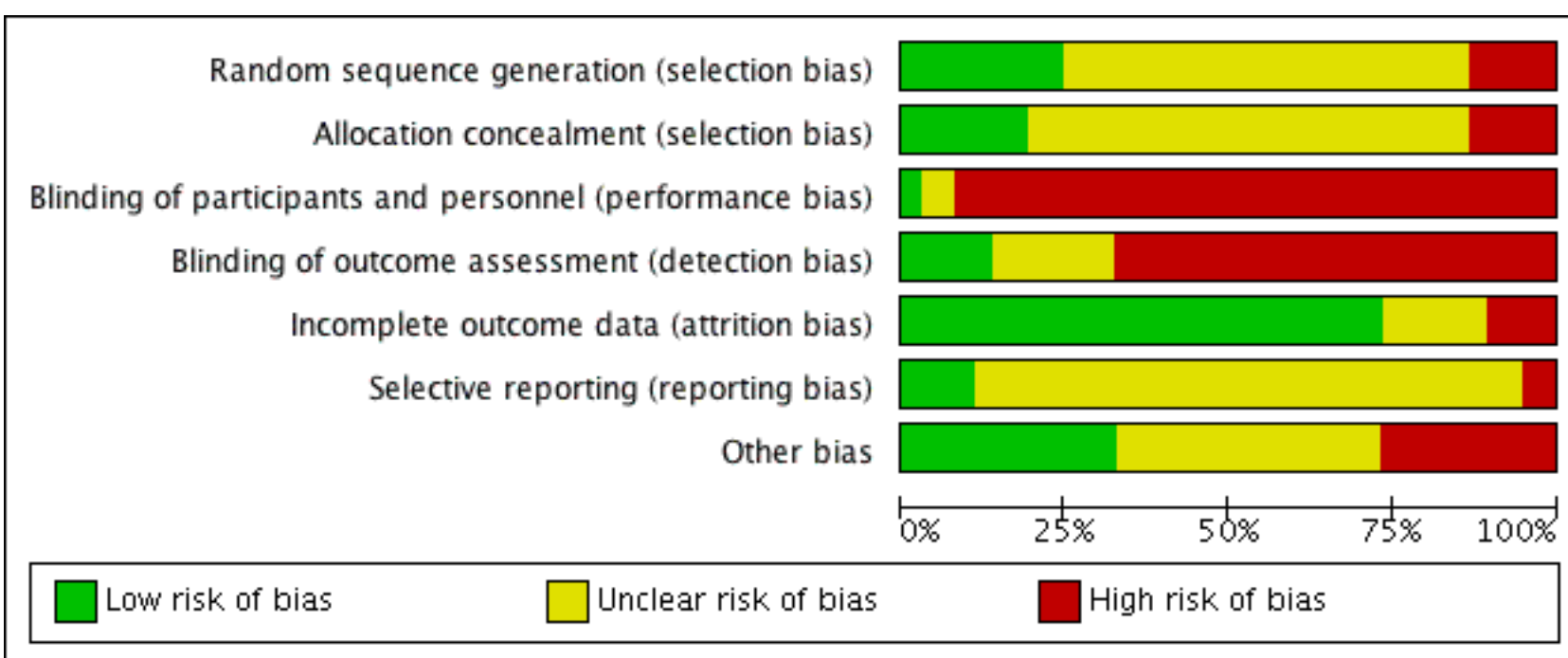




\section{Allocation}

It was rare for studies to give an adequate description of their randomisation process. Sequence generation and allocation concealment were frequently not mentioned at all so it was not possible to make a clear assessment of risk of selection bias. Only 16 of the 37 included studies gave any description of the allocation process. Of these, in nine studies the description was enough to allocate a low risk of selection bias. In the remaining seven studies the information given led us to judge that there was an unclear or high risk of selection bias.

\section{Blinding}

Due to the nature of the interventions in this context it is difficult to design studies that are blinded to participants and those delivering the intervention so performance bias is difficult to control for. See Table 1 for a list of interventions and control conditions.

Blinding in outcome assessment was mentioned more frequently than blinding for group allocation, although it was still rare.

\section{Incomplete outcome data}

A strength of the studies we identified is that they had low dropout rates even for long-term follow-up periods of over a year and there were only occasional instances of unexplained losses to follow-up.

\section{Selective reporting}

There was only one case of definite reporting bias (Andersson 1994), where an outcome had been recorded in the study but not reported in the paper. We discovered this because the data were later included in a paper (Andersson 1998), which combined data from three previous studies including Andersson 1994. In most other cases it was not possible to make a clear judgement on reporting bias due to the lack of published protocols in this context. Where protocols were available, there was no evidence of selective reporting.

\section{Other potential sources of bias}

With a few exceptions, studies were small and lacked power calculations. Some studies were funded by hearing aid manufacturers, although this should not introduce undue bias as both control and interventions groups were provided with hearing aids in all cases. In the Discussion we consider the possible implications of studying participants from a tightly defined population such as military veterans, which was an issue in several of the included studies.

\section{Effects of interventions}

See: Summary of findings for the main comparison Selfmanagement support interventions for adults with hearing loss who use hearing aids; Summary of findings 2 Delivery system design interventions for adults with hearing loss who use hearing aids; Summary of findings 3 Combined self-management support/ delivery system design interventions for adults with hearing loss who use hearing aids

Summary of findings for the main comparison summarises the evidence of effect for self-management support interventions on the primary and secondary outcomes.
Summary of findings 2 summarises the evidence of effect for delivery system design interventions on the primary and secondary outcomes.

Summary of findings 3 summarises the evidence of effect for combined self-management support/delivery system design interventions on the primary and secondary outcomes.

Where possible we have presented data on long-term outcomes. Short- and medium-term outcomes are included only where longterm outcome data were not available.

\section{Self-management support interventions}

\section{Primary outcome}

\section{Hearing aid use}

\subsection{Adherence}

We found no studies of self-management support interventions that reported adherence as an outcome.

\subsection{Daily hours of hearing aid use}

Two self-management support studies measured short- to medium-term daily hours of hearing aid use, but we were unable to combine them in a meta-analysis as they categorised daily use in a different way from our definition in this review (Fitzpatrick 2008; Saunders 2009). Fitzpatrick 2008 reported that for their auditory training intervention eight participants (57\%) wore their hearing aids all of the time before, after and during therapy and six participants (43\%) wore their hearing aids in more listening situations after therapy. In the control group (who received lectures on hearing loss, hearing aids and communication over the same time period) seven participants $(70 \%)$ wore their hearing aids all the time and three participants (30\%) wore their aids in limited situations before and after the lectures. Saunders 2009 reported that when comparing a pre-fitting demonstration of listening situations with no demonstration, $4 / 20$ participants in the intervention group and 1/20 participants in the control group wore their hearing aids for more than eight hours per day. The clinical significance of these results is unclear.

\section{Adverse effects}

No self-management support intervention studies reported on adverse effects.

\section{Secondary outcomes}

\section{Quality of life}

One self-management support intervention showed no statistically significant evidence of effect of adding psychosocial exercises to a communication training programme on short to medium-term quality of life (one study, 35 participants; mean difference (MD) $-9.10,95 \%$ confidence interval $(\mathrm{Cl})-21.33$ to 3.13 ; Analysis 1.1 ) (Preminger 2010a). This represents a reduction of 9.1 points on the World Health Organization Disability Assessment Schedule 2.0 (WHODAS 2.0) 0- to 100-point scale. On this scale a lower score indicates improved quality of life. However, the minimal important difference on this scale for hearing loss has not been established. This means we cannot comment on the clinical significance of this result. We found no self-management support studies that reported long-term quality of life. Our confidence in the 
quality of the evidence for the effect of self-management support interventions on quality of life is very low.

\section{Hearing handicap}

We were able to combine the data from two self-management support interventions that assessed short- to medium-term hearing handicap (Kricos 1996; Preminger 2010a). There was evidence of a short- to medium-term effect on hearing handicap (two studies, 87 participants; MD $-12.80,95 \% \mathrm{Cl}-23.11$ to -2.48 ; Analysis 1.2). Although this represents a statistically significant change in the mean difference, it falls below the 18.7-point difference considered to represent a minimal important difference on this 100-point scale (Ventry 1982; Weinstein 1986). The minimal important difference does fall within the confidence interval in this analysis, which suggests that there may have been a clinically significant effect on hearing handicap for some, but not all, participants. We found no self-management support interventions that reported long-term hearing handicap. Our confidence in the quality of evidence for the effect of self-management support interventions on self-reported hearing handicap is very low.

\section{Hearing aid benefit}

We found no studies of self-management support interventions that reported hearing aid benefit as an outcome.

\section{Communication}

One study that included a comparison of a self-management support intervention reported data on communication in the short to medium term (Kricos 1996). There was evidence of a shortterm effect on the use of verbal communication strategies for this intervention, which compared an active listening programme with auditory training (one study, 52 participants; MD $0.72,95 \% \mathrm{Cl} 0.21$ to 1.23; Analysis 1.3). The minimal important difference on this subscale of the communication profile for the hearing impaired is 0.93 (Demorest 1988). The mean difference and confidence intervals suggest that for some, but not all, participants there was a clinically significant difference in the use of a communication strategy. We found no self-management support interventions that reported long-term communication. Our confidence in the quality of the evidence for the effect of self-management support interventions on communication is very low.

\section{Delivery system design interventions}

\section{Primary outcome}

\section{Hearing aid use}

\subsection{Adherence}

Two delivery system design studies yielded data that could be analysed as adherence (people fitted with aids/people using aids) (Campos 2013; Collins 2013). Collins 2013 asked participants whether they wore their hearing aids or not after six months. Campos 2013 used data-logging to record those with zero hours of use over the short term. These studies involved changes in mode (group fitting versus individual fitting: Collins 2013) and format (teleconsultation versus online fitting: Campos 2013). Combining these studies shows no evidence of short- to medium-term effects on adherence for these delivery system design interventions (two studies, 686 participants; risk ratio (RR) $1.02,95 \% \mathrm{Cl} 0.99$ to 1.05; Analysis 2.1). This equates, on average, to an additional 19 people out of 1000 wearing their hearing aid up to six months post-intervention. We found no studies that reported the effect of delivery system redesign on adherence in the long term. Our confidence in the quality of the evidence for the effect of delivery system design interventions on adherence is low.

\subsection{Daily hours of hearing aid use}

Six delivery system design studies reported daily hours of hearing aid use over the short- to medium-term (Campos 2013; Cherry 1994; Collins 2013; Cunningham 2001; Lavie 2014; Ward 1981). The data from the Ward 1981 and Lavie 2014 studies could not be combined in a meta-analysis. Ward 1981 reported no significant difference in hours of use between a group given information about hearing tactics in written format versus face-to-face. Lavie 2014 reported that simultaneous bilateral hearing aid fitting resulted in significantly more hours of use per day than bilateral hearing aids fitted sequentially in two separate visits. In Campos 2013, they measured self-reported daily hours of use and data-logged hours of use. We could not use the self-reported hours of use in this analysis because no standard deviations or other measures of variance were reported in the study. However, they did report high levels of correlation $(r=0.81, P$ value $=0.00$ for the intervention group and $r=0.74$, $P$ value $=0.00$ for the control group) between the self-reported data and the data-logging. We have therefore combined the data-logging results in this analysis. There was no evidence of a short- to medium-term statistically significant effect on daily hours of hearing aid use for these delivery system design interventions (four studies, 700 participants; MD - $0.06,95 \% \mathrm{Cl}-1.06$ to 0.95; Analysis 2.2). This MD equates to the participants in the intervention groups wearing their hearing aids for three to four minutes less in each day than those in the control groups. We found no delivery system design interventions that reported daily hours of hearing aid use in the long term. Our confidence in the quality of the evidence for the effect of delivery system design interventions on daily hours of hearing aid use is very low.

\section{Adverse effects}

\subsection{No studies reported on clinical adverse events.}

2.2 Only one study looked at the number of outstanding complaints after the provision of telephone follow-up and reported no statistically significant difference in the number of complaints at one-year follow-up (one study, 98 participants; RR 0.75, 95\% Cl 0.50 to 1.12; Analysis 2.3) (Cherry 1994). This difference equates to 142 fewer complaints per 1000 participants in the group who received scheduled telephone follow-up. Clinically this might represent a significant difference although this study was underpowered to detect it, hence the wide confidence intervals. Our confidence in the quality of the evidence for the effect of delivery system design interventions on the number of outstanding complaints in the long term is very low.

\section{Secondary outcomes}

\section{Quality of life}

No delivery system design intervention studies reported quality of life as an outcome.

\section{Hearing handicap}

Two studies measured the effect of delivery system design interventions on short- to medium-term hearing handicap and yielded data in a form that we were able to combine in a quantitative analysis (Cherry 1994; Collins 2013). Data from these 
two studies showed no statistically or clinically significant shortto medium-term effect on hearing handicap, as measured using the Hearing Handicap Inventory for the Elderly (Ventry 1982), for delivery system design interventions as a whole (two studies, 628 participants; MD $-0.70,95 \% \mathrm{Cl}-5.22$ to 3.81 ; Analysis 2.4). The Cherry 1994 study compared scheduled telephone follow-ups (delivery system design intervention - change in format) with face-to-face follow-up on request (control). The Collins 2013 study compared group fitting and follow-up (delivery system design intervention change in mode) with individual fitting and follow-up. We found no delivery system design interventions that reported long-term hearing handicap. Our confidence in the quality of the evidence of the effect of delivery system design interventions on self-reported hearing handicap is very low.

\section{Hearing aid benefit}

A single delivery system design intervention showed no evidence of statistically or clinically significant effect on short- to mediumterm hearing aid benefit (one study, 582 participants; MD 1.80, $95 \% \mathrm{Cl}-3.10$ to 6.70; Analysis 2.5) (Collins 2013). We found no delivery system design studies that reported on long-term hearing aid benefit. Our confidence in the quality of the evidence of the effect of delivery system design interventions on hearing aid benefit is very low.

\section{Communication}

One delivery system design intervention reported data on communication in the short- to medium-term (Collins 2013). This showed no statistically or clinically significant effect on short- to medium-term use of verbal communication strategies for group versus individual hearing aid fittings (one study, 588 participants; MD $-0.10,95 \% \mathrm{Cl}-0.40$ to 0.20 ; Analysis 2.6$)$. We found no delivery system design studies that reported long-term communication outcome. Our confidence in the quality of the evidence of the effect of delivery system design interventions on communication is very low.

\section{Combined self-management support/delivery system design interventions}

\section{Primary outcome}

\section{Hearing aid use}

\subsection{Adherence}

One combined self-management support/delivery system design intervention study reported data on adherence as defined in this review (Ferguson 2016). They reported that at five to eight weeks post fitting no participants given access to remote learning objects post fitting were non-users compared to $5 / 88$ in the control group (one study, 162 participants; risk ratio (RR) $1.06,95 \% \mathrm{Cl} 1.00$ to 1.12; Analysis 3.1). This equates, on average, to an additional 57 people out of 1000 wearing their hearing aid up to eight weeks post fitting. We found no studies that reported the effect of combined interventions on adherence in the long term. Our confidence in the quality of the evidence for the effect of combined self-management support/delivery system design interventions on long-term adherence is low.

\subsection{Daily hours of hearing aid use}

Two combined studies measured daily hours of hearing aid use over the long term (Oberg 2008; Oberg 2009). There was no statistically or clinically significant evidence of overall long-term effect for these combined self-management support/delivery system design interventions (two studies, 69 participants; MD 0.04, 95\% Cl -0.64 to 0.73 ; Analysis 3.2). There was some heterogeneity in these data $(12=55 \%)$. The studies did not differ in self-management support content, delivery system design format or intensity as we have defined them, so our subgroup analyses failed to explain this heterogeneity. However, the participants in the Oberg 2009 study were able to gain some experience in their own home with an experimental hearing aid prior to fitting rather than only in a clinic setting as they did in the Oberg 2008 study.

Nine of the combined self-management support/delivery system design studies that measured short- to medium-term daily hours of hearing aid use yielded data in a form suitable for meta-analysis (Andersson 1995; Andersson 1997; Ferguson 2016; Kemker 2004; Lundberg 2011; Oberg 2008; Oberg 2009; Thoren 2011; Thoren 2014). There was no statistically or clinically significant evidence of overall short- to medium-term effect on daily hours of hearing aid use (see total in Analysis 3.3, nine studies, 534 participants; MD $0.19,95 \% \mathrm{Cl}-0.01$ to 0.40 ). There were no apparent subgroup differences for self-management support content (Analysis 3.3), delivery system design format (Analysis 3.4) or delivery system design intensity (Analysis 3.5).

The data from two combined self-management support/delivery system design studies could not be combined in the quantitative analysis because we could not obtain either means and/or standard deviations (Eriksson-Mangold 1990; Ward 1978). Data from two further studies could not be combined because they used variants of the same measurement instrument for the intervention and control groups to measure use (Kramer 2005; Olson 2013). This comparison may be invalid and should be interpreted with caution (Laplante-Levesque 2012).

Our confidence in the quality of the evidence of the effect of combined self-management support/delivery system design interventions on daily hours of hearing aid use is very low.

\section{Adverse effects}

No combined studies reported on clinical adverse events or the number of complaints.

\section{Secondary outcomes}

\section{Quality of life}

Two combined self-management support/delivery system design studies assessed long-term quality of life (Oberg 2008; Oberg 2009). There was no evidence of a statistically significant long-term effect on quality of life for these interventions over and above that provided by the hearing aid itself (two studies, 69 participants; MD $0.32,95 \% \mathrm{Cl}-0.17$ to 0.80 ; Analysis 3.6).

Eight combined self-management support/delivery system design interventions reported short- to medium-term quality of life (Ferguson 2016; Kramer 2005; Lundberg 2011; Oberg 2008; Oberg 2009; Preminger 2010; Thoren 2011; Thoren 2014). Overall there was no evidence of a statistically or clinically significant effect for these combined interventions on short- to medium-term quality of life (eight studies, 530 participants; standardised mean difference (SMD) $0.02,95 \% \mathrm{Cl}-0.15$ to 0.19 ). There were no significant subgroup differences by self-management support 
content (Analysis 3.7), delivery system design format (Analysis 3.8) or delivery system design intensity (Analysis 3.9).

Our confidence in the quality of the evidence of the effect of combined self-management support/delivery system design interventions on quality of life is low.

\section{Hearing handicap}

All of the studies reporting long-term hearing handicap were combined self-management support/delivery system design interventions. We were able to combine three of these studies in a meta-analysis, which showed no overall evidence of a statistically significant effect (three studies, 88 participants; SMD $-0.31,95 \% \mathrm{Cl}$ -1.06 to 0.44; Analysis 3.10) (Andersson 1994; Oberg 2008; Oberg 2009). However, there was evidence of heterogeneity in these data. A subgroup analysis by self-management support content suggests that the intervention containing components of psychosocial activation had a greater effect on hearing handicap than the two interventions that aimed to address symptom management skills. The three studies do not differ in delivery system design format or delivery system design intensity. However, we judged the Andersson 1994 study to have a high risk of bias. Based on this evidence, our confidence in the quality of the conclusion that psychosocial self-management support interventions might be more effective than symptom-focused self-management support interventions is very low.

We combined the data from 14 studies that assessed the effect of combined self-management support/delivery system design interventions on short- to medium-term hearing handicap in meta-analyses (Abrams 1992; Andersson 1995; Andersson 1997; Ferguson 2016; Kramer 2005; Kricos 1996; Lundberg 2011; Miranda 2008; Oberg 2008; Oberg 2009; Preminger 2010; Smaldino 1988; Thoren 2011; Thoren 2014) (Analysis 3.11; Analysis 3.12; Analysis 3.13). Overall there was evidence of a statistically significant effect on hearing handicap for these interventions (14 studies, 681 participants; SMD $-0.26,95 \% \mathrm{Cl}-0.50$ to -0.02$)$. A SMD of this magnitude reflects a small effect size (Cohen 1988). Subgroup analysis by self-management support content shows no significant subgroup differences (Analysis 3.11). Analysing the data by delivery system design format and delivery system design intensity suggests that an intervention involving telephone followup was more effective than interventions delivered face-to-face or remotely (Analysis 3.12) and that medium-intensity interventions are more effective than high-intensity (Analysis 3.13). However, a visual inspection suggests within-subgroup heterogeneity in these analyses. The interventions also varied by mode and location of care delivery and it is likely that interaction between these and the other variables is contributing to this heterogeneity. These subgroup analyses should therefore be viewed with caution.

\section{Hearing aid benefit}

We were able to combine two of the four combined selfmanagement support/delivery system design interventions that assessed long-term hearing aid benefit in a quantitative analysis (Oberg 2008; Oberg 2009). This showed a statistically significant effect for these combined interventions on long-term hearing aid benefit (two studies, 69 participants; MD $0.30,95 \% \mathrm{Cl} 0.02$ to 0.58; Analysis 3.14). However, this does not represent a clinically significant difference on this scale (Cox 2002; Smith 2009). Both studies assessed the effect of changes in self-management support content (activate - symptoms versus no intervention) and delivery system design intensity (medium-intensity versus no intervention). We have therefore not performed a subgroup analysis of these data.

In the short to medium term there was no evidence of a statistically or clinically significant effect for combined self-management support/delivery system design interventions (see total in Analysis 3.15; seven studies, 361 participants; SMD $0.10,95 \% \mathrm{Cl}-0.15$ to 0.36). There were no apparent significant subgroup differences by self-management support content (Analysis 3.15), delivery system design format (Analysis 3.16) or delivery system design intensity (Analysis 3.17).

Our confidence in the quality of the evidence of the effect of combined self-management support/delivery system design interventions on hearing aid benefit is low.

\section{Communication}

Only two of the studies reported an overall single score measure of communication (Preminger 2010; Sweetow 2006), but we were unable to combine these in meta-analyses. The Sweetow 2006 study reported only combined data from both periods of their cross-over study and contact with the authors confirmed that it was not possible to extract the data for the first period of the study separately. The Preminger 2010 study included data on two cochlear implant users and we were not able to separate the data for the hearing aid users only. The remaining studies used the Communication Profile for the Hearing Impaired to measure communication ability (Demorest 1987), with some choosing to use only the communication strategies subscale of this measure. This measures whether people use verbal, non-verbal and maladaptive strategies for communication. There was evidence of selective reporting in these data, with at least one of the studies reporting data only from scales where significant differences were seen (Kricos 1996).

Only two studies reported effects on long-term communication for combined self-management support/delivery system design interventions (Chisolm 2004; Oberg 2008). Chisolm 2004 only provided mean scores with no measures of variance so data are only available from the Oberg 2008 study. This showed no evidence of a statistically or clinically significant effect on the use of verbal communication strategies over the long term (one study, 34 participants; MD $0.30,95 \% \mathrm{Cl}-0.20$ to 0.80 ; Analysis 3.18).

A meta-analysis of the four combined self-management support/ delivery system design studies reporting short- to medium-term communication outcomes that we were able to combine showed evidence of a statistically significant short- to medium-term effect on the use of verbal communication for these combined selfmanagement support/delivery system design interventions (see total Analysis 3.19; four studies, 223 participants; MD 0.45, 95\% $\mathrm{Cl} 0.15$ to 0.74) (Chisolm 2004; Kricos 1996; Oberg 2008; Turbin 2006). However, this mean difference does not represent a clinically significant difference based on a minimal important difference of 0.93 for this scale (Demorest 1988). All the studies involved faceto-face delivery and there were no significant subgroup differences by self-management support content (Analysis 3.19) and delivery system design intensity (Analysis 3.20). Our confidence in the quality of the evidence of the effect of combined interventions on communication is very low. 


\section{Decision support interventions}

We found no studies that investigated the potential effects of decision support interventions.

\section{Clinical information system interventions}

We found no studies that investigated the potential effects of clinical information system interventions.

\section{Community interventions}

We found no studies that investigated the potential effects of community interventions.

\section{Health system interventions}

We found no studies that investigated the potential effects of health system interventions.

\section{DISCUSSION}

\section{Summary of main results}

We reviewed the range, nature and long-term effects of any intervention supplementing, but not including, hearing aid fitting that had the aim of improving or encouraging hearing aid use in adult auditory rehabilitation.

All the studies we identified could be classified using the chronic care model (CCM) as self-management support and/or delivery system design interventions.

We found no self-management support studies that investigated the effect of self-management support on adherence, adverse effects or hearing aid benefit. Two studies reported daily hours of hearing aid use but we were unable to combine these in a meta-analysis. There was no evidence of a statistically significant effect on quality of life over the short to medium term (one study, 35 participants; mean difference (MD) -9.10, 95\% confidence interval $(\mathrm{Cl})-21.33$ to 3.13). Self-management support interventions reduce short- to medium-term hearing handicap (two studies, 87 participants; MD $-12.80,95 \% \mathrm{Cl}-23.11$ to -2.48 ) and increase the use of verbal communication strategies in the short to medium term (one study, 52 participants; MD $0.72,95 \% \mathrm{Cl} 0.21$ to 1.23). The clinical significance of these statistical findings is open to question but, based on the minimal important differences on the scales used, it is likely that the outcomes were clinically significant for some, but not all, participants. Our confidence in the quality of this evidence was very low. No self-management support studies reported long-term outcomes (see Summary of findings for the main comparison).

Delivery system design interventions did not significantly effect adherence (two studies, 686 participants; risk ratio (RR) 1.02, 95\% $\mathrm{Cl} 0.99$ to 1.05 ) or daily hours of hearing aid use (four studies, 700 participants; MD $-0.06,95 \% \mathrm{Cl}-1.06$ to 0.95 ) in the short to medium term or adverse effects in the long term (one study, 98 participants; $\mathrm{RR} 0.75,95 \% \mathrm{Cl} 0.50$ to 1.12 ). We found no studies that investigated the effect of delivery system design changes on quality of life. There was no evidence of a statistically or clinically significant effect on hearing handicap (two studies, 628 participants; MD $-0.70,95 \% \mathrm{Cl}-5.22$ to 3.81 ), hearing aid benefit (one study, 582 participants; MD $1.80,95 \% \mathrm{Cl}-3.10$ to 6.70 ) or the use of verbal communication strategies (one study, 588 participants, MD -0.10, $95 \% \mathrm{Cl}-0.40$ to 0.20 ) in the short to medium term. Our confidence in the quality of this evidence was low or very low. Long-term outcome measurement was rare in delivery system design comparisons (see Summary of findings 2).

We found no studies that investigated the effect of complex interventions combining components of self-management support and delivery system redesign on adverse effects. A single study showed a probable effect on adherence in the short term (one study, 162 participants; risk ratio (RR) $1.06,95 \% \mathrm{Cl} 1.00$ to 1.12 ). There was no evidence of a statistically or clinically significant effect on daily hours of hearing aid use over the long term (two studies, 69 participants; MD $0.04,95 \% \mathrm{Cl}-0.64$ to 0.73 ) or short to medium term (nine studies, 534 participants; MD 0.19, 95\% Cl-0.01 to 0.40 ). Similarly, there was no evidence of an effect on quality of life over the long term (two studies, 69 participants; MD 0.32, $95 \% \mathrm{Cl}-0.17$ to 0.80 ) or short to medium term (eight studies, 530 participants; standardised mean difference (SMD) 0.02, 95\% Cl-0.15 to 0.19 ). Combined interventions reduced hearing handicap in the short to medium term (14 studies, 681 participants; SMD - $0.26,95 \%$ $\mathrm{Cl}-0.50$ to -0.02$)$. This represents a small to moderate effect size but there is no evidence of a statistically significant effect over the long term (three studies, 88 participants; SMD $-0.31,95 \% \mathrm{Cl}-1.06$ to 0.44$)$. There was evidence of a statistically, but not clinically, significant effect on long-term hearing aid benefit (two studies, 69 participants; MD $0.30,95 \% \mathrm{Cl} 0.02$ to 0.58 ), but no evidence of an effect over the short to medium term (seven studies, 361 participants; SMD $0.10,95 \% \mathrm{Cl}-0.15$ to 0.36 ). There was evidence of a statistically, but not clinically, significant effect on the use of verbal communication strategies in the short term (four studies, 223 participants; MD $0.45,95 \% \mathrm{Cl} 0.15$ to 0.74 ), but not the long term (one study, 34 participants; $\mathrm{MD} 0.30,95 \% \mathrm{Cl}-0.20$ to 0.80 ). Our confidence in the quality of this evidence was low or very low (see Summary of findings 3 ).

There were no studies investigating the effect of decision support, the use of clinical information systems, community resources or health system changes.

\section{Overall completeness and applicability of evidence}

\section{Completeness}

In terms of interventions, although we were able to identify 37 studies for inclusion in this review we classified all of them as delivery system design and/or self-management support interventions. There was a lack of randomised controlled trial (RCT) evidence looking at decision support, clinical information systems, community support or health system changes. Some components of delivery system design and self-management support have also not been fully explored. For example, there were no studies that specifically addressed the effect of supporting hearing aid use with the provision of additional services such as battery replacement services and the provision of, or referral for, additional equipment to improve hearing aid benefit. No studies involved the explicit use of collaborative goal-setting or action-planning and the patients' central role in managing their own health was often not explicitly acknowledged. These are central tenets of a selfmanagement support approach. There has been relatively little focus on low-intensity interventions and no studies that consider the reorganisation of staff roles. Using a framework such as the CCM has helped to highlight considerable gaps in the evidence base in terms of interventions that have been tested in RCTs in this context. The majority of interventions we found included components of 
both delivery system design and self-management support. This is consistent with the results of the review by Tsai 2005 for long-term conditions.

The CCM and other similar frameworks are general so that they can be applied in any healthcare context. This can mean that some of the detail about what works and what does not work can be lost. We hoped that the subgroup analyses might provide a useful model to explore what components of interventions may be most effective in changing particular outcomes. In the majority of cases our subgroup analyses did not help to answer this question. Partly this was due to a lack of data. Even for those comparisons and outcomes where we had more data (e.g. Analysis 3.13), there was a lack of data in some groups but not others, which makes a valid assessment of subgroup differences difficult. In addition, we did not analyse our data using other subgroups suggested by Barlow 2002, such as target population or delivery location. One possible avenue may be to explore not only the purpose of participant activation (addressing practical, symptom-management and psychosocial management skills) as we have done, but also the depth of activation. We would welcome a discussion on the potential viability of comparing interventions in which the minimum level of participant engagement is attendance, those that require some engagement in practical activities under the direct supervision of clinicians in a clinic-based environment and those which engage the participants in collaboratively agreed 'homework' under indirect professional guidance with appropriate follow-up. It would also be interesting to look more closely at the self-management support interventions and analyse the content in terms of behaviour change technique employed, for example using the behaviour change technique taxonomy (version 1) (Michie 2013). Combining this with a meta-regression could yield a more granular understanding of the relative contribution of different active ingredients of an intervention.

In terms of the primary outcomes, there was a relative lack of data on adherence and adverse effects. The problem of hearing aid nonuse is always stated in terms of adherence (or lack of it) and so it is disappointing that few studies chose to report the outcome of their interventions in this way. It makes it difficult to relate the results of the studies back to the original problem. Adherence, using the definition we have adopted from the World Health Organization, implies a level of agreement with the chosen management option. For the purposes of this review we assumed that a hearing aid fitting was the agreed course of action. However, the level of collaboration between patient and clinician was not mentioned explicitly in any of the studies we included, something highlighted in our subgroup analyses by self-management support content. It is possible that the included studies were therefore measuring compliance rather than adherence as we have defined it. When studies did consider hearing aid use it was usually measured as self-reported hours of use per day. It was rare for studies to make any mention of the potential for adverse effects, which is a limitation in study design and outcome measurement to date.

Patient-reported secondary outcomes were measured with a variety of metrics even for the same outcome. Hearing loss has complex consequences and the measurement of outcome is therefore complex (Granberg 2014). There is a lack of consensus over which outcomes are important in hearing health and a lack of agreement on which specific scales should be used to measure those outcomes (Hanratty 2000; Humes 2011). This diversity was reflected in this review and made meta-analysis for some of the outcomes difficult. Our results suggest that any positive outcomes due to changes in the way care is delivered are small and incremental compared to the benefits of the hearing aid itself. All of the scales used in our meta-analyses had minimal important differences of approximately $20 \%$ of the total scale score. This means that interventions would need to produce average mean differences of that magnitude to be considered clinically significant. Studies aiming to measure these potential incremental benefits should bear this in mind in their choice of patient-reported outcome measure.

This review also highlights the need for further studies that consider long-term outcomes over a year or more. It is of great importance to know whether a particular intervention has lasting effects over the long term, especially in the context of managing a long-term condition. It is not safe to assume that short-term positive outcomes translate into the long term. A patient may persevere with hearing aid use while they are still receiving relatively intense support from their clinician but then lapse when they are left to self-manage their condition over the longer term. However, the reverse may also be true for some outcomes. Positive outcomes may not been seen in the short term but may only be evident in the long term once participants have had the benefit of extended practice and experience.

The number of studies that provided data in a form that could be included in a meta-analysis was relatively low. This is not unusual in systematic reviews (Johnston 2013), but is not something to be applauded. Sometimes raw data were not available, with only the overall conclusion being reported in the paper, and sometimes particular figures such as standard deviations or other measures of data spread were missing. A significant amount of data could not be combined or had high standard deviations relative to the means and therefore carried a high risk of skew. This variability in the data highlights the need to include a priori estimates of effect size so that studies are appropriately statistically powered.

\section{Applicability}

All of the studies identified were carried out in countries with well-developed health systems; this limits the applicability of the findings beyond such systems.

Some of the studies involved the use of veterans as participants (Abrams 1992; Chisolm 2004; Collins 2013; Kemker 2004; Preminger 2010a; Saunders 2016; Turbin 2006). While in terms of study numbers these were a minority, in terms of participants they represented almost a third of the total (1297/4129 participants). This weights the results towards a largely male, highly motivated population, which limits the generalisability of the findings to the non-military population, a limitation acknowledged in most of these studies.

The studies all had specific inclusion/exclusion criteria that often meant that people with comorbid conditions were excluded. Some had age restrictions either at the younger or older end, sometimes both. Again this limits the generalisability of the findings.

There were no large-scale effectiveness trials conducted in unselected populations. 


\section{Quality of the evidence}

Twelve studies have publication dates from 2001 to 2009 but none referenced the CONSORT 2001 guidelines. A further 13 studies were published after 2010 and the updated CONSORT guidelines (CONSORT 2010), but only four referenced the updated guidance (Ferguson 2016; Saunders 2016; Thoren 2011; Thoren 2014).

The studies were of variable methodological rigour (see Figure 3) and many of them did not report raw data or reported data in such a way that they could not be included in a meta-analysis. There was a diversity of outcome metrics, which sometimes made comparisons between studies difficult.

We have assessed the results for the primary and secondary outcomes using GRADE protocols and the results are included in the 'Summary of findings' tables (Summary of findings for the main comparison; Summary of findings 2; Summary of findings 3). For self-management support interventions, delivery system design interventions and combined interventions we judged the limited evidence to be of very low to low quality against the GRADE criteria (Higgins 2011). Where evidence was downgraded this was due limitations in study design (high or unclear risk of bias across studies for a particular outcome), indirectness (in terms of population and outcome measurement) and imprecision (small sample sizes, large confidence intervals, high risk of skewed data).

\section{Potential biases in the review process}

We cannot exclude the possibility that other studies have been published showing positive or negative results, which have not been included here, but we are confident that the extensive electronic search and subsequent reference checking has captured most of the relevant literature. However, we invite readers to notify us of any trials or studies we may have missed so that they might be included in subsequent updates to this review. Similarly, although we did make efforts to contact study authors directly to clarify study methods and obtain raw data where possible, we were not always able to do so. We would very much welcome contact from any of the authors cited in this review who feel that their data could be included in the meta-analysis in future updates.

Some of the studies were excluded on the basis that their outcomes did not meet the inclusion criteria for this review. As far as we are aware, based on an assessment of the methods sections of these studies, the relevant outcomes were not available because they were not measured. However, it is possible that other outcomes were measured and not reported. We invite the authors of these studies to contact us if additional outcomes, which could be included in future updates, were measured but not reported.

Two review authors independently selected trials, extracted data, assessed risk of bias and graded the quality of evidence in order to minimise bias in the review process.

None of the review authors had any involvement in any of the trials. This has not been the case in some previous systematic reviews in the context of hearing healthcare (Chisolm 2011; Sweetow 2005).

\section{Agreements and disagreements with other studies or reviews}

Like Barlow 2002, Kreindler 2009 and Tsai 2005, we found in our review that many interventions were a complex combination of delivery system design and self-management support components. Developing the skills necessary to become a self-manager of a long-term condition requires information and support for behaviour change to deal with the symptom, physical and psychosocial consequences of the condition (Barlow 2002; Lorig 2003; Pearson 2007). We feel that the CCM has been a useful starting framework within which to separate out the possible effects of different aspects of complex interventions, e.g. components of self-management support and components of delivery system design. In their review of self-management approaches for people with long-term conditions, Barlow 2002 sought to identify approaches to self-management and to consider the effectiveness of these approaches. Of the 145 studies they identified, only one looked at a sensory problem: tinnitus (Jakes 1986). The results of our review suggest that many of the studies we identified could be included if the Barlow 2002 review were to be updated. Barlow 2002 found that self-management support interventions rarely target carers. In our review many of the studies included content addressing communication, which is necessarily a two-way process, but only one specifically addressed the effect of explicit involvement of significant others or communication partners (Preminger 2010). In the Barlow 2002 review, approximately half the studies were RCTs but with small sample sizes (20 to 30 ) and short follow-up periods (four to six months). They called, like us, for RCTs of sufficient power to enable change to be detected and for longer-term follow-up.

In the context of hearing health care, previous reviews have tended to concentrate on specific intervention types, such as auditory training or changes in delivery such as group versus individual delivery.

A previous systematic review conducted by Sweetow 2005, subsequently updated to include a meta-analysis by Chisolm 2011, addressed the evidence for individual auditory training. This type of intervention involves the patient participating in a programme of training designed to enhance speech perception. Training is typically provided on a repeated basis over a number of sessions and involves practice with listening and recognition of speechbased material. The speech-based training material may be broken down into its constituent parts with the aim of improving the discrimination and recognition of those parts (analytic training), or presented in sentence-length structures with the aim of improving listening skill and overall comprehension (synthetic training). Both the original Sweetow 2005 review and the Chisolm 2011 update included RCTs but also cohort and before/after study designs where participants may act as their own controls. Sweetow 2005 identified six studies for inclusion with four studies being added in the Chisolm 2011 update. Six of these 10 studies were RCTs and three of these were included in our review also (Kricos 1992; Kricos 1996; Sweetow 2006). The three other RCTs were excluded from this review because their only reported outcome was speech perception (see Characteristics of excluded studies). They concluded that there was evidence of improvement in speech perception in adults with hearing loss who undertake auditory training at least in the short term (i.e. immediately after training). A more recent systematic review of individual computer-based auditory training by Henshaw et al concluded that the published evidence for the efficacy of auditory training for adults with hearing loss is not robust (Henshaw 2013). 
A review by Hawkins 2005 (and subsequently updated by Chisolm 2011) assessed the evidence for counselling-based group auditory rehabilitation programmes. They looked at effects on short- and long-term self-perceived benefits, satisfaction or both. Like the Sweetow 2005 review they did not limit inclusion to RCTs. Hawkins 2005 highlighted the need for further well-controlled studies, with adequate numbers of participants, given the variability evident in the reviewed studies. We would echo this call. Chisolm 2011 updated this review, focusing particularly on RCTs but also including studies that included people who were not using hearing aids. They identified 10 studies, seven of which also met the inclusion criteria for this review (two were excluded as they included non-hearing aid users (Hallberg 1994; Hickson 2007), and one was excluded as it was a second paper on the same set of participants as an already included study (Chisolm 2004)). Chisolm 2011 conducted a meta-analysis looking at hearing handicap as an outcome. They found a small but significant effect of group auditory rehabilitation on short-term hearing handicap. However, their analysis did include some double-counting, with the participants in Chisolm 2004 counted twice and the control participants for Preminger 2010 and Smaldino 1988 counted three times. They highlighted the variability present in their data but did not investigate possible reasons for the apparent heterogeneity.

A major weakness of both of these reviews is that they do not consider interactions between the content and delivery of interventions and comparisons. Auditory training is typically delivered over many sessions and would therefore constitute a high-intensity intervention as we have defined it, but it is often compared with standard care which is low- or mediumintensity. It is rare for auditory training studies to control for this, although Kricos 1996, Fitzpatrick 2008 and Saunders 2016 did do this and have hence been defined in our review as selfmanagement support interventions. They therefore provide more robust evidence on the effect of changing the content of an intervention. We found a similar issue when comparing group interventions versus individual interventions. Studies often do not control for variations in what is delivered between intervention and control groups. The one study we found that did control for content showed no significant difference in hearing handicap between group and individual delivery mode when the same content was delivered to both (Collins 2013).

A second weakness in both of these reviews is a lack of acknowledgement or assessment of risk of bias and other factors impacting on confidence in the quality of the evidence as recommended in GRADE protocols.

Using the CCM and work by Barlow 2002 and Pearson 2007 as a framework for this review has demonstrated clearly that most interventions in hearing health care are a complex mix of selfmanagement support and delivery system design changes. Using this framework we have attempted to identify some of the potential active components of these complex interventions. While we have been only partially successful we have at least highlighted that this issue exists. Careful delineation of the different factors that may have an impact on outcome for these complex interventions is essential in drawing conclusions when reviews are undertaken or updated in future.

\section{AUTHORS' CONCLUSIONS}

\section{Implications for practice}

There is some low to very low quality evidence to support the use of self-management support and complex interventions combining components of self-management support and delivery system design in hearing health care. However, the range of interventions that have been tested is relatively narrow. Data on long-term outcomes are sparse.

\section{Implications for research}

There are many opportunities for further research in this context. The design and funding of future research should include a focus on investigating long-term outcomes. This has also been highlighted in other systematic reviews (Barlow 2002; Chisolm 2011; Hawkins 2005; Sweetow 2005), as has the need for larger, appropriately powered studies in this context.

Using the chronic care model (CCM) and the literature on selfmanagement support and its delivery as a theoretical backbone for this review has highlighted gaps in the evidence base, particularly in the elements of decision support, clinical information systems, health system and community-based interventions, where there is a total lack of high-level evidence. Some specific intervention types have received more attention, such as educative, counsellingbased self-management support and auditory training. However, the implementation of these interventions frequently also necessitates changes in delivery system design. The interaction between these two elements is rarely explicitly explored in hearing health care research. In future it would be helpful if researchers clearly delineate and describe the potentially active components of their interventions and use mixed methods to investigate the relative contribution of different components of any intervention. Even within the CCM elements where data are available relatively little research has looked at explicitly engaging the patient as an active participant in their own rehabilitation. Collaborative goalsetting and problem-solving is an area that would benefit from further investigation.

In relation to the primary outcome in this review it would be helpful to see more studies consider behavioural outcomes such as hearing aid use in terms of adherence rather than hours of use per day. Careful consideration needs to be given to the definition of adherence used. As defined in this review it acts both as a behavioural outcome but also brings in a need to acknowledge explicitly collaborative goal-setting in intervention study design. Otherwise studies may choose to measure a purely behavioural outcome (is the patient wearing their hearing aid?) or compliance (is the patient wearing their hearing aid as recommended?). It would be useful to supplement self-report data on hearing aid use (either defined as adherence or use in hours per day) with datalogging. More recent studies are starting to do this. Although datalogging is not a perfect measure of actual behaviour it can act to triangulate purely self-reported results. Previous authors have called for more standardisation in the way that hearing aid use is assessed and categorised (Perez 2012). Researchers should also be alert to the possibility of adverse effects of interventions.

A wide variety of patient-reported outcomes measures were reported in this review. It would be beneficial, in terms of combining study results and comparing interventions, to agree a set of core 
outcomes for future research into auditory rehabilitation, both in terms of outcome type (e.g. benefit, hearing handicap, quality of life etc.) and in the measure used to record that outcome. Agreed measures of outcome would also allow mean differences rather than standardised mean differences to be used, which will make it easier to convert results back into meaningful changes on the relevant scales. This will make results easier to interpret and relate back to clinical practice using minimal important differences where available. Measures used for patient-reported outcomes should be sensitive enough to detect incremental changes in outcome over and above those provided by a hearing aid.

This review has highlighted the variable risk of bias in studies to date (Figure 3). Although performance bias is difficult to remove or control for in studies of this type, it is possible to do a better job with detection bias (blinding of outcome assessment) and this would significantly reduce the risk of bias in many of these studies (see, for example, Hickson 2007). Studies should include a better description of the randomisation procedure to allow an accurate assessment of the risk of selection bias to be made. Wider publication of study protocols would allow a clearer assessment of publication bias.
It should be a priority for future randomised controlled trials to cite and adhere to the CONSORT guidelines (CONSORT 2010), something that has been largely lacking in the evidence thus far.

\section{ACKNOWLEDGEMENTS}

The authors would like to acknowledge the support and advice of Cochrane ENT and the UK Cochrane Centre, particularly Lee-Yee Chong.

The authors would like to acknowledge the support and advice of Cochrane Schizophrenia for their work on generic content, some of which has been adapted for use in this review (with permission).

This project was supported by the National Institute for Health Research, via Cochrane Infrastructure, Cochrane Programme Grant or Cochrane Incentive funding to Cochrane ENT. The views and opinions expressed therein are those of the authors and do not necessarily reflect those of the Systematic Reviews Programme, NIHR, NHS or the Department of Health. 
REFE RE N CES

\section{References to studies included in this review}

Abrams 1992 \{published data only\}

Abrams HB, Hnath-Chisolm T, Guerreiro SM, Ritterman SI. The effects of intervention strategy on self-perception of hearing handicap. Ear and Hearing 1992;13:371-7.

\section{Andersson 1994 \{published data only\}}

Andersson G, Melin L, Scott B, Lindberg P. Behavioral counselling for subjects with acquired hearing loss. A new approach to hearing tactics. Scandinavian Audiology 1994;23(4):249-56.

\section{Andersson 1995 \{published data only\}}

Andersson G, Melin L, Scott B, Lindberg P. A two-year follow up examination of a behavioural treatment approach to hearing tactics. British Journal of Audiology 1995;29:347-54.

* Andersson G, Melin L, Scott B, Lindberg P. An evaluation of a behavioural treatment approach to hearing impairment. Behavioural Research and Therapy 1995;33(3):283-92.

\section{Andersson 1997 \{published data only\}}

Andersson G, Green M, Melin L. Behavioural hearing tactics: a controlled trial of a short treatment programme. Behavioural Research and Therapy 1997;35(6):523-30.

\section{Beynon 1997 \{published data only\}}

Beynon GJ, Thornton FL, Poole C. A randomized, controlled trial of the efficacy of a communication course for first time hearing aid users. British Journal of Audiology 1997;31(5):345-51.

\section{Campos 2013 \{published data only\}}

Campos PD, Ferrari DV. Teleaudiology: evaluation of teleconsultation efficacy for hearing aid fitting. Jornal da Sociedade Brasileira de Fonoaudiologia 2012;24(4):301-8.

\section{Cherry 1994 \{published data only\}}

* Cherry R, Rubinstein A. The effect of telephone intervention on success with amplification. Ear and Hearing 1994;15(3):256-61.

Cherry R, Rubinstein A. The long-term effect of early telephone intervention on hearing aid success. Scandinavian Audiology 1995;24(4):243-6.

\section{Chisolm 2004 \{published data only\}}

Abrams H, Chisolm TH, McArdle R. A cost-utility analysis of adult group audiologic rehabilitation: are the benefits worth the cost?. Journal of Rehabilitation Research and Development 2002;39:549-57.

* Chisolm TH, Abrams HB, McArdle R. Short- and long-term outcomes of adult audiological rehabilitation. Ear and Hearing 2004;25(5):464-77.

\section{Collins 2013 \{published data only\}}

* Collins MP, Liu CF, Taylor L, Souza P, Yueh B. Hearing aid effectiveness after aural rehabilitation: individual vs. group
(HEARING) trial results. Journal of Rehabilitation Research and Development 2013;50(4):585-98.

Collins MP, Souza PE, Liu CF, Heagerty PJ, Amtmann D, Yueh B. Hearing aid effectiveness after aural rehabilitation - individual versus group (HEARING) trial: RCT design and baseline characteristics. BMC Health Services Research 2009;9:233.

\section{Cunningham 2001 \{published data only\}}

Cunningham DR, Williams KJ, Goldsmith LJ. Effects of providing and withholding postfitting fine-tuning adjustments on outcome measures in novice hearing aid users: a pilot study. American Journal of Audiology 2001;10:13-23.

\section{Eriksson-Mangold 1990 \{published data only\}}

Eriksson-Mangold M, Ringdahl A, Björklund AK, Wåhlin B. The active fitting (AF) programme of hearing aids: a psychological perspective. British Journal of Audiology 1990;24(4):277-85

Ferguson 2016 \{published data only\}

Ferguson M, Brandreth M, Brassington W, Leighton $\mathrm{P}$, Wharrad $\mathrm{H}$. A randomised controlled trial to evaluate the benefits of a multimedia educational program for first-time hearing aid users. Ear and Hearing 2016;37(2):123-36.

Fitzpatrick 2008 \{unpublished data only\} Fitzpatrick D. Effects of Auditory Training on Speech Recognition for Persons within Binaural Sensorineural Hearing Loss [PhD thesis]. New York University, 2008.

Gil 2010 \{published data only\} Gil D, lorio MC. Formal auditory training in adult hearing aid users. Clinics (Sao Paulo) 2010;65:165-74.

Kemker 2004 \{published data only\}

Kemker BE, Holmes AE. Analysis of prefitting versus postfitting hearing aid orientation using the Glasgow Hearing Aid Benefit Profile (GHABP). Journal of the American Academy of Audiology 2004;15(4):311-23.

Kramer 2005 \{published data only\}

Kramer SE, Allessie GH, Dondorp AW, Zekveld AA, Kapteyn TS. A home education program for older adults with hearing impairment and their significant others: a randomized trial evaluating short- and long-term effects. International Journal of Audiology 2005;44(5):255-64.

Kricos 1992 \{published data only\}

Kricos P, Holmes AE, Doyle D. Efficacy of a communication training program for hearing-impaired elderly adults. Journal of the Academy of Rehabilitative Audiology 1992;25:69-80.

Kricos 1996 \{published data only\} Kricos PB, Holmes AE. Efficacy of audiologic rehabilitation for older adults. Journal of the American Academy of Audiology 1996; 7:219-29. 
Lavie 2014 \{published data only\}

Lavie L, Banai K, Attias J, Karni A. Better together: reduced compliance after sequential versus simultaneous bilateral hearing aids fitting. American Journal of Audiology 2014;23:93-8.

\section{Lundberg 2011 \{published data only\}}

Lundberg M, Andersson G, Lunner T. A randomized, controlled trial of the short-term effects of complementing an educational program for hearing aid users with telephone consultations. Journal of the American Academy of Audiology 2011;22(10):654-62.

\section{Miranda 2008 \{published data only\}}

Miranda EC, Gil D, lorio MC. Formal auditory training in elderly hearing aid users. Brazilian Journal of Otorhinolaryngology 2008;74:919-25.

\section{Oberg 2008 \{published data only\}}

Oberg M. Approaches to Audiological Rehabilitation with Hearing Aids: Studies on Pre-fitting Strategies and Assessment of Outcomes [PhD dissertation]. Linkoping University, 2008.

* Oberg M, Andersson G, Wanstrom G, Lunner T. The effects of a sound awareness pre-fitting intervention: a randomized controlled trial. Audiological Medicine 2008;6(6):129-40.

\section{Oberg 2009 \{published data only\}}

Oberg M. Approaches to Audiological Rehabilitation with Hearing Aids: Studies on Pre-fitting Strategies and Assessment of Outcomes [PhD dissertation]. Linkoping University, 2008.

* Oberg M, Andersson G, Wanstrom G, Lunner T. The effects of a pre-fitting intervention on hearing aid benefit: a randomized controlled trial. Audiological Medicine 2009;7(4):211-25.

\section{Olson 2013 \{published data only\}}

Olson AD. Auditory training at home for adult hearing aid users. Dissertation Abstracts International: Section B: The Sciences and Engineering. 2015.

Olson AD, Preminger JE, Shinn JB. The effect of LACE DVD training in new and experienced hearing aid users. Journal of the American Academy of Audiology 2013;24(3):214-30.

\section{Preminger 2008 \{published data only\}}

Preminger JE, Ziegler $\mathrm{CH}$. Can auditory and visual speech perception be trained within a group setting?. American Journal of Audiology 2008;17:80-97.

\section{Preminger 2010 \{published data only\}}

Preminger JE, Meeks S. Evaluation of an audiological rehabilitation program for spouses of people with hearing loss. Journal of the American Academy of Audiology 2010;21(5):315-28.

\section{Preminger 2010a \{published data only\}}

Preminger JE, Yoo JK. Do group audiologic rehabilitation activities influence psychosocial outcomes?. American Journal of Audiology 2010;19(2):109-25.

\section{Saunders 2009 \{published data only\}}

Saunders GH, Lewis MS, Forsline A. Expectations, prefitting counseling, and hearing aid outcome. Journal of the American Academy of Audiology 2009;20:320-34.

\section{Saunders 2016 \{published data only\}}

Saunders GH, Smith SL, Chisolm TH, Frederick MT, McArdle RA, Wilson $\mathrm{RH}$. A randomized control trial: supplementing hearing aid use with listening and communication enhancement (LACE) auditory training. Ear and Hearing 2016;37(4):381-96.

\section{Smaldino 1988 \{published data only\}}

Smaldino SE, Smaldino JJ. The influence of aural rehabilitation and cognitive style disclosure on the perception of hearing handicap. Journal of the Academy of Rehabilitative Audiology 1988;21:57-64.

\section{Sweetow 2006 \{published data only\}}

Sweetow RW, Sabes JH. The need for and development of an adaptive Listening and Communication Enhancement (LACE) Program. Journal of the American Academy of Audiology 2006;17(8):538-58.

\section{Thoren 2011 \{published data only\}}

Thoren E, Svensson M, Tornqvist A, Andersson G, Carlbring P, Lunner T. Rehabilitative online education versus internet discussion group for hearing aid users: a randomized controlled trial. Journal of the American Academy of Audiology 2011;22:274-85.

Thoren ES, Oberg M, Andersson G, Lunner T. Internet interventions for hearing loss. American Journal of Audiology 2015;24(3):316-9.

\section{Thoren 2014 \{published data only\}}

Thoren ES, Oberg M, Andersson G, Lunner T. Internet interventions for hearing loss. American Journal of Audiology 2015;24(3):316-9.

Thoren ES, Oberg M, Wanstrom G, Andersson G, Lunner T. A randomized controlled trial evaluating the effects of online rehabilitative intervention for adult hearing-aid users. International Journal of Audiology 2014;53(7):452-62.

Turbin 2006 \{published data only\} Department of Veterans Affairs. Clinical Trial of the "Living Well With Hearing Loss Workshop". http://clinicaltrials.gov/ct2/ show/NCT00323427 2006.

* Turbin M. Patient-centred, single session group AR: how it works and why it does. Conference presentation (obtained from the author).

\section{Vreeken 2015 \{published data only\}}

Vreeken HL, van Rens GH, Kramer SE, Knol DL, van Nispen RM. Effects of a dual sensory loss protocol on hearing aid outcomes: a randomized controlled trial. Ear and Hearing 2015;36(4):166-75. 
Ward 1978 \{published data only\}

Ward PR, Tudor CA, Gowers JI. Evaluation of follow up services for elderly people prescribed hearing aids: report of a pilot project. British Journal of Audiology 1978;12:127-34.

\section{Ward 1981 \{published data only\}}

* Ward PR, Gowers JI. Hearing tactics: the long-term effects of instruction. British Journal of Audiology 1981;15:261-2.

Ward PR, Gowers JI. Teaching hearing-aid skills to elderly people: hearing tactics. British Journal of Audiology 1981;15(4):257-9.

\section{References to studies excluded from this review}

Aazh 2016 \{published data only\}

Aazh $\mathrm{H}$. Feasibility of conducting a randomized controlled trial to evaluate the effect of motivational interviewing on hearingaid use. International Journal of Audiology 2016;55(3):149-56.

\section{Andersson 1998 \{published data only\}}

Andersson G. Decreased use of hearing aids following training in hearing tactics. Perceptual and Motor Skills 1998;87(2):703-6.

Bevilacqua 2013 \{published data only (unpublished sought but not used)\}

Bevilacqua MC, Costa Filho OA, Castiquini EA, Zambonatto TC, Morettin M, Moret AL, et al. Hearing aid fitting at SUS (Brazilian Public Health Care System) compared with a compact fitting model. Brazilian Journal of Otorhinolaryngology 2013;79(3):276-84.

\section{Boymans 2012 \{published data only\}}

Boymans M, Dreschler WA. Audiologist-driven versus patient-driven fine tuning of hearing instruments. Trends in Amplification 2012;16:49-58.

\section{Cardemil 2014 \{published data only\}}

Cardemil F, Barria T, Aguayo L, Esquivel P, Rahal M, Fuente A, et al. Assessment of the active communication education program for audiological rehabilitation in patients with hearing loss users of hearing aids. Rev Otorrhinolaryngol Cir Cabeza Cuello 2014;74:93-100.

\section{Hallberg 1994 \{published data only\}}

Hallberg LR, Barrenas ML. Group rehabilitation of middleaged males with noise-induced hearing loss and their spouses: evaluation of short- and long-term effects. British Journal of Audiology 1994;28:71-9.

\section{Hennig 2012 \{published data only\}}

Hennig TR, Costa MJ, Rossi AG, Moraes AB. Auditory rehabilitation effects on the temporal ordering ability in elderly hearing aids users. Jornal da Sociedade Brasileira de Fonoaudiologia 2012;24:26-33.

\section{Hickson 2007 \{published data only\}}

Hickson L, Worrall L, Scarinci N. A randomized controlled trial evaluating the active communication education program for older people with hearing impairment. Ear and Hearing 2007;28(2):212-30.

Kuk 2014 \{published data only\}

Kuk F, Keenan DM, Lau C, Crose B, Schumacher J. Evaluation of a localization training program for hearing impaired listeners. Ear and Hearing 2014;35:652-66.

Lavie 2013 \{published data only\}

Lavie L, Attias J, Karni A. Semi-structured listening experience (listening training) in hearing aid fitting: influence on dichotic listening. American Journal of Audiology 2013;22:347-50.

\section{Montgomery 1984 \{published data only\}}

Montgomery AA, Walden BE, Schwartz DM, Prosek RA. Training auditory-visual speech reception in adults with moderate sensorineural hearing loss. Ear and Hearing 1984;5(1):30-6.

\section{Norman 1994 \{published data only\}}

Norman M, George CR, McCarthy D. The effect of pre-fitting counselling on the outcome of hearing aid fittings. Scandinavian Audiology 1994;23:257-63.

\section{Preminger 2003 \{published data only\}}

Preminger JE. Should significant others be encouraged to join adult group audiologic rehabilitation classes?. Journal of the American Academy of Audiology 2003;14:545-55.

Reber 2005 \{published data only\}

Reber MB, Kompis M. Acclimatization in first-time hearing aid users using three different fitting protocols. Auris Nasus Larynx 2005;32:345-51.

\section{Ruschel 2007 \{published data only\}}

Ruschel CV, Carvalho CR de, Guarinello AC. The efficiency of an auditory rehabilitation program in elderly people with presbycusis and their family [A eficiência de um programa de reabilitação audiológica em idosos com presbiacusia e seus familiares]. Revista da Sociedade Brasileira de Fonoaudiologia 2007;12(2):95-8.

\section{Stecker 2006 \{published data only\}}

Stecker GC, Bowman GA, Yund EW, Herron TJ, Roup CM, Woods DL. Perceptual training improves syllable identification in new and experienced hearing aid users. Journal of Rehabilitation Research and Development 2006;43(4):537-52.

Walden 1981 \{published data only\}

* Walden BE, Erdman SA, Montgomery AA, Schwartz DM, Prosek RA. Some effects of training on speech recognition by hearing-impaired adults. Journal of Speech and Hearing Research 1981;24(2):207-16.

Yueh 2010 \{published data only\}

Liu CF, Collins MP, Souza PE, Yueh B. Long-term costeffectiveness of screening strategies for hearing loss. Journal of Rehabilitation Research and Development 2011;48(3):235-43.

Yueh B. Audiology visits after screening for hearing loss. Department of Veterans Affairs 2005. 
* Yueh B, Collins MP, Souza PE, Boyko EJ, Loovis CF, Heagerty PJ, et al. Long-term effectiveness of screening for hearing loss: the screening for auditory impairment--which hearing assessment test (SAI-WHAT) randomized trial. Journal of American Geriatric Society 2010;58(3):427-34.

Yueh B, Collins MP, Souza PE, Heagerty PJ, Liu CF, Boyko EJ, et al. Screening for auditory impairment-which hearing assessment test (SAI-WHAT): RCT design and baseline characteristics. Contemporary Clinical Trials 2007;28(3):303-15.

\section{References to studies awaiting assessment}

Henshaw 2013 \{published data only\}

Henshaw $\mathrm{H}$, Ferguson MA. Working memory training for adult hearing aid users: study protocol for a double-blind randomized active controlled trial. Trials 2013;14:417.

\section{Malmberg 2015 \{published data only\}}

Malmberg M, Lunner T, Kahari K, Jansson G, Andersson G. Implementing internet-based aural rehabilitation in a general clinical practice. American Journal of Audiology 2015;24:325-8.

\section{References to ongoing studies}

\section{ISRCTN77340339 \{published data only\}}

Pronk M. A study on the effectiveness of a support programme (SUPR) for adult hearing aid users. http://www.isrctn.com/ ISRCTN77340339.

\section{NCT02233361 \{published data only\}}

Solheim J. Use of hearing aids. Development and implementation of a counselling program for hearing aid users. http://clinicaltrials.gov/show/NCT02233361.

\section{NCT02264314 \{published data only\}}

Cardemil F. Tele-educative program to improve adherence to the use of hearing aids in patients with hearing loss. http:// clinicaltrials.gov/show/NCT02264314.

\section{Additional references}

\section{Alpiner 1978}

Alpiner JG, Chevrette W, Glascoe G, Metz M, Olsen B. The Denver scale of communication function. In: Alpiner J editor(s). Adult Rehabilitative Audiology. Baltimore MD: Williams \& Wilkins, 1978:53-6.

\section{Altman 1996}

Altman DJ, Bland JM. Detecting skewness from summary information. BMJ 1996;313(7066):1200.

\section{Andersson 1995a}

Andersson G, Melin L, Lindberg P, Scott B. Development of a short scale for self-assessment of experiences of hearing loss: the hearing coping assessment. Scandinavian Audiology 1995;24(3):147-54.

\section{Arlinger 2003}

Arlinger S. Negative consequences of uncorrected hearing loss: a review. International Journal of Audiology 2003;42(Suppl 2):17-20.

\section{Bainbridge 2014}

Bainbridge KE, Wallhagen MI. Hearing loss in an aging American population: extent, impact, and management. Annual Review of Public Health 2014;35:139-52.

\section{Barker 2015}

Barker F, Munro KJ, de Lusignan S. Supporting living well with hearing loss: a Delphi review of self-management support. International Journal of Audiology 2015;54(10):691-9.

\section{Barlow 2002}

Barlow J, Wright C, Sheasby J, Turner A, Hainsworth J. Selfmanagement approaches for people with chronic conditions: a review. Patient Education and Counseling 2002;48:177-87.

\section{Bodenheimer 2002}

Bodenheimer T, Wagner EH, Grumbach K. Improving primary care for patients with chronic illness. JAMA 2002;288(14):1775-9. [PUBMED: 12365965]

\section{Boissel 1999}

Boissel JP, Cucherat M, Li W, Chatellier G, Gueyffier F, Buyse $M$, et al. The problem of therapeutic efficacy indices. 3. Comparison of the indices and their use [Apercu sur la problematique des indices d'efficacite therapeutique, 3 : comparaison des indices et utilisation. Groupe d'Etude des Indices D'efficacite]. Therapie 1999;54(4):405-11.

\section{Borg 2015}

Borg J, Ostergren PO. Users' perspectives on the provision of assistive technologies in Bangladesh: awareness, providers, costs and barriers. Disability \& Rehabilitation: Assistive Technology 2015;10(4):301-8.

\section{Brooks 1985}

Brooks DN. Factors relating to the under-use of postaural hearing aids. British Journal of Audiology 1985;19(3):211-7. [PUBMED: 4063557]

\section{Brooks 2001}

Brooks DN, Hallam RS, Mellor PA. The effects on significant others of providing a hearing aid to the hearing-impaired partner. British Journal of Audiology 2001;35(3):165-71.

\section{Chisolm 2007}

Chisolm TH, Johnson CE, Danhauer JL, Portz LJ, Abrams HB, Lesner S, et al. A systematic review of health-related quality of life and hearing aids: final report of the American Academy of Audiology Task Force on the Health-Related Quality of Life Benefits of Amplification in Adults. Journal of the American Academy of Audiology 2007;18(2):151-83. [PUBMED: 17402301]

\section{Chisolm 2011}

Chisolm T, Arnold M. Evidence about the effectiveness of aural rehabilitation programs for adults. In: Wong L, Hickson 
L editor(s). Evidence-based Practice in Audiology. Plural Publishing, 2011:237-66.

\section{Cohen 1988}

Cohen J. Statistical Power Analysis for the Behavioural Sciences. 2nd Edition. Hillsdale, NJ: Erlbaum, 1988.

\section{CONSORT 2010}

CONSORT (Consolidated Standards of Reporting Trials). http:// www.consort-statement.org/home 2010.

\section{Costa 1992}

Costa PT, McCrae RR. Professional manual: revised NEO personality inventory (NEO-PI-R) and NEO five-factor inventory (NEO-FFI). Psychological Assessment Resources 1992.

\section{Cox 1995}

Cox RM, Alexander GC. The abbreviated profile of hearing aid benefit. Ear and Hearing 1995;16(2):176-86.

\section{Cox 1998}

Cox RM, Alexander GC, Gilmore C, Pusakulich KM. Use of Connected Speech Test (CST) with hearing impaired listeners. Ear and Hearing 1998;9:198-207.

\section{Cox 1999}

Cox RM, Alexander GC. Measuring satisfaction with amplification in daily life: the SADL scale. Ear and Hearing 1999;20(4):306-20.

\section{Cox 2000}

Cox R, Alexander GC. Expectations about hearing aids and their relationship to fitting outcome. Journal of the American Academy of Audiology 2000;11:368-82.

\section{Cox 2002}

Cox RM, Alexander CG. The International Outcome Inventory for Hearing Aids (IOI-HA): psychometric properties of the English version. International Journal of Audiology 2002;41(1):30-5.

\section{Cox 2014}

Cox RM, Johnson JA, Xu J. Impact of advanced hearing aid technology on speech understanding for older listeners with mild to moderate, adult-onset, sensorineural hearing loss. Gerontology 2014;60:557-68.

\section{Davis 2007}

Davis A, Smith P, Ferguson M, Stephens D, Gianopoulos I. Acceptability, benefit and costs of early screening for hearing disability: a study of potential screening tests and models. Health Technology Assessment 2007;11(42):1-294.

\section{Dawes 2013}

Dawes P, Hopkins R, Munro KJ. Placebo effects in hearingaid trials are reliable. International Journal of Audiology 2013;52:472-7.

\section{Day 2002}

Day H, Jutai J, Campbell K. Development of a scale to measure the psychosocial impact of assistive devices: lessons learned and the road ahead. Disability and Rehabilitation 2002;24(1-3):31-7.

\section{Deeks 2000}

Deeks J. Issues in the selection for meta-analyses of binary data. Proceedings of the 8th International Cochrane Colloquium 2000 Oct 25-28. Cape Town: The Cochrane Collaboration, 2000.

\section{Demorest 1987}

Demorest ME, Erdman SA. Development of the communication profile for the hearing impaired. Journal of Speech and Hearing Disorders 1987;52(2):129-43.

\section{Demorest 1988}

Demorest ME, Erdman SA. Retest stability of the communication profile for the hearing impaired. Ear and Hearing 1988;9(5):237-42

\section{Desjardins 2009}

Desjardins JL, Doherty KA. Do experienced hearing aid users know how to use their hearing aids correctly?. American Journal of Audiology 2009;18(1):69-76.

\section{DH 2007}

Research evidence on the effectiveness of self care support. Department of Health, London 2007.

\section{Dillon 1997}

Dillon H, James A, Ginis J. Client Orientated Scale of Improvement (COSI) and its relationship to several others measures of satisfaction and benefit provided by hearing aids. Journal of the American Academy of Audiology 1997;8:27-43.

\section{Divine 1992}

Divine GW, Brown JT, Frazier LM. The unit of analysis error in studies about physicians' patient care behavior. Journal of General Internal Medicine 1992;7(6):623-9. [PUBMED: 1453246]

\section{Dubno 1981}

Dubno JR, Levitt H. Predicting consonant confusions from acoustic analysis. Journal of the Acoustical Society of America 1981;69:249-61.

\section{Egger 1997}

Egger M, Smith GD, Schneider M, Minder C. Bias in meta-analysis detected by a simple, graphical test. $B M J$ 1997;315(7109):629-34.

\section{EuroQol 1990}

The EuroQol Group. EuroQol-a new facility for the measurement of health-related quality of life. Health Policy 1990;16(3):199-208.

\section{Ferguson 2015}

Ferguson M, Brandreth M, Brassington W, Wharrad H. Information retention and overload in first time hearing aid users: an interactive multi-media educational solution. American Journal of Audiology 2015;24:329-32. 


\section{Folkman 1988}

Folkman S, Lazarus RS. Ways of Coping Questionnaire. Consulting Psychologists Press, 1988.

\section{Gatehouse 1999}

Gatehouse S. A self-report outcome measure for the evaluation of hearing aid fittings and services. Health Bulletin 1999;57(6):424-36.

\section{Gatehouse 2004}

Gatehouse S, Noble W. Speech, spatial and qualities of hearing scale (SSQ). International Journal of Audiology 2004;43:85-99.

\section{Gimsing 2008}

Gimsing S. Use of hearing aids five years after issue [Brug af horeapparater fem ar efter tildelingen]. Ugeskrift for Laeger 2008;170(43):3407-11. [PUBMED: 18976596]

\section{Giolas 1979}

Giolas TG, Owens E, Lamb SH, Schubert ED. Hearing performance inventory. Journal of Speech and Hearing Disorders 1979;44(2):169-95

\section{Glasgow 2003}

Glasgow RE, Davis CL, Funnell MM, Beck A. Implementing practical interventions to support chronic illness selfmanagement. Joint Commission Journal on Quality and Safety 2003;29(11):563-74.

\section{Granberg 2014}

Granberg S, Pronk M, Swanepoel DW, Kramer SE, Hagsten H, Hjaldahl J, et al. The ICF core sets for hearing loss project: functioning and disability from the patient perspective. International Journal of Audiology 2014;53:777-86.

\section{Grenness 2014}

Grenness C, Hickson L, Laplante-Lévesque A, Davidson B. Patient-centred care: a review for rehabilitative audiologists. International Journal of Audiology 2014;53 Suppl 1:S68-75.

\section{Hallberg 1993}

Hallberg LR, Barrenas ML. Living with a male with noise-induced hearing loss: experiences from the perspective of spouses. British Journal of Audiology 1993;27(4):255-61.

\section{Hanratty 2000}

Hanratty B, Lawlor DA. Effective management of the elderly hearing impaired: a review. Journal of Public Health Medicine 2000;22(4):512-7.

\section{Hawkins 2005}

Hawkins DB. Effectiveness of counseling-based adult group aural rehabilitation programs: a systematic review of the evidence. Journal of the American Academy of Audiology 2005;16:485-93.

\section{Henshaw 2013}

Henshaw H, Ferguson M. Efficacy of individual computer-based auditory training for people with hearing loss: a systematic review of the evidence. PLoS One 2013;8(5):e62836.

\section{Hibbard 2005}

Hibbard JH, Mahoney ER, Stockard J, Tusler M. Development and testing of a short form of the patient activation measure. 2005 Health Services Research;40:1918-39.

\section{Higgins 2011}

Higgins JPT, Green S (editors). Cochrane Handbook for Systematic Reviews of Interventions Version 5.1.0 [updated March 2011]. The Cochrane Collaboration, 2011. Available from www.cochrane-handbook.org.

\section{Hougaard 2011}

Hougaard S, Ruf S. EuroTrak I: A consumer survey about hearing aids in Germany, France and the UK. Hearing Review 2011;18(2):12-28.

\section{Humes 2011}

Humes LE, Krull V. Hearing aids for adults. In: Wong L, Hickson L editor(s). Evidence-based Practice in Audiology. Plural Publishing, 2011:61-91.

\section{Jakes 1986}

Jakes SC, Hallam RS, Rachman S, Hinchcliffe R. The effects of reassurance, relaxation training and distraction on chronic tinnitus sufferers. Behaviour Research and Therapy 1986:24:497-507.

\section{Johnston 2013}

Johnston BC, Patrick DL, Busse JW, Schunemann HJ, Agarwal A, Guyatt GH. Patient-reported outcomes in meta-analyses - part 1: Assessing risk of bias and combining outcomes. Health and Quality of Life Outcomes 2013;11:109.

\section{Kaplan 1997}

Kaplan H, Bally S, Brandt F, Busacco D, Pray J. Communication scale for older adults (CSOA). Journal of the American Academy of Audiology 1997;8(3):203-17.

\section{Kochkin 2009}

Kochkin S. MarkeTrak VIII: 25-year trends in the hearing health market. Hearing Review 2009;16(11):12-31.

\section{Kreindler 2009}

Kreindler SA. Lifting the burden of chronic disease: What has worked? What hasn't? What's next?. Healthcare Quarterly 2009;12(2):30-40.

\section{Laplante-Levesque 2012}

Laplante-Levesque A, Hickson L, Worrall L. Comparing response options for the international inventory for hearing aids (IOI$\mathrm{HA}$ ) and for alternative interventions (IOI-AI) daily-use items. International Journal of Audiology 2012;51:788-91.

\section{Lawton 1992}

Lawton MP, Kleban MH, Rajagopal D, Parmelee PA. The factorial generality of brief positive and negative affect measures. Journal of Gerontology 1992;47:228-37. 


\section{Lin 2011}

Lin FR, Metter EJ, O'Brien RJ, Resnick SM, Zonderman AB, Ferrucci L. Hearing loss and incident dementia. Archives of Neurology 2011;68(2):214-20.

\section{Lorig 2003}

Lorig KR, Holman HR. Self-management education: history, definition, outcomes, and mechanisms. Annals of Behavioural Medicine 2003;26:1-7.

\section{Lupsakko 2005}

Lupsakko TA, Kautiainen HJ, Sulkava R. The non-use of hearing aids in people aged 75 years and over in the city of Kuopio in Finland. European Archives of Oto-Rhino-Laryngology 2005;262(3):165-9. [PUBMED: 15133689]

\section{Michie 2013}

Michie S, Richardson M, Johnston M, Abraham C, Francis J, Hardeman W, et al. The behavior change technique taxonomy (v1) of 93 hierarchically clustered techniques: building an international consensus for the reporting of behavior change interventions. Annals of Behavioural Medicine 2013;46(1):81-95.

\section{Mulrow 1992}

Mulrow CD, Tuley MR, Aquilar C. Sustained benefits of hearing aids. Journal of Speech and Hearing Research 1992;35(6):1402-5.

\section{National Council on Aging $\mathbf{2 0 0 0}$}

National Council on Aging. The consequences of untreated hearing loss in older persons. Head and Neck Nursing 2000; Vol. 18 , issue 1.

\section{Navran 1967}

Navran L. Communication and adjustment in marriage. Family Process 1967;6:173-84.

\section{NHS 2006}

Improving care for people with long term conditions: a review of UK and international frameworks. NHS Institute for Innovation and Improvement, London 2006.

\section{Noble 1970}

Noble WG, Atherley GRC. The hearing measurement scale: a questionnaire for the assessment of auditory disability. Journal of Auditory Research 1970;10:229-50.

\section{Owens 1977}

Owens E, Schubert ED. The development of the California Consonant Test. Journal of Speech and Hearing Research 1977;20:463-74.

\section{Pearson 2007}

Pearson ML, Mattke S, Shaw R, Ridgely MS, Wiseman SH. Patient Self-Management Support Programs: an evaluation. Final contract report (prepared by RAND Health under contract no. 282-00-0005). Agency for Healthcare Research and Quality 2007.

\section{Perez 2012}

Perez E, Edmonds BA. A systematic review of studies measuring and reporting hearing aid usage in older adults since 1999: a descriptive summary of measurement tools. PloS One 2012;7(3):e31831.

\section{RevMan 2014 [Computer program]}

The Nordic Cochrane Centre, The Cochrane Collaboration. Review Manager (RevMan). Version 5.3. Copenhagen: The Nordic Cochrane Centre, The Cochrane Collaboration, 2014.

\section{Saito 2010}

Saito H, Nishiwaki Y, Michikawa T, Kikuchi Y, Mizutari K, Takebayashi $\mathrm{T}$, et al. Hearing handicap predicts the development of depressive symptoms after 3 years in older community-dwelling Japanese. Journal of American Geriatrics Society 2010;58(1):93-7.

\section{Schow 1980}

Schow RL, Nerbonne MA. Hearing handicap and Denver scales: applications, categories and interpretation. Journal of Academy of Rehabilitative Audiology 1980;13:66-77.

\section{Smeeth 2002}

Smeeth L, Fletcher AE, Ng ES, Stirling S, Nunes M, Breeze E, et al. Reduced hearing, ownership, and use of hearing aids in elderly people in the UK--the MRC Trial of the Assessment and Management of Older People in the Community: a crosssectional survey. Lancet 2002;359(9316):1466-70. [PUBMED: 11988245]

\section{Smith 2009}

Smith SL, Noe CM, Alexander GC. Evaluation of the international outcome inventory for hearing aids in a veteran sample. Journal of the American Academy of Audiology 2009;20(6):374-80.

\section{Sorri 1984}

Sorri M, Luotonen M, Laitakari K. Use and non-use of hearing aids. British Journal of Audiology 1984;18(3):169-72. [PUBMED: 6487851]

\section{Swan 2012}

Swan IRC, Guy FH, Akeroyd MA. Health-related quality of life before and after management in adults referred to otolaryngology: a prospective national study. Clinical Otolaryngology 2012;37:35-43.

\section{Sweetow 2005}

Sweetow R, Palmer CV. Efficacy of individual auditory training in adults: a systematic review of the evidence. Journal of the American Academy of Audiology 2005;16:494-504.

\section{Thodi 2013}

Thodi C, Parazzini M, Kramer SE, Davis A, Stenfelt S, Janssen T, et al. Adult hearing screening: follow-up and outcomes. American Journal of Audiology 2013;22:183-5.

\section{Tillman 1966}

Tillman TW, Carhart R. An expanded test for speech discrimination utilizing CNC monosyllable words. Northwestern University Auditory Test No. 6 (Technical Report, SAM-TR-66-55). USAF School of Aerospace Medicine 1966. 


\section{Tsai 2005}

Tsai AC, Morton SC, Mangione CM, Keeler EB. A meta-analysis of interventions to improve care for chronic illnesses. American Journal of Managed Care 2005;11(8):478-88.

\section{Ventry 1982}

Ventry IM, Weinstein BE. The hearing handicap inventory for the elderly: a new tool. Ear and Hearing 1982;3(3):128-34.

\section{Vuorialho 2006}

Vuorialho A, Sorri M, Nuojua I, Muhli A. Changes in hearing aid use over the past 20 years. European Archives of Oto-RhinoLaryngology 2006;263(4):355-60. [PUBMED: 16283199]

\section{Ware 1992}

Ware JE, Sherbourne CD. The MOS 36-item short-form health survey (SF-36): I. Conceptual framework and item selection. Medical Care 1992;30:473-81.

\section{Ware 1998}

Ware JE, Kosinski M, Keller SD. How to Score the SF-12 Physical and Mental Health Summary Scales. 2nd Edition. Boston, MA: The Health Institute, New England Medical Center, 1998.

\section{Weinstein 1986}

Weinstein BE, Spitzer JB, Ventry IM. Test-retest reliability of the hearing handicap inventory for the elderly. Ear and Hearing 1986; 7:295-9.

\section{Whitlock 2002}

Whitlock EP, Orleans CT, Pender N, Allan J. Evaluating primary care behavioural counseling interventions: an evidencebased approach. American Journal of Preventative Medicine 2002;22(4):267-84

\section{WHO 2000}

Mathers C, Smith A, Concha M. Global burden of hearing loss in the year 2000. World Health Organization 2000.

\section{WHO 2001}

World Health Organization. International Classification of Functioning, Disability and Health (ICF). Geneva, Switzerland: World Health Organization, 2001.

\section{WHO 2002}

World Health Organization. Innovative Care for Chronic Conditions: Building Blocks for Action. Geneva, Switzerland: World Health Organization, 2002.

\section{WHO 2003}

World Health Organization. Adherence to Long-term Therapies: Evidence for Action. Geneva, Switzerland: World Health Organization, 2003.

\section{WHO 2011}

World Health Organization. Global Aging and Health. Geneva, Switzerland: World Health Organization, 2011.

\section{WHO 2012}

World Health Organization. Facts about deafness. http:// www.who.int/pbd/deafness/facts/en/ (accessed 18 December 2012).

\section{Yueh 2005}

Yueh B, McDowell JA, Collins MP, Souza PE, Loovis CF, Deyo RA. Development and validation of the effectiveness of auditory rehabilitation (EAR) scales. Archives of Otolaryngology -- Head and Neck Surgery 2005;131:851-6.

\section{Zigmond 1983}

Zigmond AS, Snaith RP. The Hospital Anxiety and Depression Scale. Acta Psychiatrica Scandinavica 1983;67:361-70.

\section{References to other published versions of this review Barker 2013}

Barker F, Mackenzie E, Elliott L, Jones S, de Lusignan S. Interventions to improve hearing aid use in adult auditory rehabilitation. Cochrane Database of Systematic Reviews 2013, Issue 2. [DOI: 10.1002/14651858.CD010342]

\section{Barker 2014}

Barker F, Mackenzie E, Elliott L, Jones S, de Lusignan S. Interventions to improve hearing aid use in adult auditory rehabilitation. Cochrane Database of Systematic Reviews 2014, Issue 7. [DOI: 10.1002/14651858.CD010342.pub2]

* Indicates the major publication for the study

\section{CHARACTERISTICS OF STUDIES}

Characteristics of included studies [ordered by study ID]

Abrams 1992

Methods Randomised trial (also had a control group with no intervention but control group inclusion was determined by eligibility for VA-funded HA so not randomised)

Participants

$\mathrm{N}=22$ in randomised groups

Age: 55 and over, PTA 4 frequency average $>30 \mathrm{~dB}$ HL in better ear, no previous HA use, women not excluded but none in study 
Abrams 1992 (Continued)

Excluded known neurological deficiencies

\begin{tabular}{ll}
\hline Interventions & HA + AR group programme versus HA alone \\
& AR programme was 90-minute group session once a week for 3 weeks post-fitting \\
\hline Outcomes & Short-term: baseline and 2 months \\
& HANDICAP Hearing Handicap Inventory for the Elderly (HHIE) total score, emotional subscale and social \\
& subscale \\
\hline Notes & -
\end{tabular}

\section{Risk of bias}

Bias Authors' judgement Support for judgement

Random sequence genera- Unclear risk Quote: "those who received hearing aids were randomly assigned to one of the tion (selection bias) two treatment groups"

Comment: no details given about how sequence was generated

Control group not randomised

\begin{tabular}{|c|c|c|}
\hline $\begin{array}{l}\text { Allocation concealment } \\
\text { (selection bias) }\end{array}$ & Unclear risk & $\begin{array}{l}\text { Comment: no information about how sequence generated or whether it was } \\
\text { concealed }\end{array}$ \\
\hline
\end{tabular}

\begin{tabular}{|c|c|c|}
\hline $\begin{array}{l}\text { Blinding of participants } \\
\text { and personnel (perfor- } \\
\text { mance bias) } \\
\text { All outcomes }\end{array}$ & High risk & $\begin{array}{l}\text { Comment: participants not blinded (due to the nature of the intervention) and } \\
\text { experimenters almost certainly not, but it was not explicitly stated in the text }\end{array}$ \\
\hline
\end{tabular}

\begin{tabular}{ll}
\hline Blinding of outcome as- & High risk \\
sessment (detection bias) & \\
All outcomes &
\end{tabular}

\begin{tabular}{l}
\hline Incomplete outcome data Low risk Comment: no missing data \\
(attrition bias) \\
All outcomes
\end{tabular}

\begin{tabular}{lll}
\hline $\begin{array}{l}\text { Selective reporting (re- } \\
\text { porting bias) }\end{array}$ & Unclear risk & No study protocol available \\
\hline Other bias & Low risk & Study appears to be free of other sources of bias \\
\hline
\end{tabular}

Andersson 1994

\begin{tabular}{ll}
\hline Methods & Randomised \\
\hline Participants & $\mathrm{N}=20$ \\
& Age: range 64 to 72 \\
& "Recently" retired, existing HA users (mean duration 2.8 years) \\
\hline Interventions & HA alone versus HA + AR \\
\hline
\end{tabular}


Andersson 1994 (Continued)

AR: 60-minute behavioural counselling session over 3 consecutive weeks with homework tasks - could be group, individual or combined depending on functional analysis and practical considerations

\section{Outcomes}

Short-term: baseline and 4 weeks later (post AR) - Life Orientation Test (PSYCHOLOGICAL/OPTIMISM)

Long-term: 15 months post-intervention - Hearing Coping Assessment (HANDICAP/DISABILITY)

Notes

Could not include Hearing Questionnaire developed by the authors for this study and post-counselling questions also developed for this study

Have included Hearing Coping Assessment as it was separately validated (although by the same authors)

\section{Risk of bias}

\begin{tabular}{|c|c|c|}
\hline Bias & Authors' judgement & Support for judgement \\
\hline $\begin{array}{l}\text { Random sequence genera- } \\
\text { tion (selection bias) }\end{array}$ & Unclear risk & $\begin{array}{l}\text { Quote: "subjects were randomly assigned to one of two groups" } \\
\text { Comment: no details of randomisation process given }\end{array}$ \\
\hline $\begin{array}{l}\text { Allocation concealment } \\
\text { (selection bias) }\end{array}$ & Unclear risk & Comment: no details of randomisation process \\
\hline $\begin{array}{l}\text { Blinding of participants } \\
\text { and personnel (perfor- } \\
\text { mance bias) } \\
\text { All outcomes }\end{array}$ & High risk & Comment: not blinded due to the nature of the intervention \\
\hline $\begin{array}{l}\text { Blinding of outcome as- } \\
\text { sessment (detection bias) } \\
\text { All outcomes }\end{array}$ & High risk & $\begin{array}{l}\text { Comment: authors comment in discussion on the potential effect on non- } \\
\text { blinding }\end{array}$ \\
\hline $\begin{array}{l}\text { Incomplete outcome data } \\
\text { (attrition bias) } \\
\text { All outcomes }\end{array}$ & Low risk & $\begin{array}{l}\text { Comment: } 1 \text { patient in the intervention group not reached at long-term FU - } \\
\text { not clear whether results for long-term FU analysed on an intention-to-treat } \\
\text { basis but only } 1 \text { patient lost }\end{array}$ \\
\hline $\begin{array}{l}\text { Selective reporting (re- } \\
\text { porting bias) }\end{array}$ & High risk & $\begin{array}{l}\text { Comment: no protocol available } \\
\text { Also, in a later } 1998 \text { paper they describe how HA use was measured in this } \\
\text { study but not reported }\end{array}$ \\
\hline Other bias & Unclear risk & $\begin{array}{l}2 \text { of the outcome measures in the study could not be used as they were devel- } \\
\text { oped specifically for this study by the authors }\end{array}$ \\
\hline
\end{tabular}

\section{Andersson 1995}

\begin{tabular}{ll}
\hline Methods & Randomised after initial interview and video session \\
\hline Participants & $\mathrm{N}=24$ \\
& Age: range 64 to 72 (mean 69.8) \\
& 14 male, 10 female \\
Recently retired HA users
\end{tabular}


Andersson 1995 (Continued)

AR consisted of $4 \times 2$-hour sessions including video feedback, applied relaxation, information and homework

\begin{tabular}{ll}
\hline Outcomes & $\begin{array}{l}\text { Short-term: baseline and post-intervention (5 weeks) - USE of aid (hours/day), VAS scores for daily hear- } \\
\text { ing problems, Hearing Coping Assessment (HANDICAP/DISABILITY) }\end{array}$ \\
& $\begin{array}{l}\text { Long-term: } 2 \text {-year follow-up - Hearing Coping Assessment (HANDICAP/DISABILITY), Communication } \\
\text { Profile Hearing Impaired-Communication Strategy Subscale (COMMUNICATION) }\end{array}$ \\
\hline Notes & 4 patients lost to long-term follow-up - 2 in each group
\end{tabular}

\section{Risk of bias}

\begin{tabular}{lll}
\hline Bias & Authors' judgement & Support for judgement \\
\hline $\begin{array}{ll}\text { Random sequence genera- } \\
\text { tion (selection bias) }\end{array}$ & Unclear risk & $\begin{array}{l}\text { Quote: "after which a code was broken and subjects were assigned to respec- } \\
\text { tive groups" } \\
\end{array}$ \\
& & Comment: probably done
\end{tabular}

\begin{tabular}{lll}
\hline $\begin{array}{l}\text { Allocation concealment } \\
\text { (selection bias) }\end{array}$ & Unclear risk & \\
\hline
\end{tabular}

Blinding of participants High risk Participants were not blinded due to the nature of the intervention
and personnel (perfor-
mance bias)
All outcomes

\begin{tabular}{lll}
\hline Blinding of outcome as- & Unclear risk & $\begin{array}{l}\text { Interviewers appear to have been blinded to group allocation but these data } \\
\text { sessment (detection bias) }\end{array}$ \\
$\begin{array}{l}\text { All outcomes not included in our outcomes } \\
\text { were }\end{array}$
\end{tabular}

\begin{tabular}{lll}
\hline $\begin{array}{l}\text { Incomplete outcome data } \\
\text { (attrition bias) } \\
\text { All outcomes }\end{array}$ & Low risk & $\begin{array}{l}\text { No missing data in the original phase of the study and number/reasons for } \\
\text { dropout given in follow-up paper }\end{array}$ \\
\hline $\begin{array}{l}\text { Selective reporting (re- } \\
\text { porting bias) }\end{array}$ & Unclear risk & No protocol available \\
\hline Other bias & High risk & $\begin{array}{l}\text { The HCA was developed and validated by the author } \\
\text { In a follow-up study, after dropouts, the 2 groups differed at baseline on HCA } \\
\text { score }\end{array}$ \\
\hline
\end{tabular}

\section{Andersson 1997}

\begin{tabular}{ll}
\hline Methods & Randomised \\
\hline Participants & $\mathrm{N}=19$ \\
& Age: range 67 to 75, mean 71.5 \\
& 11 male, 8 female \\
& Inclusion criteria: HA users, 65 to 80 years old, able to use telephone \\
& Exclusion: previous attendance at a rehabilitation course at the centre, severe tinnitus or vestibular \\
& symptoms
\end{tabular}


Andersson 1997 (Continued)

Interventions

$\mathrm{HA}$ alone versus $\mathrm{HA}+$ self-help manual supplied with 1-hour face-to-face training session including relaxation training followed by telephone contacts during 4 consecutive weeks

Outcomes

Short-term: post-intervention: USE hours/day, Hearing Coping Assessment (HANDICAP), VAS scores, Communication Profile Hearing Impaired-Communication Strategy Subscale (COMMUNICATION)

\section{Notes}

\section{Risk of bias}

\begin{tabular}{|c|c|c|}
\hline Bias & Authors' judgement & Support for judgement \\
\hline $\begin{array}{l}\text { Random sequence genera- } \\
\text { tion (selection bias) }\end{array}$ & Unclear risk & $\begin{array}{l}\text { Quote: "following the structured interview a code was broken and they were } \\
\text { assigned to the groups" } \\
\text { Comment: probably done }\end{array}$ \\
\hline $\begin{array}{l}\text { Allocation concealment } \\
\text { (selection bias) }\end{array}$ & Unclear risk & Comment: probably done \\
\hline $\begin{array}{l}\text { Blinding of participants } \\
\text { and personnel (perfor- } \\
\text { mance bias) } \\
\text { All outcomes }\end{array}$ & High risk & Participants not blinded due to the nature of the intervention \\
\hline $\begin{array}{l}\text { Blinding of outcome as- } \\
\text { sessment (detection bias) } \\
\text { All outcomes }\end{array}$ & Unclear risk & $\begin{array}{l}\text { Single-blinded interviewer at FU - blind to allocation } \\
\text { BUT cannot use these outcomes }\end{array}$ \\
\hline $\begin{array}{l}\text { Incomplete outcome data } \\
\text { (attrition bias) } \\
\text { All outcomes }\end{array}$ & Low risk & No missing data \\
\hline $\begin{array}{l}\text { Selective reporting (re- } \\
\text { porting bias) }\end{array}$ & Unclear risk & No protocol available \\
\hline Other bias & Low risk & Study appears to be free of other sources of bias \\
\hline
\end{tabular}

Beynon 1997

\begin{tabular}{ll}
\hline Methods & Quasi-randomised using last digit of hospital number \\
\hline Participants & $\mathrm{N}=53$ randomised but data analysed from 47 after dropouts \\
& Age: range 47 to 80 \\
& 20 male, 27 female \\
Inclusion criteria: first-time HA users, patients had to attend 3 out of 4 intervention sessions \\
Exclusion criteria: over 80 years old, severe or profound hearing loss \\
\hline HA alone versus HA + AR group course \\
AR course: 4 weekly sessions, 5 to 7 people, not clear how long the sessions were \\
\hline Outcomes & Medium-term: 13 weeks - QDS (HANDICAP) \\
\hline \hline
\end{tabular}


Beynon 1997 (Continued)

Notes

\section{Risk of bias}

\begin{tabular}{|c|c|c|}
\hline Bias & Authors' judgement & Support for judgement \\
\hline $\begin{array}{l}\text { Random sequence genera- } \\
\text { tion (selection bias) }\end{array}$ & High risk & $\begin{array}{l}\text { Comment: allocation by odd or even hospital record number so quasi-ran- } \\
\text { domised }\end{array}$ \\
\hline $\begin{array}{l}\text { Allocation concealment } \\
\text { (selection bias) }\end{array}$ & Unclear risk & $\begin{array}{l}\text { Allocation by hospital number, which presumably investigators knew in ad- } \\
\text { vance }\end{array}$ \\
\hline $\begin{array}{l}\text { Blinding of participants } \\
\text { and personnel (perfor- } \\
\text { mance bias) } \\
\text { All outcomes }\end{array}$ & High risk & Participants not blinded due to the nature of the intervention \\
\hline $\begin{array}{l}\text { Blinding of outcome as- } \\
\text { sessment (detection bias) } \\
\text { All outcomes }\end{array}$ & High risk & No apparent blinding of outcome measurement \\
\hline $\begin{array}{l}\text { Incomplete outcome data } \\
\text { (attrition bias) } \\
\text { All outcomes }\end{array}$ & Low risk & Some missing data but reasons given. Post hoc analysis with imputed data \\
\hline $\begin{array}{l}\text { Selective reporting (re- } \\
\text { porting bias) }\end{array}$ & Unclear risk & No protocol available \\
\hline Other bias & Low risk & Study appears to be free of other sources of bias \\
\hline
\end{tabular}

Campos 2013

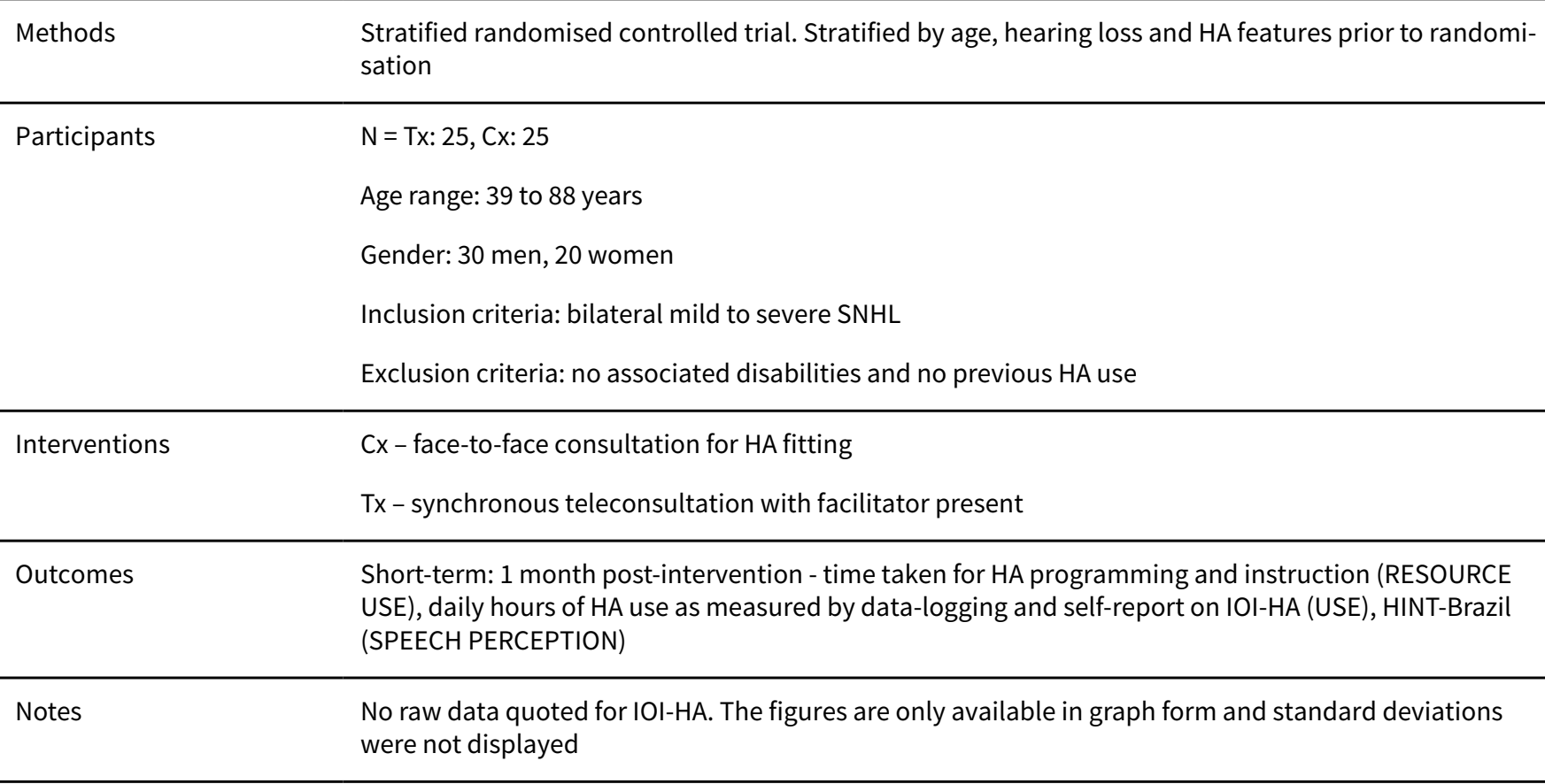


Campos 2013 (Continued)

Risk of bias

\begin{tabular}{|c|c|c|}
\hline Bias & Authors' judgement & Support for judgement \\
\hline $\begin{array}{l}\text { Random sequence genera- } \\
\text { tion (selection bias) }\end{array}$ & Low risk & $\begin{array}{l}\text { Quote "an equal number of participants from each stratum were allocated to } \\
\text { experimental or control groups by a simple raffle" }\end{array}$ \\
\hline $\begin{array}{l}\text { Allocation concealment } \\
\text { (selection bias) }\end{array}$ & Unclear risk & Comment - no details of allocation concealment \\
\hline $\begin{array}{l}\text { Blinding of participants } \\
\text { and personnel (perfor- } \\
\text { mance bias) } \\
\text { All outcomes }\end{array}$ & High risk & Not blinded \\
\hline $\begin{array}{l}\text { Blinding of outcome as- } \\
\text { sessment (detection bias) } \\
\text { All outcomes }\end{array}$ & Low risk & Evaluator was blinded \\
\hline $\begin{array}{l}\text { Incomplete outcome data } \\
\text { (attrition bias) } \\
\text { All outcomes }\end{array}$ & Low risk & $\begin{array}{l}\text { There were dropouts but the authors explained and accounted for these as far } \\
\text { as possible }\end{array}$ \\
\hline $\begin{array}{l}\text { Selective reporting (re- } \\
\text { porting bias) }\end{array}$ & Unclear risk & No protocol available \\
\hline Other bias & High risk & $\begin{array}{l}\text { Quote: "It must be emphasized that three participants in the experimental } \\
\text { group failed to perform the evaluation of speech perception in quiet and in } \\
\text { noise, despite the various attempts made by the evaluator. Thus, the values of } \\
\text { the SRT and the S/N ratio of these participants were not included in calculat- } \\
\text { ing the average, which may have contributed to the results of the experimental } \\
\text { group being more favorable (lower values)" }\end{array}$ \\
\hline
\end{tabular}

\section{Cherry 1994}

\begin{tabular}{ll}
\hline Methods & Randomised \\
\hline Participants & $\mathrm{N}=60$ \\
& Age: range not given but all over 50 years \\
& Gender: not specified \\
& Inclusion criteria: 50 years old or over, unaided speech recognition thresholds no greater than 70 dB \\
& HL in the aided ear, agreement to buy a HA and kept them at the end of the trial period, mix of new and \\
previous HA users
\end{tabular}

\section{Risk of bias}


Cherry 1994 (Continued)

\begin{tabular}{|c|c|c|}
\hline Bias & Authors' judgement & Support for judgement \\
\hline $\begin{array}{l}\text { Random sequence genera- } \\
\text { tion (selection bias) }\end{array}$ & Unclear risk & $\begin{array}{l}\text { Quote: "randomly assigned" } \\
\text { Comment: no details of randomisation process }\end{array}$ \\
\hline $\begin{array}{l}\text { Allocation concealment } \\
\text { (selection bias) }\end{array}$ & Unclear risk & Comment: no details of randomisation process \\
\hline $\begin{array}{l}\text { Blinding of participants } \\
\text { and personnel (perfor- } \\
\text { mance bias) } \\
\text { All outcomes }\end{array}$ & High risk & Participants and personnel not blinded due to the nature of the intervention \\
\hline $\begin{array}{l}\text { Blinding of outcome as- } \\
\text { sessment (detection bias) } \\
\text { All outcomes }\end{array}$ & High risk & Not blinded \\
\hline $\begin{array}{l}\text { Incomplete outcome data } \\
\text { (attrition bias) } \\
\text { All outcomes }\end{array}$ & Unclear risk & $\begin{array}{l}\text { Comment: there was a dropout rate for the interview and questionnaire that } \\
\text { was not completely addressed. Results were not analysed on an intention-to- } \\
\text { treat basis but there was a similar dropout in both groups, although reasons } \\
\text { are not clear so not sure whether they would be relevant }\end{array}$ \\
\hline $\begin{array}{l}\text { Selective reporting (re- } \\
\text { porting bias) }\end{array}$ & Unclear risk & No protocol available \\
\hline Other bias & Low risk & The study appears to be free of other sources of bias \\
\hline
\end{tabular}

Chisolm 2004

\begin{tabular}{ll} 
Methods & Randomised \\
& VA funded \\
May 1999 to December 2001 \\
\hline
\end{tabular}

\begin{tabular}{ll}
\hline Participants & $\mathrm{N}=106$ \\
& Age: range not given - average approximately 75 years \\
& 68 male, 38 female \\
& Inclusion criteria: US veterans, new HA users \\
& Exclusion criteria: more than mild depression on Beck Depression Inventory \\
\hline Interventions & HA alone versus HA + AR \\
\hline Outcomes & AR = 4-week group programme, 2 hours once a week \\
\hline Notes & Short-term: 8 weeks - CPHI (HANDICAP and COMMUNICATION), SF-36V (QUALITY OF LIFE) \\
\hline Risk of bias & - \\
\hline
\end{tabular}


Chisolm 2004 (Continued)
Random sequence genera- Unclear risk
Quote: "randomly assigned"
tion (selection bias)
Comment: no details of randomisation process given

\begin{tabular}{lll}
\hline $\begin{array}{l}\text { Allocation concealment } \\
\text { (selection bias) }\end{array}$ & Unclear risk & Comment: no details given \\
\hline $\begin{array}{l}\text { Blinding of participants } \\
\text { and personnel (perfor- }\end{array}$ & High risk & Participants and personnel not blinded due to the nature of the intervention \\
$\begin{array}{l}\text { mance bias) } \\
\text { All outcomes }\end{array}$ &
\end{tabular}

\begin{tabular}{ll}
\hline Blinding of outcome as- & High risk $\quad$ No apparent blinding in measurement of outcome \\
sessment (detection bias) & \\
All outcomes &
\end{tabular}

\begin{tabular}{lll}
\hline $\begin{array}{l}\text { Incomplete outcome data } \\
\text { (attrition bias) } \\
\text { All outcomes }\end{array}$ & Low risk & Missing data at long-term FU but this was accounted for statistically \\
\hline $\begin{array}{l}\text { Selective reporting (re- } \\
\text { porting bias) }\end{array}$ & Unclear risk & No protocol available \\
\hline Other bias & Low risk & Study appears to be free of other sources of bias \\
\hline
\end{tabular}

Collins 2013

\begin{tabular}{l} 
Methods $\begin{array}{l}\text { Cluster-randomised after enrolment } \\
\text { VA provided HAs free of charge and participants paid USD } 50 \text { if they completed all the questionnaires } \\
\text { February } 2006 \text { to October } 2007\end{array}$ \\
\hline
\end{tabular}

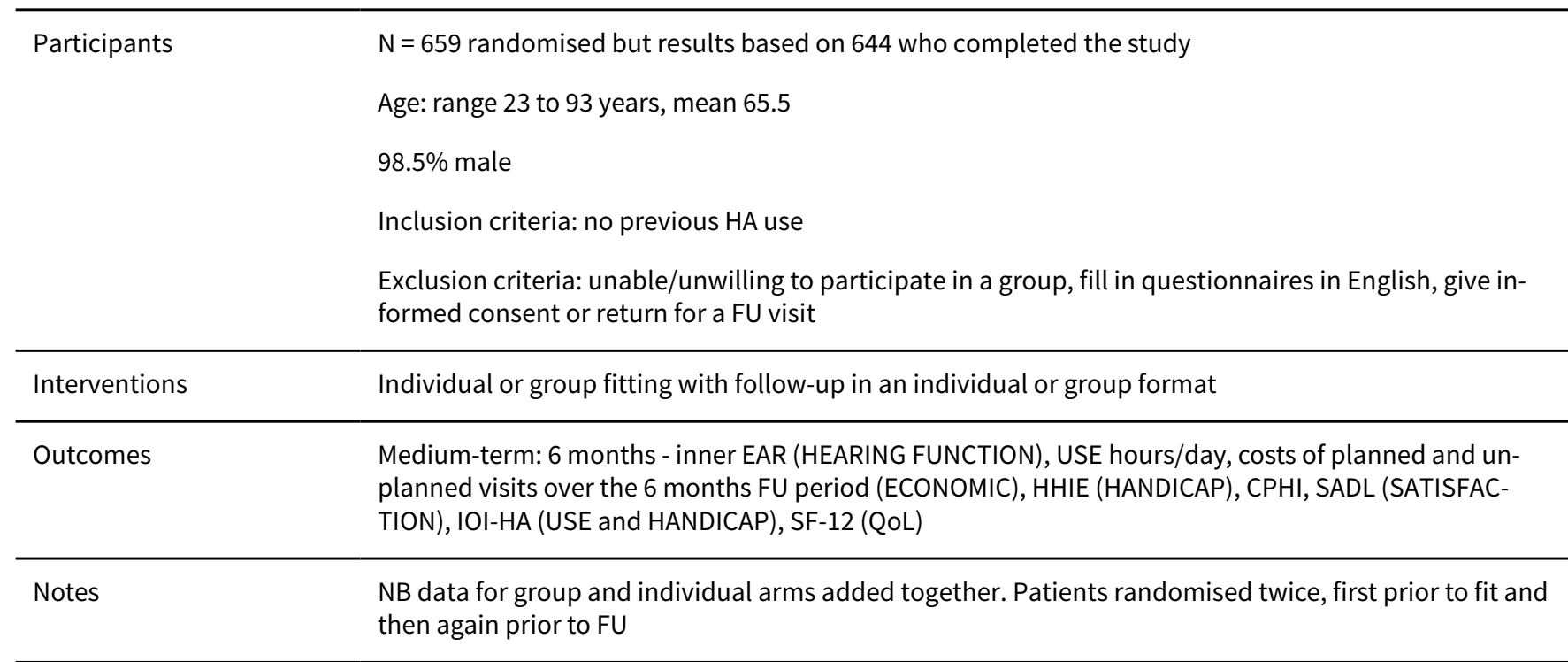

\section{Risk of bias}

Bias Authors' judgement Support for judgement


Collins 2013 (Continued)
Random sequence genera- Unclear risk
Quote: "randomized"
tion (selection bias)
Comment: no details of randomisation protocol but probably done

\begin{tabular}{lll}
\hline $\begin{array}{l}\text { Allocation concealment } \\
\text { (selection bias) }\end{array}$ & Low risk & Quote: "sealed opaque envelopes" \\
\hline $\begin{array}{l}\text { Blinding of participants } \\
\text { and personnel (perfor- } \\
\text { mance bias) }\end{array}$ & High risk & Acknowledged limitations - shame as could have been single-blinded \\
All outcomes &
\end{tabular}

\begin{tabular}{lll}
\hline $\begin{array}{l}\text { Blinding of outcome as- } \\
\text { sessment (detection bias) } \\
\text { All outcomes }\end{array}$ & High risk & No apparent blinding of outcome assessment \\
\hline $\begin{array}{l}\text { Incomplete outcome data } \\
\text { (attrition bias) } \\
\text { All outcomes }\end{array}$ & Low risk & $\begin{array}{l}\text { Some dropouts but overall quite low in this large cohort so unlikely to affect } \\
\text { results }\end{array}$ \\
\hline $\begin{array}{l}\text { Selective reporting (re- } \\
\text { porting bias) }\end{array}$ & Low risk & Protocol published in 2009 so able to compare aims with outcomes \\
\hline Other bias & Unclear risk & Participants paid for their participation \\
\hline
\end{tabular}

Cunningham 2001

\begin{tabular}{ll}
\hline Methods & Randomised \\
& Funding: participants were provided with ITEs free of charge, Mary and Mason Rudd Surgical Research \\
& Fund, Siemens provided the HAs
\end{tabular}

\begin{tabular}{|c|c|c|}
\hline \multirow[t]{4}{*}{ Participants } & \multicolumn{2}{|l|}{$N=18$} \\
\hline & \multicolumn{2}{|c|}{ Age: mean intervention 65.22 , control 68.78} \\
\hline & \multicolumn{2}{|c|}{$\begin{array}{l}\text { Inclusion criteria: } 50 \text { to } 75 \text { years, moderate symmetrical SNHL, no Hx of otologic/neurologic disease, } \\
\text { good general health }\end{array}$} \\
\hline & \multicolumn{2}{|c|}{ Exclusion criteria: other aural or vestibular signs or Sx, previous HA use } \\
\hline Interventions & \multicolumn{2}{|c|}{ Control 'usual care' versus as many post-fitting adjustments as patients requested } \\
\hline Outcomes & \multicolumn{2}{|c|}{$\begin{array}{l}\text { Medium-term: APHAB (BENEFIT), SIN test (SPEECH PERCEPTION), hours per day (USE), satisfaction } \\
\text { scale }\end{array}$} \\
\hline Notes & \multicolumn{2}{|l|}{-} \\
\hline \multicolumn{3}{|l|}{ Risk of bias } \\
\hline Bias & Authors' judgement & Support for judgement \\
\hline \multirow{2}{*}{$\begin{array}{l}\text { Random sequence genera- } \\
\text { tion (selection bias) }\end{array}$} & \multirow[t]{2}{*}{ Unclear risk } & Quote: "randomly assigned" \\
\hline & & Comment: no detail given and indeed no detail given of number in each group \\
\hline
\end{tabular}


Cunningham 2001 (Continued)

Allocation concealment Unclear risk $\quad$ No detail on allocation procedure
(selection bias)

\begin{tabular}{|c|c|c|}
\hline $\begin{array}{l}\text { Blinding of participants } \\
\text { and personnel (perfor- } \\
\text { mance bias) } \\
\text { All outcomes }\end{array}$ & High risk & No blinding \\
\hline $\begin{array}{l}\text { Blinding of outcome as- } \\
\text { sessment (detection bias) } \\
\text { All outcomes }\end{array}$ & High risk & No blinding \\
\hline $\begin{array}{l}\text { Incomplete outcome data } \\
\text { (attrition bias) } \\
\text { All outcomes }\end{array}$ & Low risk & No apparent missing data post-randomisation \\
\hline $\begin{array}{l}\text { Selective reporting (re- } \\
\text { porting bias) }\end{array}$ & Unclear risk & No protocol available \\
\hline Other bias & Unclear risk & $\begin{array}{l}\text { Patients given access to previous test scores for APHAB administration } \\
\text { No power calculation to determine if sufficient numbers to demonstrate an ef- } \\
\text { fect }\end{array}$ \\
\hline
\end{tabular}

Eriksson-Mangold 1990

$\begin{array}{ll}\text { Methods } & \text { Randomised } \\ & \text { Conducted in } 1985\end{array}$

\begin{tabular}{|c|c|}
\hline \multirow[t]{5}{*}{ Participants } & $\mathrm{N}=56$ "picked out from the waiting list of new hearing aid candidates" probably randomly \\
\hline & 28 in AF group \\
\hline & 28 in control group \\
\hline & Age: range 50 to 74 years \\
\hline & Inclusion criteria: hearing loss at least $35 \mathrm{~dB}$ across 3 frequencies, speech discrimination $50 \%$ or more \\
\hline Interventions & $\begin{array}{l}\text { HA plus standard FU appointments versus 'active fitting' programme (including task-orientated diary to } \\
\text { complete at home) }\end{array}$ \\
\hline Outcomes & Medium-term: 10 months post-fit structured telephone interview including a 5-point scale of daily use \\
\hline Notes & - \\
\hline
\end{tabular}

\section{Risk of bias}

\begin{tabular}{lll}
\hline Bias & Authors' judgement & Support for judgement \\
\hline $\begin{array}{l}\text { Random sequence genera- } \\
\text { tion (selection bias) }\end{array}$ & Unclear risk & Quote: "randomised into 2 groups" \\
& & Comment: procedure for randomisation not given \\
\hline $\begin{array}{l}\text { Allocation concealment } \\
\text { (selection bias) }\end{array}$ & Unclear risk & Comment: no information given on allocation \\
\hline
\end{tabular}


Eriksson-Mangold 1990 (Continued)
Blinding of participants
High risk
Participants not blinded due to the nature of the intervention and personnel (perfor- mance bias)
All outcomes

\begin{tabular}{|c|c|c|}
\hline $\begin{array}{l}\text { Blinding of outcome as- } \\
\text { sessment (detection bias) } \\
\text { All outcomes }\end{array}$ & Low risk & $\begin{array}{l}\text { Comment: psychologists carrying out the FU interview were blind to group al- } \\
\text { location }\end{array}$ \\
\hline $\begin{array}{l}\text { Incomplete outcome data } \\
\text { (attrition bias) } \\
\text { All outcomes }\end{array}$ & Low risk & Low numbers of dropouts and reasons given \\
\hline $\begin{array}{l}\text { Selective reporting (re- } \\
\text { porting bias) }\end{array}$ & Unclear risk & No protocol available \\
\hline Other bias & Low risk & Study appears to be free of other sources of bias \\
\hline
\end{tabular}

Ferguson 2016

\begin{tabular}{|c|c|c|}
\hline Methods & \multicolumn{2}{|l|}{ Randomised } \\
\hline \multirow[t]{5}{*}{ Participants } & \multicolumn{2}{|c|}{$N=203 ; 103$ intervention, 100 control } \\
\hline & \multicolumn{2}{|c|}{ Age range: 42 to 94 years } \\
\hline & \multicolumn{2}{|l|}{ Gender: $41 \%$ female } \\
\hline & \multicolumn{2}{|c|}{$\begin{array}{l}\text { Inclusion criteria: aged => 18, first time hearing aid user, English as a first language or good understand- } \\
\text { ing of English }\end{array}$} \\
\hline & \multicolumn{2}{|c|}{$\begin{array}{l}\text { Exclusion criteria: unable to access PC, DVD or internet, unable to complete questionnaires due to age- } \\
\text { related problems }\end{array}$} \\
\hline Interventions & \multicolumn{2}{|c|}{$\begin{array}{l}\text { Educational material delivered via DVD, PC or internet (patient preference) post fitting. } 7 \text { modules cov- } \\
\text { ering acclimatisation, getting to know the hearing aid, insertion of hearing aid, troubleshooting, expec- } \\
\text { tations, phones and assistive listening devices, communication }\end{array}$} \\
\hline Outcomes & \multicolumn{2}{|c|}{$\begin{array}{l}\text { Short term: GHABP, PHAST, SADL, IOI-HA, HHIE, HACK, HADS, PAM, EQ-5D, IT literacy and data logged } \\
\text { HA use }\end{array}$} \\
\hline Notes & \multicolumn{2}{|l|}{-} \\
\hline \multicolumn{3}{|l|}{ Risk of bias } \\
\hline Bias & Authors' judgement & Support for judgement \\
\hline \multirow{2}{*}{$\begin{array}{l}\text { Random sequence genera- } \\
\text { tion (selection bias) }\end{array}$} & \multirow[t]{2}{*}{ Low risk } & Quote: "allocation was based on a computer-generated pseudo-random code" \\
\hline & & Comment: sequence generation was adequate \\
\hline \multirow[t]{2}{*}{$\begin{array}{l}\text { Allocation concealment } \\
\text { (selection bias) }\end{array}$} & Low risk & $\begin{array}{l}\text { Quote: "allocations were revealed to the research team on completion of the } \\
\text { study" }\end{array}$ \\
\hline & & Comment: adequate allocation concealment \\
\hline
\end{tabular}


Ferguson 2016 (Continued)

Blinding of participants and personnel (performance bias)

All outcomes
High risk The participants could not be blinded due to the nature of the intervention and control

\begin{tabular}{|c|c|c|}
\hline $\begin{array}{l}\text { Blinding of outcome as- } \\
\text { sessment (detection bias) }\end{array}$ & Unclear risk & $\begin{array}{l}\text { Attempts were made to blind researchers to group allocation at the assess- } \\
\text { ment stage but this was reportedly not always successful }\end{array}$ \\
\hline
\end{tabular}

All outcomes

Incomplete outcome data Low risk Incomplete outcome data were accounted for
(attrition bias)

(attrition bias)

\begin{tabular}{lll}
\hline $\begin{array}{l}\text { Selective reporting (re- } \\
\text { porting bias) }\end{array}$ & Low risk & Trial was registered. All expected outcomes appear to have been reported \\
\hline Other bias & Low risk & The study appears free of other sources of bias \\
& References CONSORT guidelines \\
\hline
\end{tabular}

\section{Fitzpatrick 2008}

\begin{tabular}{ll}
\hline Methods & Randomised but control participants crossed over to intervention after the control sessions \\
\hline Participants & $\mathrm{N}=24$ (14 intervention and 10 control) \\
& Age: range intervention 45 to 86, mean 69.5 ; control 61 to 88, mean 70.1 \\
& intervention 9 female, 5 male; control 6 females, 4 male \\
& $\begin{array}{l}\text { Inclusion criteria: } 18 \text { years plus, have high school diploma, native English speakers, SNHL, used binaur- } \\
\text { al HAs for at least } 6 \text { weeks }\end{array}$ \\
& $\begin{array}{l}\text { Exclusion criteria: SF-12 score < 50\%, word recognition score < } 60 \%, \text { no known neurological or psychi- } \\
\text { atric problems }\end{array}$ \\
\hline Interventions & Auditory training versus lectures on HL and HAs and discussion of communication tactics \\
& Auditory training consisted for 16 sessions - 13 training and 3 test sessions of 1 hour each \\
\hline Outcomes & Medium-term: NU-6, CST, CCT (SPEECH PERCEPTION), HA use and satisfaction questionnaire (USE) \\
\hline Notes & -
\end{tabular}

\section{Risk of bias}

\begin{tabular}{lll}
\hline Bias & Authors' judgement & Support for judgement \\
\hline $\begin{array}{l}\text { Random sequence genera- } \\
\text { tion (selection bias) }\end{array}$ & Low risk & $\begin{array}{l}\text { Comment: random numbers table used - even number experimental, odd } \\
\text { numbers control }\end{array}$ \\
\hline $\begin{array}{l}\text { Allocation concealment } \\
\text { (selection bias) }\end{array}$ & Unclear risk & $\begin{array}{l}\text { Comment: although random number tables used it is unclear who undertook } \\
\text { the allocation and whether this was concealed from the researchers }\end{array}$ \\
\hline $\begin{array}{l}\text { Blinding of participants } \\
\text { and personnel (perfor- } \\
\text { mance bias) }\end{array}$ & High risk & Participants not blind due to the nature of the intervention \\
\hline
\end{tabular}


Fitzpatrick 2008 (Continued)

All outcomes

\begin{tabular}{|c|c|c|}
\hline $\begin{array}{l}\text { Blinding of outcome as- } \\
\text { sessment (detection bias) }\end{array}$ & High risk & Not blinded \\
\hline
\end{tabular}

All outcomes

Incomplete outcome data Low risk Apparently no missing data - must have had very highly motivated patients

(attrition bias)

All outcomes

\begin{tabular}{lll}
\hline $\begin{array}{l}\text { Selective reporting (re- } \\
\text { porting bias) }\end{array}$ & Unclear risk & No protocol available
\end{tabular}

\begin{tabular}{|c|c|c|}
\hline Other bias & High risk & $\begin{array}{l}\text { Intervention group had training with one of the tests used in the evaluation } \\
\text { sessions }\end{array}$ \\
\hline & & $\begin{array}{l}\text { Also there was a baseline difference between the groups with the control } \\
\text { group having higher scores on } 2 \text { of the speech perception tests }\end{array}$ \\
\hline
\end{tabular}

Gil 2010

\begin{tabular}{ll}
\hline Methods & Randomised \\
\hline Participants & $\mathrm{N}=14$ (7 control, 7 intervention) \\
& Age: details of actual age range not given but all must have been under 60 \\
& Inclusion criteria: 16 to 60 years old, mild to moderate bilateral sloping SNHL, word recognition $72 \%$ or \\
more, 3 months + HA use & Exclusion criteria: other neurological, psychological, cognitive disorders or mental disturbances \\
\hline
\end{tabular}

\begin{tabular}{ll}
\hline Interventions & Auditory training - $8 \times 1$-hour sessions held twice a week for 4 weeks \\
\hline Outcomes & $\begin{array}{l}\text { Short-term: electrophysiological (long-latency auditory evoked potentials), behavioural auditory pro- } \\
\text { cessing (sound localisation, memory for verbal sounds in sequence, memory for non-verbal sounds in } \\
\text { sequence, word recognition score, speech in noise test, synthetic sentence identification, dichotic dig- } \\
\text { its), APHAB (BENEFIT) }\end{array}$ \\
\hline Notes & -
\end{tabular}

\section{Risk of bias}

\begin{tabular}{lll}
\hline Bias & Authors' judgement & Support for judgement \\
\hline $\begin{array}{l}\text { Random sequence genera- } \\
\text { tion (selection bias) }\end{array}$ & Unclear risk & Quote: "randomly divided" \\
& & Comment: no details given on procedure \\
\hline $\begin{array}{l}\text { Allocation concealment } \\
\text { (selection bias) }\end{array}$ & Unclear risk & No details of allocation procedure \\
\hline $\begin{array}{l}\text { Blinding of participants } \\
\text { and personnel (perfor- } \\
\text { mance bias) } \\
\text { All outcomes }\end{array}$ & High risk & Participants not blinded due to the nature of the intervention \\
\hline
\end{tabular}


Gil 2010 (Continued)

Blinding of outcome as- Low risk Evaluation after intervention was carried out by a researcher who was blind to sessment (detection bias) the participant's group and was blind to participant's baseline results

All outcomes

\begin{tabular}{lll}
\hline $\begin{array}{l}\text { Incomplete outcome data } \\
\text { (attrition bias) } \\
\text { All outcomes }\end{array}$ & Low risk & No apparent missing data \\
\hline $\begin{array}{l}\text { Selective reporting (re- } \\
\text { porting bias) }\end{array}$ & Unclear risk & No protocol available \\
\hline Other bias & High risk & $\begin{array}{l}\text { Only change scores presented and there was a reported difference between } \\
\text { groups at baseline, which may have affected the outcome and was not fully } \\
\text { addressed }\end{array}$ \\
\hline
\end{tabular}

Kemker 2004

\begin{tabular}{ll}
\hline Methods & Randomised but with balanced group allocation \\
\hline Participants & $\mathrm{N}=45$ (1 participant excluded and his data not included so 44 - he was in the post-fit group) \\
& Age: range 60 to 80 \\
& Inclusion criteria: new HA users, US veterans, 23 or higher on mini mental state exam \\
& Exclusion criteria: patients being followed by VA visual impairment team \\
\hline Interventions & HA alone versus pre-fitting hearing aid orientation + HA versus HA + pre and post-fit hearing aid orienta- \\
tion & Orientation was $2 \times 1$-hour sessions 1 week apart \\
\hline Outcomes & Short-term: GHABP (which includes measure of USE) \\
\hline Notes & -
\end{tabular}

\section{Risk of bias}

\begin{tabular}{lll}
\hline Bias & Authors' judgement & Support for judgement \\
\hline $\begin{array}{l}\text { Random sequence genera- } \\
\text { tion (selection bias) }\end{array}$ & Unclear risk & Quote: "systematic random sampling scheme" \\
& $\begin{array}{l}\text { Comment: to give } 15 \text { in each group - process not described beyond that except } \\
\text { that word recognition scores were monitored to ensure balancing. Insufficient } \\
\text { detail }\end{array}$
\end{tabular}

\begin{tabular}{|c|c|c|}
\hline $\begin{array}{l}\text { Allocation concealment } \\
\text { (selection bias) }\end{array}$ & High risk & $\begin{array}{l}\text { Clearly not as the groups were balanced on the basis of word recognition } \\
\text { scores }\end{array}$ \\
\hline $\begin{array}{l}\text { Blinding of participants } \\
\text { and personnel (perfor- } \\
\text { mance bias) } \\
\text { All outcomes }\end{array}$ & Unclear risk & $\begin{array}{l}\text { Quote: "double-blind" } \\
\text { Comment: participant would know which group they were in }\end{array}$ \\
\hline
\end{tabular}

\begin{tabular}{|c|c|c|}
\hline $\begin{array}{l}\text { Blinding of outcome as- } \\
\text { sessment (detection bias) }\end{array}$ & Unclear risk & $\begin{array}{l}\text { Not stated whether researchers administering the questionnaires/analysing } \\
\text { results knew which group patients were in }\end{array}$ \\
\hline
\end{tabular}


Kemker 2004 (Continued)

All outcomes

\begin{tabular}{lll}
\hline $\begin{array}{l}\text { Incomplete outcome data } \\
\text { (attrition bias) } \\
\text { All outcomes }\end{array}$ & Low risk & $\begin{array}{l}\text { 1 patient dropped out - reasons given and not study related; their data were } \\
\text { excluded }\end{array}$ \\
\hline $\begin{array}{l}\text { Selective reporting (re- } \\
\text { porting bias) }\end{array}$ & Unclear risk & No protocol available \\
\hline Other bias & Unclear risk & $\begin{array}{l}\text { No power calculation to determine if sufficient numbers to demonstrate an ef- } \\
\text { fect }\end{array}$ \\
\hline
\end{tabular}

Kramer 2005

\begin{tabular}{ll}
\hline Methods & Randomised \\
\hline Participants & $\mathrm{N}=24$ intervention and 24 control (plus their significant others) completed all and data analysed but \\
58 were initially recruited and randomised. 2 dropped out of training group (ill health and problems op- \\
erating the video) and 8 further HI participants failed to return questionnaires (not clear which group \\
they were in) \\
Inclusion criteria: mix of new and existing HA users
\end{tabular}

Interventions $\quad$ HA alone versus HA plus home education programme for patients and significant others
Home education programme - 5 video tapes and an instruction booklet
Tapes sent out one at a time - only sent next one when returned previous

\begin{tabular}{ll}
\hline Outcomes & Medium-term: 6 months post-intervention \\
IOI-HA/IOI-AI
\end{tabular}

Notes

Cannot include these outcomes in a meta-analysis as the 2 versions of the questionnaire are measuring different things - not a valid comparison

The other outcomes were amended from other questionnaires for this study and so could not be used

\begin{tabular}{|c|c|c|}
\hline \multicolumn{3}{|l|}{ Risk of bias } \\
\hline Bias & Authors' judgement & Support for judgement \\
\hline Random sequence genera- & Unclear risk & Quote: "randomly allocated" \\
\hline पार & & Comment: no details given on procedure \\
\hline $\begin{array}{l}\text { Allocation concealment } \\
\text { (selection bias) }\end{array}$ & Unclear risk & No details given on randomisation procedure \\
\hline $\begin{array}{l}\text { Blinding of participants } \\
\text { and personnel (perfor- } \\
\text { mance bias) } \\
\text { All outcomes }\end{array}$ & High risk & Participants could not be blinded due to the nature of the intervention \\
\hline $\begin{array}{l}\text { Blinding of outcome as- } \\
\text { sessment (detection bias) } \\
\text { All outcomes }\end{array}$ & High risk & No apparent blinding in collection of outcomes \\
\hline
\end{tabular}


Kramer 2005 (Continued)

$\begin{array}{ll}\begin{array}{l}\text { Incomplete outcome data } \\ \text { (attrition bias) }\end{array} & \text { High risk } \\ \text { All outcomes } & \begin{array}{l}\text { Details are not given about numbers in each randomised group - only N post } \\ \text { dropout/non-returned questionnaires. No details about which group the non- } \\ \text { returners were in. } 1 \text { patient in intervention group dropped out due to prob- } \\ \text { lems with using the video - their results were not included }\end{array}\end{array}$

\begin{tabular}{lll}
\hline $\begin{array}{l}\text { Selective reporting (re- } \\
\text { porting bias) }\end{array}$ & Unclear risk & No protocol available \\
\hline Other bias & High risk & $\begin{array}{l}\text { The intervention group and control group were evaluated using different ver- } \\
\text { sions of the same questionnaire. Subsequent research suggests this is not } \\
\text { valid }\end{array}$ \\
Also no power calculation
\end{tabular}

Kricos 1992

\begin{tabular}{ll}
\hline Methods & Randomised \\
\hline Participants & $\mathrm{N}=26$ (control 13, intervention 13) \\
& Age: range 61 to 83 years, mean 70.8 \\
& Inclusion criteria: HA users, no previous AR, bilateral SNHL, corrected vision of 20/30 \\
\hline Interventions & $\begin{array}{l}\text { 4-week communication training programme - individual, twice a week 1-hour sessions - } 8 \text { hours in to- } \\
\text { tal }\end{array}$ \\
\hline Outcomes & Short-term: HHIE (HANDICAP), speech recognition test - audiovisual and audio only Central Institute \\
for the Deaf Everyday Sentence Test \% syllables correctly identified
\end{tabular}

\section{Risk of bias}

\begin{tabular}{|c|c|c|}
\hline Bias & Authors' judgement & Support for judgement \\
\hline $\begin{array}{l}\text { Random sequence genera- } \\
\text { tion (selection bias) }\end{array}$ & Unclear risk & No details given of randomisation procedure \\
\hline $\begin{array}{l}\text { Allocation concealment } \\
\text { (selection bias) }\end{array}$ & Unclear risk & No details given \\
\hline $\begin{array}{l}\text { Blinding of participants } \\
\text { and personnel (perfor- } \\
\text { mance bias) } \\
\text { All outcomes }\end{array}$ & High risk & The participants were not blinded due to the nature of the intervention \\
\hline $\begin{array}{l}\text { Blinding of outcome as- } \\
\text { sessment (detection bias) } \\
\text { All outcomes }\end{array}$ & High risk & No apparent blinding \\
\hline $\begin{array}{l}\text { Incomplete outcome data } \\
\text { (attrition bias) } \\
\text { All outcomes }\end{array}$ & Unclear risk & No apparent missing data but not explicitly stated \\
\hline
\end{tabular}


Kricos 1992 (Continued)

Selective reporting (re- $\quad$ Unclear risk $\quad$ No protocol available
porting bias)

Other bias Unclear risk No power calculation

\section{Kricos 1996}

\begin{tabular}{ll}
\hline Methods & Assigned on a rotating basis to 1 of 3 groups \\
\hline Participants & $\mathrm{N}=78$ \\
& Age: range 52 to 85 \\
& $\begin{array}{l}\text { Inclusion criteria: significant handicap score on HHIE, native English speakers with adult onset HL, ex- } \\
\text { isting HA users, 20/40 corrected vision }\end{array}$ \\
\hline Interventions & Analytic auditory training (N = 26) same/different judgements between syllable pairs \\
& Active listening (N = 26) communication training \\
& Control (N = 26) \\
\hline Outcomes & Short-term: CST (SPEECH PERCEPTION), HHIE (HANDICAP), CPHI (PSYCHOSOCIAL FUNCTION, COM- \\
\hline MUNICATION AND HANDICAP)
\end{tabular}

\section{Risk of bias}

\begin{tabular}{lll}
\hline Bias & Authors' judgement & Support for judgement \\
\hline $\begin{array}{l}\text { Random sequence genera- } \\
\text { tion (selection bias) }\end{array}$ & High risk & Assigned on a rotating basis to 1 of 3 groups - quasi-randomised \\
\hline $\begin{array}{l}\text { Allocation concealment } \\
\text { (selection bias) }\end{array}$ & High risk & No allocation concealment \\
\hline $\begin{array}{l}\text { Blinding of participants } \\
\text { and personnel (perfor- } \\
\text { mance bias) }\end{array}$ & High risk & Participants not blinded due to the nature of the intervention \\
$\begin{array}{l}\text { All outcomes } \\
\text { Blinding of outcome as- } \\
\text { sessment (detection bias) }\end{array}$ & High risk & Not blinded \\
All outcomes & & \\
\hline $\begin{array}{l}\text { Incomplete outcome data } \\
\text { (attrition bias) } \\
\text { All outcomes }\end{array}$ & Low risk & No apparent missing data \\
\hline $\begin{array}{l}\text { Selective reporting (re- } \\
\text { porting bias) }\end{array}$ & Unclear risk & No protocol available \\
\hline \begin{tabular}{l} 
Other bias \\
\hline
\end{tabular} & Unclear risk & It is unclear whether there are further sources of bias \\
\hline
\end{tabular}


Lavie 2014

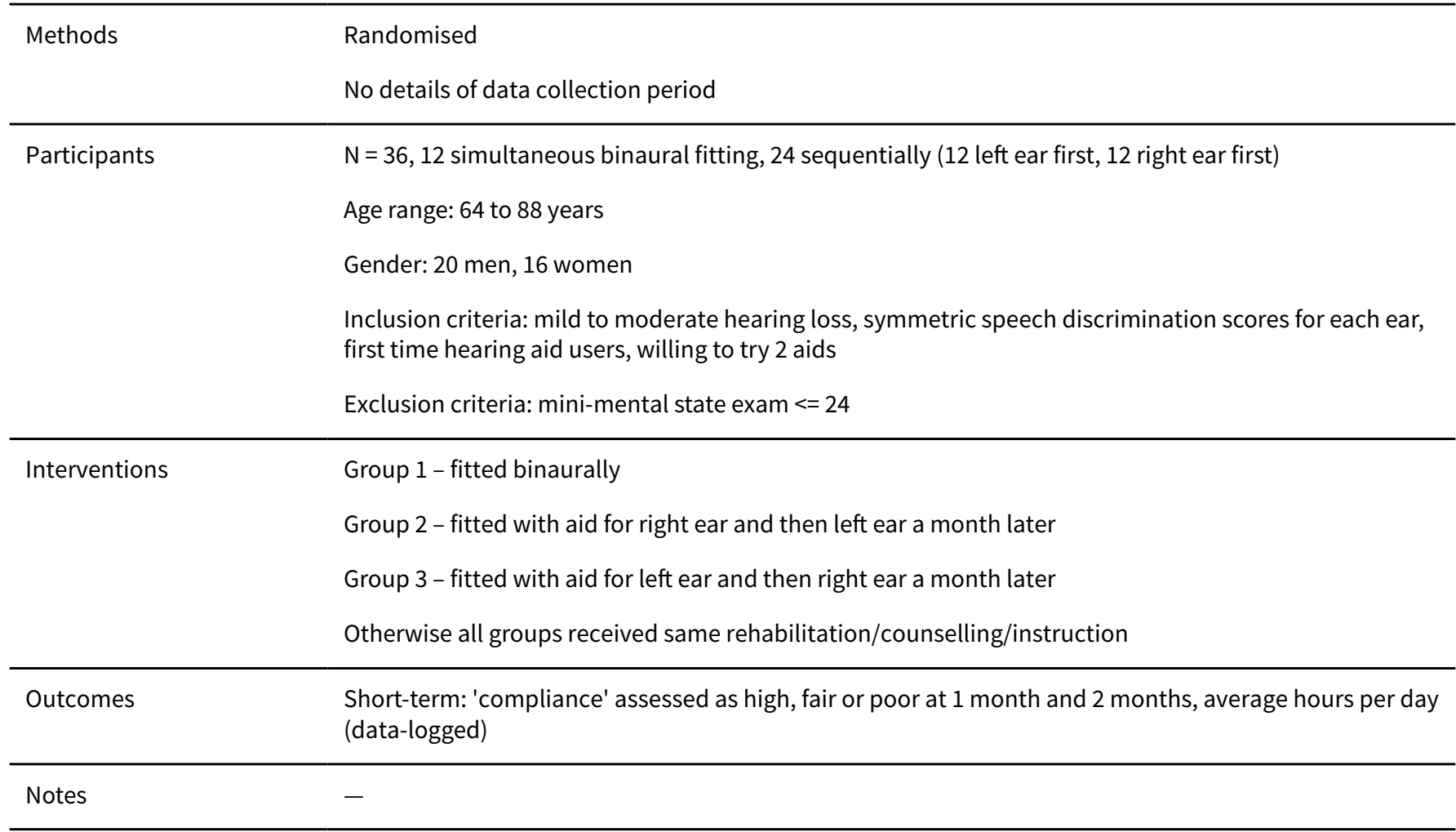

\section{Risk of bias}

\begin{tabular}{|c|c|c|}
\hline Bias & Authors' judgement & Support for judgement \\
\hline $\begin{array}{l}\text { Random sequence genera- } \\
\text { tion (selection bias) }\end{array}$ & Unclear risk & $\begin{array}{l}\text { Quote: "Participants were randomly divided in to three equal-size groups" } \\
\text { Comment: no further details of how this was done }\end{array}$ \\
\hline $\begin{array}{l}\text { Allocation concealment } \\
\text { (selection bias) }\end{array}$ & High risk & $\begin{array}{l}\text { Comment: unable to conceal allocation from participants or investigators dur- } \\
\text { ing the first month, unclear whether allocation concealment from investiga- } \\
\text { tors was achieved in the second month }\end{array}$ \\
\hline $\begin{array}{l}\text { Blinding of participants } \\
\text { and personnel (perfor- } \\
\text { mance bias) } \\
\text { All outcomes }\end{array}$ & High risk & Participants not blinded due to the nature of the intervention \\
\hline $\begin{array}{l}\text { Blinding of outcome as- } \\
\text { sessment (detection bias) } \\
\text { All outcomes }\end{array}$ & High risk & Investigators not blinded \\
\hline $\begin{array}{l}\text { Incomplete outcome data } \\
\text { (attrition bias) } \\
\text { All outcomes }\end{array}$ & Low risk & Some data excluded but reasons given \\
\hline $\begin{array}{l}\text { Selective reporting (re- } \\
\text { porting bias) }\end{array}$ & Unclear risk & No protocol available but published data include all expected outcomes \\
\hline Other bias & Low risk & The study appears to be free of other sources of bias \\
\hline
\end{tabular}


Lundberg 2011

\begin{tabular}{ll} 
Methods & $\begin{array}{l}\text { Randomised } \\
\text { Data collection } 2007 \text { to } 2008\end{array}$ \\
\hline Participants & $\begin{array}{l}\mathrm{N}=69 \text { final numbers but there is some discrepancy in the way this was reached depending on where } \\
\text { you read in the text } \\
\text { Inclusion criteria: } 60 \text { to } 75 \text { years of age, mild-moderate HL, to have had HA fitted at least } 1 \text { year prior to } \\
\text { study, to have HHIE score of }>20 \text { (indicative of residual handicap) }\end{array}$ \\
\hline $\begin{array}{l}\text { Intervention group received a booklet with weekly topic-based reading instructions based on chapters } \\
\text { of the book plus } 5 \times 10 \text { - to } 15 \text {-minute telephone calls with an audiologist to discuss the content of the } \\
\text { book } \\
\text { Control group received the booklet but no instructions or telephone follow-up }\end{array}$
\end{tabular}

\begin{tabular}{ll}
\hline Outcomes & Short-term: HHIE (HANDICAP), HADS (PSYCHOLOGICAL IMPACT), IOI-HA (inc USE) \\
\hline Notes & - \\
\hline
\end{tabular}

\section{Risk of bias}

\begin{tabular}{lll}
\hline Bias & Authors' judgement & Support for judgement \\
\hline $\begin{array}{l}\text { Random sequence genera- } \\
\text { tion (selection bias) }\end{array}$ & Unclear risk & Quote: "randomised" \\
& & $\begin{array}{l}\text { Comment: probably done but no details of exact randomisation procedure } \\
\text { given }\end{array}$
\end{tabular}

\begin{tabular}{lll}
\hline $\begin{array}{l}\text { Allocation concealment } \\
\text { (selection bias) }\end{array}$ & Unclear risk & $\begin{array}{l}\text { Randomisation was carried out by someone independent of the study data } \\
\text { collection but not clear whether concealed }\end{array}$ \\
\hline $\begin{array}{l}\text { Blinding of participants } \\
\text { and personnel (perfor- } \\
\text { mance bias) }\end{array}$ & High risk & Participants not blinded due to the nature of the intervention \\
All outcomes & \\
\hline
\end{tabular}

\begin{tabular}{|c|c|c|}
\hline $\begin{array}{l}\text { Blinding of outcome as- } \\
\text { sessment (detection bias) } \\
\text { All outcomes }\end{array}$ & High risk & $\begin{array}{l}\text { Comment: authors do comment that blinding the questionnaire administra- } \\
\text { tors may have improved quality of the study. They recognised the potential } \\
\text { bias }\end{array}$ \\
\hline
\end{tabular}

\begin{tabular}{|c|c|c|}
\hline \multirow{2}{*}{$\begin{array}{l}\text { Incomplete outcome data } \\
\text { (attrition bias) } \\
\text { All outcomes }\end{array}$} & Unclear risk & $\begin{array}{l}\text { They did explain how many dropped out and gave reasons and those included } \\
\text { under ITT where included on a LOCF basis }\end{array}$ \\
\hline & & $\begin{array}{l}1 \text { participant in the control group was deemed an outlier and was thereby ex- } \\
\text { cluded from analyses because the participant's data differed by more than } 2 \\
\text { SD from the control group mean measured before and after the intervention. } \\
\text { Unclear whether this is appropriate }\end{array}$ \\
\hline
\end{tabular}

Selective reporting (re- Unclear risk No protocol available
porting bias)

Other bias Low risk Authors give a good discussion of other potential sources of bias


Miranda 2008

\begin{tabular}{ll}
\hline Methods & Randomised \\
& Data collection 2005 and first quarter 2006 \\
\hline Participants & $\mathrm{N}=13$ (control 7, intervention $=6)$ \\
& Age: range 60 to 74 years, mean 65.3 \\
& Inclusion criteria: mild to moderately severe bilateral sensorineural hearing, symmetrical hearing loss \\
of flat or slightly descending curve shape in the high frequencies; speech recognition index equal to or \\
above $72 \%$ bilaterally; received a HA donation in the last 3 months; use or have the indication to use in- \\
tracanal HAs in binaural fitting; not having perceivable cognitive alteration or speech alteration; more \\
than 60 years of age
\end{tabular}

\begin{tabular}{ll}
\hline Interventions & Auditory training: 7 sessions, held once a week, with duration of 50 minutes each \\
\hline Outcomes & Short-term: HHIE (HANDICAP), speech perception \\
\hline Notes & - \\
\hline
\end{tabular}

\section{Risk of bias}

\begin{tabular}{lll}
\hline Bias & Authors' judgement & Support for judgement \\
\hline $\begin{array}{l}\text { Random sequence genera- } \\
\text { tion (selection bias) }\end{array}$ & Low risk & $\begin{array}{l}\text { Quote: "the individuals themselves pick a number to be randomized to which } \\
\text { group they would be sent to" }\end{array}$ \\
& $\begin{array}{l}\text { Comment: not } 100 \% \text { clear how this worked but almost certainly randomised } \\
\begin{array}{l}\text { Allocation concealment } \\
\text { (selection bias) }\end{array}\end{array}$ Unclear risk & $\begin{array}{l}\text { Exact randomisation procedure unclear but may have been concealed if out of } \\
\text { a hat }\end{array}$ \\
\hline
\end{tabular}

\begin{tabular}{|c|c|c|}
\hline $\begin{array}{l}\text { Blinding of participants } \\
\text { and personnel (perfor- } \\
\text { mance bias) } \\
\text { All outcomes }\end{array}$ & High risk & $\begin{array}{l}\text { Participants not blinded due to the nature of the intervention } \\
\text { Those in control group who were interested in training were offered the } \\
\text { chance - not clear whether this offer was made before or after the study }\end{array}$ \\
\hline $\begin{array}{l}\text { Blinding of outcome as- } \\
\text { sessment (detection bias) } \\
\text { All outcomes }\end{array}$ & Low risk & $\begin{array}{l}\text { Single-blinded - evaluations carried out but researcher blind to treatment } \\
\text { group }\end{array}$ \\
\hline $\begin{array}{l}\text { Incomplete outcome data } \\
\text { (attrition bias) } \\
\text { All outcomes }\end{array}$ & Low risk & No apparent missing data \\
\hline $\begin{array}{l}\text { Selective reporting (re- } \\
\text { porting bias) }\end{array}$ & Unclear risk & No protocol available \\
\hline Other bias & High risk & $\begin{array}{l}\text { Significant difference between the groups at baseline } \\
\text { For the treatment group they reported the results for the } 2 \text { ears separately to } \\
\text { double the sample size - incorrect assumption }\end{array}$ \\
\hline
\end{tabular}

Oberg 2008

Methods Randomised


Oberg 2008 (Continued)

Data collection Autumn 2005

\begin{tabular}{ll}
\hline Participants & Diagnosis: symmetrical mild to moderate SNHL \\
& $\mathrm{N}=38$ (19 intervention, 19 control) \\
& Age: range not given but mean intervention 67.1 and control 65.5 \\
& Inclusion criteria: first-time users aged 20 to 80 , good general health, fluent in Swedish \\
& Exclusion criteria: evidence of cognitive deficits during the interview or on a test of verbal fluency \\
\hline Interventions & Individual pre-fitting sound awareness training \\
& 3 visits each with different listening exercises and also use of the experimental adjustable aid \\
\hline Outcomes & Short-term: post-fitting - HHIE, SADL, CSS, HADS, IOI-HA \\
& Long-term: 1 year - HHIE, SADL, CSS, HADS, IOI-HA, COSI, speech recognition \\
\hline Notes & -
\end{tabular}

\section{Risk of bias}

\begin{tabular}{|c|c|c|}
\hline Bias & Authors' judgement & Support for judgement \\
\hline $\begin{array}{l}\text { Random sequence genera- } \\
\text { tion (selection bias) }\end{array}$ & Low risk & $\begin{array}{l}\text { Quote: "the randomisation procedure was performed by an independent re- } \\
\text { searcher. The researcher allocated the participants according to a comput- } \\
\text { er-generated randomisation list" }\end{array}$ \\
\hline $\begin{array}{l}\text { Allocation concealment } \\
\text { (selection bias) }\end{array}$ & Low risk & The audiologists who saw the participants in the clinic were blind to this list \\
\hline $\begin{array}{l}\text { Blinding of participants } \\
\text { and personnel (perfor- } \\
\text { mance bias) } \\
\text { All outcomes }\end{array}$ & High risk & The participants were not blinded due to the nature of the intervention \\
\hline $\begin{array}{l}\text { Blinding of outcome as- } \\
\text { sessment (detection bias) } \\
\text { All outcomes }\end{array}$ & Unclear risk & All telephone consultations were conducted by an "independent audiologist" \\
\hline $\begin{array}{l}\text { Incomplete outcome data } \\
\text { (attrition bias) } \\
\text { All outcomes }\end{array}$ & Unclear risk & $\begin{array}{l}\text { Comment: missing outcome data balanced across groups with similar reasons } \\
\text { across groups but sometimes reasons for dropouts not clear }\end{array}$ \\
\hline $\begin{array}{l}\text { Selective reporting (re- } \\
\text { porting bias) }\end{array}$ & Low risk & No protocol published but was described in thesis (which we have) \\
\hline Other bias & Unclear risk & $\begin{array}{l}\text { Study was under-powered } \\
\text { Non-responders who declined the telephone interview but completed the IOI- } \\
\text { HA reported significantly less use of aids than responders - not clear which } \\
\text { groups the non-responders came from }\end{array}$ \\
\hline
\end{tabular}

Oberg 2009

Methods Randomised


Oberg 2009 (Continued)

Data collection autumn 2004

\begin{tabular}{ll}
\hline Participants & Diagnosis: symmetrical mild to moderate SNHL \\
$\mathrm{N}=39$ (19 intervention, 20 control) \\
Age: range not given, mean 68.6 intervention and 69.8 control \\
Inclusion criteria: first-time users aged 20 to 80 , good general health, fluent in Sw \\
Exclusion criteria: evidence of cognitive deficits during the interview or on a test \\
\hline 3 visits to clinic - 1 per week \\
First week fitted with a user-controlled adjustment experimental aid \\
Subsequent visits they adjusted the aid to preferred settings \\
Wore aids at home in between \\
Short-term: week 6 post-intervention (pre HA) - HHIE, ECHO, CSS, HADS, COSI \\
Medium-term: week 18 post-fitting - HHIE, SADL, CSS, HADS, IOI-HA \\
Long-term: 1 year FU - HHIE, SADL, CSS, HADS, IOI-HA, COSI \\
\hline Notes
\end{tabular}

Risk of bias

\begin{tabular}{|c|c|c|}
\hline Bias & Authors' judgement & Support for judgement \\
\hline $\begin{array}{l}\text { Random sequence genera- } \\
\text { tion (selection bias) }\end{array}$ & Low risk & $\begin{array}{l}\text { Quote: "the randomisation procedure was performed by an independent re- } \\
\text { searcher. The researcher allocated the participants according to a comput- } \\
\text { er-generated randomisation list." }\end{array}$ \\
\hline $\begin{array}{l}\text { Allocation concealment } \\
\text { (selection bias) }\end{array}$ & Low risk & The audiologists who saw the participants in the clinic were blind to this list \\
\hline $\begin{array}{l}\text { Blinding of participants } \\
\text { and personnel (perfor- } \\
\text { mance bias) } \\
\text { All outcomes }\end{array}$ & High risk & The participants were not blinded due to the nature of the intervention \\
\hline $\begin{array}{l}\text { Blinding of outcome as- } \\
\text { sessment (detection bias) } \\
\text { All outcomes }\end{array}$ & Unclear risk & All telephone consultations were conducted by an "independent audiologist" \\
\hline $\begin{array}{l}\text { Incomplete outcome data } \\
\text { (attrition bias) } \\
\text { All outcomes }\end{array}$ & Low risk & $\begin{array}{l}\text { Comment: missing outcome data balanced across groups with similar reasons } \\
\text { across groups }\end{array}$ \\
\hline $\begin{array}{l}\text { Selective reporting (re- } \\
\text { porting bias) }\end{array}$ & Low risk & No protocol published but was described in thesis (which we have) \\
\hline Other bias & Low risk & The study appears to be free of other sources of bias \\
\hline
\end{tabular}


Olson 2013

$\begin{array}{ll}\text { Methods } & \text { Randomised trial (also had a group of experienced HA users who received training but allocation to this } \\ \text { group was not randomised) }\end{array}$
group was not randomised)

\section{Participants}

$$
\begin{aligned}
& \mathrm{N}=29 \text { in total but we cannot include data for experienced users. } \mathrm{N}=8 \text { new users plus training, } \mathrm{N}=7 \\
& \text { new users control }
\end{aligned}
$$

Age range: mean 66 years in both groups

Inclusion criteria: 'new' HA users (4 week to 6 months experience), 50 to 81 years old, mild-moderate bilateral SNHL and bilateral HAs, native speakers of American English, adequate vision, daily access to TV and DVD player with remote control

\begin{tabular}{|c|c|c|}
\hline Interventions & \multicolumn{2}{|c|}{ LACE DVD - $20 \times 30$-minute sessions at home over a 4-week period } \\
\hline Outcomes & \multicolumn{2}{|c|}{$\begin{array}{l}\text { Short-term: at end of 4-week home training period - QuickSIN, Compressed Speech Test (word recogni- } \\
\text { tion), Synthetic Sentence Identification (competing speaker task) ALL SPEECH PERCEPTION, IOI-HA/AI, } \\
\text { Speech, Spatial and Qualities of Hearing Scale - only } 2 \text { subscales as spatial considered not relevant }\end{array}$} \\
\hline Notes & \multicolumn{2}{|l|}{-} \\
\hline \multicolumn{3}{|l|}{ Risk of bias } \\
\hline Bias & Authors' judgement & Support for judgement \\
\hline $\begin{array}{l}\text { Random sequence genera- } \\
\text { tion (selection bias) }\end{array}$ & Low risk & $\begin{array}{l}\text { Quote: "New HA users were randomly assigned to the training or control (non- } \\
\text { training) group as determined by random tables" }\end{array}$ \\
\hline $\begin{array}{l}\text { Allocation concealment } \\
\text { (selection bias) }\end{array}$ & Unclear risk & No details of allocation concealment given \\
\hline $\begin{array}{l}\text { Blinding of participants } \\
\text { and personnel (perfor- } \\
\text { mance bias) } \\
\text { All outcomes }\end{array}$ & High risk & Not blinded \\
\hline $\begin{array}{l}\text { Blinding of outcome as- } \\
\text { sessment (detection bias) } \\
\text { All outcomes }\end{array}$ & High risk & Not blinded \\
\hline $\begin{array}{l}\text { Incomplete outcome data } \\
\text { (attrition bias) } \\
\text { All outcomes }\end{array}$ & Unclear risk & $\begin{array}{l}\text { There were } 4 \text { dropouts. The reasons were given and were unrelated to the } \\
\text { study in } 2 \text { cases but it is not clear which groups they came from. } N \text { in each } \\
\text { group prior to the dropouts was not quoted. The data from the } 4 \text { participants } \\
\text { that did not complete the study were excluded from the analysis }\end{array}$ \\
\hline $\begin{array}{l}\text { Selective reporting (re- } \\
\text { porting bias) }\end{array}$ & High risk & $\begin{array}{l}\text { No protocol available but data for SSQ not reported although it was listed as } \\
\text { an outcome measure }\end{array}$ \\
\hline \multirow[t]{3}{*}{ Other bias } & High risk & $\begin{array}{l}\text { The Tx group had an additional test session at } 2 \text { weeks, which the control } \\
\text { group did not have, and so they had extra experience with the test situation } \\
\text { and material }\end{array}$ \\
\hline & & The study was also under-powered after dropouts by their own calculation \\
\hline & & Subjects were paid for their participation \\
\hline
\end{tabular}

Exclusion criteria: neurological, psychiatric disorder, conductive or asymmetric hearing loss 
Preminger 2008

\begin{tabular}{ll}
\hline Methods & Randomised \\
\hline Participants & $\mathrm{N}=53$ (3 dropped out during study and were not included in analysis) \\
& Age: control mean 66, training + psychosocial ( $\mathrm{T}+\mathrm{P}) 65.3$, training only (TO) 64.9 \\
& Gender: control $75 \%$ male, $\mathrm{T}+\mathrm{P} 37.5 \%, \mathrm{TO} 66.7 \%$ apparently not statistically significant on Chi ${ }^{2}$ test \\
& BUT is a big difference \\
& Inclusion criteria: aged 55 to 75, at least 3 months HA experience and $>20$ score on HHIE or HHIA, cor- \\
& rected binocular visual acuity 20/40, passed MMSE, passed a screen for APD
\end{tabular}

Training plus psychosocial exercises: as above plus an extra 30 minutes psychosocial exercises

At least 2 instructors per class

\begin{tabular}{ll}
\hline Outcomes & Short-term: 6 weeks - CUNY AB wordlists auditory and audio-visual (SPEECH PERCEPTION), CUNY top- \\
ic-related sentences auditory and audio-visual (SPEECH PERCEPTION), HHIE (HANDICAP, HEARING RE- \\
LATED QoL), WHO Disability Assessment Schedule II (GENERIC QoL) \\
Medium-term: 6 months - AS ABOVE
\end{tabular}

Notes - -

\section{Risk of bias}

\begin{tabular}{|c|c|c|}
\hline Bias & Authors' judgement & Support for judgement \\
\hline $\begin{array}{l}\text { Random sequence genera- } \\
\text { tion (selection bias) }\end{array}$ & Unclear risk & $\begin{array}{l}\text { Quote: "randomly allocated" } \\
\text { Comment: no details of procedure given }\end{array}$ \\
\hline $\begin{array}{l}\text { Allocation concealment } \\
\text { (selection bias) }\end{array}$ & Unclear risk & Comment: no details given \\
\hline $\begin{array}{l}\text { Blinding of participants } \\
\text { and personnel (perfor- } \\
\text { mance bias) } \\
\text { All outcomes }\end{array}$ & High risk & Not blinded \\
\hline $\begin{array}{l}\text { Blinding of outcome as- } \\
\text { sessment (detection bias) } \\
\text { All outcomes }\end{array}$ & High risk & Not blinded \\
\hline $\begin{array}{l}\text { Incomplete outcome data } \\
\text { (attrition bias) } \\
\text { All outcomes }\end{array}$ & Unclear risk & $\begin{array}{l}3 \text { dropouts which were excluded from the study - only evident from reading } \\
\text { carefully. All dropouts from treatment groups. Reasons given but only partially } \\
\text { clear; sensible management of dropouts in analysis }\end{array}$ \\
\hline $\begin{array}{l}\text { Selective reporting (re- } \\
\text { porting bias) }\end{array}$ & Unclear risk & No protocol available \\
\hline Other bias & Unclear risk & $\begin{array}{l}\text { Quality of life measures completed with researcher present } \\
\text { The gender and hearing handicap differences present at baseline, while not } \\
\text { statistically significant between groups, apparently may have had an effect }\end{array}$ \\
\hline
\end{tabular}


Preminger 2010

\begin{tabular}{ll}
\hline Methods & Randomised BUT was made on basis of preference regarding class time so 'quasi-randomised' \\
\hline Participants & $\mathrm{N}=36$ \\
& Age range: no range given but average Cx 72.2, Tx 63.5 - significant difference \\
& $\begin{array}{l}\text { Inclusion criteria: all PHL had to score over } 20 \text { on HHIE, scores below } 25 \text { on QuickSIN so they would } \\
\text { have no problems communicating in group class, SO had to have PTA over } 30 \mathrm{~dB} H L \text { (near normal hear- } \\
\text { ing at least) }\end{array}$
\end{tabular}

\begin{tabular}{ll}
\hline Interventions & $\begin{array}{l}\text { AR group programme just for people with hearing loss (spouses no treatment) versus AR group pro- } \\
\text { gramme plus separate group programme for spouses } \\
\text { 90-minute sessions } 1 \times \text { weekly for } 4 \text { weeks (no specific homework) }\end{array}$ \\
\hline Outcomes & $\begin{array}{l}\text { Short-term: } 4 \text { weeks - HHIE (HEARING HANDICAP), perceived stress scale and affect rating scale (PSY- } \\
\text { CHOLOGICAL), primary communication inventory (COMMUNICATION) } \\
\text { Medium-term: } 6 \text { months - as above }\end{array}$ \\
\hline Notes & -
\end{tabular}

\section{Risk of bias}

Bias Authors' judgement Support for judgement

Random sequence genera- High risk tion (selection bias)

Quote: "Couples were assigned to either the control or the experimental AR sessions based on the couples' preferred class meeting times. Participants were only given class meeting times and no information about the class content (control versus experimental); in this way they could not choose to be in either the control group or the experimental group."

Comment: quasi-randomised

\begin{tabular}{|c|c|c|}
\hline $\begin{array}{l}\text { Allocation concealment } \\
\text { (selection bias) }\end{array}$ & High risk & $\begin{array}{l}\text { No information re sequence generation but researchers presumably knew } \\
\text { which class was which and therefore which participants were choosing }\end{array}$ \\
\hline
\end{tabular}

Blinding of participants High risk Participants were not blinded due to the nature of the intervention
and personnel (perfor-

mance bias)

All outcomes

$\begin{array}{ll}\text { Blinding of outcome as- } & \text { High risk No apparent blinding of outcome assessment } \\ \text { sessment (detection bias) } & \end{array}$

All outcomes

Incomplete outcome data Low risk No apparent dropouts or missing data
(attrition bias)

All outcomes

Selective reporting (re- Unclear risk No protocol available
porting bias)

\begin{tabular}{ll}
\hline Other bias & Participants were a mix of $\mathrm{Cl}$ and $\mathrm{HA}$ patients \\
& Also age difference in groups and in mood scores pre-intervention
\end{tabular}


Preminger 2010 (Continued)

Scales all completed in presence of a researcher "to answer questions and make sure they were filled out correctly"

Preminger 2010a

\begin{tabular}{ll}
\hline Methods & Randomised on the basis of their choice of class time \\
\hline Participants & $\begin{array}{l}\mathrm{N}=52 \text { (18 group } 1,17 \text { group 2, } 17 \text { Group 3) but there were } 4 \text { on top of this who dropped out but were } \\
\text { not included }\end{array}$ \\
Age: no range given - no significant differences in means between groups. Overwhelmingly male, VA \\
population \\
Inclusion criteria: 55 to 75 , experience HA users (3 months plus), score at least 20 on HHIE, corrected \\
binocular vision 20/40, passed MMSE, passed screen for APD described in 2008 study \\
Exclusion criteria: fluctuating hearing loss during study
\end{tabular}

Interventions

Group 1: communication strategies group

Group 2: communication plus psychosocial group

Group 3: informational lecture plus psychosocial group

1-hour lecture per week for 6 weeks - all participants completed 5 of the 6 classes

\begin{tabular}{ll} 
Outcomes & Short-term: post-intervention - HHIE/A (HEARING RELATED QoL, HANDICAP), WHODAS 2.0 (GENERIC \\
& QoL) \\
& Medium-term: 6 months post-class - as above \\
\hline Notes & -
\end{tabular}

\section{Risk of bias}

\begin{tabular}{lll}
\hline Bias & Authors' judgement & Support for judgement \\
\hline $\begin{array}{l}\text { Random sequence genera- } \\
\text { tion (selection bias) }\end{array}$ & High risk & $\begin{array}{l}\text { Quote: "Participants were randomly assigned to each treatment group based } \\
\text { on their preferred class meeting times. Participants were given class meeting } \\
\text { times and no information about the class content" } \\
\text { Comment: quasi-randomised }\end{array}$ \\
\hline $\begin{array}{l}\text { Allocation concealment } \\
\text { (selection bias) }\end{array}$ & High risk & $\begin{array}{l}\text { Patients given the choice based on the above - researchers knew which group } \\
\text { was at which time }\end{array}$ \\
\hline $\begin{array}{l}\text { Blinding of participants } \\
\text { and personnel (perfor- } \\
\text { mance bias) }\end{array}$ & High risk & Participants were not blinded due to the nature of the intervention \\
$\begin{array}{l}\text { All outcomes } \\
\begin{array}{l}\text { Blinding of outcome as- } \\
\text { sessment (detection bias) } \\
\text { All outcomes }\end{array}\end{array}$ & High risk \\
\hline $\begin{array}{l}\text { Incomplete outcome data } \\
\text { (attrition bias) } \\
\begin{array}{l}\text { All outcomes } \\
\hline\end{array}\end{array}$ & Low risk & No blinding of outcome measurement \\
\hline
\end{tabular}


Preminger 2010a (Continued)

\begin{tabular}{lll}
$\begin{array}{l}\text { Selective reporting (re- } \\
\text { porting bias) }\end{array}$ & Unclear risk & No protocol available \\
\hline Other bias & High risk & $\begin{array}{l}\text { Questionnaires completed in the presence of a researcher (who was not blind } \\
\text { to the group allocation) }\end{array}$
\end{tabular}

Saunders 2009

\begin{tabular}{|c|c|}
\hline Methods & Randomised \\
\hline \multirow[t]{4}{*}{ Participants } & Diagnosis: symmetrical SNHL (< $15 \mathrm{~dB}$ HL difference between ears on 4 frequencies average) \\
\hline & $\begin{array}{l}\mathrm{N}=60 \text { ( } 18 \text { female, } 42 \text { male), } 2 \text { dropouts ( } 1 \text { from group } 1 \text { and } 1 \text { dropout from group } 2 \text {, reasons given); } \\
\text { analysed data from } 58 \text { people }\end{array}$ \\
\hline & Age: range 55 to 81 years \\
\hline & Inclusion criteria: first-time users \\
\hline
\end{tabular}

Interventions
Group 1: pre-fitting counselling including demonstration of listening situations, post-fit fine tune if
Group 2: pre-fitting counselling including demonstration of listening situations but no fine tuning
Group 3: pre-fitting counselling but no demonstration and no fine tune post-fit
Pre-fitting counselling based on COSI

Outcomes Short-term: 8 to 10 weeks - HHIE/A aided, APHAB-A, PIADS-A, SADL, categorical assessment of USE

PIADS = Psychosocial Impact of Assistive Devices Scale

Notes - P

\section{Risk of bias}

\begin{tabular}{|c|c|c|}
\hline Bias & Authors' judgement & Support for judgement \\
\hline $\begin{array}{l}\text { Random sequence genera- } \\
\text { tion (selection bias) }\end{array}$ & Unclear risk & $\begin{array}{l}\text { Quote: "randomly assigned" } \\
\text { Comment: no details given }\end{array}$ \\
\hline $\begin{array}{l}\text { Allocation concealment } \\
\text { (selection bias) }\end{array}$ & Unclear risk & No details given \\
\hline $\begin{array}{l}\text { Blinding of participants } \\
\text { and personnel (perfor- } \\
\text { mance bias) } \\
\text { All outcomes }\end{array}$ & High risk & Not blinded \\
\hline $\begin{array}{l}\text { Blinding of outcome as- } \\
\text { sessment (detection bias) } \\
\text { All outcomes }\end{array}$ & High risk & Not blinded \\
\hline $\begin{array}{l}\text { Incomplete outcome data } \\
\text { (attrition bias) } \\
\text { All outcomes }\end{array}$ & Low risk & $\begin{array}{l}2 \text { missing data - reasons given and not both from same group so unlikely to af- } \\
\text { fect analysis }\end{array}$ \\
\hline
\end{tabular}


Saunders 2009 (Continued)

Selective reporting (re- $\quad$ Unclear risk $\quad$ No protocol available
porting bias)

\begin{tabular}{ll}
\hline Other bias & Questionnaires completed in clinic - not clear whether researcher present \\
& No power calculation \\
& No control group who were only aided without the pre-fitting counselling \\
\hline
\end{tabular}

Saunders 2016

\begin{tabular}{ll}
\hline Methods & Randomised \\
\hline Participants & N = 279: 136 were new HA users and 143 experienced users \\
& Age range: age range not specified but average age was approx 68 across the 4 groups of new users \\
& Gender: not specified but given that these were veterans it is very likely that they were nearly all or all \\
male & \\
Inclusion criteria: English as first language, MMSE scores age appropriate, ability to read at 5 th grade \\
level or higher, good corrected vision, symmetrical hearing loss, 3 frequency average hearing loss $<50$ \\
dB HL, unaided speech recognition scores of $>40 \%$, had to be willing to have HAs set to NAL prescrip- \\
tion \\
Exclusion criteria: no external ear disease, conductive or retrocochlear pathology, comorbidities that \\
would interfere with participation
\end{tabular}

Interventions
LACE DVD: auditory training $10 \times 30$-minute sessions over a 2-week period at home on DVD
LACE C: auditory training $20 \times 30$-minute sessions over a 4-week period at home on computer
Placebo: listening to an audio book $20 \times 30$-minute sessions over a 4-week period
Control: standard HA fitting

\begin{tabular}{|c|c|c|}
\hline Outcomes & \multicolumn{2}{|c|}{$\begin{array}{l}\text { Short-term: } 2 \text { to } 6 \text { weeks - HHIE/A, } 5 \text { behavioural measures of speech reception } \\
\text { Medium-term: } 6 \text { months - as above }\end{array}$} \\
\hline Notes & - & \\
\hline \multicolumn{3}{|l|}{ Risk of bias } \\
\hline Bias & Authors' judgement & Support for judgement \\
\hline $\begin{array}{l}\text { Random sequence genera- } \\
\text { tion (selection bias) }\end{array}$ & Low risk & $\begin{array}{l}\text { Quote: "Each site was provided with sequentially numbered randomization } \\
\text { envelopes that specified the intervention group to which the participant was } \\
\text { assigned. A block randomization scheme with a block size of eight was uti- } \\
\text { lized with stratification of hearing aid experience (new or experienced listener) } \\
\text { across the four intervention groups." }\end{array}$ \\
\hline $\begin{array}{l}\text { Allocation concealment } \\
\text { (selection bias) }\end{array}$ & Unclear risk & No information about allocation concealment \\
\hline
\end{tabular}


Saunders 2016 (Continued)

Blinding of participants Low risk Quote: "...participants in the LACEDVD, LACE-C, and placebo groups were and personnel (performasked regarding whether they were receiving experimental or placebo trainmance bias)

All outcomes ing"

\section{Blinding of outcome as- High risk} sessment (detection bias)

All outcomes

Quote: "The research audiologists were not blinded to the participant's intervention-arm assignment"

Incomplete outcome data Low risk

(attrition bias)

Attrition was clearly explained and reasons for dropouts given

All outcomes

Selective reporting (re- Unclear risk No protocol available but paper includes all expected outcomes
porting bias)
porting bias)

Other bias Low risk The study appears to be free of other sources of bias

Smaldino 1988

\begin{tabular}{ll}
\hline Methods & Randomised \\
\hline Participants & $\mathrm{N}=40$ (19 females and 21 males) 10 in each group \\
& Age: range 30 to 90 years, mean 69 \\
Inclusion criteria: new HA users
\end{tabular}

\begin{tabular}{ll}
\hline Interventions & Control group: HA with simple orientation \\
& Cognitive style: as control but also given information about their learning style \\
Cognitive + AR - 4-week AR programme plus information on cognitive style \\
AR was individual computer-based \\
\hline Outcomes & Short-term: HPI (HANDICAP) \\
\hline Notes & - \\
\hline
\end{tabular}

\section{Risk of bias}

\begin{tabular}{lll}
\hline Bias & Authors' judgement & Support for judgement \\
\hline $\begin{array}{l}\text { Random sequence genera- } \\
\text { tion (selection bias) }\end{array}$ & Unclear risk & Protocol for randomisation not given \\
\hline $\begin{array}{l}\text { Allocation concealment } \\
\text { (selection bias) }\end{array}$ & Unclear risk & No details provided \\
\hline $\begin{array}{l}\text { Blinding of participants } \\
\text { and personnel (perfor- } \\
\text { mance bias) } \\
\text { All outcomes }\end{array}$ & High risk & Not blinded \\
\hline $\begin{array}{l}\text { Blinding of outcome as- } \\
\text { sessment (detection bias) }\end{array}$ & High risk & Not blinded \\
\hline
\end{tabular}


Smaldino 1988 (Continued)

All outcomes

Incomplete outcome data Low risk No missing data
(attrition bias)

(attrition bias)

All outcomes

Selective reporting (re- Unclear risk $\quad$ No protocol available
porting bias)

porting bias)

Other bias Unclear risk Only change scores available - not post-score

Not clear whether there was a difference at baseline in the outcome measure

as handicap was assessed pre-intervention with a different measure

Sweetow 2006

\begin{tabular}{ll}
\hline Methods & Randomised cross-over trial \\
\hline Participants & N $=65$ across 5 sites \\
& Age: range - trained 28 to 85 (average 63.15); control 32 to 82 (average 64.2 years) \\
\hline Interventions & Home-based interactive PC-based program (Listening and Communication Enhancement LACE) \\
& 30 minutes 5 times a week for 4 weeks \\
\hline Outcomes & $\begin{array}{l}\text { Short-term: } 4 \text { weeks - QuickSIN, Hearing in Noise Test (HINT) (SPEECH PERCEPTION), HHIE/A (HANDI- } \\
\text { CAP), Communication Scale for Older Adults (COMMUNICATION) }\end{array}$ \\
\hline Notes & $\begin{array}{l}\text { Group } 2 \text { cross-over arm - as there were no significant differences between group 1 and cross-over arm } \\
\text { of group } 2 \text { they pooled the data for these groups meaning we cannot use the data. Also data from HA } \\
\text { users mixed with non-users. This means that the data from this study have not been included in any } \\
\text { meta-analysis }\end{array}$ \\
Outcomes for a 'subset' of participants - not clear how this set was decided on
\end{tabular}

\section{Risk of bias}

Bias Authors' judgement Support for judgement

Random sequence genera- Unclear risk No details of sequence generation

tion (selection bias)

\begin{tabular}{lll}
\hline $\begin{array}{l}\text { Allocation concealment } \\
\text { (selection bias) }\end{array}$ & Unclear risk & No details of randomisation protocol
\end{tabular}

Blinding of participants High risk This study was not blinded due to the nature of the intervention

and personnel (perfor-

mance bias)

All outcomes

Blinding of outcome as- $\quad$ High risk
sessment (detection bias)

All outcomes 
Sweetow 2006 (Continued)

Incomplete outcome data High risk Some confusion over numbers for how many started and completed in each (attrition bias) group. $\mathrm{N}$ is stated as 65 but this is not the number randomised - it is the numAll outcomes ber who completed. Number randomised is unclear

\begin{tabular}{|c|c|c|}
\hline $\begin{array}{l}\text { Selective reporting (re- } \\
\text { porting bias) }\end{array}$ & Unclear risk & No protocol available \\
\hline \multirow[t]{3}{*}{ Other bias } & High risk & Participants at one of the sites were paid \\
\hline & & $\begin{array}{l}\text { Data not available separately for users versus non-users, for different sites or } \\
\text { for the } 2 \text { arms of the trial }\end{array}$ \\
\hline & & $\begin{array}{l}\text { The authors have a financial interest in the company that produces the inter- } \\
\text { vention LACE }\end{array}$ \\
\hline
\end{tabular}
vention LACE

Thoren 2011

\begin{tabular}{|c|c|}
\hline Methods & Randomised \\
\hline \multirow[t]{5}{*}{ Participants } & $\begin{array}{l}N=59 \text { (intervention group 29, control 30) recruited through adverts in newspapers and referred to a } \\
\text { website }\end{array}$ \\
\hline & Age: range 24 to 84 , mean 63.5 \\
\hline & 29 women and 30 men; majority (67\%) had education equivalent to university level \\
\hline & $\begin{array}{l}\text { Inclusion criteria: experienced HA users, hearing impairment with subjective significant communica- } \\
\text { tion difficulties (defined as over } 20 \text { on HHIE), using HA for at least } 1 \text { year, } 18 \text { years plus, Swedish as first } \\
\text { language, access to PC and internet }\end{array}$ \\
\hline & Exclusion criteria: not able to have a conversation by telephone, severe tinnitus, Ménière's \\
\hline \multirow[t]{2}{*}{ Interventions } & $\begin{array}{l}\text { Intervention: online education programme including professional guidance (5-week programme in- } \\
\text { cluding information, tasks, assignments and professional contact) }\end{array}$ \\
\hline & Control: online discussion forum with weekly topics but no professional guidance \\
\hline \multirow[t]{2}{*}{ Outcomes } & $\begin{array}{l}\text { Short-term: immediately post-intervention - questionnaires administered online HHIE, IOI-HA, SADL, } \\
\text { HADS }\end{array}$ \\
\hline & Medium-term: 6 months - as above \\
\hline \multirow[t]{2}{*}{ Notes } & This was a well-designed study with a good attempt made to include a placebo intervention \\
\hline & References CONSORT guidelines \\
\hline
\end{tabular}

\section{Risk of bias}

\begin{tabular}{lll}
\hline Bias & Authors' judgement & Support for judgement \\
\hline $\begin{array}{l}\text { Random sequence genera- } \\
\text { tion (selection bias) }\end{array}$ & Unclear risk & Quote: "...randomly assigned by an independent researcher" \\
& & Comment: almost certainly done \\
\hline $\begin{array}{l}\text { Allocation concealment } \\
\text { (selection bias) }\end{array}$ & Low risk & Allocation undertaken by researcher independent of the study \\
\hline
\end{tabular}


Thoren 2011 (Continued)
Blinding of participants
Unclear risk
Comment: probably was blinded to the participants - they were all given the and personnel (perfor- same instructions pre-study and both intervention and control group involved mance bias)
All outcomes the internet
However, blinding not explicitly stated but implied

\begin{tabular}{lll}
$\begin{array}{l}\text { Blinding of outcome as- } \\
\text { sessment (detection bias) } \\
\text { All outcomes }\end{array}$ & Unclear risk & Outcome assessment was online \\
\hline $\begin{array}{l}\text { Incomplete outcome data } \\
\text { (attrition bias) }\end{array}$ & Low risk & $\begin{array}{l}\text { Results analysed on ITT LOCF - very clearly explained. Reasons for dropouts } \\
\text { given }\end{array}$ \\
\hline
\end{tabular}

\begin{tabular}{lll}
\hline $\begin{array}{l}\text { Selective reporting (re- } \\
\text { porting bias) }\end{array}$ & Unclear risk & As far as one can tell but no protocol available \\
\hline Other bias & Low risk & This study appears to be free of other sources of bias. Limitations discussed. \\
& No 'no treatment' control but the placebo control group was well thought out \\
\hline
\end{tabular}

\section{Thoren 2014}

\begin{tabular}{ll}
\hline Methods & Randomised \\
\hline Participants & $\mathrm{N}=76$ (38 in each group) \\
& Age range: 26 to 81 years \\
& Gender: 32 women, 44 men \\
& $\begin{array}{l}\text { Inclusion criteria: } 1 \text { year + HA use, over } 18 \text { years of age, significant hearing impairment and significant } \\
\text { communication difficulties }\end{array}$ \\
\hline Interventions & $\begin{array}{l}\text { Online rehabilitation for hearing aid users including self-study, training and professional coaching in } \\
\text { hearing physiology, hearing aids and communication strategies, as well as online contact with peers } \\
\text { across } 5 \text { weekly modules. The intervention group was compared to a waiting list control group }\end{array}$ \\
\hline Outcomes & Short-term: immediately following intervention, IOI-HA, HHEl and HADS \\
\hline Motes & Medium-term: at 3 months measures repeated \\
\hline
\end{tabular}

\section{Risk of bias}

Bias Authors' judgement Support for judgement

\begin{tabular}{ll}
\hline $\begin{array}{l}\text { Random sequence genera- } \\
\text { tion (selection bias) }\end{array}$ & Unclear risk
\end{tabular} $\begin{aligned} & \begin{array}{l}\text { Quote: "The participants were randomized by an independent person (not in- } \\
\text { volved in the study or recruitment) to either participate in the intervention } \\
\text { group or in the control group." }\end{array} \\
& \begin{array}{l}\text { Comment: insufficient information about the sequence generation process in } \\
\text { study }\end{array}\end{aligned}$

\begin{tabular}{|c|c|c|}
\hline $\begin{array}{l}\text { Allocation concealment } \\
\text { (selection bias) }\end{array}$ & Low risk & $\begin{array}{l}\text { Comment: the use of an independent person performing the randomisation is } \\
\text { suggestive of allocation concealment }\end{array}$ \\
\hline
\end{tabular}


Thoren 2014 (Continued)

\begin{tabular}{|c|c|c|}
\hline $\begin{array}{l}\text { Blinding of participants } \\
\text { and personnel (perfor- } \\
\text { mance bias) } \\
\text { All outcomes }\end{array}$ & High risk & Not blinded \\
\hline $\begin{array}{l}\text { Blinding of outcome as- } \\
\text { sessment (detection bias) } \\
\text { All outcomes }\end{array}$ & High risk & Not blinded \\
\hline $\begin{array}{l}\text { Incomplete outcome data } \\
\text { (attrition bias) } \\
\text { All outcomes }\end{array}$ & Low risk & $\begin{array}{l}\text { Missing outcome data balanced in numbers across intervention groups; it was } \\
\text { explained and due to attrition. Missing data were imputed using appropriate } \\
\text { methods. }\end{array}$ \\
\hline $\begin{array}{l}\text { Selective reporting (re- } \\
\text { porting bias) }\end{array}$ & Unclear risk & No protocol available \\
\hline Other bias & Unclear risk & $\begin{array}{l}\text { Quote: "Of the participants, } 75 \% \text { had completed education at university level." } \\
\text { Comment: study appears to have a risk of recruitment bias }\end{array}$ \\
\hline
\end{tabular}

Turbin 2006

\begin{tabular}{|c|c|c|}
\hline Methods & \multicolumn{2}{|l|}{ Randomised } \\
\hline \multirow[t]{4}{*}{ Participants } & \multicolumn{2}{|c|}{$\mathrm{N}=135$ (only 1 female), $90 \%$ non-Hispanic whites } \\
\hline & \multicolumn{2}{|l|}{ Age: range 46 to 85} \\
\hline & \multicolumn{2}{|c|}{ Inclusion criteria: new and experienced HA users } \\
\hline & \multicolumn{2}{|c|}{$\begin{array}{l}\text { Exclusion criteria: participated in AR in last } 5 \text { years, no neurological, neuromuscular, psychiatric diag- } \\
\text { nosis to interfere with use of HA or participation in age-normal social activities }\end{array}$} \\
\hline Interventions & \multicolumn{2}{|c|}{ HA alone $(\mathrm{N}=66)$ versus HA plus single AR workshop $(\mathrm{N}=69)$} \\
\hline Outcomes & \multicolumn{2}{|c|}{$\begin{array}{l}\text { Short-term: } 8 \text { weeks post-fit - CPHI (communication strategies subscale, personal adjustment subscale, } \\
\text { other scales), COSI, NEO-FFI - 5-factor personality inventory, WOCQ - ways of coping questionnaire }\end{array}$} \\
\hline & \multicolumn{2}{|c|}{ Medium-term: 6 months - as above } \\
\hline Notes & \multicolumn{2}{|l|}{-} \\
\hline \multicolumn{3}{|l|}{ Risk of bias } \\
\hline Bias & Authors' judgement & Support for judgement \\
\hline $\begin{array}{l}\text { Random sequence genera- } \\
\text { tion (selection bias) }\end{array}$ & Unclear risk & Author reports group allocation was randomised but process not clear \\
\hline $\begin{array}{l}\text { Allocation concealment } \\
\text { (selection bias) }\end{array}$ & Unclear risk & No details available \\
\hline $\begin{array}{l}\text { Blinding of participants } \\
\text { and personnel (perfor- } \\
\text { mance bias) } \\
\text { All outcomes }\end{array}$ & High risk & Not blinded \\
\hline
\end{tabular}


Turbin 2006 (Continued)

$\begin{array}{lll}\text { Blinding of outcome as- } & \text { High risk } & \text { Not blinded } \\ \text { sessment (detection bias) } & \\ \text { All outcomes } & \end{array}$

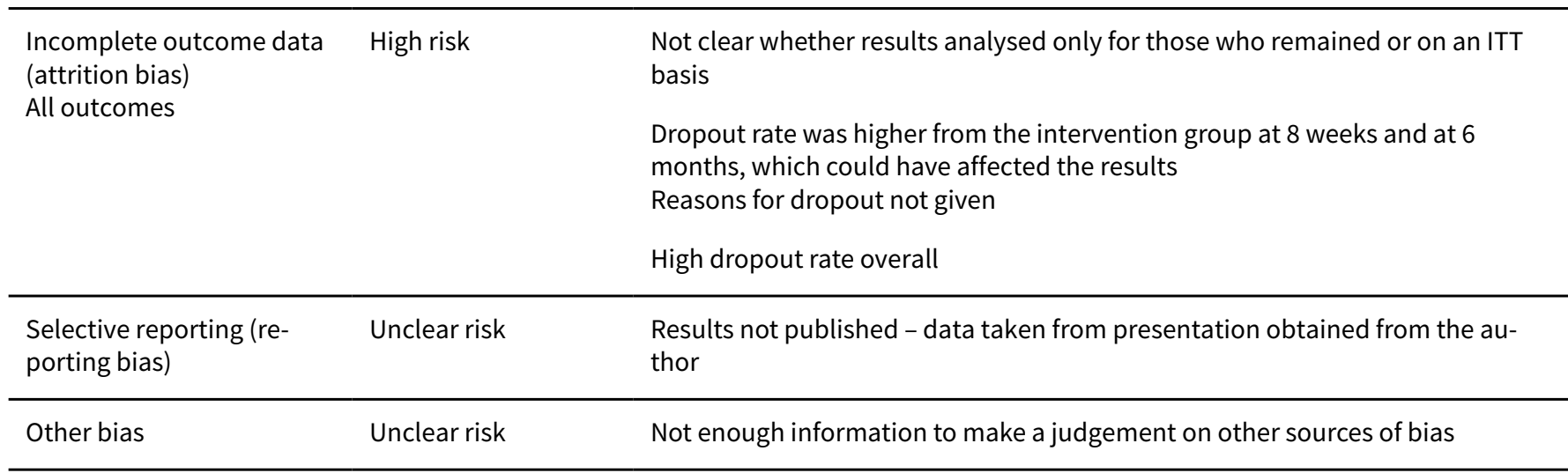

\section{Vreeken 2015}

\begin{tabular}{|c|c|c|}
\hline Methods & \multicolumn{2}{|l|}{ Randomised } \\
\hline \multirow[t]{4}{*}{ Participants } & \multicolumn{2}{|c|}{$N=131: 64$ intervention group, 67 in control group } \\
\hline & \multicolumn{2}{|c|}{$\begin{array}{l}\text { Age range: intervention group - mean age in years } 81.2 \text { (SD 10.0), control group - mean age in years } 81.8 \\
\text { (SD 10.1) }\end{array}$} \\
\hline & \multicolumn{2}{|c|}{ Gender: intervention group - $41.3 \%$ female, control group - $60 \%$ female } \\
\hline & \multicolumn{2}{|c|}{$\begin{array}{l}\text { Inclusion criteria: reported hearing disability, possessed a HA and had the cognitive ability (reported by } \\
\text { a spouse, other relative or care personnel) and sufficient knowledge of the Dutch language to compre- } \\
\text { hend or respond to questions. Attendance at a low vision clinic, reporting hearing disability and owned } \\
\text { a hearing aid. }\end{array}$} \\
\hline Interventions & \multicolumn{2}{|c|}{$\begin{array}{l}\text { Dual sensory loss protocol consisting of a handbook with background information and a checklist ac- } \\
\text { companied with exercises. The intervention was delivered in } 3 \text { to } 5 \text { weekly home visits. The protocol } \\
\text { covered: hearing aid use, maintenance and handling; living environment; and hearing assistive devices } \\
\text { and communication strategies and coping with DSL. The intervention group was compared to a waiting } \\
\text { list control group }\end{array}$} \\
\hline Outcomes & \multicolumn{2}{|c|}{ Medium-term: at 3 months IOI-HA } \\
\hline Notes & \multicolumn{2}{|l|}{-} \\
\hline \multicolumn{3}{|l|}{ Risk of bias } \\
\hline Bias & Authors' judgement & Support for judgement \\
\hline \multirow[t]{2}{*}{$\begin{array}{l}\text { Random sequence genera- } \\
\text { tion (selection bias) }\end{array}$} & \multirow[t]{2}{*}{ Low risk } & $\begin{array}{l}\text { Quote: "randomization was stratified per OTs' area of practice (eight strata). } \\
\text { After completion of baseline measurements, an independent researcher not } \\
\text { involved in the trial used randomization software to assign participants in } \\
\text { each stratum. Participants were randomly allocated to either the IG or CG in } \\
\text { blocks of two." }\end{array}$ \\
\hline & & Comment: randomisation was appropriate \\
\hline
\end{tabular}


Vreeken 2015 (Continued)

$\begin{array}{ll}\begin{array}{l}\text { Allocation concealment } \\ \text { (selection bias) }\end{array} & \begin{array}{l}\text { The use of an independent person performing the randomisation is suggestive } \\ \text { of appropriate allocation concealment }\end{array}\end{array}$

Blinding of participants High risk Participants were not blinded

and personnel (perfor-

mance bias)

All outcomes

\begin{tabular}{|c|c|c|}
\hline $\begin{array}{l}\text { Blinding of outcome as- } \\
\text { sessment (detection bias) }\end{array}$ & Low risk & $\begin{array}{l}\text { Quote: "The investigators and research assistants performing the measure- } \\
\text { ment were not aware of the treatment allocation." }\end{array}$ \\
\hline
\end{tabular}

All outcomes

\begin{tabular}{ll}
$\begin{array}{l}\text { Incomplete outcome data Low risk } \\
\text { (attrition bias) }\end{array}$ & $\begin{array}{l}\text { Detailed information was provided on the numbers of participants not receiv- } \\
\text { ing the intervention and those lost to follow-up and how the data were includ- } \\
\text { All outcomes }\end{array}$ \\
\hline
\end{tabular}

\begin{tabular}{lll}
\hline $\begin{array}{l}\text { Selective reporting (re- } \\
\text { porting bias) }\end{array}$ & Unclear risk & No protocol available \\
\hline Other bias & Unclear risk & The study may have been under-powered \\
\hline
\end{tabular}

Ward 1978

\begin{tabular}{|c|c|c|}
\hline Methods & \multicolumn{2}{|c|}{6 consecutive patients in each group } \\
\hline \multirow[t]{5}{*}{ Participants } & \multicolumn{2}{|c|}{ Diagnosis: better ear 35 to $62 \mathrm{~dB}$ across 3 frequencies } \\
\hline & \multicolumn{2}{|c|}{$\begin{array}{l}\mathrm{N}=36 \text { (1 dropout who was discovered to have already had a } \mathrm{HA}), 15 \% \text { of those fitted over that period sc } \\
\text { admit group was more selective than they intended }\end{array}$} \\
\hline & \multicolumn{2}{|l|}{ Age: range 60 to 80} \\
\hline & \multicolumn{2}{|c|}{ Inclusion criteria: new HA users, over retirement age } \\
\hline & \multicolumn{2}{|c|}{ Exclusion criteria: over 80 years old, predominantly conductive losses } \\
\hline \multirow[t]{4}{*}{ Interventions } & \multicolumn{2}{|c|}{ Group 1: fitting plus 2 group sessions of 2 hours each at 2 and 4 weeks post-fit } \\
\hline & \multicolumn{2}{|c|}{ Group 2: fitting plus 4 group sessions of 2 hours each at 2-week intervals } \\
\hline & \multicolumn{2}{|l|}{ Group 3: fitting only } \\
\hline & \multicolumn{2}{|c|}{ Up to 6 patients in each group } \\
\hline Outcomes & \multicolumn{2}{|c|}{$\begin{array}{l}\text { Medium-term: } 6 \text { months - hours of USE (patient report and battery use), change in hearing handicap } \\
\text { (Hearing Measurement Scale), AB word lists score }\end{array}$} \\
\hline Notes & \multicolumn{2}{|l|}{-} \\
\hline \multicolumn{3}{|l|}{ Risk of bias } \\
\hline Bias & Authors' judgement & Support for judgement \\
\hline $\begin{array}{l}\text { Random sequence genera- } \\
\text { tion (selection bias) }\end{array}$ & High risk & Comment: in fact a cluster quasi-randomised trial \\
\hline
\end{tabular}


Ward 1978 (Continued)

\begin{tabular}{|c|c|c|}
\hline $\begin{array}{l}\text { Allocation concealment } \\
\text { (selection bias) }\end{array}$ & Unclear risk & $\begin{array}{l}\text { No details given, but as it was possibly allocated on a rotating basis every } 6 \text { pa- } \\
\text { tients allocation concealment is unlikely }\end{array}$ \\
\hline
\end{tabular}
(selection bias)

High risk

Participants not blinded due to the nature of the intervention

Blinding of participants and personnel (performance bias)

All outcomes

$\begin{array}{lll}\text { Blinding of outcome as- } & \text { High risk } & \text { Not blinded } \\ \text { sessment (detection bias) } & \end{array}$

(detection bias)

All outcomes

\section{Incomplete outcome data High risk}

(attrition bias)

Comment: data for group 2 not analysed at all due to high dropout rate. Rea-

All outcomes sons for dropout given

Selective reporting (re- Unclear risk No protocol available

porting bias)

Other bias Unclear risk Not enough information to make a judgement about other sources of bias

Ward 1981

\begin{tabular}{ll}
\hline Methods & Randomised \\
\hline Participants & $\mathrm{N}=31$ \\
& $\begin{array}{l}\text { Age: range not given } \\
\text { Inclusion criteria: sequential patients seen } 3 \text { months post-fitting, over } 65, \text { scored } 2 \text { or more on a ques- } \\
\text { tionnaire on hearing tactics (poor performance), only measured for those who had a HMS score of } 15 \text { or } \\
\text { more and who wore aids for less than } 8 \text { hours per day (so were capable of improvement) at } 3 \text { months }\end{array}$ \\
& Exclusion criteria: frail, poor sight \\
\hline Interventions & $\begin{array}{l}\text { Control ( } N=13) \text { versus self-instruction package on hearing tactics ( } N=9 \text { ) versus hearing tactics instruc- } \\
\text { tion (individual) ( } \mathrm{N}=9 \text { ) }\end{array}$ \\
\hline Outcomes & Medium-term: 6 months after fitting - change in HMS score 3 to 6 months \\
\hline Notes & - \\
\hline
\end{tabular}

\section{Risk of bias}

\begin{tabular}{lll}
\hline Bias & Authors' judgement & Support for judgement \\
\hline $\begin{array}{l}\text { Random sequence genera- } \\
\text { tion (selection bias) }\end{array}$ & Unclear risk & $\begin{array}{l}\text { Quote: "each person was randomly allocated" } \\
\text { Comment: no details of sequence generation }\end{array}$ \\
\hline $\begin{array}{l}\text { Allocation concealment } \\
\text { (selection bias) }\end{array}$ & Unclear risk & No details given \\
\hline $\begin{array}{l}\text { Blinding of participants } \\
\text { and personnel (perfor- } \\
\text { mance bias) }\end{array}$ & High risk & No blinding \\
\hline
\end{tabular}


Ward 1981 (Continued)

All outcomes

\begin{tabular}{lll}
\hline Blinding of outcome as- & High risk & No blinding \\
sessment (detection bias) & & \\
All outcomes &
\end{tabular}

\begin{tabular}{lll}
\hline $\begin{array}{l}\text { Incomplete outcome data } \\
\text { (attrition bias) } \\
\text { All outcomes }\end{array}$ & Low risk & Reasons for dropouts given and numbers balanced across groups \\
\hline $\begin{array}{l}\text { Selective reporting (re- } \\
\text { porting bias) }\end{array}$ & Unclear risk & No protocol available \\
\hline Other bias & High risk & $\begin{array}{l}\text { The study was small and the high number of exclusions prior to randomisation } \\
\text { meant that groups were not balanced for age or gender }\end{array}$
\end{tabular}

Abbreviations used:

AF: active fitting

APD: auditory processing disorder

APHAB: Abbreviated Profile of Hearing Aid Benefit (Cox 1995)

AR: auditory rehabilitation

ARS: Affect Rating Scale (Lawton 1992)

CCT: California Consonant Test (Owens 1977)

$\mathrm{Cl}$ : cochlear implant

COSI: Client Orientated Scale of Improvement (Dillon 1997)

CPHI: Communication Profile for the Hearing Impaired (Demorest 1987)

CSOA: Communication Scale for Older Adults (Kaplan 1997)

CSS: Communication Strategies Scale (Demorest 1987)

CST: Connected Speech Test (Cox 1998)

CUNY: City University of New York

CX: control group

ECHO: Expected Consequences of Hearing Aid Ownership (Cox 2000)

EQ-5D: EuroQoL 5D (EuroQol 1990)

FU: follow-up

GHABP: Glasgow Hearing Aid Benefit Profile (Gatehouse 1999)

$H A$ : hearing aid

HACK: Hearing Aid Communication Knowledge (Ferguson 2015)

HADS: Hospital Anxiety and Depression Scale (Zigmond 1983)

HCA: Hearing Coping Assessment (Andersson 1995a)

HF: high frequency

$\mathrm{HI}$ : hearing impaired

HHIE: Hearing Handicap Inventory for the Elderly (Ventry 1982)

$\mathrm{HL}$ : hearing loss

HMS: Hearing Measurement Scale (Noble 1970)

HPI: Hearing Performance Inventory (Giolas 1979)

HR QoL: Hearing-Related Quality of Life

$\mathrm{Hx}$ : history

inner EAR and outer EAR: Effectiveness of Auditory Rehabilitation scales (Yueh 2005)

IOI-AI: International Outcome Inventory - Alternative Interventions

IOI-HA: International Outcome Inventory for Hearing Aids (Cox 2002)

IT: information technology

ITE: in-the-ear

ITT: intention-to-treat

LACE: Listening And Communication Enhancement (Sweetow 2006)

LOCF: last observation carried forward

MMSE: mini mental state exam

NEO-FFI: Neuroticism Extroversion Openness Five Factor Inventory (Costa 1992)

NST: Nonsense Syllable Test (Dubno 1981)

NU-6: Northwestern University auditory test no. 6 (Tillman 1966) 
PAM: Patient Activation Measure (Hibbard 2005)

PCI: Primary Communication Inventory (Navran 1967)

PHAST: Practical Hearing Aid Skills Test (Desjardins 2009)

PHL: person with hearing loss

PIADS-A: Psychological Impact of Assistive Devices Scale (Day 2002)

PTA: pure tone audiogram, a standardised measure of hearing threshold

QDS: Quantified Denver Scale of Communication (Alpiner 1978; Schow 1980)

QoL: quality of life

SADL: Satisfaction with Amplification in Daily Life (Cox 1999)

SD: standard deviation

SF-12: Short form 12 (Ware 1998)

SF-36: Short form 36 (Ware 1992)

SIN: Speech In Noise

SNHL: sensorineural hearing loss

SO: significant other

SSQ: Speech, Spatial and Qualities of hearing scale (Gatehouse 2004)

Sx: symptoms

Tx: treatment/intervention group

VA: (United States) Veterans Association

VAS: visual analogue scale

WHODAS 2.0: World Health Organization Disability Assessment Scale (WHO 2001)

WOCQ: Ways of Coping Questionnaire (Folkman 1988)

Characteristics of excluded studies [ordered by study ID]

\begin{tabular}{ll}
\hline Study & Reason for exclusion \\
\hline Aazh 2016 & ALLOCATION: randomised \\
& $\begin{array}{l}\text { PARTICIPANTS: at the level of randomisation participants were people who had been previously fit- } \\
\text { ted with hearing aids but were not using them. }\end{array}$ \\
\hline Andersson 1998 & $\begin{array}{l}\text { Collated data on hearing aid use from } 3 \text { previous studies (see Andersson 1994; Andersson 1995; An- } \\
\text { dersson 1997). Where possible we have included the relevant data on hearing aid use as reported in } \\
\text { the original studies }\end{array}$
\end{tabular}

BLLilacqua $2013 \quad \begin{aligned} & \text { PARTICIPANTS: not all adults according to the definition given in this review and cannot extract the } \\ & \text { data for the adults separately }\end{aligned}$

Boymans $2012 \quad$ ALLOCATION: randomised

PARTICIPANTS: new and experienced adult hearing aid users

INTERVENTION: audiologist versus patient-driven fine tuning

OUTCOME: speech perception measures

\begin{tabular}{ll}
\hline Cardemil 2014 & ALLOCATION: unclear in published study but not randomised according to trial registration \\
\hline Hallberg 1994 & $\begin{array}{l}\text { ALLOCATION: randomised } \\
\text { PARTICIPANTS: not all hearing aid users and cannot extract the data for the hearing aid users inde- } \\
\text { pendently }\end{array}$ \\
\hline Hennig 2012 & ALLOCATION: not randomised \\
\hline Hickson 2007 & $\begin{array}{l}\text { ALLOCATION: randomised } \\
\text { PARTICIPANTS: not all hearing aid users and cannot extract the data for the hearing aid users inde- } \\
\text { pendently }\end{array}$ \\
\hline
\end{tabular}




\begin{tabular}{|c|c|}
\hline Study & Reason for exclusion \\
\hline Kuk 2014 & ALLOCATION: not randomised \\
\hline \multirow[t]{4}{*}{ Lavie 2013} & ALLOCATION: randomised \\
\hline & PARTICIPANTS: adult new hearing aid users \\
\hline & INTERVENTION: individual listening training \\
\hline & OUTCOME: speech perception measures only \\
\hline \multirow[t]{4}{*}{ Montgomery 1984} & ALLOCATION: randomised \\
\hline & PARTICIPANTS: new adult hearing aid users \\
\hline & INTERVENTION: individual versus group auditory training \\
\hline & OUTCOME: speech perception measures \\
\hline Norman 1994 & ALLOCATION: not randomised \\
\hline Preminger 2003 & ALLOCATION: part-randomised and data not available for randomised participants only \\
\hline Reber 2005 & ALLOCATION: part-randomised and data not available for randomised participants only \\
\hline \multirow[t]{5}{*}{ Ruschel 2007} & ALLOCATION: randomised \\
\hline & PARTICIPANTS: new adult hearing aid users \\
\hline & INTERVENTION: 5 sessions of auditory rehabilitation including guidance on communication strate- \\
\hline & gy \\
\hline & OUTCOME: non-validated questionnaire relating to ease of use and communication \\
\hline
\end{tabular}

Stecker 2006 ALLOCATION: randomised

PARTICIPANTS: new adult hearing aid users

INTERVENTION: 40 × 1-hour sessions of analytic auditory training

OUTCOME: speech perception measures

\begin{tabular}{ll}
\hline Walden 1981 & ALLOCATION: randomised \\
PARTICIPANTS: new adult hearing aid users \\
INTERVENTION: 7 hours of individual versus group auditory training \\
OUTCOME: speech perception measures \\
\hline Yueh 2010 \\
ALLOCATION: randomised \\
PARTICIPANTS: at the level of randomisation no participants were hearing aid users and only a pro- \\
Portion became hearing aid users
\end{tabular}

Characteristics of studies awaiting assessment [ordered by study ID] 
Henshaw 2013

\begin{tabular}{ll}
\hline Methods & Randomised \\
\hline Participants & Adult existing hearing aid users ( 50 to 74 years old) with mild to moderate hearing loss \\
\hline Interventions & Working memory training \\
\hline Outcomes & Self-reported hearing ability HHIE and GHABP at baseline, 2, 7 and 31 weeks \\
\hline Notes & $\begin{array}{l}\text { Study has been completed } \\
\text { We made attempts to obtain study data for this review but data were unavailable in time for the } \\
\text { update }\end{array}$ \\
\hline
\end{tabular}

Malmberg 2015

\begin{tabular}{ll}
\hline Methods & Randomised \\
\hline Participants & Adults with hearing loss. Not clear if they were fitted with hearing aids for this study. \\
\hline Interventions & Auditory rehabilitation delivered over the internet \\
\hline Outcomes & Self-reported hearing handicap HHIE, CSS, CPHI, HADs and IOI-HA at 5 weeks and 6 months \\
\hline Notes & Study is reported as being completed but only implementation challenges so far reported \\
\hline
\end{tabular}

Characteristics of ongoing studies [ordered by study ID]

\section{ISRCTN77340339}

\begin{tabular}{ll}
\hline Trial name or title & A study on the effectiveness of a support programme (SUPR) for adult hearing aid users \\
\hline Methods & Randomised controlled trial \\
\hline Participants & $\begin{array}{l}\text { Hearing-impaired hearing aid users, aged } 50 \text { and over, including both first-time hearing aid users } \\
\text { and experienced hearing aid users, and their communication partners }\end{array}$ \\
\hline Interventions & $\begin{array}{l}\text { Hearing aid dispenser shops are randomly allocated to offer their customers either care as usual } \\
\text { (hearing aid care) or hearing aid care including the SUPR support programme }\end{array}$ \\
\hline Outcomes & Measurements (CPHI) are performed at the start of the study and after 6,12 and 18 months \\
\hline Starting date & February 2015 \\
\hline Contact information & Dr M Pronk \\
Dept. of Otolaryngology - Head and Neck Surgery \\
section Ear \& Hearing \\
Room pk2Y150 \\
P.O. Box 7057 \\
Amsterdam \\
1007 MB \\
Netherlands
\end{tabular}


ISRCTN77340339 (Continued)

Notes

\begin{tabular}{ll} 
Trial name or title & $\begin{array}{l}\text { Use of hearing aids development and implementation of a counselling program for hearing aid } \\
\text { users }\end{array}$ \\
\hline Methods & Randomised controlled trial \\
\hline Participants & $\begin{array}{l}\text { New hearing aid users, aged } 65 \text { years and over } \\
\text { Interventions }\end{array}$ \\
$\begin{array}{l}\text { The intervention group will be informed in advance of a follow-up appointment } 6 \text { months after } \\
\text { they have received their hearing aid. They will know that support will be given and time-use of the } \\
\text { hearing aid will be checked. Counselling on hearing aid use will be given. } \\
\text { The control group will not receive any information about a follow-up appointment. However, they } \\
\text { will receive a notice on this after } 6 \text { months. }\end{array}$ \\
\hline Outcomes & Hours per day of hearing aid use (measured using data-logging) at 6 months post fitting \\
\hline Starting date & January 2014 \\
\hline Contact information & jorunn.solheim@lds.no \\
\hline Notes
\end{tabular}

\section{NCT02264314}

Trial name or title Tele-educative program to improve adherence to the use of hearing aids in patients with hearing
loss

\begin{tabular}{ll}
\hline Methods & Randomised controlled trial \\
\hline Participants & New hearing aid users, aged 65 years and older \\
\hline Interventions & $\begin{array}{l}\text { The active arm consists of the implementation of an educational programme called Active Commu- } \\
\text { nication Education, consisting of } 4 \text { sessions with a trained rehabilitator. Participants will be also } \\
\text { monitored by telephone headset use by personnel trained for } 3 \text { months. }\end{array}$ \\
\hline Outcomes & $\begin{array}{l}\text { The control arm will consist of the usual care received by these patients } \\
\text { months post randomisation }\end{array}$ \\
\hline Starting date & July 2012 \\
\hline Contact information & Felipe Cardemil, MD, University of Chile \\
\hline Notes & -
\end{tabular}


DATA AND ANALYSES

Comparison 1. Self-management support interventions versus control

\begin{tabular}{lllll}
\hline Outcome or subgroup title & No. of studies & $\begin{array}{l}\text { No. of partici- } \\
\text { pants }\end{array}$ & Statistical method & Effect size \\
\hline 1 Quality of life - short/medium-term & 1 & 35 & $\begin{array}{l}\text { Mean Difference (IV, Ran- } \\
\text { dom, 95\% Cl) }\end{array}$ & $-9.10[-21.33,3.13]$ \\
\hline $\begin{array}{l}\text { 2 Self-reported hearing handicap - } \\
\text { short/medium-term }\end{array}$ & 2 & 87 & $\begin{array}{l}\text { Mean Difference (IV, Ran- } \\
\text { dom, 95\% CI) }\end{array}$ & $\begin{array}{l}-12.80[-23.11, \\
-2.48]\end{array}$ \\
\hline $\begin{array}{l}\text { 3 Use of verbal communication strate- } \\
\text { gy - short-term }\end{array}$ & 1 & 52 & $\begin{array}{l}\text { Mean Difference (IV, Ran- } \\
\text { dom, 95\% Cl) }\end{array}$ & 0.72 [0.21, 1.23] \\
\hline
\end{tabular}

Analysis 1.1. Comparison 1 Self-management support interventions versus control, Outcome 1 Quality of life - short/medium-term.

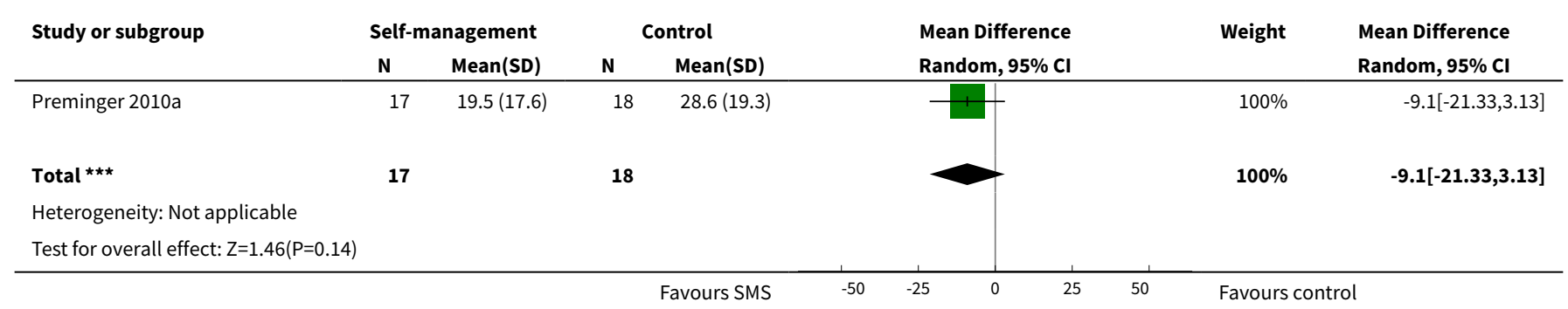

Analysis 1.2. Comparison 1 Self-management support interventions versus control, Outcome 2 Self-reported hearing handicap - short/medium-term.

\begin{tabular}{|c|c|c|c|c|c|c|c|}
\hline \multirow[t]{2}{*}{ Study or subgroup } & \multicolumn{2}{|c|}{ Self-management } & \multicolumn{2}{|c|}{ Control } & \multirow{2}{*}{$\begin{array}{l}\text { Mean Difference } \\
\text { Random, } 95 \% \mathrm{Cl}\end{array}$} & \multirow[t]{2}{*}{ Weight } & \multirow{2}{*}{$\begin{array}{l}\text { Mean Difference } \\
\text { Random, } 95 \% \mathrm{CI}\end{array}$} \\
\hline & $\mathbf{N}$ & Mean(SD) & $\mathbf{N}$ & Mean(SD) & & & \\
\hline Kricos 1996 & 26 & $30.4(19.1)$ & 26 & $39(26.3)$ & 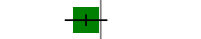 & $61.15 \%$ & $-8.6[-21.09,3.89]$ \\
\hline Preminger 2010a & 17 & $39.2(23.4)$ & 18 & $58.6(24.9)$ & $\rightarrow$ & $38.85 \%$ & $-19.4[-35.4,-3.4]$ \\
\hline 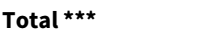 & 43 & & 44 & & & $100 \%$ & $-12.8[-23.11,-2.48]$ \\
\hline \multicolumn{8}{|c|}{ Heterogeneity: $\mathrm{Tau}^{2}=4.68 ; \mathrm{Chi}^{2}=1.09, \mathrm{df}=1(\mathrm{P}=0.3) ; \mathrm{I}^{2}=8.02 \%$} \\
\hline \multicolumn{3}{|c|}{ Test for overall effect: $Z=2.43(P=0.02)$} & & & & & \\
\hline
\end{tabular}

Analysis 1.3. Comparison 1 Self-management support interventions versus control, Outcome 3 Use of verbal communication strategy - short-term.

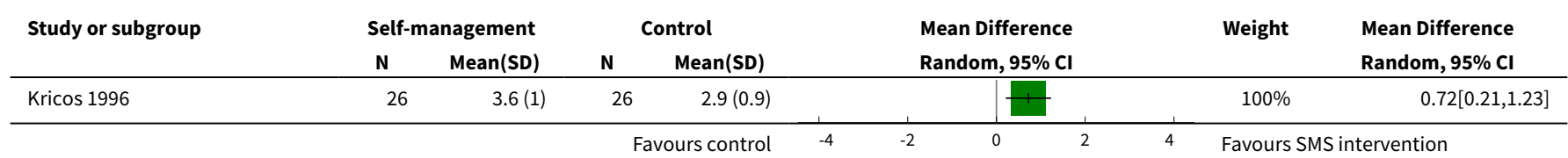




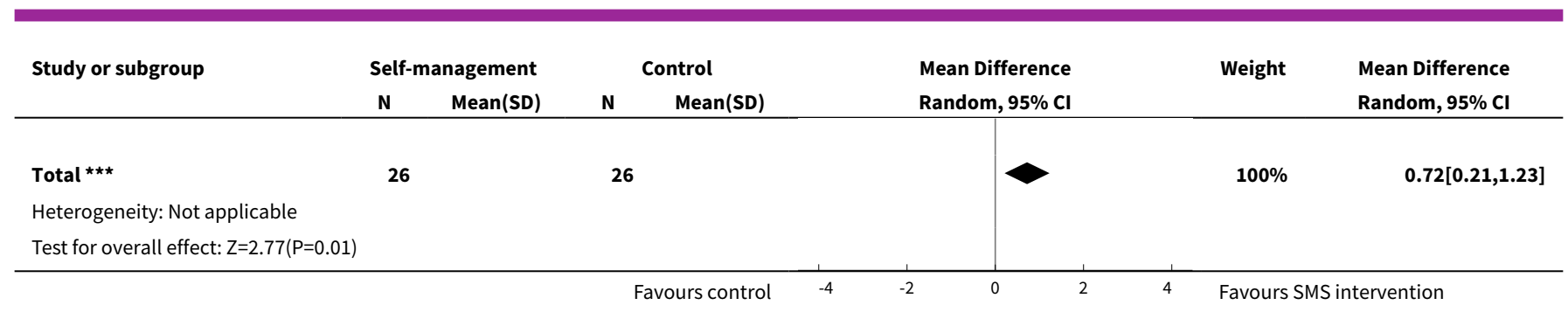

\section{Comparison 2. Delivery system design interventions versus control}

\begin{tabular}{lllll}
\hline Outcome or subgroup title & No. of studies & $\begin{array}{l}\text { No. of partici- } \\
\text { pants }\end{array}$ & Statistical method & Effect size \\
\hline 1 Adherence - short/medium-term & 2 & 686 & $\begin{array}{l}\text { Risk Ratio (M-H, Random, 95\% } \\
\mathrm{CI})\end{array}$ & 1.02 [0.99, 1.05] \\
\hline $\begin{array}{l}\text { 2 Daily hours of hearing aid use - } \\
\text { short/medium-term }\end{array}$ & 4 & 700 & $\begin{array}{l}\text { Mean Difference (IV, Random, } \\
95 \% \text { Cl) }\end{array}$ & -0.06 [-1.06, 0.95] \\
\hline 3 Adverse effects - long-term & 1 & 98 & $\begin{array}{l}\text { Risk Ratio (M-H, Random, 95\% } \\
\mathrm{CI})\end{array}$ & 0.75 [0.50, 1.12] \\
\hline $\begin{array}{l}\text { 4 Self-reported hearing handicap - } \\
\text { short/medium-term }\end{array}$ & 2 & 628 & $\begin{array}{l}\text { Mean Difference (IV, Random, } \\
95 \% \text { CI) }\end{array}$ & -0.70 [-5.22, 3.81] \\
\hline $\begin{array}{l}\text { 5 Hearing aid benefit - short/medi- } \\
\text { um-term }\end{array}$ & 1 & 582 & $\begin{array}{l}\text { Mean Difference (IV, Random, } \\
95 \% \text { CI) }\end{array}$ & 1.80 [-3.10, 6.70] \\
\hline $\begin{array}{l}\text { 6 Use of verbal communication } \\
\text { strategy }\end{array}$ & 1 & 588 & $\begin{array}{l}\text { Mean Difference (IV, Random, } \\
95 \% \text { CI) }\end{array}$ & -0.10 [-0.40, 0.20] \\
\hline
\end{tabular}

Analysis 2.1. Comparison 2 Delivery system design interventions versus control, Outcome 1 Adherence - short/medium-term.

\begin{tabular}{|c|c|c|c|c|c|}
\hline \multirow[t]{2}{*}{ Study or subgroup } & $\begin{array}{l}\text { DSD inter- } \\
\text { vention }\end{array}$ & Control & Risk Ratio & Weight & Risk Ratio \\
\hline & $\mathbf{n} / \mathbf{N}$ & $n / N$ & M-H, Random, 95\% Cl & & M-H, Random, 95\% CI \\
\hline Collins 2013 & $311 / 321$ & $307 / 323$ & & $98.02 \%$ & $1.02[0.99,1.05]$ \\
\hline Campos 2013 & $18 / 21$ & $19 / 21$ & t & $1.98 \%$ & $0.95[0.76,1.18]$ \\
\hline Total $(95 \% \mathrm{Cl})$ & 342 & 344 & 7 & $100 \%$ & $1.02[0.99,1.05]$ \\
\hline \multicolumn{6}{|c|}{ Heterogeneity: $\operatorname{Tau}^{2}=0 ; \mathrm{Chi}^{2}=0.43, \mathrm{df}=1(\mathrm{P}=0.51) ; \mathrm{I}^{2}=0 \%$} \\
\hline \multicolumn{6}{|c|}{ Test for overall effect: $Z=1.11(P=0.27)$} \\
\hline
\end{tabular}


Analysis 2.2. Comparison 2 Delivery system design interventions versus control, Outcome 2 Daily hours of hearing aid use - short/medium-term.

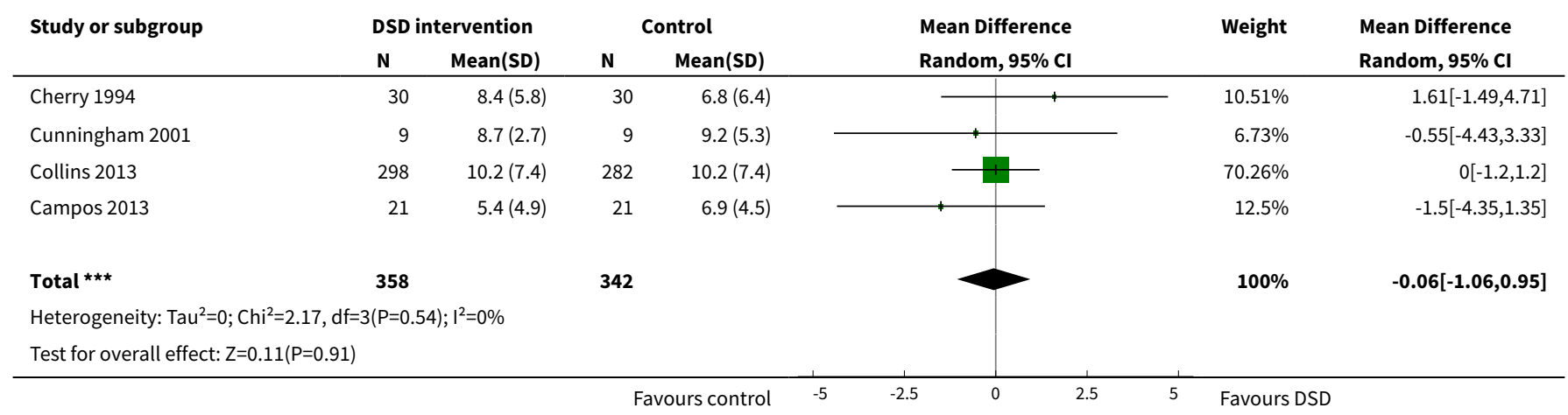

Analysis 2.3. Comparison 2 Delivery system design interventions versus control, Outcome 3 Adverse effects - long-term.

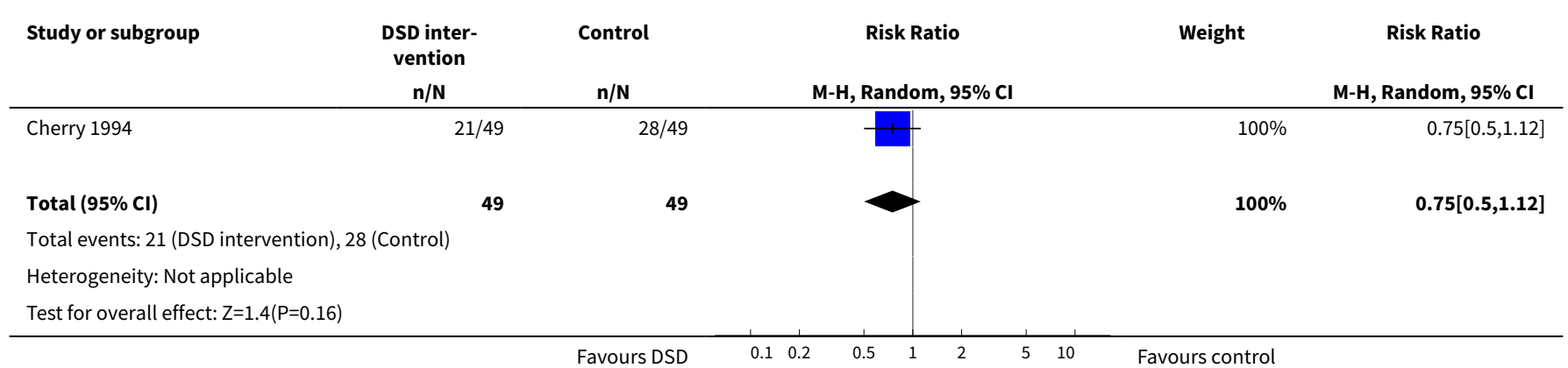

Analysis 2.4. Comparison 2 Delivery system design interventions versus control, Outcome 4 Self-reported hearing handicap - short/medium-term.

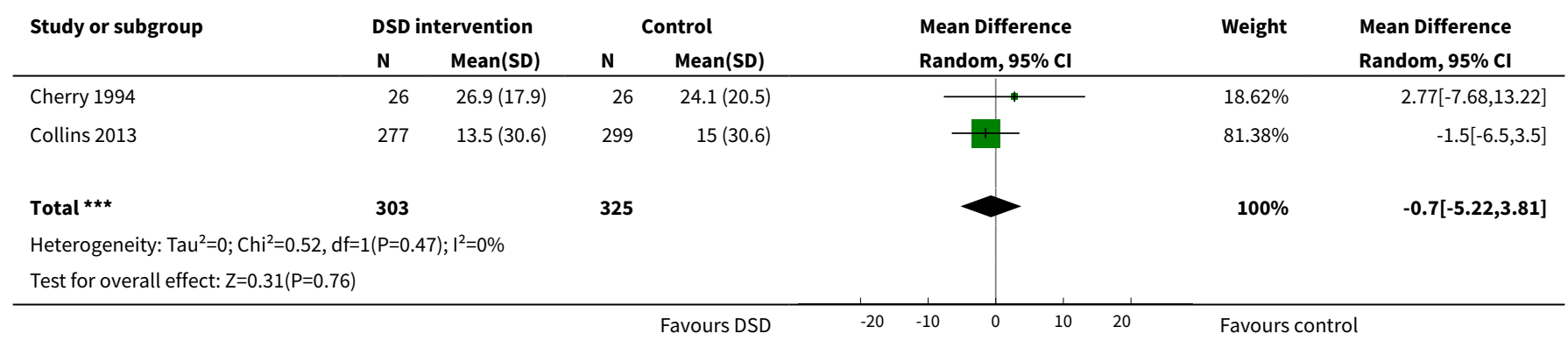


Analysis 2.5. Comparison 2 Delivery system design interventions versus control, Outcome 5 Hearing aid benefit - short/medium-term.

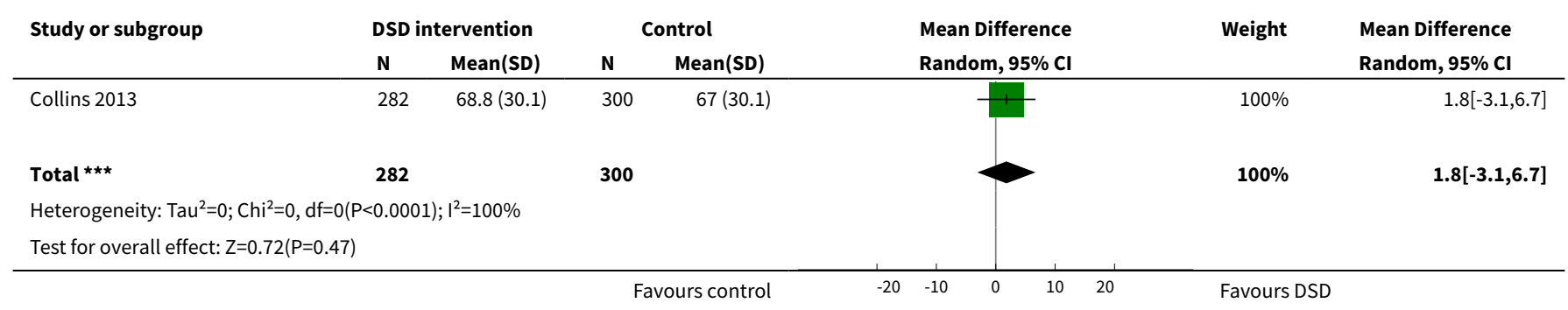

\section{Analysis 2.6. Comparison 2 Delivery system design interventions versus control, Outcome 6 Use of verbal communication strategy.}

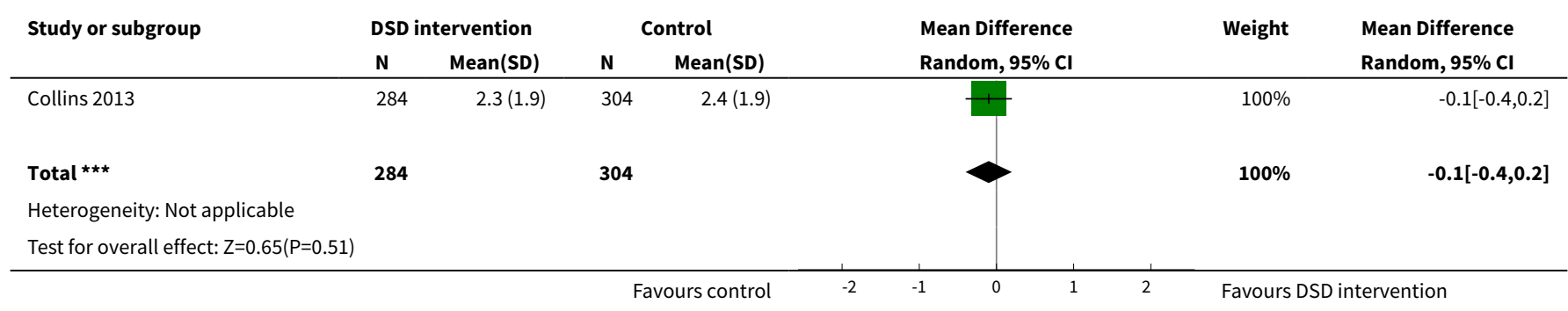

\section{Comparison 3. Combined SMS/DSD interventions versus control}

\begin{tabular}{|c|c|c|c|c|}
\hline Outcome or subgroup title & No. of studies & $\begin{array}{l}\text { No. of partici- } \\
\text { pants }\end{array}$ & Statistical method & Effect size \\
\hline $\begin{array}{l}1 \text { Adherence - short/medi- } \\
\text { um-term }\end{array}$ & 1 & 167 & Risk Ratio (M-H, Random, 95\% Cl) & $1.06[1.00,1.12]$ \\
\hline $\begin{array}{l}2 \text { Daily hours of hearing aid } \\
\text { use - long-term }\end{array}$ & 2 & 69 & Mean Difference (IV, Random, 95\% CI) & $0.04[-0.64,0.73]$ \\
\hline $\begin{array}{l}3 \text { Daily hours of hearing aid } \\
\text { use - short/medium-term - } \\
\text { SMS content }\end{array}$ & 9 & 534 & Mean Difference (IV, Random, 95\% Cl) & $0.19[-0.01,0.40]$ \\
\hline 3.1 Advise & 1 & 44 & Mean Difference (IV, Random, 95\% CI) & $0.08[-1.18,1.34]$ \\
\hline 3.2 Activate - practical & 0 & 0 & Mean Difference (IV, Random, 95\% CI) & $0.0[0.0,0.0]$ \\
\hline 3.3 Activate - symptoms & 2 & 76 & Mean Difference (IV, Random, 95\% CI) & $0.28[-0.04,0.59]$ \\
\hline 3.4 Activate - psychosocial & 6 & 414 & Mean Difference (IV, Random, 95\% CI) & $0.10[-0.24,0.45]$ \\
\hline 3.5 Assist & 0 & 0 & Mean Difference (IV, Random, 95\% CI) & $0.0[0.0,0.0]$ \\
\hline 3.6 Agree & 0 & 0 & Mean Difference (IV, Random, 95\% CI) & $0.0[0.0,0.0]$ \\
\hline
\end{tabular}




\begin{tabular}{|c|c|c|c|c|}
\hline Outcome or subgroup title & No. of studies & $\begin{array}{l}\text { No. of partici- } \\
\text { pants }\end{array}$ & Statistical method & Effect size \\
\hline $\begin{array}{l}4 \text { Daily hours of hearing aid } \\
\text { use - short/medium-term - } \\
\text { DSD format }\end{array}$ & 9 & 534 & Mean Difference (IV, Random, 95\% CI) & $0.19[-0.01,0.40]$ \\
\hline 4.1 Face-to-face & 5 & 163 & Mean Difference (IV, Random, 95\% Cl) & $0.24[-0.06,0.54]$ \\
\hline 4.2 Telephone & 1 & 69 & Mean Difference (IV, Random, 95\% Cl) & $0.20[-0.30,0.70]$ \\
\hline 4.3 Booklet & 0 & 0 & Mean Difference (IV, Random, 95\% CI) & $0.0[0.0,0.0]$ \\
\hline $\begin{array}{l}\text { 4.4 Remote (online, PC, } \\
\text { video/DVD) }\end{array}$ & 3 & 302 & Mean Difference (IV, Random, 95\% CI) & $0.08[-0.55,0.71]$ \\
\hline $\begin{array}{l}5 \text { Daily hours of hearing aid } \\
\text { use - short/medium-term - } \\
\text { DSD intensity }\end{array}$ & 9 & 534 & Mean Difference (IV, Random, 95\% CI) & $0.19[-0.01,0.40]$ \\
\hline 5.1 Low-intensity & 0 & 0 & Mean Difference (IV, Random, 95\% CI) & $0.0[0.0,0.0]$ \\
\hline 5.2 Medium-intensity & 4 & 189 & Mean Difference (IV, Random, 95\% Cl) & $0.25[-0.01,0.51]$ \\
\hline 5.3 High-intensity & 5 & 345 & Mean Difference (IV, Random, 95\% CI) & $0.03[-0.49,0.55]$ \\
\hline 6 Quality of life - long-term & 2 & 69 & Mean Difference (IV, Random, 95\% Cl) & $0.32[-0.17,0.80]$ \\
\hline $\begin{array}{l}7 \text { Quality of life - short/ } \\
\text { medium-term - SMS content }\end{array}$ & 8 & 530 & $\begin{array}{l}\text { Std. Mean Difference (IV, Random, } \\
95 \% \mathrm{CI})\end{array}$ & $0.02[-0.15,0.19]$ \\
\hline 7.1 Advise & 1 & 48 & $\begin{array}{l}\text { Std. Mean Difference (IV, Random, } \\
95 \% \mathrm{CI})\end{array}$ & $0.11[-0.46,0.67]$ \\
\hline 7.2 Activate - practical & 0 & 0 & $\begin{array}{l}\text { Std. Mean Difference (IV, Random, } \\
95 \% \mathrm{CI})\end{array}$ & $0.0[0.0,0.0]$ \\
\hline 7.3 Activate - symptoms & 2 & 76 & $\begin{array}{l}\text { Std. Mean Difference (IV, Random, } \\
95 \% \mathrm{CI})\end{array}$ & $-0.07[-0.52,0.38]$ \\
\hline 7.4 Activate - psychosocial & 5 & 406 & $\begin{array}{l}\text { Std. Mean Difference (IV, Random, } \\
95 \% \mathrm{CI})\end{array}$ & $0.04[-0.18,0.25]$ \\
\hline 7.5 Assist & 0 & 0 & $\begin{array}{l}\text { Std. Mean Difference (IV, Random, } \\
95 \% \mathrm{CI})\end{array}$ & $0.0[0.0,0.0]$ \\
\hline 7.6 Agree & 0 & 0 & $\begin{array}{l}\text { Std. Mean Difference (IV, Random, } \\
95 \% \mathrm{CI})\end{array}$ & $0.0[0.0,0.0]$ \\
\hline $\begin{array}{l}8 \text { Quality of life - short/ } \\
\text { medium-term - DSD format }\end{array}$ & 8 & 530 & $\begin{array}{l}\text { Std. Mean Difference (IV, Random, } \\
95 \% \mathrm{CI})\end{array}$ & $0.02[-0.15,0.19]$ \\
\hline 8.1 Face-to-face & 3 & 111 & $\begin{array}{l}\text { Std. Mean Difference (IV, Random, } \\
95 \% \mathrm{CI})\end{array}$ & $0.10[-0.28,0.47]$ \\
\hline 8.2 Telephone & 1 & 69 & $\begin{array}{l}\text { Std. Mean Difference (IV, Random, } \\
95 \% \mathrm{CI})\end{array}$ & $0.30[-0.18,0.77]$ \\
\hline
\end{tabular}




\begin{tabular}{|c|c|c|c|c|}
\hline Outcome or subgroup title & No. of studies & $\begin{array}{l}\text { No. of partici- } \\
\text { pants }\end{array}$ & Statistical method & Effect size \\
\hline 8.3 Booklet & 0 & 0 & $\begin{array}{l}\text { Std. Mean Difference (IV, Random, } \\
95 \% \mathrm{Cl} \text { ) }\end{array}$ & $0.0[0.0,0.0]$ \\
\hline 8.4 Remote & 4 & 350 & $\begin{array}{l}\text { Std. Mean Difference (IV, Random, } \\
95 \% \mathrm{CI} \text { ) }\end{array}$ & $-0.05[-0.26,0.16]$ \\
\hline $\begin{array}{l}9 \text { Quality of life - short/ } \\
\text { medium-term - DSD intensi- } \\
\text { ty }\end{array}$ & 8 & 530 & $\begin{array}{l}\text { Std. Mean Difference (IV, Random, } \\
95 \% \mathrm{CI} \text { ) }\end{array}$ & $0.02[-0.15,0.19]$ \\
\hline 9.1 Low-intensity & 0 & 0 & $\begin{array}{l}\text { Std. Mean Difference (IV, Random, } \\
95 \% \mathrm{Cl} \text { ) }\end{array}$ & $0.0[0.0,0.0]$ \\
\hline 9.2 Medium-intensity & 3 & 111 & $\begin{array}{l}\text { Std. Mean Difference (IV, Random, } \\
95 \% \mathrm{Cl} \text { ) }\end{array}$ & $0.10[-0.28,0.47]$ \\
\hline 9.3 High-intensity & 5 & 419 & $\begin{array}{l}\text { Std. Mean Difference (IV, Random, } \\
95 \% \mathrm{CI} \text { ) }\end{array}$ & $0.00[-0.19,0.20]$ \\
\hline $\begin{array}{l}10 \text { Self-reported hearing } \\
\text { handicap - long-term }\end{array}$ & 3 & 88 & $\begin{array}{l}\text { Std. Mean Difference (IV, Random, } \\
95 \% \mathrm{CI} \text { ) }\end{array}$ & $-0.31[-1.06,0.44]$ \\
\hline 10.1 Advise & 0 & 0 & $\begin{array}{l}\text { Std. Mean Difference (IV, Random, } \\
95 \% \mathrm{CI} \text { ) }\end{array}$ & $0.0[0.0,0.0]$ \\
\hline 10.2 Activate - practical & 0 & 0 & $\begin{array}{l}\text { Std. Mean Difference (IV, Random, } \\
95 \% \mathrm{Cl} \text { ) }\end{array}$ & $0.0[0.0,0.0]$ \\
\hline 10.3 Activate - symptoms & 2 & 69 & $\begin{array}{l}\text { Std. Mean Difference (IV, Random, } \\
95 \% \mathrm{Cl} \text { ) }\end{array}$ & $0.04[-0.43,0.51]$ \\
\hline 10.4 Activate - psychosocial & 1 & 19 & $\begin{array}{l}\text { Std. Mean Difference (IV, Random, } \\
95 \% \mathrm{Cl} \text { ) }\end{array}$ & $-1.27[-2.28,-0.26]$ \\
\hline 10.5 Assist & 0 & 0 & $\begin{array}{l}\text { Std. Mean Difference (IV, Random, } \\
95 \% \mathrm{CI} \text { ) }\end{array}$ & $0.0[0.0,0.0]$ \\
\hline 10.6 Agree & 0 & 0 & $\begin{array}{l}\text { Std. Mean Difference (IV, Random, } \\
95 \% \mathrm{CI} \text { ) }\end{array}$ & $0.0[0.0,0.0]$ \\
\hline $\begin{array}{l}11 \text { Self-reported hearing } \\
\text { handicap - short/medi- } \\
\text { um-term - SMS content }\end{array}$ & 14 & 681 & $\begin{array}{l}\text { Std. Mean Difference (IV, Random, } \\
95 \% \mathrm{CI} \text { ) }\end{array}$ & $-0.26[-0.50,-0.02]$ \\
\hline 11.1 Advise & 3 & 106 & $\begin{array}{l}\text { Std. Mean Difference (IV, Random, } \\
95 \% \mathrm{CI} \text { ) }\end{array}$ & $-0.27[-0.65,0.12]$ \\
\hline 11.2 Activate - practical & 0 & 0 & $\begin{array}{l}\text { Std. Mean Difference (IV, Random, } \\
95 \% \mathrm{CI} \text { ) }\end{array}$ & $0.0[0.0,0.0]$ \\
\hline 11.3 Activate - symptoms & 3 & 89 & $\begin{array}{l}\text { Std. Mean Difference (IV, Random, } \\
95 \% \mathrm{CI} \text { ) }\end{array}$ & $-0.34[-0.76,0.08]$ \\
\hline 11.4 Activate - psychosocial & 8 & 486 & $\begin{array}{l}\text { Std. Mean Difference (IV, Random, } \\
95 \% \mathrm{Cl} \text { ) }\end{array}$ & $-0.24[-0.61,0.13]$ \\
\hline
\end{tabular}




\begin{tabular}{|c|c|c|c|c|}
\hline Outcome or subgroup title & No. of studies & $\begin{array}{l}\text { No. of partici- } \\
\text { pants }\end{array}$ & Statistical method & Effect size \\
\hline 11.5 Assist & 0 & 0 & $\begin{array}{l}\text { Std. Mean Difference (IV, Random, } \\
95 \% \mathrm{CI} \text { ) }\end{array}$ & $0.0[0.0,0.0]$ \\
\hline 11.6 Agree & 0 & 0 & $\begin{array}{l}\text { Std. Mean Difference (IV, Random, } \\
95 \% \mathrm{CI})\end{array}$ & $0.0[0.0,0.0]$ \\
\hline $\begin{array}{l}12 \text { Self-reported hearing } \\
\text { handicap - short/medi- } \\
\text { um-term - DSD format }\end{array}$ & 14 & 681 & $\begin{array}{l}\text { Std. Mean Difference (IV, Random, } \\
95 \% \mathrm{CI})\end{array}$ & $-0.26[-0.50,-0.02]$ \\
\hline 12.1 Face-to-face & 8 & 242 & $\begin{array}{l}\text { Std. Mean Difference (IV, Random, } \\
95 \% \mathrm{CI} \text { ) }\end{array}$ & $-0.14[-0.39,0.12]$ \\
\hline 12.2 Telephone & 1 & 69 & $\begin{array}{l}\text { Std. Mean Difference (IV, Random, } \\
95 \% \mathrm{CI})\end{array}$ & $-0.83[-1.33,-0.34]$ \\
\hline 12.3 Booklet & 0 & 0 & $\begin{array}{l}\text { Std. Mean Difference (IV, Random, } \\
95 \% \mathrm{CI})\end{array}$ & $0.0[0.0,0.0]$ \\
\hline 12.4 Remote & 5 & 370 & $\begin{array}{l}\text { Std. Mean Difference (IV, Random, } \\
95 \% \mathrm{CI})\end{array}$ & $-0.28[-0.72,0.16]$ \\
\hline $\begin{array}{l}13 \text { Self-reported hearing } \\
\text { handicap - short/medi- } \\
\text { um-term - DSD intensity }\end{array}$ & 14 & 681 & $\begin{array}{l}\text { Std. Mean Difference (IV, Random, } \\
95 \% \mathrm{CI})\end{array}$ & $-0.26[-0.50,-0.02]$ \\
\hline 13.1 Low-intensity & 0 & 0 & $\begin{array}{l}\text { Std. Mean Difference (IV, Random, } \\
95 \% \mathrm{CI})\end{array}$ & $0.0[0.0,0.0]$ \\
\hline 13.2 Medium-intensity & 6 & 202 & $\begin{array}{l}\text { Std. Mean Difference (IV, Random, } \\
95 \% \mathrm{CI})\end{array}$ & $-0.37[-0.67,-0.08]$ \\
\hline 13.3 High-intensity & 8 & 479 & $\begin{array}{l}\text { Std. Mean Difference (IV, Random, } \\
95 \% \mathrm{CI})\end{array}$ & $-0.17[-0.52,0.17]$ \\
\hline $\begin{array}{l}14 \text { Hearing aid benefit - } \\
\text { long-term }\end{array}$ & 2 & 69 & Mean Difference (IV, Random, 95\% CI) & $0.30[0.02,0.58]$ \\
\hline $\begin{array}{l}15 \text { Hearing aid benefit - } \\
\text { short/medium-term - SMS } \\
\text { content }\end{array}$ & 7 & 361 & $\begin{array}{l}\text { Std. Mean Difference (IV, Random, } \\
95 \% \mathrm{CI})\end{array}$ & $0.10[-0.15,0.36]$ \\
\hline 15.1 Advise & 2 & 92 & $\begin{array}{l}\text { Std. Mean Difference (IV, Random, } \\
95 \% \mathrm{CI})\end{array}$ & $-0.14[-1.10,0.83]$ \\
\hline 15.2 Activate - practical & 0 & 0 & $\begin{array}{l}\text { Std. Mean Difference (IV, Random, } \\
95 \% \mathrm{CI})\end{array}$ & $0.0[0.0,0.0]$ \\
\hline 15.3 Activate - symptoms & 2 & 76 & $\begin{array}{l}\text { Std. Mean Difference (IV, Random, } \\
95 \% \mathrm{CI} \text { ) }\end{array}$ & $0.17[-0.28,0.62]$ \\
\hline 15.4 Activate - psychosocial & 3 & 193 & $\begin{array}{l}\text { Std. Mean Difference (IV, Random, } \\
95 \% \mathrm{CI})\end{array}$ & $0.22[-0.07,0.50]$ \\
\hline
\end{tabular}




\begin{tabular}{|c|c|c|c|c|}
\hline Outcome or subgroup title & No. of studies & $\begin{array}{l}\text { No. of partici- } \\
\text { pants }\end{array}$ & Statistical method & Effect size \\
\hline 15.5 Assist & 0 & 0 & $\begin{array}{l}\text { Std. Mean Difference (IV, Random, } \\
95 \% \mathrm{CI})\end{array}$ & $0.0[0.0,0.0]$ \\
\hline 15.6 Agree & 0 & 0 & $\begin{array}{l}\text { Std. Mean Difference (IV, Random, } \\
95 \% \mathrm{Cl} \text { ) }\end{array}$ & $0.0[0.0,0.0]$ \\
\hline $\begin{array}{l}16 \text { Hearing aid benefit - } \\
\text { short/medium-term - DSD } \\
\text { format }\end{array}$ & 7 & 361 & $\begin{array}{l}\text { Std. Mean Difference (IV, Random, } \\
95 \% \mathrm{Cl} \text { ) }\end{array}$ & $0.10[-0.15,0.36]$ \\
\hline 16.1 Face-to-face & 3 & 120 & $\begin{array}{l}\text { Std. Mean Difference (IV, Random, } \\
95 \% \mathrm{Cl} \text { ) }\end{array}$ & $0.24[-0.13,0.60]$ \\
\hline 16.2 Telephone & 1 & 69 & $\begin{array}{l}\text { Std. Mean Difference (IV, Random, } \\
95 \% \mathrm{Cl} \text { ) }\end{array}$ & $0.38[-0.09,0.86]$ \\
\hline 16.3 Booklet & 0 & 0 & $\begin{array}{l}\text { Std. Mean Difference (IV, Random, } \\
95 \% \mathrm{CI} \text { ) }\end{array}$ & $0.0[0.0,0.0]$ \\
\hline 16.4 Remote & 3 & 172 & $\begin{array}{l}\text { Std. Mean Difference (IV, Random, } \\
95 \% \mathrm{Cl} \text { ) }\end{array}$ & $-0.12[-0.63,0.39]$ \\
\hline $\begin{array}{l}17 \text { Hearing aid benefit - } \\
\text { short/medium-term - DSD } \\
\text { intensity }\end{array}$ & 7 & 361 & $\begin{array}{l}\text { Std. Mean Difference (IV, Random, } \\
95 \% \mathrm{CI})\end{array}$ & $0.10[-0.15,0.36]$ \\
\hline 17.1 Low-intensity & 0 & 0 & $\begin{array}{l}\text { Std. Mean Difference (IV, Random, } \\
95 \% \mathrm{Cl} \text { ) }\end{array}$ & $0.0[0.0,0.0]$ \\
\hline 17.2 Medium-intensity & 3 & 120 & $\begin{array}{l}\text { Std. Mean Difference (IV, Random, } \\
95 \% \mathrm{Cl})\end{array}$ & $0.24[-0.13,0.60]$ \\
\hline 17.3 High-intensity & 4 & 241 & $\begin{array}{l}\text { Std. Mean Difference (IV, Random, } \\
95 \% \mathrm{CI})\end{array}$ & $0.01[-0.41,0.43]$ \\
\hline $\begin{array}{l}18 \text { Use of verbal communi- } \\
\text { cation strategy - long-term }\end{array}$ & 1 & 34 & Mean Difference (IV, Random, 95\% Cl) & $0.30[-0.20,0.80]$ \\
\hline $\begin{array}{l}19 \text { Use of verbal commu- } \\
\text { nication strategy - short/ } \\
\text { medium-term - SMS content }\end{array}$ & 4 & 223 & Mean Difference (IV, Random, 95\% Cl) & $0.45[0.15,0.74]$ \\
\hline 19.1 Advise & 1 & 115 & Mean Difference (IV, Random, 95\% CI) & $0.25[-0.07,0.57]$ \\
\hline 19.2 Activate - practical & 0 & 0 & Mean Difference (IV, Random, 95\% Cl) & $0.0[0.0,0.0]$ \\
\hline 19.3 Activate - symptoms & 1 & 37 & Mean Difference (IV, Random, 95\% CI) & $0.40[-0.06,0.86]$ \\
\hline 19.4 Activate - psychosocial & 2 & 71 & Mean Difference (IV, Random, 95\% CI) & $0.70[0.01,1.39]$ \\
\hline 19.5 Assist & 0 & 0 & Mean Difference (IV, Random, 95\% Cl) & $0.0[0.0,0.0]$ \\
\hline 19.6 Agree & 0 & 0 & Mean Difference (IV, Random, 95\% Cl) & $0.0[0.0,0.0]$ \\
\hline $\begin{array}{l}20 \text { Use of verbal commu- } \\
\text { nication strategy - short/ }\end{array}$ & 4 & 223 & Mean Difference (IV, Random, 95\% Cl) & $0.45[0.15,0.74]$ \\
\hline
\end{tabular}




\begin{tabular}{lllll}
\hline Outcome or subgroup title & No. of studies & $\begin{array}{l}\text { No. of partici- } \\
\text { pants }\end{array}$ & Statistical method & Effect size \\
\hline $\begin{array}{l}\text { medium-term - DSD intensi- } \\
\text { ty }\end{array}$ & 1 & & & \\
\hline 20.1 Low-intensity & 2 & 115 & Mean Difference (IV, Random, 95\% Cl) & $0.25[-0.07,0.57]$ \\
\hline 20.2 Medium-intensity & 89 & 19 & Mean Difference (IV, Random, 95\% Cl) & $1.1[0.43,1.77]$ \\
\hline 20.3 High-intensity & 1 & & & $0.40[0.07,0.72]$ \\
\hline
\end{tabular}

Analysis 3.1. Comparison 3 Combined SMS/DSD interventions versus control, Outcome 1 Adherence - short/medium-term.

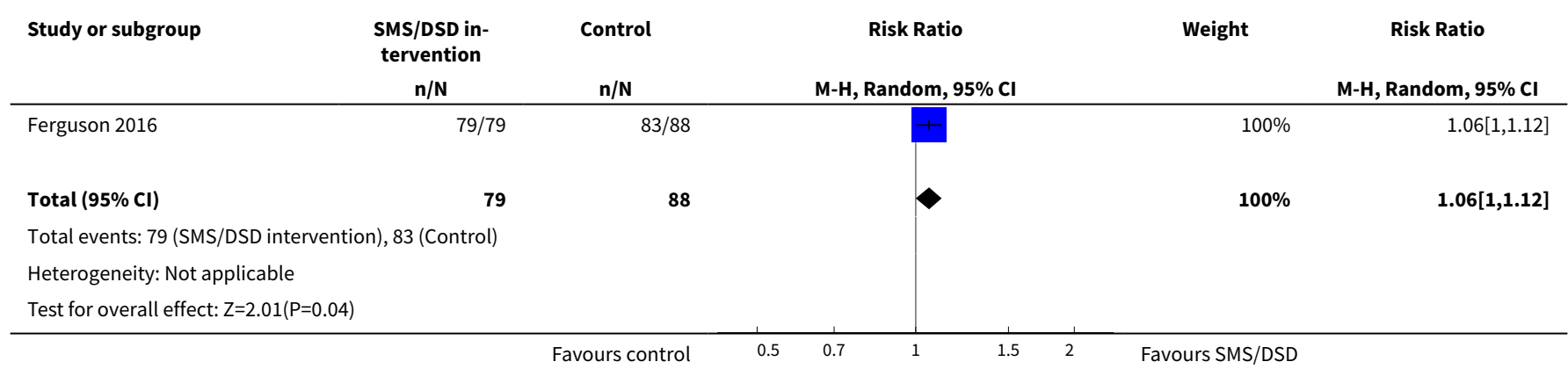

Analysis 3.2. Comparison 3 Combined SMS/DSD interventions versus control, Outcome 2 Daily hours of hearing aid use - long-term.

\begin{tabular}{|c|c|c|c|c|c|c|c|}
\hline \multirow{3}{*}{$\begin{array}{l}\text { Study or subgroup } \\
\text { Oberg } 2008\end{array}$} & \multicolumn{2}{|c|}{$\begin{array}{l}\text { SMS/DSD in- } \\
\text { tervention }\end{array}$} & \multicolumn{2}{|c|}{ Control } & \multirow{2}{*}{$\begin{array}{l}\text { Mean Difference } \\
\text { Random, } 95 \% \mathrm{CI}\end{array}$} & \multirow[t]{2}{*}{ Weight } & \multirow{2}{*}{$\begin{array}{l}\text { Mean Difference } \\
\text { Random, } 95 \% \mathrm{Cl}\end{array}$} \\
\hline & $\mathbf{N}$ & $\operatorname{Mean}(S D)$ & $\mathbf{N}$ & Mean(SD) & & & \\
\hline & 16 & $3.7(0.9)$ & 18 & $4(1)$ & \begin{tabular}{l|l}
11 & \\
+
\end{tabular} & $50.84 \%$ & $-0.3[-0.94,0.34]$ \\
\hline Oberg 2009 & 17 & $4.1(1)$ & 18 & $3.7(1)$ & 1 & $49.16 \%$ & $0.4[-0.26,1.06]$ \\
\hline 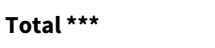 & 33 & & 36 & & & $100 \%$ & $0.04[-0.64,0.73]$ \\
\hline \multicolumn{8}{|c|}{ Test for overall effect: $Z=0.13(P=0.9)$} \\
\hline
\end{tabular}

Analysis 3.3. Comparison 3 Combined SMS/DSD interventions versus control, Outcome 3 Daily hours of hearing aid use - short/medium-term - SMS content.

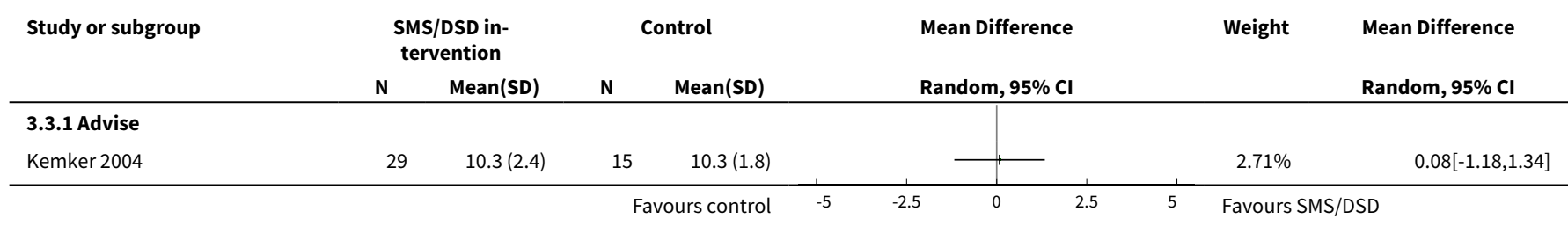




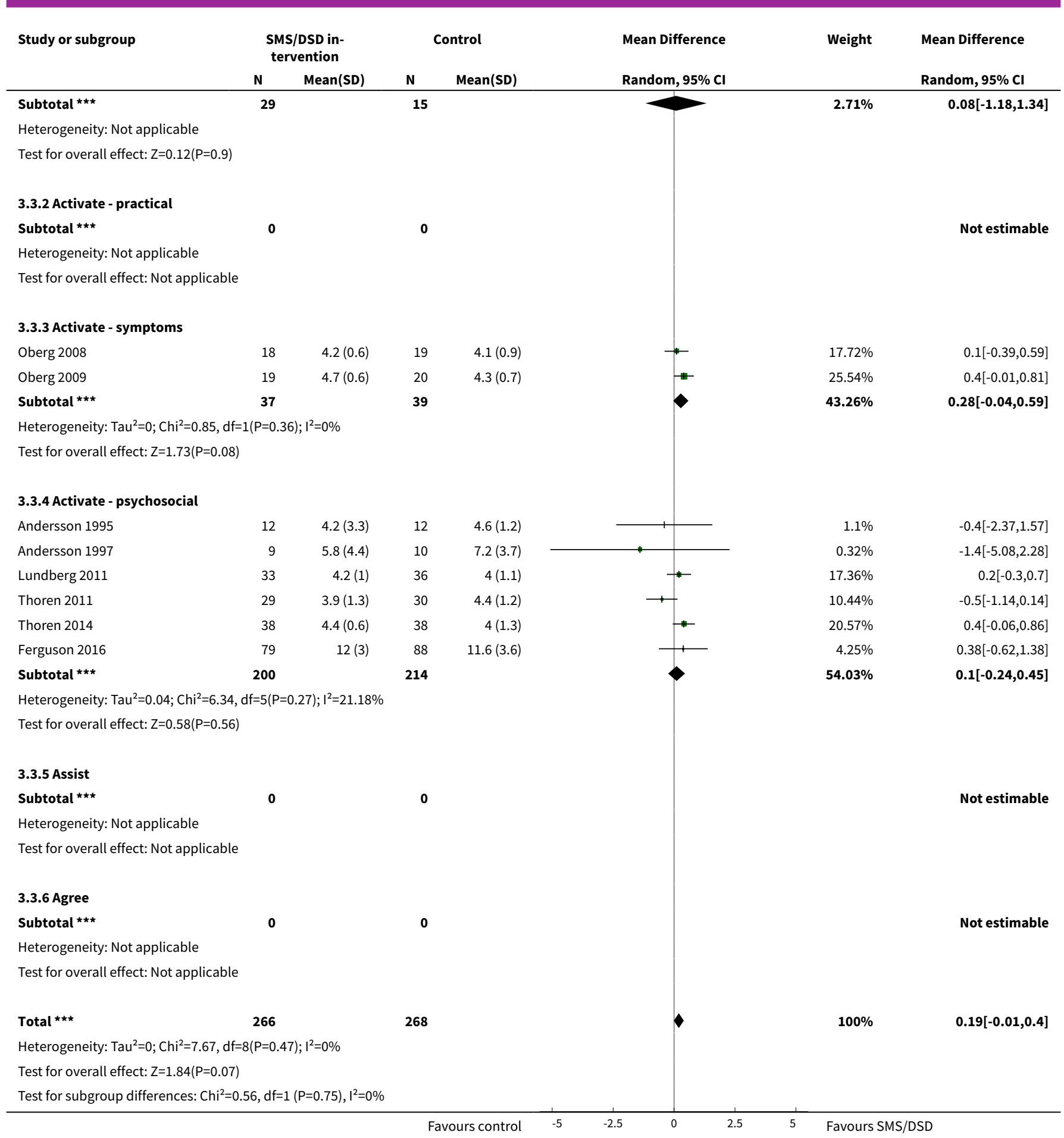


Analysis 3.4. Comparison 3 Combined SMS/DSD interventions versus control, Outcome 4 Daily hours of hearing aid use - short/medium-term - DSD format.

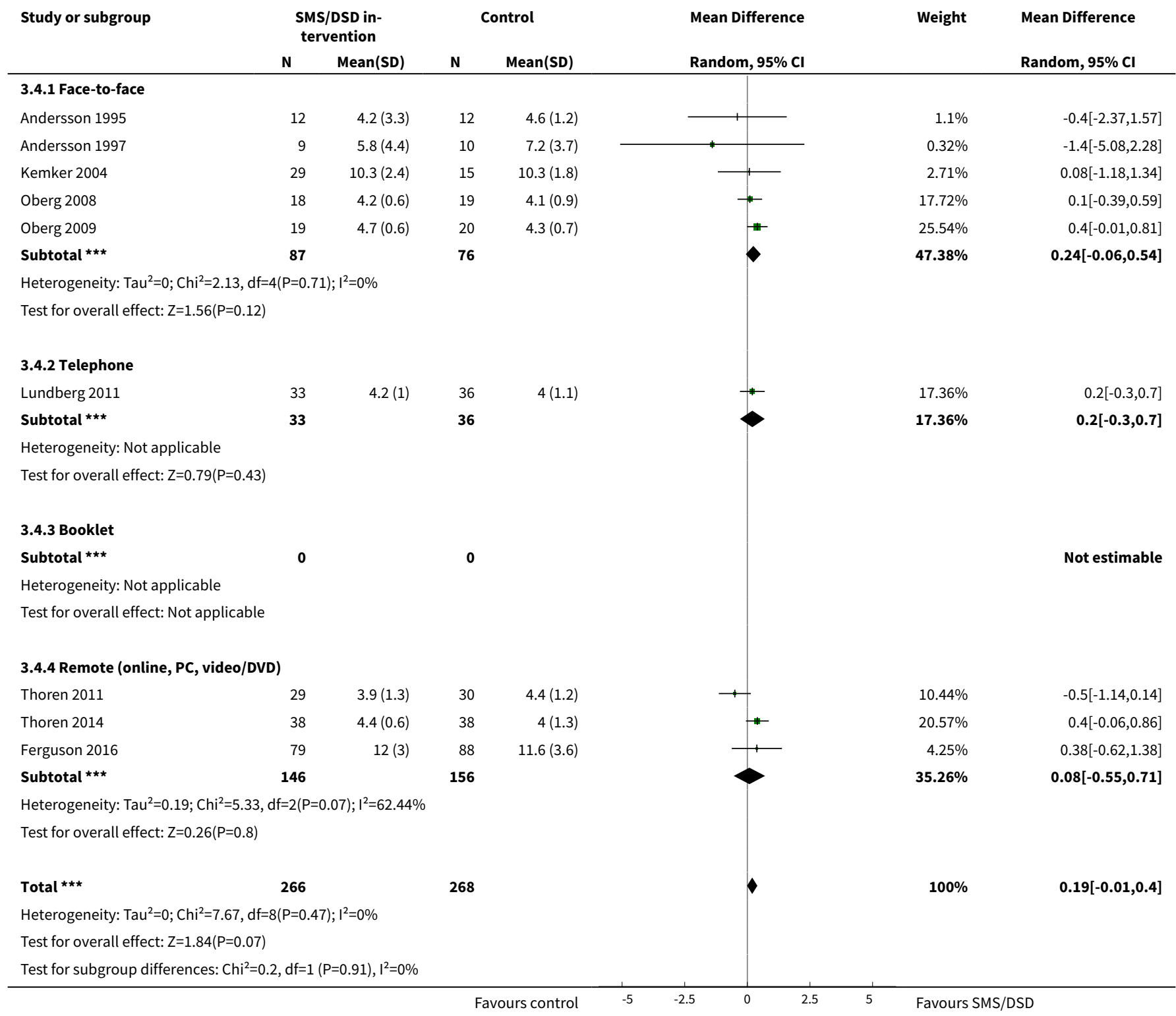

Analysis 3.5. Comparison 3 Combined SMS/DSD interventions versus control, Outcome 5 Daily hours of hearing aid use - short/medium-term - DSD intensity.

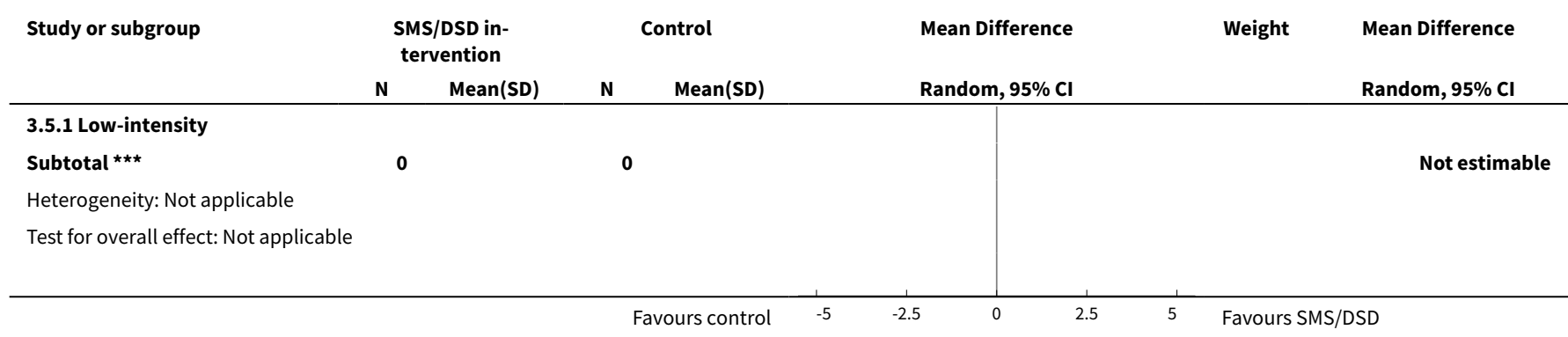




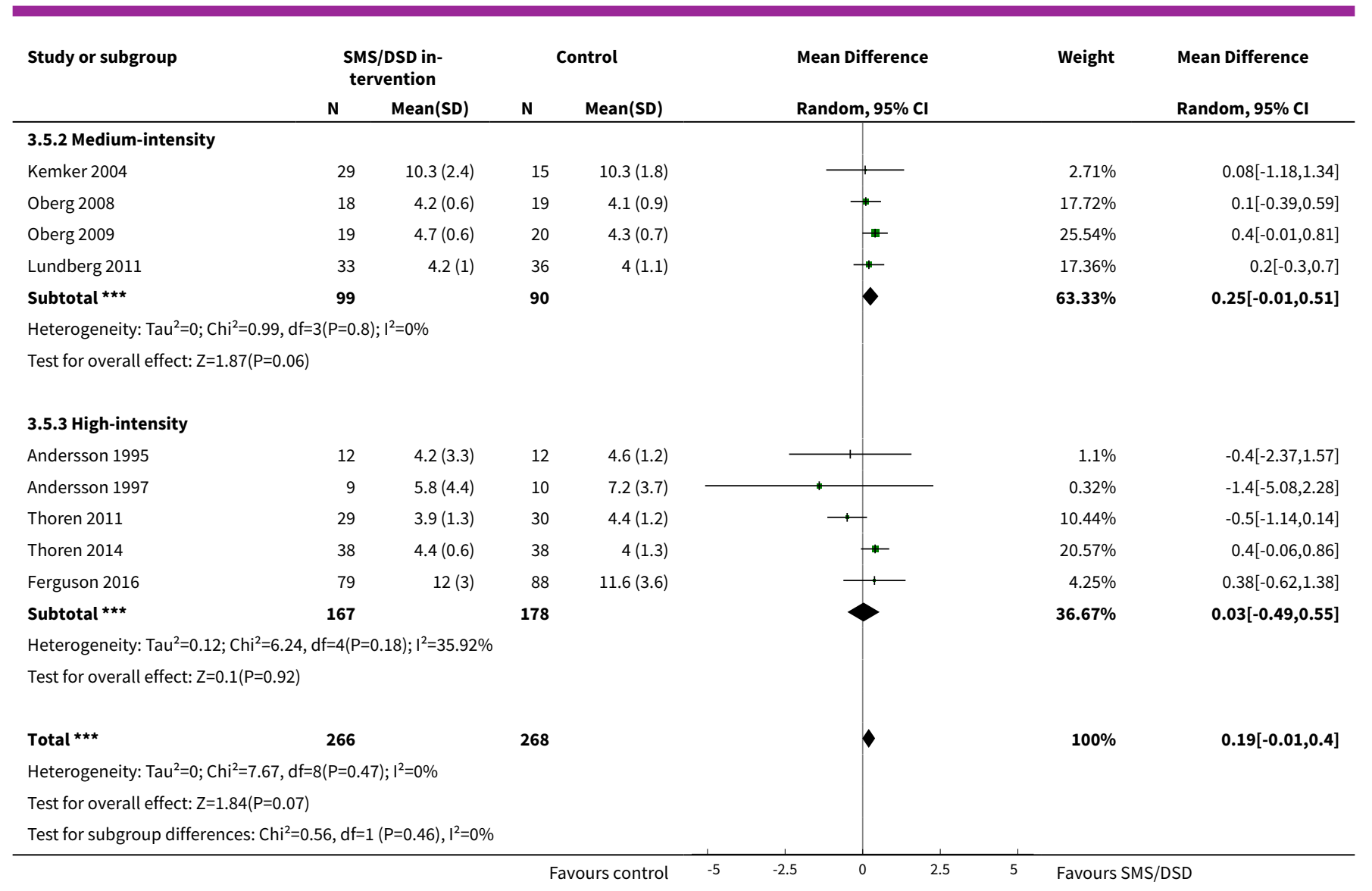

Analysis 3.6. Comparison 3 Combined SMS/DSD interventions versus control, Outcome 6 Quality of life - long-term.

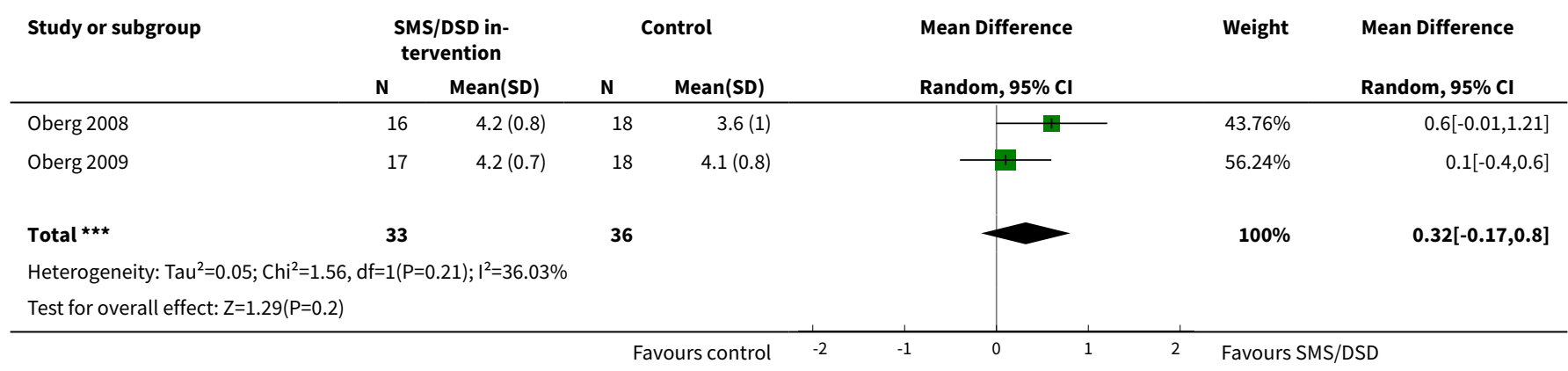

Analysis 3.7. Comparison 3 Combined SMS/DSD interventions versus control, Outcome 7 Quality of life - short/medium-term - SMS content.

\begin{tabular}{|c|c|c|c|c|c|c|c|c|}
\hline \multirow[t]{2}{*}{ Study or subgroup } & \multicolumn{2}{|c|}{$\begin{array}{l}\text { SMS/DSD in- } \\
\text { tervention }\end{array}$} & \multicolumn{2}{|c|}{ Control } & \multirow{2}{*}{\multicolumn{2}{|c|}{$\begin{array}{l}\text { Std. Mean Difference } \\
\text { Random, } 95 \% \mathrm{Cl}\end{array}$}} & \multirow[t]{2}{*}{ Weight } & \multirow{2}{*}{$\begin{array}{c}\text { Std. Mean Difference } \\
\text { Random, } 95 \% \mathrm{Cl} \\
\end{array}$} \\
\hline & $\mathbf{N}$ & Mean(SD) & $\mathbf{N}$ & Mean(SD) & & & & \\
\hline \multicolumn{9}{|l|}{ 3.7.1 Advise } \\
\hline Kramer 2005 & 24 & $3.6(0.8)$ & 24 & $3.5(1)$ & & + & $9.1 \%$ & $0.11[-0.46,0.67]$ \\
\hline
\end{tabular}




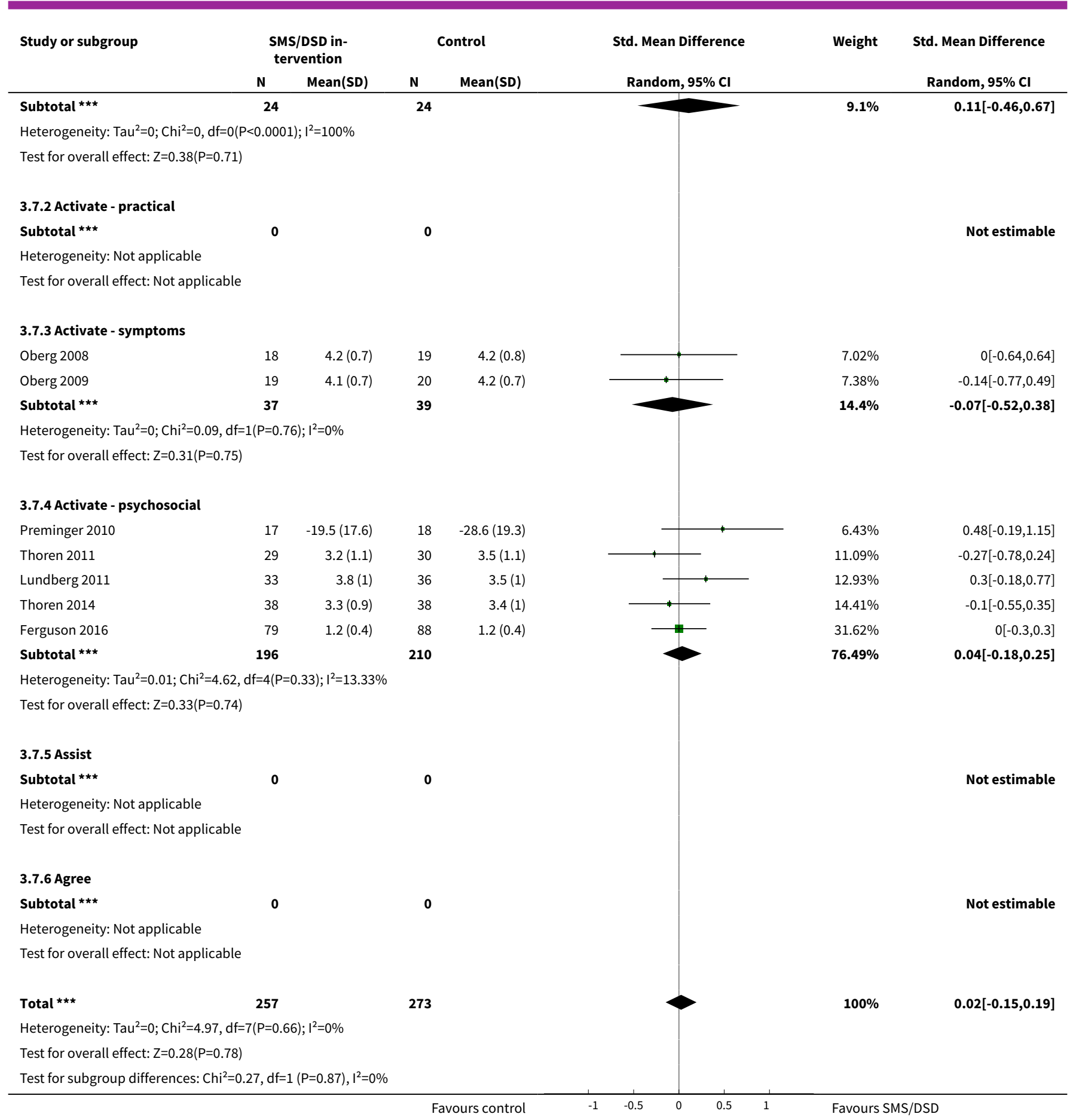

Analysis 3.8. Comparison 3 Combined SMS/DSD interventions versus control, Outcome 8 Quality of life - short/medium-term - DSD format.

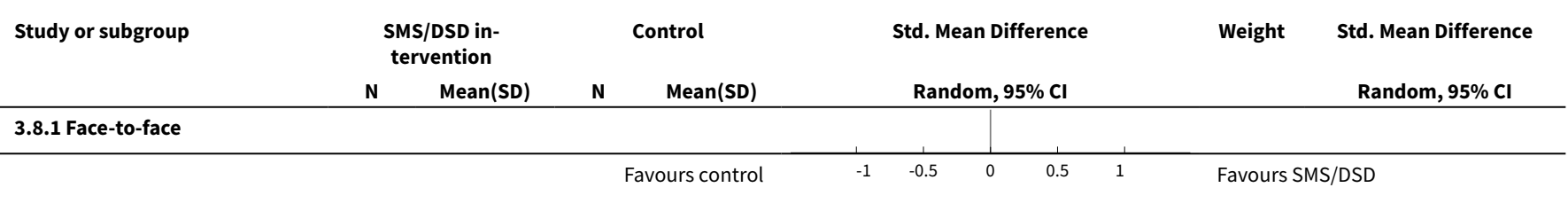




\begin{tabular}{|c|c|c|c|c|c|c|c|}
\hline \multirow{3}{*}{$\begin{array}{l}\text { Study or subgroup } \\
\text { Oberg } 2008\end{array}$} & \multicolumn{2}{|c|}{$\begin{array}{l}\text { SMS/DSD in- } \\
\text { tervention }\end{array}$} & \multicolumn{2}{|c|}{ Control } & \multirow{2}{*}{$\begin{array}{l}\text { Std. Mean Difference } \\
\text { Random, } 95 \% \mathrm{Cl}\end{array}$} & \multirow{3}{*}{$\begin{array}{l}\text { Weight } \\
7.02 \%\end{array}$} & \multirow{2}{*}{$\begin{array}{l}\text { Std. Mean Difference } \\
\text { Random, } 95 \% \mathrm{Cl}\end{array}$} \\
\hline & $\mathbf{N}$ & Mean(SD) & $\mathbf{N}$ & Mean(SD) & & & \\
\hline & 18 & $4.2(0.7)$ & 19 & $4.2(0.8)$ & $\bar{I}$ & & $0[-0.64,0.64]$ \\
\hline Oberg 2009 & 19 & $4.1(0.7)$ & 20 & $4.2(0.7)$ & & $7.38 \%$ & $-0.14[-0.77,0.49]$ \\
\hline Preminger 2010 & 17 & $-19.5(17.6)$ & 18 & $-28.6(19.3)$ & & $6.43 \%$ & $0.48[-0.19,1.15]$ \\
\hline Subtotal $\star \star \star$ & 54 & & 57 & & & $20.84 \%$ & $0.1[-0.28,0.47]$ \\
\hline \multicolumn{8}{|c|}{ Heterogeneity: $\operatorname{Tau}^{2}=0 ; \mathrm{Chi}^{2}=1.88, \mathrm{df}=2(\mathrm{P}=0.39) ; \mathrm{I}^{2}=0 \%$} \\
\hline \multicolumn{8}{|c|}{ Test for overall effect: $Z=0.52(P=0.6)$} \\
\hline \multicolumn{8}{|l|}{ 3.8.2 Telephone } \\
\hline Lundberg 2011 & 33 & $3.8(1)$ & 36 & $3.5(1)$ & - & $12.93 \%$ & $0.3[-0.18,0.77]$ \\
\hline Subtotal $\star \star \star$ & 33 & & 36 & & & $12.93 \%$ & $0.3[-0.18,0.77]$ \\
\hline \multicolumn{8}{|c|}{ Test for overall effect: $\mathrm{Z}=1.22(\mathrm{P}=0.22)$} \\
\hline \multicolumn{8}{|l|}{ 3.8.3 Booklet } \\
\hline 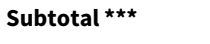 & 0 & & 0 & & & & Not estimable \\
\hline \multicolumn{8}{|c|}{ Heterogeneity: Not applicable } \\
\hline \multicolumn{8}{|c|}{ Test for overall effect: Not applicable } \\
\hline \multicolumn{8}{|l|}{ 3.8.4 Remote } \\
\hline Kramer 2005 & 24 & $3.6(0.8)$ & 24 & $3.5(1)$ & $\overline{-}$ & $9.1 \%$ & $0.11[-0.46,0.67]$ \\
\hline Thoren 2011 & 29 & $3.2(1.1)$ & 30 & $3.5(1.1)$ & & $11.09 \%$ & $-0.27[-0.78,0.24]$ \\
\hline Thoren 2014 & 38 & $3.3(0.9)$ & 38 & $3.4(1)$ & 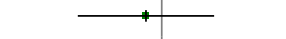 & $14.41 \%$ & $-0.1[-0.55,0.35]$ \\
\hline Ferguson 2016 & 79 & $1.2(0.4)$ & 88 & $1.2(0.4)$ & & $31.62 \%$ & $0[-0.3,0.3]$ \\
\hline Subtotal $\star \star \star ~$ & 170 & & 180 & & & $66.23 \%$ & $-0.05[-0.26,0.16]$ \\
\hline Total $* \star \star$ & 257 & & 273 & & & $100 \%$ & $0.02[-0.15,0.19]$ \\
\hline \multicolumn{8}{|c|}{ Heterogeneity: $\mathrm{Tau}^{2}=0 ; \mathrm{Chi}^{2}=4.97, \mathrm{df}=7(\mathrm{P}=0.66) ; \mathrm{I}^{2}=0 \%$} \\
\hline \multicolumn{8}{|c|}{ Test for overall effect: $Z=0.28(P=0.78)$} \\
\hline \multicolumn{8}{|c|}{ Test for subgroup differences: $\mathrm{Chi}^{2}=1.93, \mathrm{df}=1(\mathrm{P}=0.38), \mathrm{I}^{2}=0 \%$} \\
\hline
\end{tabular}

Analysis 3.9. Comparison 3 Combined SMS/DSD interventions versus control, Outcome 9 Quality of life - short/medium-term - DSD intensity.

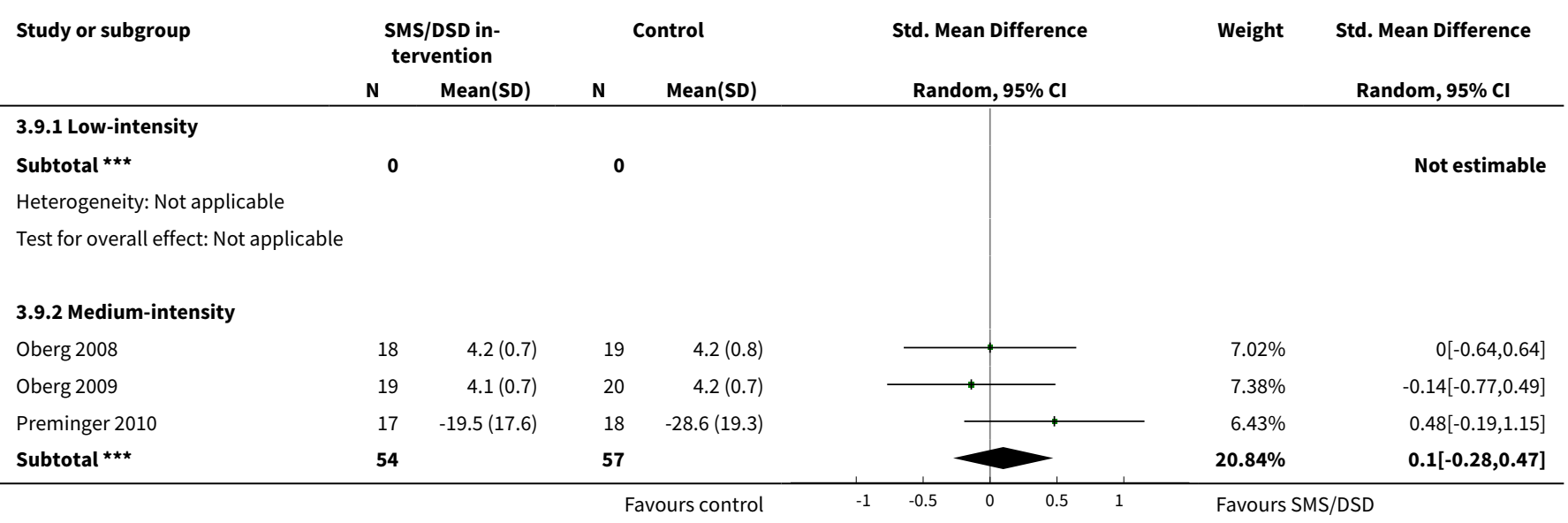




\begin{tabular}{|c|c|c|c|c|c|c|c|}
\hline \multirow[t]{2}{*}{ Study or subgroup } & \multicolumn{2}{|c|}{$\begin{array}{c}\text { SMS/DSD in- } \\
\text { tervention }\end{array}$} & \multicolumn{2}{|c|}{ Control } & \multirow{2}{*}{$\begin{array}{l}\text { Std. Mean Difference } \\
\text { Random, } 95 \% \mathrm{Cl} \\
\end{array}$} & \multirow[t]{2}{*}{ Weight } & \multirow{2}{*}{$\begin{array}{l}\text { Std. Mean Difference } \\
\text { Random, } 95 \% \mathrm{Cl} \\
\end{array}$} \\
\hline & $\mathbf{N}$ & Mean(SD) & $\mathbf{N}$ & Mean(SD) & & & \\
\hline \multicolumn{8}{|c|}{ Heterogeneity: $\mathrm{Tau}^{2}=0 ; \mathrm{Chi}^{2}=1.88, \mathrm{df}=2(\mathrm{P}=0.39) ; \mathrm{I}^{2}=0 \%$} \\
\hline \multicolumn{8}{|c|}{ Test for overall effect: $Z=0.52(P=0.6)$} \\
\hline \multicolumn{8}{|l|}{ 3.9.3 High-intensity } \\
\hline Thoren 2011 & 29 & $3.2(1.1)$ & 30 & $3.5(1.1)$ & & $11.09 \%$ & $-0.27[-0.78,0.24]$ \\
\hline Lundberg 2011 & 33 & $3.8(1)$ & 36 & $3.5(1)$ & 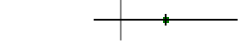 & $12.93 \%$ & $0.3[-0.18,0.77]$ \\
\hline Thoren 2014 & 38 & $3.3(0.9)$ & 38 & $3.4(1)$ & $\longrightarrow$ & $14.41 \%$ & $-0.1[-0.55,0.35]$ \\
\hline Ferguson 2016 & 79 & $1.2(0.4)$ & 88 & $1.2(0.4)$ & & $31.62 \%$ & $0[-0.3,0.3]$ \\
\hline Subtotal $* * \star$ & 203 & & 216 & & & $79.16 \%$ & $0[-0.19,0.2]$ \\
\hline \multicolumn{8}{|c|}{ Heterogeneity: $\mathrm{Tau}^{2}=0 ; \mathrm{Chi}^{2}=2.9, \mathrm{df}=4(\mathrm{P}=0.57) ; \mathrm{I}^{2}=0 \%$} \\
\hline Total $\star \star \star ~$ & 257 & & 273 & & & $100 \%$ & $0.02[-0.15,0.19]$ \\
\hline \multicolumn{8}{|c|}{ Heterogeneity: $\operatorname{Tau}^{2}=0 ; \mathrm{Chi}^{2}=4.97, \mathrm{df}=7(\mathrm{P}=0.66) ; \mathrm{I}^{2}=0 \%$} \\
\hline \multicolumn{8}{|c|}{ Test for overall effect: $\mathrm{Z}=0.28(\mathrm{P}=0.78)$} \\
\hline Test for subgroup dif & $19, \mathrm{df}=$ & $P=0.66), I^{2}=0 \%$ & & & & & \\
\hline
\end{tabular}

\section{Analysis 3.10. Comparison 3 Combined SMS/DSD interventions versus control, Outcome 10 Self-reported hearing handicap - long-term.}

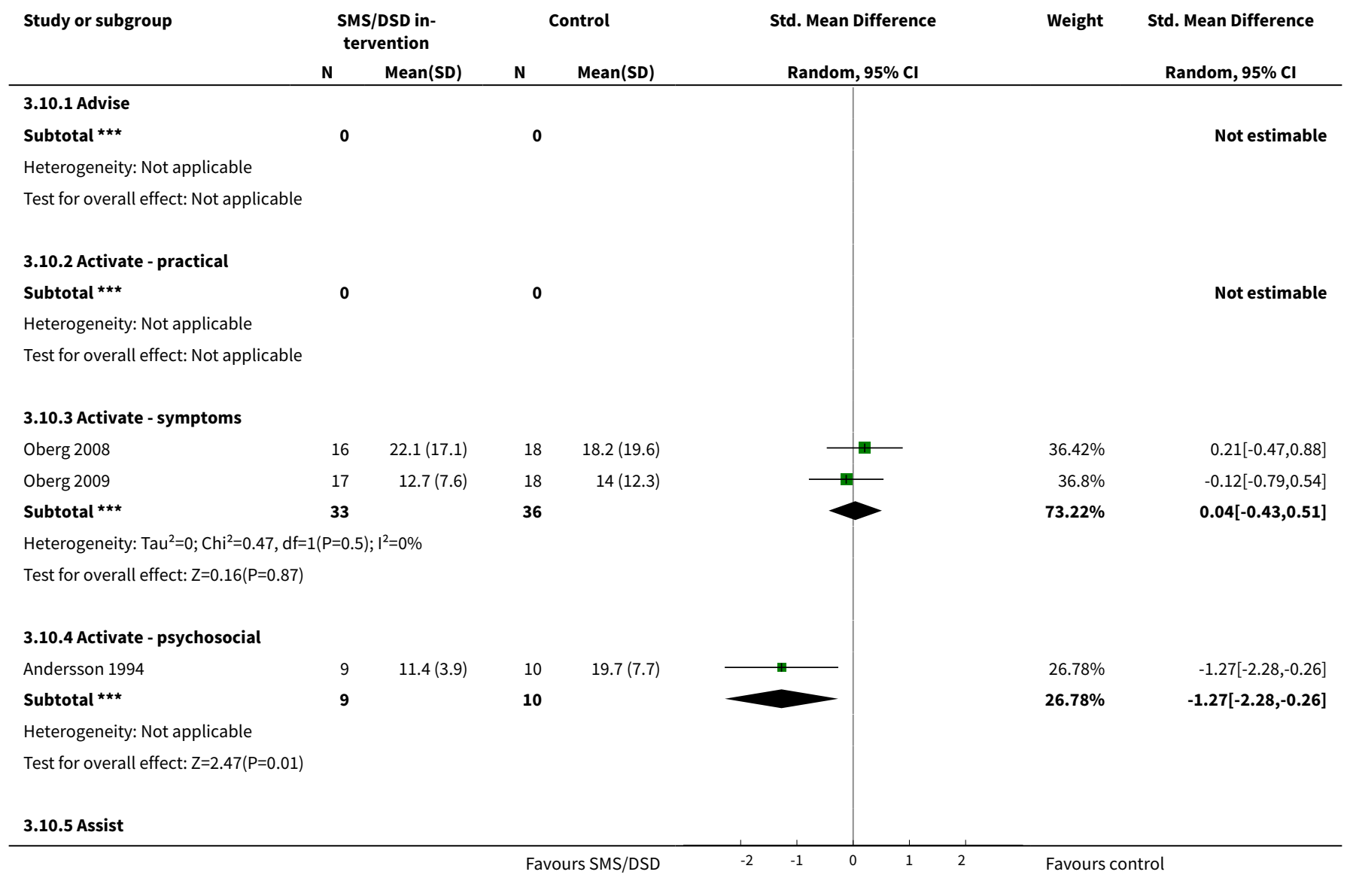




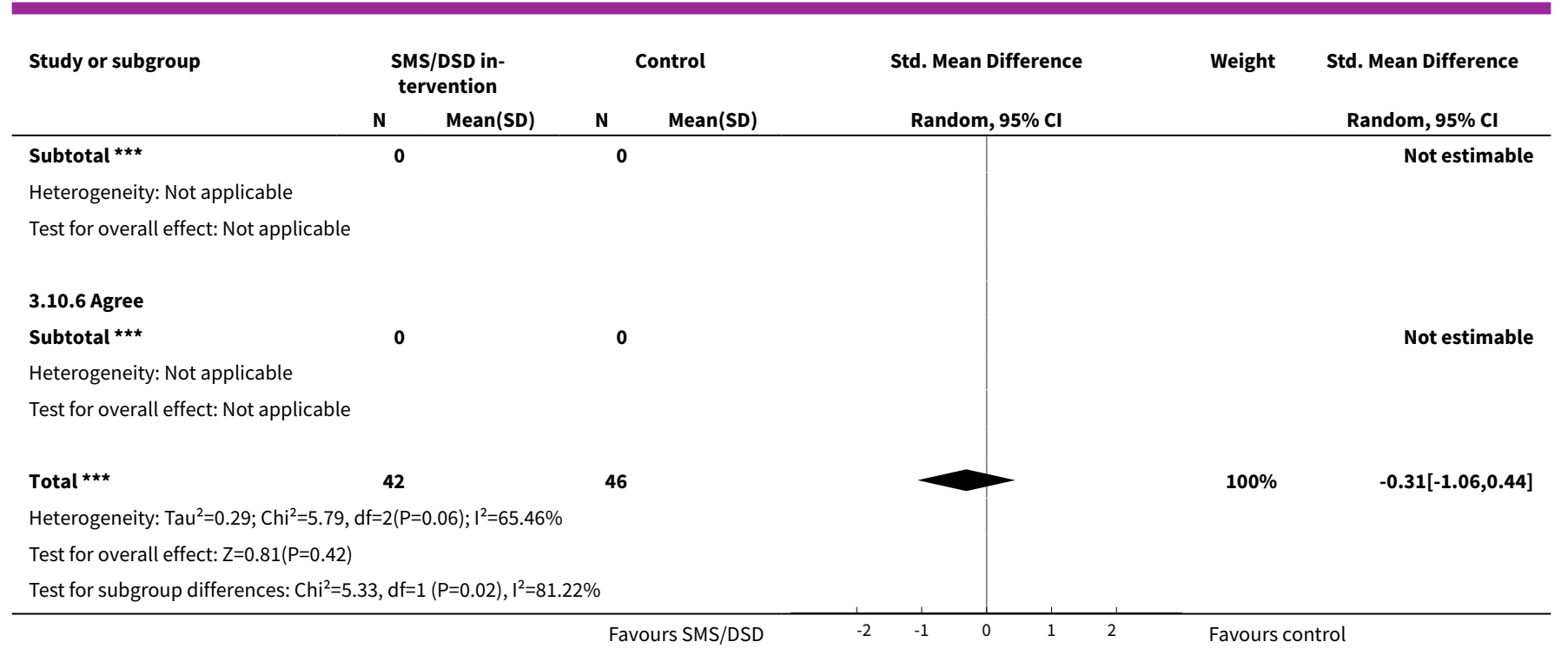

Analysis 3.11. Comparison 3 Combined SMS/DSD interventions versus control, Outcome 11 Self-reported hearing handicap - short/medium-term - SMS content.

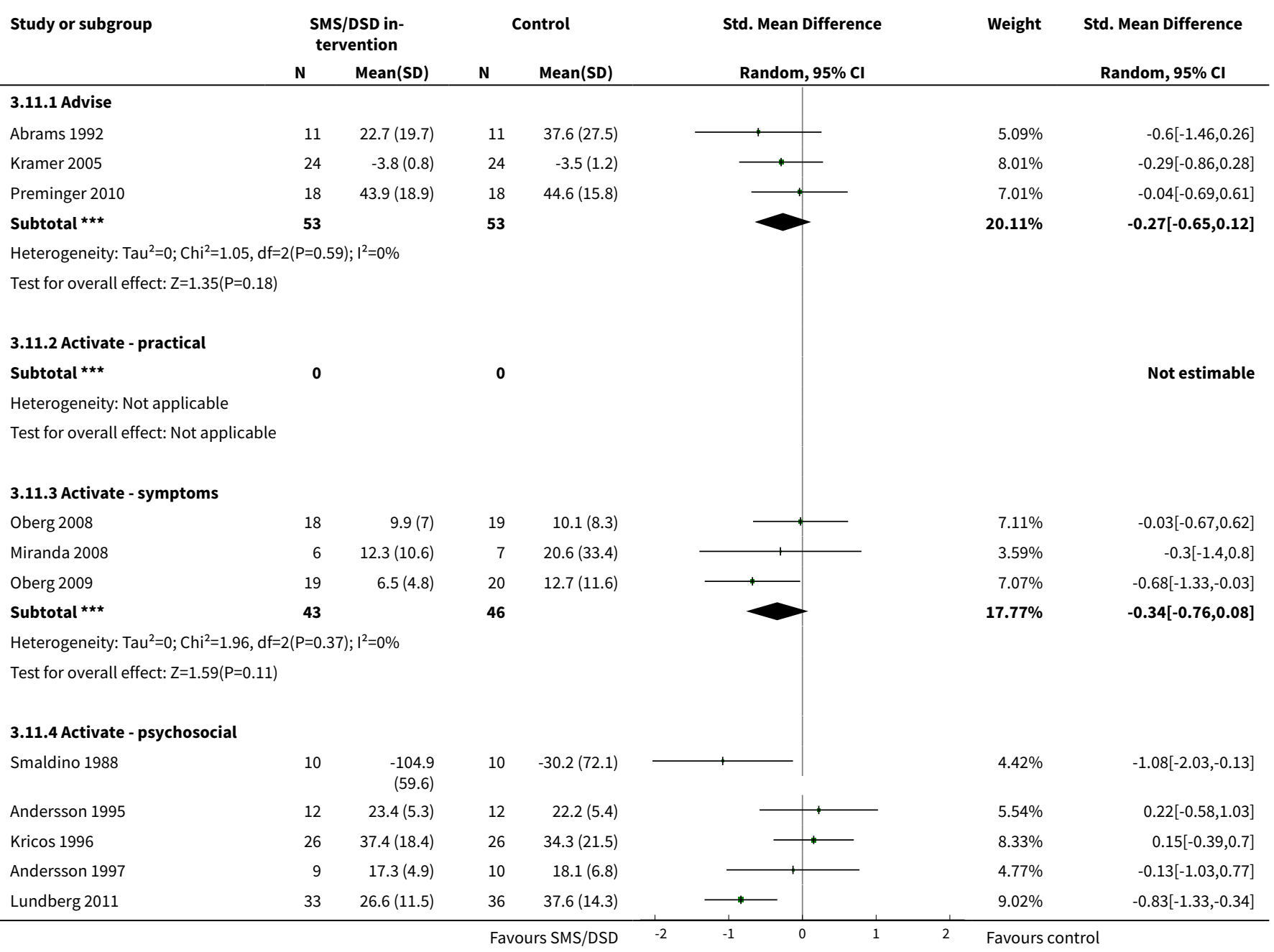




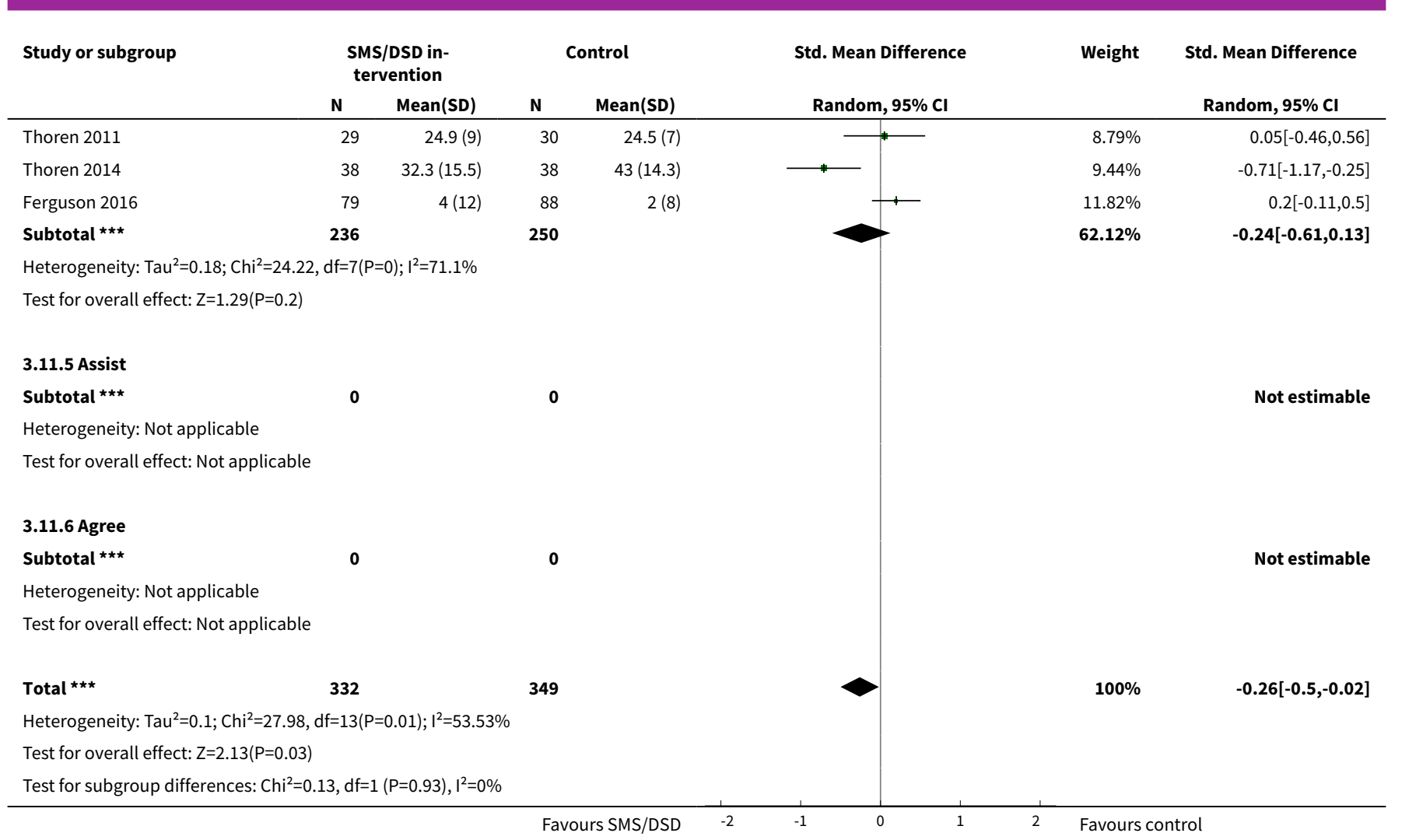

Analysis 3.12. Comparison 3 Combined SMS/DSD interventions versus control, Outcome 12 Self-reported hearing handicap - short/medium-term - DSD format.

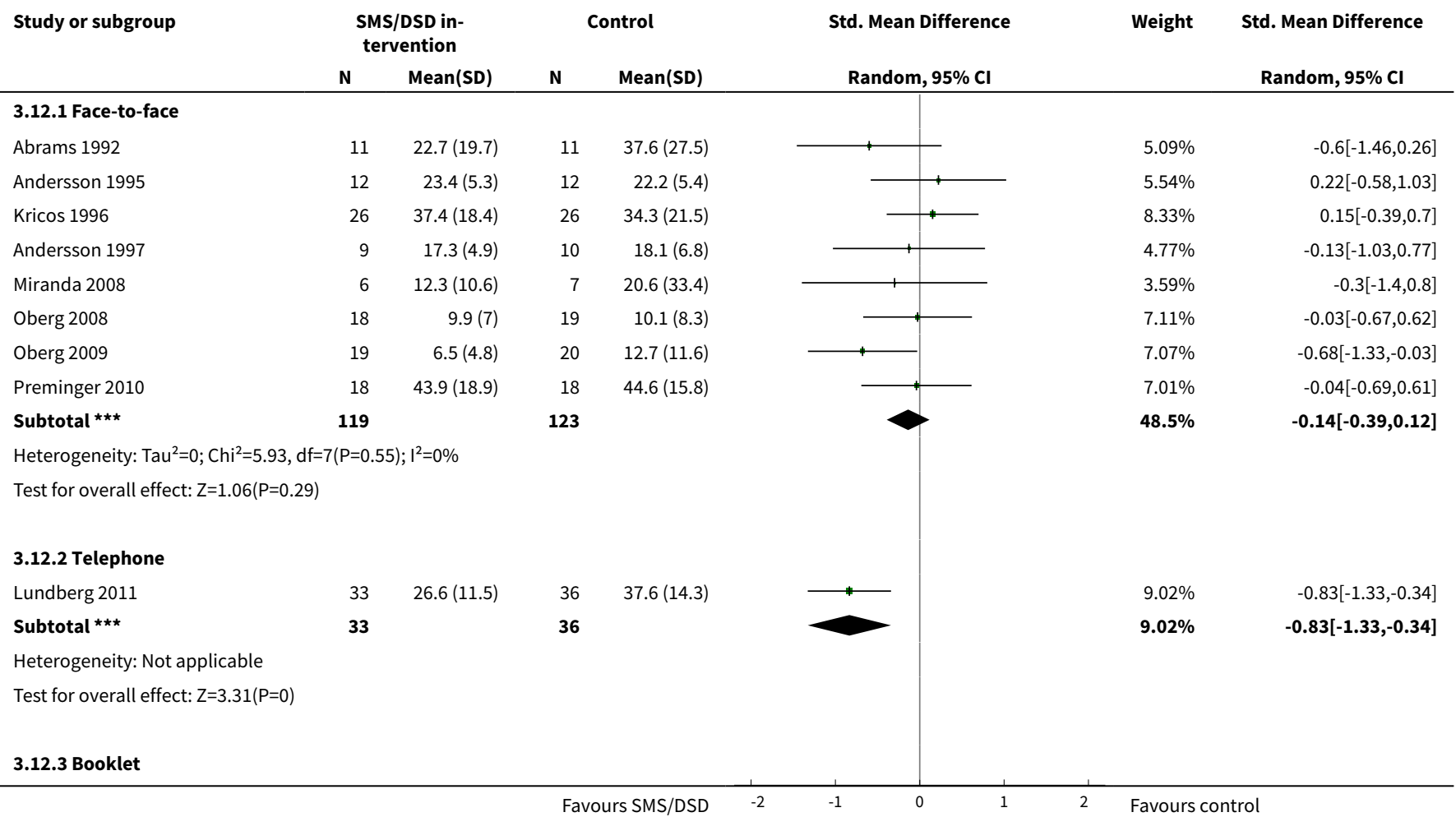




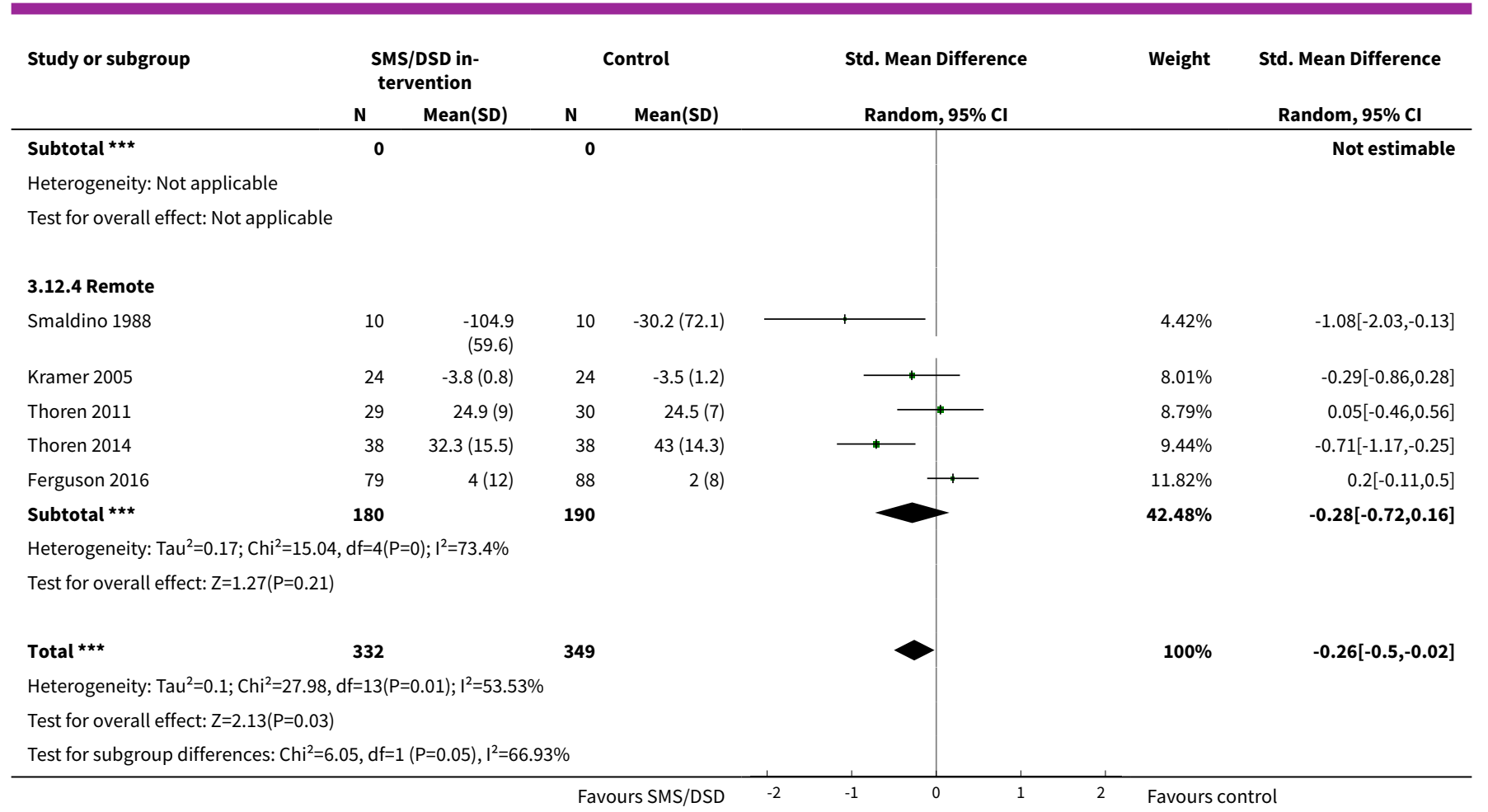

Analysis 3.13. Comparison 3 Combined SMS/DSD interventions versus control, Outcome 13 Self-reported hearing handicap - short/medium-term - DSD intensity.

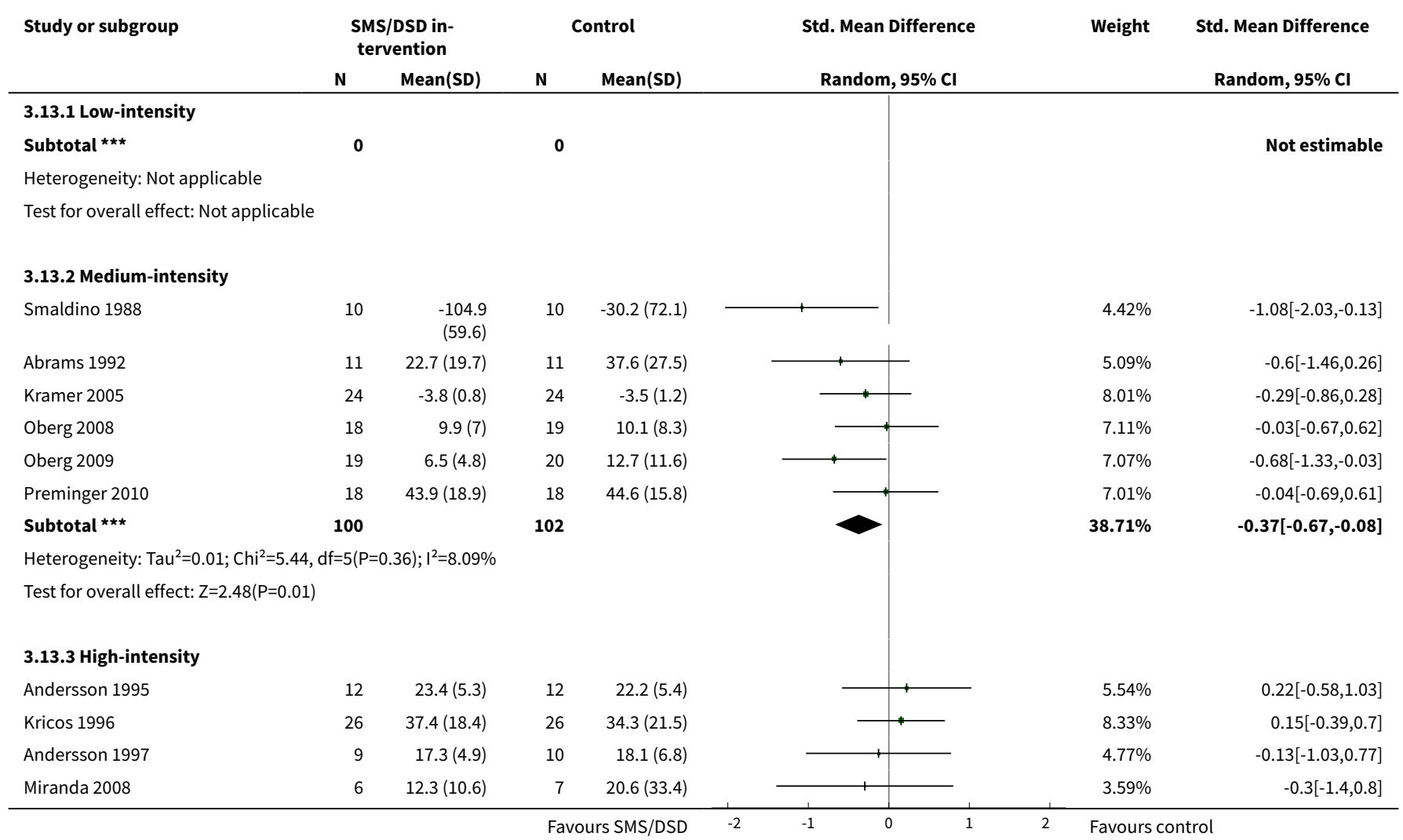




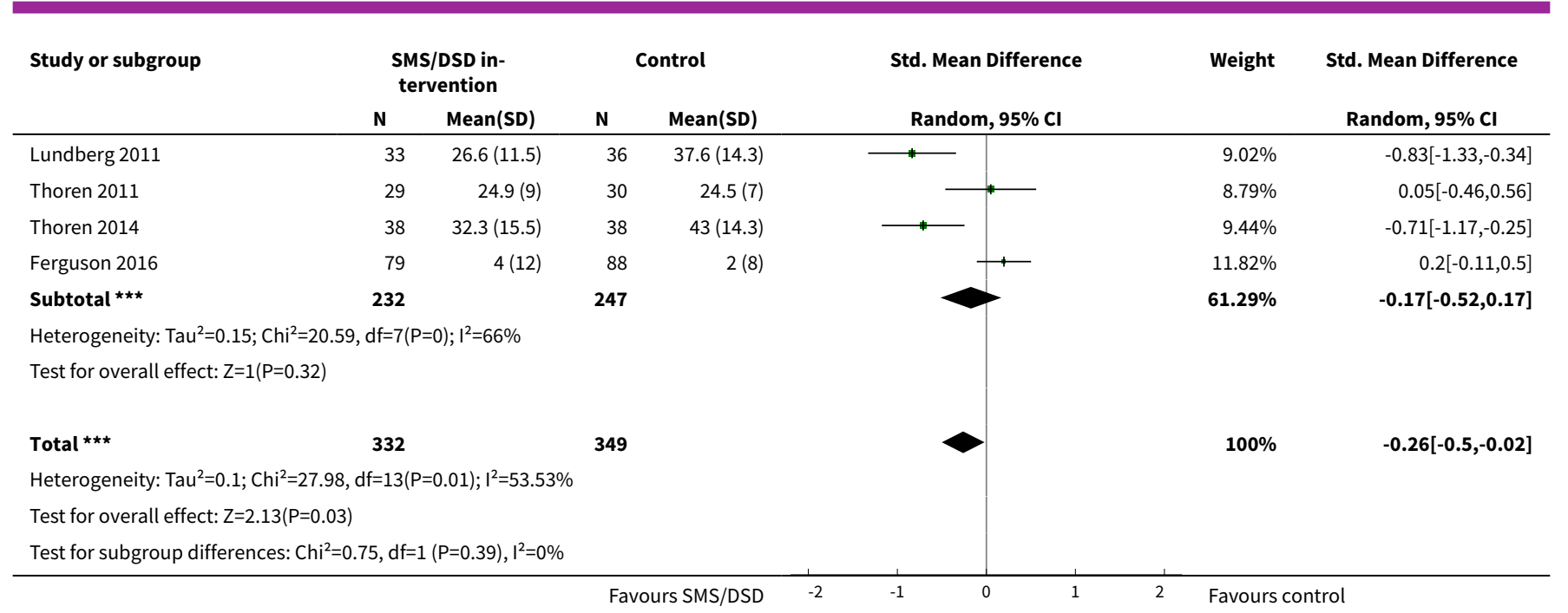

\section{Analysis 3.14. Comparison 3 Combined SMS/DSD interventions} versus control, Outcome 14 Hearing aid benefit - long-term.

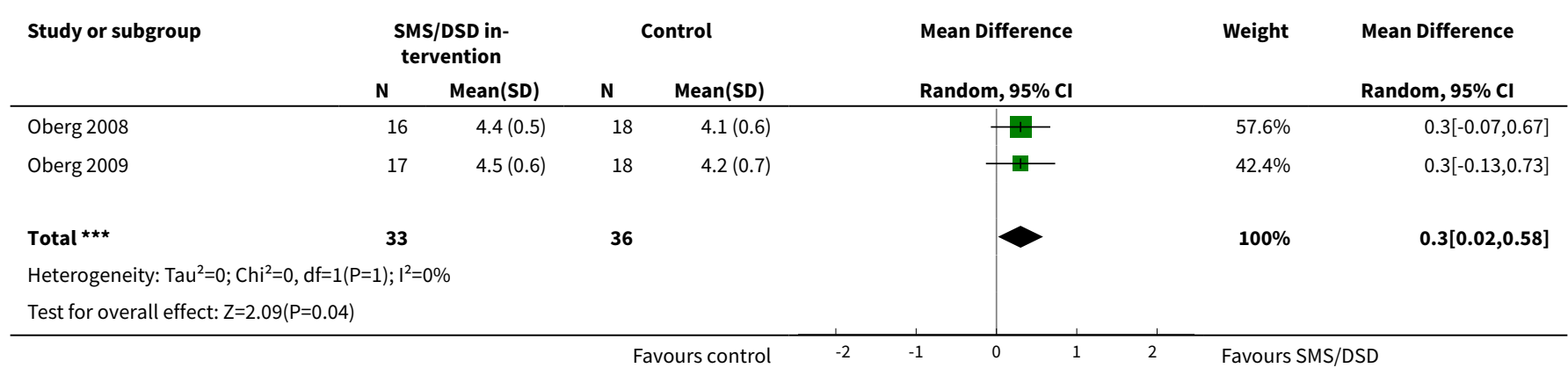

Analysis 3.15. Comparison 3 Combined SMS/DSD interventions versus control, Outcome 15 Hearing aid benefit - short/medium-term - SMS content.

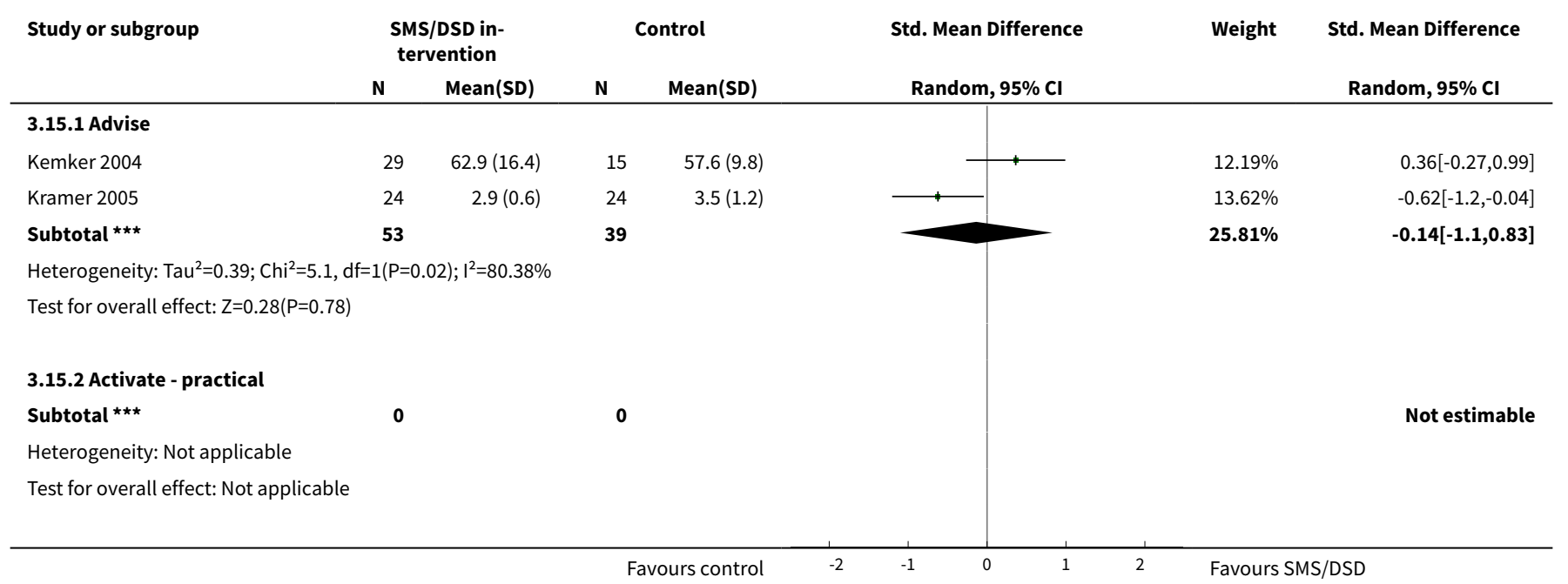




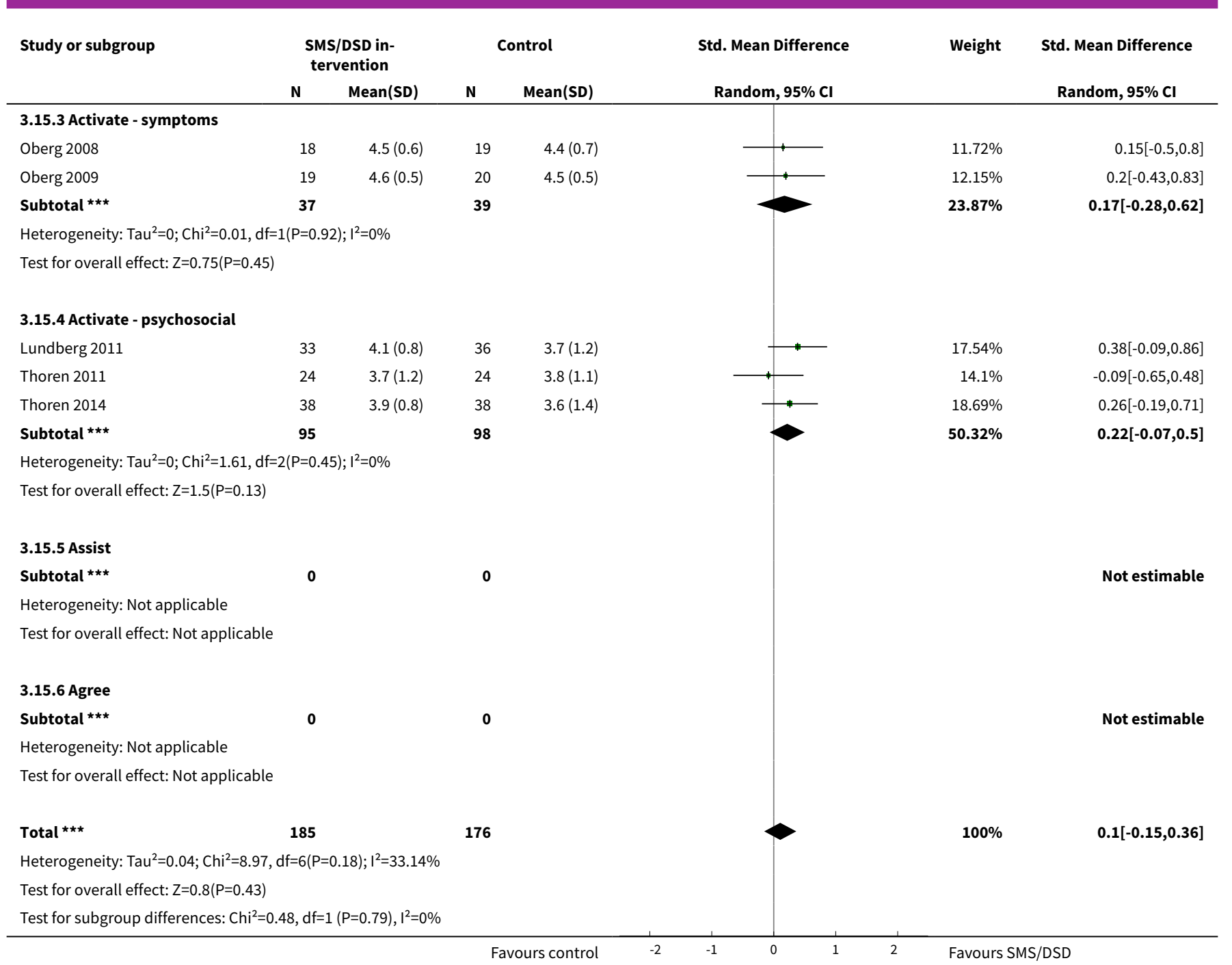

Analysis 3.16. Comparison 3 Combined SMS/DSD interventions versus control, Outcome 16 Hearing aid benefit - short/medium-term - DSD format.

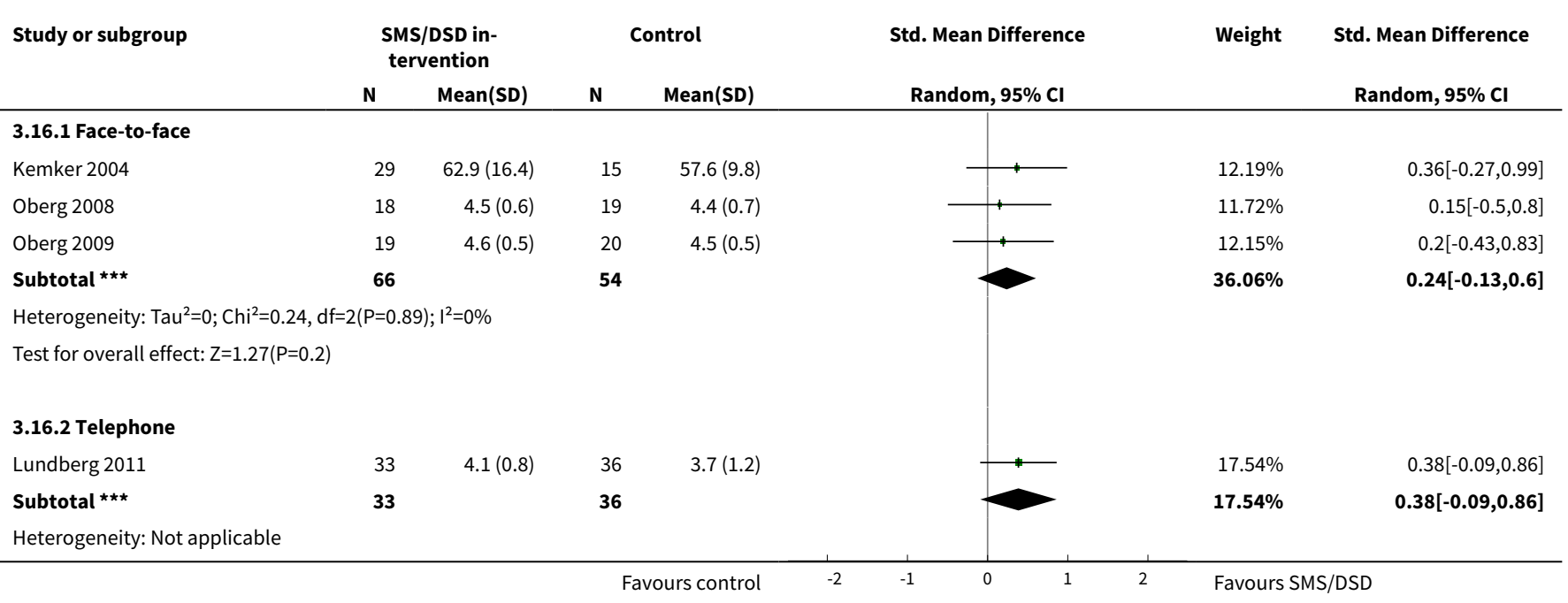




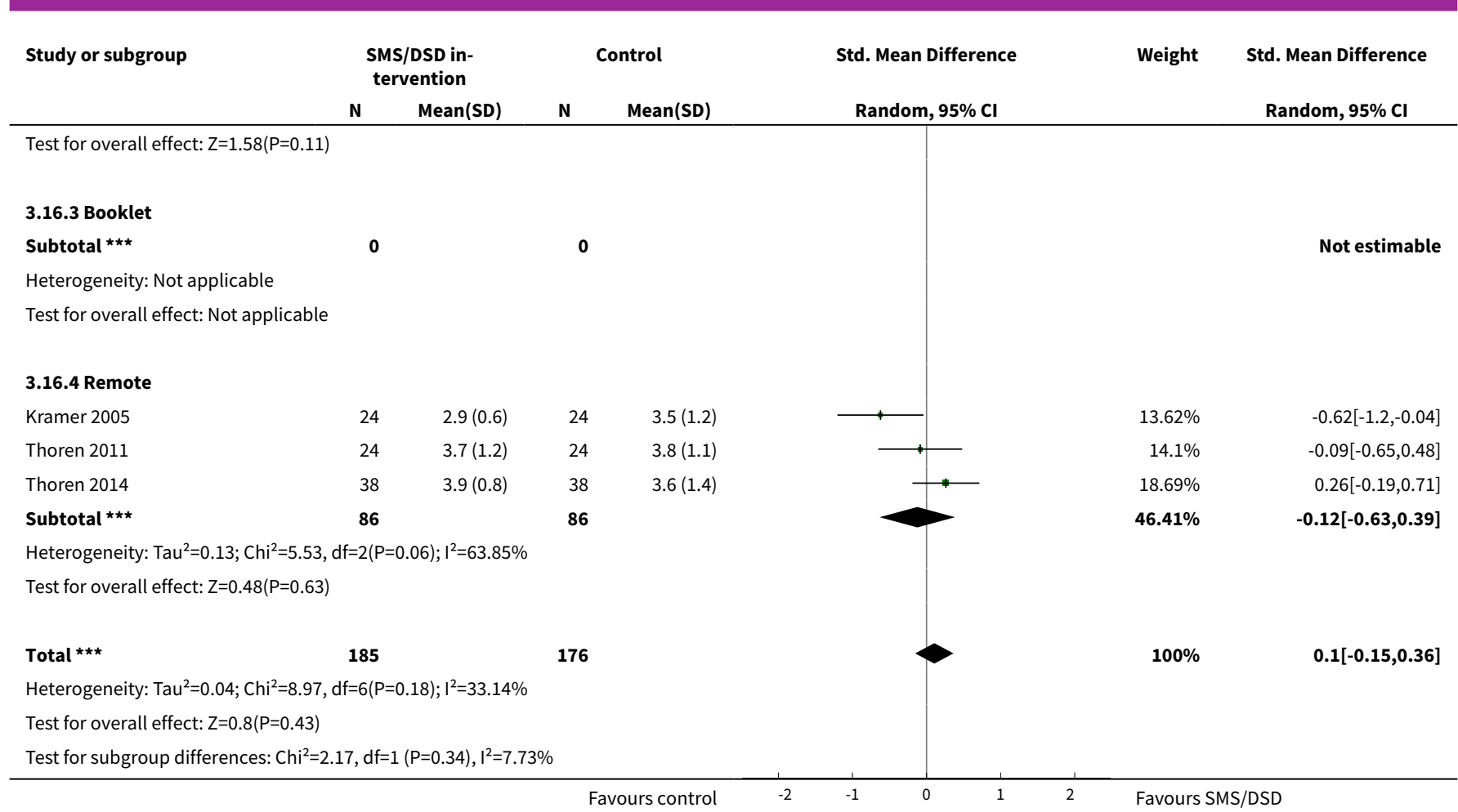

Analysis 3.17. Comparison 3 Combined SMS/DSD interventions versus control, Outcome 17 Hearing aid benefit - short/medium-term - DSD intensity.

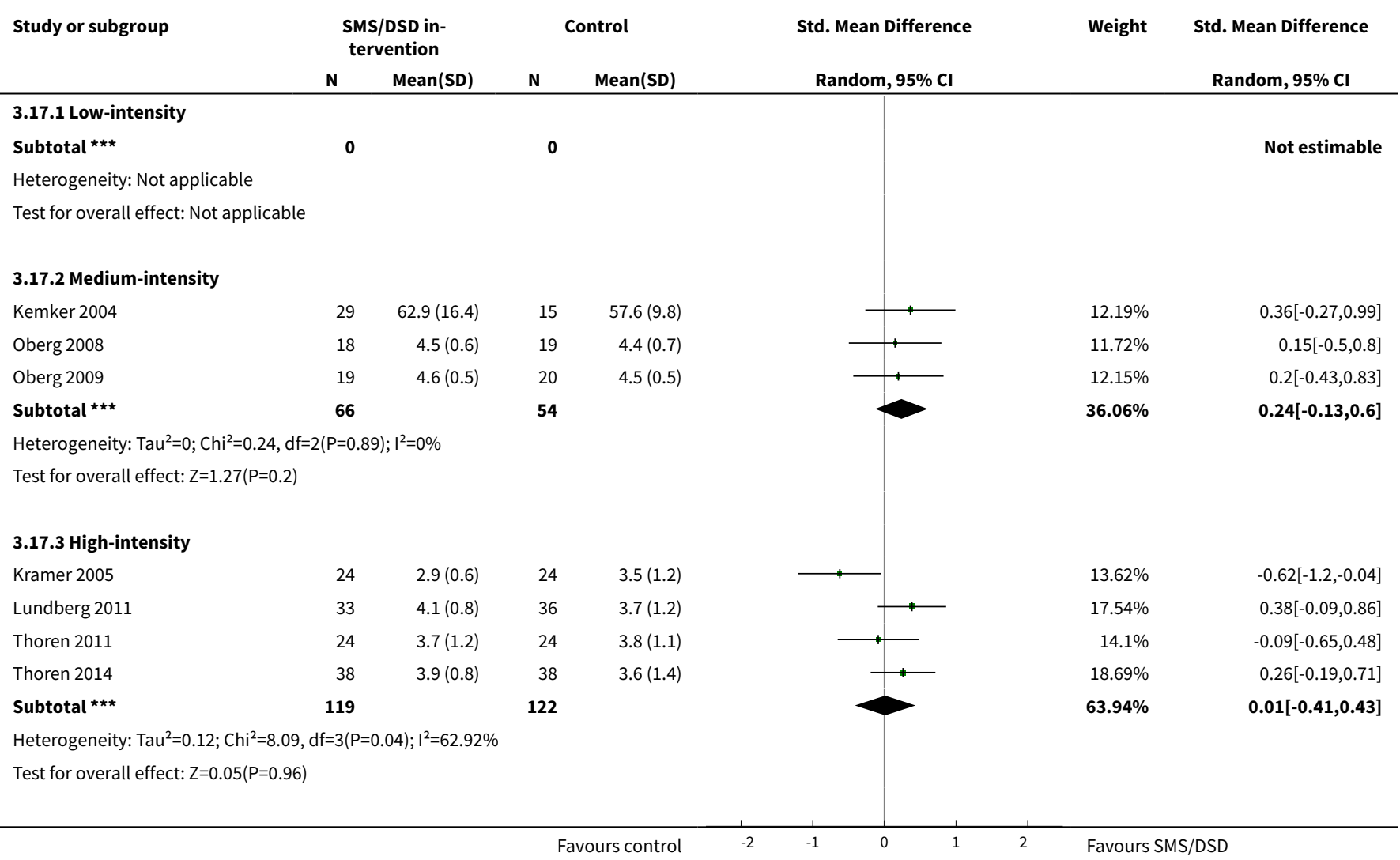




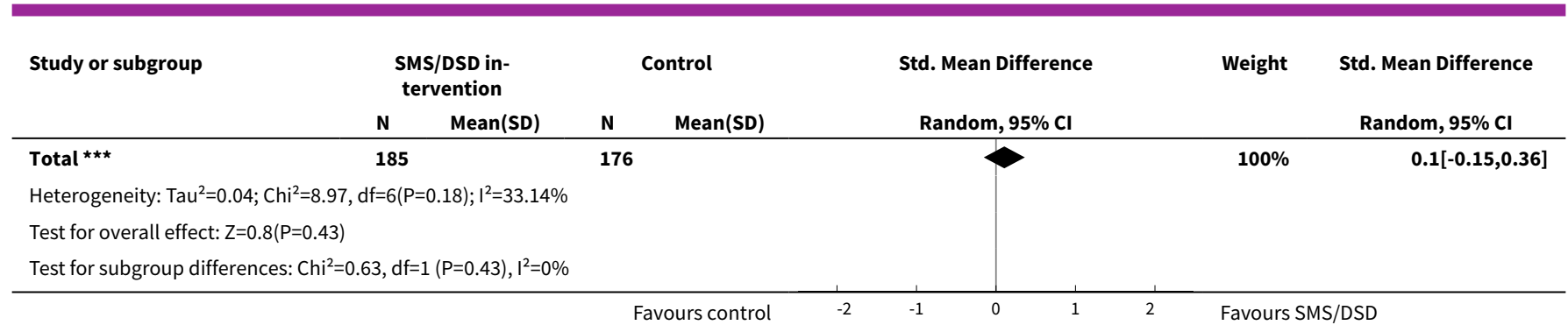

Analysis 3.18. Comparison 3 Combined SMS/DSD interventions versus control, Outcome 18 Use of verbal communication strategy - long-term.

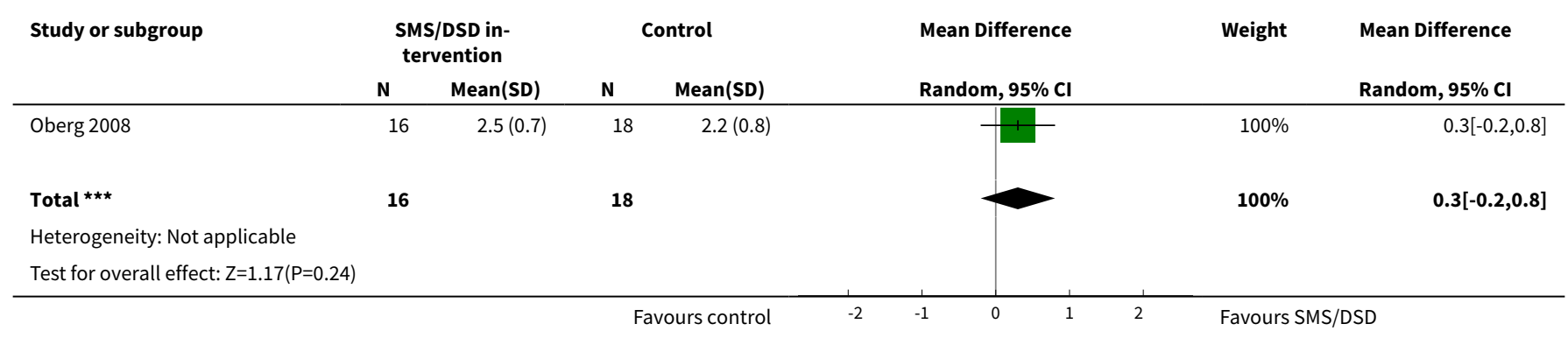

Analysis 3.19. Comparison 3 Combined SMS/DSD interventions versus control, Outcome 19 Use of verbal communication strategy - short/medium-term - SMS content.

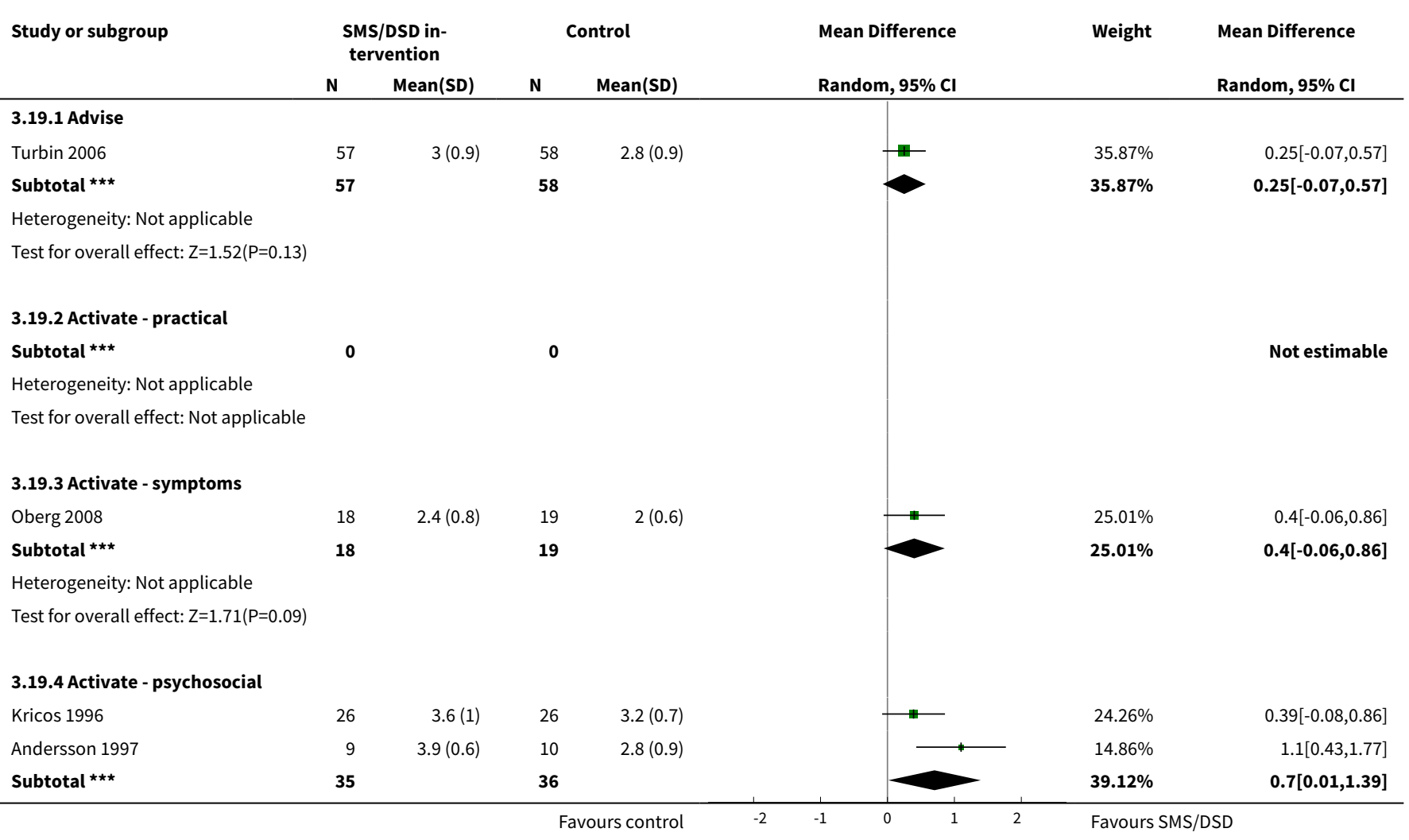




\begin{tabular}{|c|c|c|c|c|c|c|c|}
\hline \multirow[t]{2}{*}{ Study or subgroup } & \multicolumn{2}{|c|}{$\begin{array}{c}\text { SMS/DSD in- } \\
\text { tervention }\end{array}$} & \multicolumn{2}{|c|}{ Control } & \multirow{2}{*}{$\begin{array}{l}\text { Mean Difference } \\
\text { Random, } 95 \% \mathrm{Cl}\end{array}$} & \multirow[t]{2}{*}{ Weight } & \multirow{2}{*}{$\begin{array}{l}\text { Mean Difference } \\
\text { Random, } 95 \% \mathrm{Cl}\end{array}$} \\
\hline & $\mathbf{N}$ & $\operatorname{Mean}(S D)$ & $\mathbf{N}$ & Mean(SD) & & & \\
\hline \multicolumn{8}{|c|}{ Heterogeneity: $\mathrm{Tau}^{2}=0.17 ; \mathrm{Chi}^{2}=2.9, \mathrm{df}=1(\mathrm{P}=0.09) ; \mathrm{I}^{2}=65.49 \%$} \\
\hline Subtotal $\star \star \star$ & 0 & & 0 & & & & Not estimable \\
\hline \multicolumn{8}{|c|}{ Heterogeneity: Not applicable } \\
\hline \multicolumn{8}{|c|}{ Test for overall effect: Not applicable } \\
\hline \multicolumn{8}{|l|}{ 3.19.6 Agree } \\
\hline 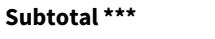 & 0 & & 0 & & & & Not estimable \\
\hline \multicolumn{8}{|c|}{ Heterogeneity: Not applicable } \\
\hline \multicolumn{8}{|c|}{ Test for overall effect: Not applicable } \\
\hline Total $\star \star \star$ & 110 & & 113 & & & $100 \%$ & $0.45[0.15,0.74]$ \\
\hline \multicolumn{8}{|c|}{ Heterogeneity: $\mathrm{Tau}^{2}=0.04 ; \mathrm{Chi}^{2}=5.04, \mathrm{df}=3(\mathrm{P}=0.17) ; \mathrm{I}^{2}=40.42 \%$} \\
\hline \multicolumn{8}{|c|}{ Test for overall effect: $Z=2.97(P=0)$} \\
\hline Test for subgroup dif & 42, $\mathrm{df}=$ & $P=0.49), I^{2}=0$ & & & & & \\
\hline
\end{tabular}

Analysis 3.20. Comparison 3 Combined SMS/DSD interventions versus control, Outcome 20 Use of verbal communication strategy - short/medium-term - DSD intensity.

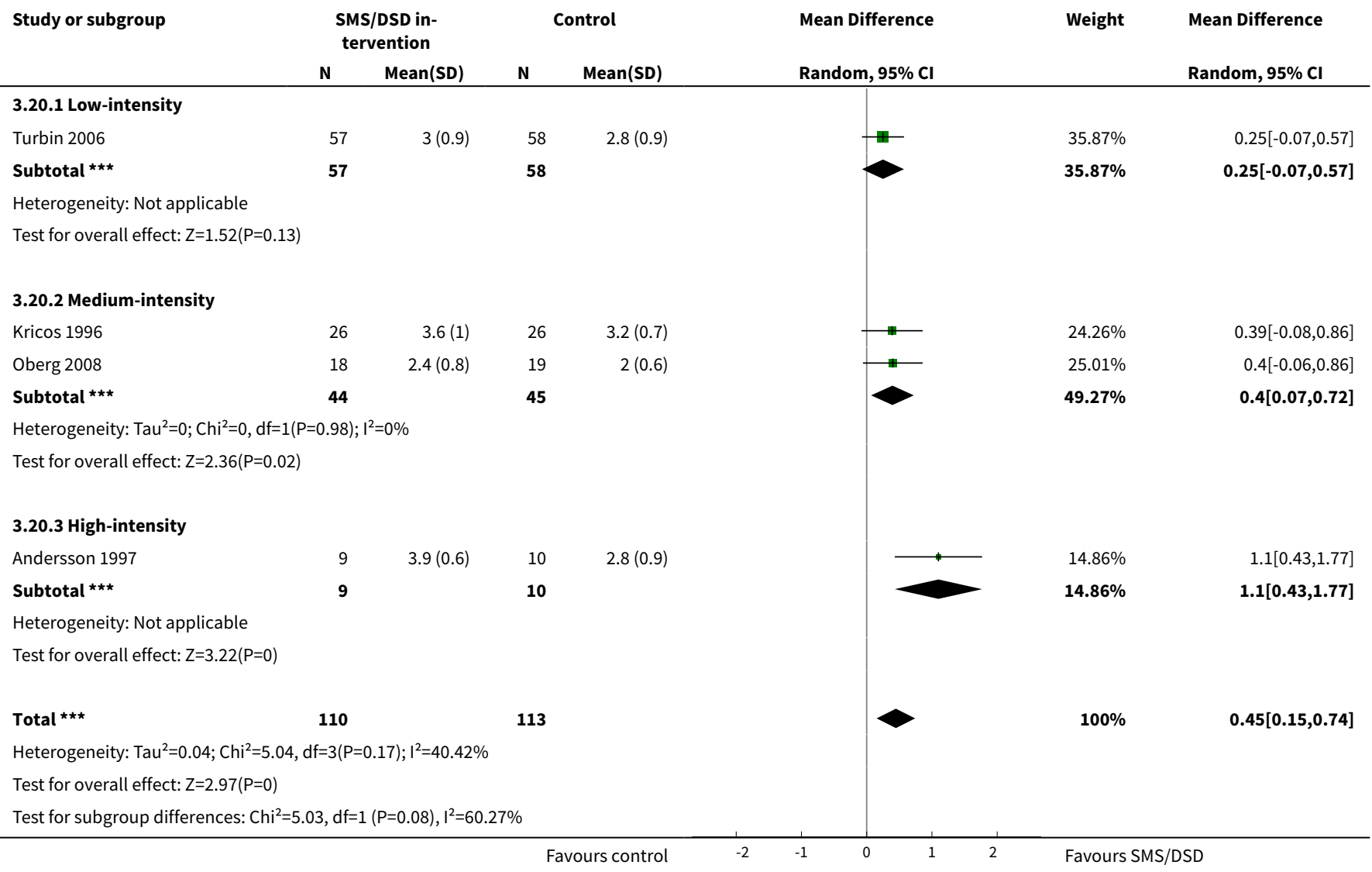




\begin{tabular}{|c|c|c|c|c|c|c|c|c|c|c|}
\hline 它 & $\begin{array}{l}\text { A D D I T I O N } \\
\text { Table 1. Inte }\end{array}$ & $\begin{array}{l}\text { A L T A B L E } \\
\text { vention rang }\end{array}$ & and type & & & & & & & \\
\hline 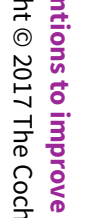 & $\begin{array}{l}\text { CCM ele- } \\
\text { ment }\end{array}$ & $\begin{array}{l}\text { Study refer- } \\
\text { ence }\end{array}$ & Hearing healthcare intervention & $\begin{array}{l}\text { Control in- } \\
\text { tervention }\end{array}$ & $\begin{array}{l}\text { Self-man- } \\
\text { agement } \\
\text { support } \\
\text { (SMS) sub- } \\
\text { type }\end{array}$ & $\begin{array}{l}\text { Delivery } \\
\text { system de- } \\
\text { sign (DSD) } \\
\text { format }\end{array}$ & $\begin{array}{l}\text { Delivery } \\
\text { system de- } \\
\text { sign (DSD) } \\
\text { intensity }\end{array}$ & $\begin{array}{l}\text { Delivery } \\
\text { system de- } \\
\text { sign (DSD) } \\
\text { mode }\end{array}$ & $\begin{array}{l}\text { Sub- } \\
\text { group(s) } \\
\text { compared }\end{array}$ & 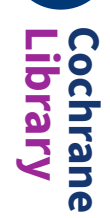 \\
\hline 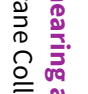 & $\begin{array}{l}\text { Health sys- } \\
\text { tem }\end{array}$ & None found & - & & & & & & & 罾点 \\
\hline 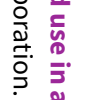 & $\begin{array}{l}\text { Community } \\
\text { resources }\end{array}$ & None found & & & & & & & & 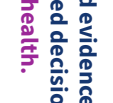 \\
\hline 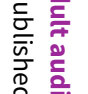 & $\begin{array}{l}\text { Decision } \\
\text { support }\end{array}$ & None found & & & & & & & & \\
\hline 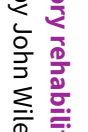 & $\begin{array}{l}\text { Clinical in- } \\
\text { formation } \\
\text { system }\end{array}$ & None found & & & & & & & & \\
\hline 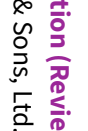 & $\begin{array}{l}\text { Delivery sys- } \\
\text { tem design }\end{array}$ & $\begin{array}{l}\text { Campos } \\
2013\end{array}$ & Remote online fitting & $\begin{array}{l}\text { Face-to-face } \\
\text { fitting }\end{array}$ & $\begin{array}{l}\text { Activate - } \\
\text { practical }\end{array}$ & $\begin{array}{l}\text { Remote (on- } \\
\text { line) versus } \\
\text { face-to-face }\end{array}$ & Low & Individual & DSD format & \\
\hline & & Cherry 1994 & $\begin{array}{l}\text { Telephone follow-up at } 6,9 \text { and } 12 \text { weeks } \\
\text { post-fitting - questions answered, trou- } \\
\text { ble-shooting and counselling }\end{array}$ & $\begin{array}{l}\text { Face-to-face } \\
\text { follow-up } \\
\text { on request }\end{array}$ & $\begin{array}{l}\text { Activate - } \\
\text { symptom }\end{array}$ & $\begin{array}{l}\text { Telephone } \\
\text { versus face- } \\
\text { to-face }\end{array}$ & $\begin{array}{l}\text { Medium ver- } \\
\text { sus low }\end{array}$ & Individual & $\begin{array}{l}\text { DSD format } \\
\text { and intensi- } \\
\text { ty }\end{array}$ & \\
\hline & & Collins 2013 & $\begin{array}{l}\text { 60-minute group orientation with PowerPoint } \\
\text { presentation covering use, care and mainte- } \\
\text { nance of the hearing aid }\end{array}$ & $\begin{array}{l}\text { 30-minute } \\
\text { individual } \\
\text { orientation } \\
\text { with hand- } \\
\text { out of same } \\
\text { PowerPoint } \\
\text { presenta- } \\
\text { tion }\end{array}$ & Advise & Face-to-face & Low & $\begin{array}{l}\text { Group ver- } \\
\text { sus individ- } \\
\text { ual }\end{array}$ & DSD mode & 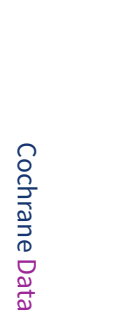 \\
\hline & & $\begin{array}{l}\text { Cunning- } \\
\text { ham } 2001\end{array}$ & $\begin{array}{l}\text { As many post-fitting adjustments as patients } \\
\text { requested }\end{array}$ & $\begin{array}{l}\text { No post-fit- } \\
\text { ting adjust- } \\
\text { ments }\end{array}$ & $\begin{array}{l}\text { Activate - } \\
\text { symptom }\end{array}$ & Face-to-face & $\begin{array}{l}\text { Medium ver- } \\
\text { sus low }\end{array}$ & Individual & $\begin{array}{l}\text { DSD intensi- } \\
\text { ty }\end{array}$ & 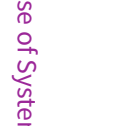 \\
\hline 5 & & Lavie 2014 & Simultaneous binaural fitting & $\begin{array}{l}\text { Sequential } \\
\text { binaural fit- } \\
\text { ting }\end{array}$ & $\begin{array}{l}\text { Activate - } \\
\text { practical }\end{array}$ & $\begin{array}{l}\text { Face-to-face } \\
\text { but simulta- } \\
\text { neous ver- }\end{array}$ & Low & Individual & DSD format & 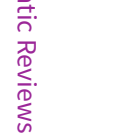 \\
\hline
\end{tabular}




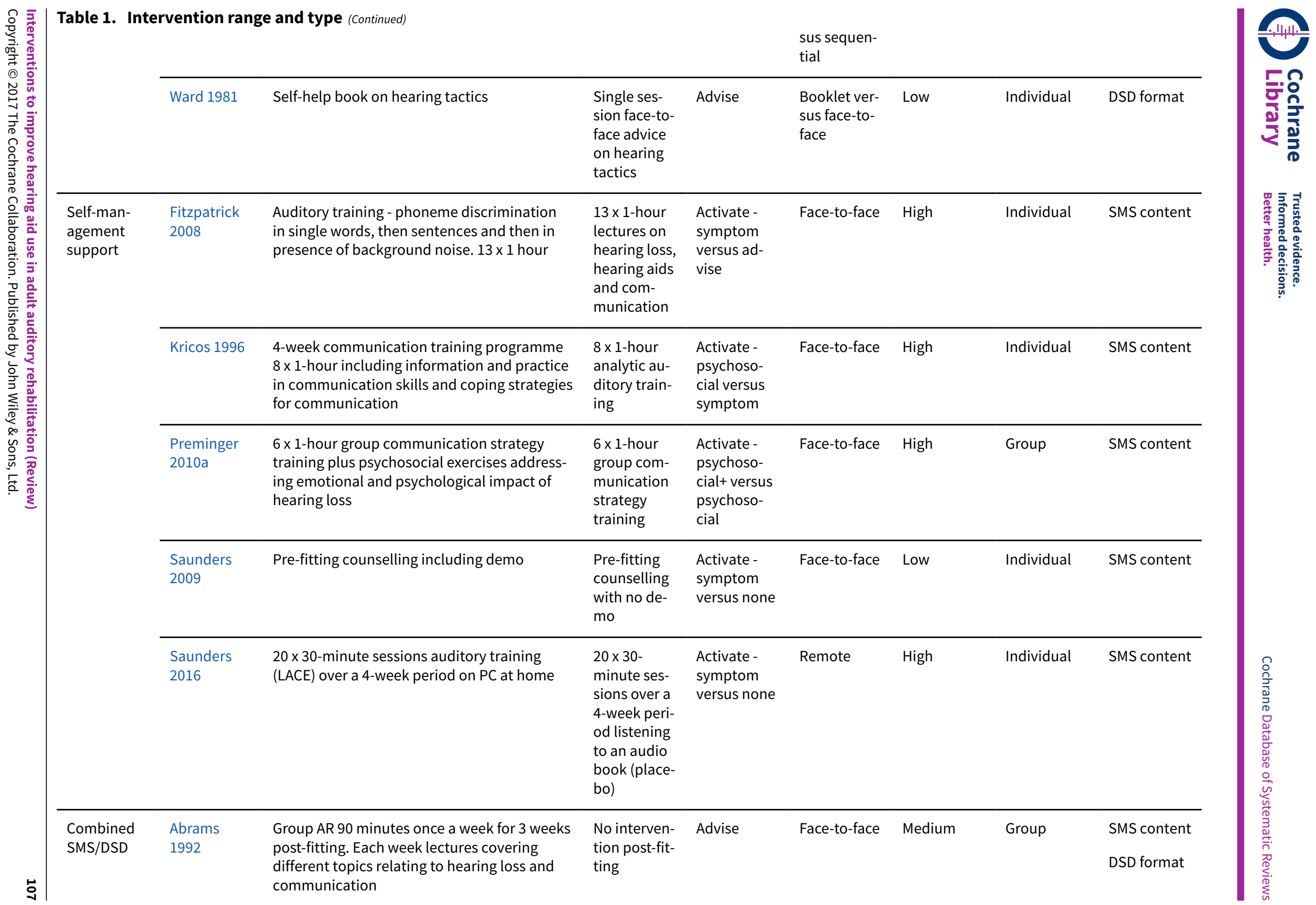




\begin{tabular}{|c|c|c|c|c|c|c|c|c|}
\hline \multirow{9}{*}{\multicolumn{2}{|c|}{ 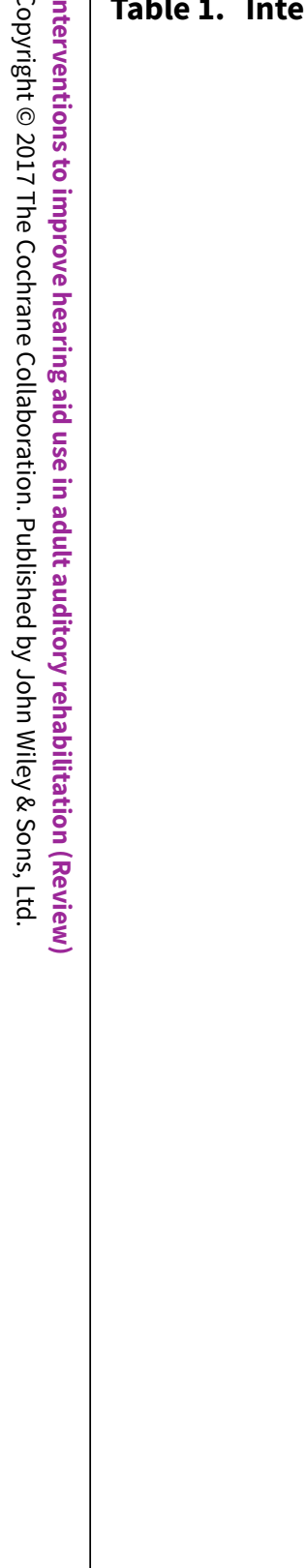 }} & & & & & & & $\begin{array}{l}\text { DSD intensi- } \\
\text { ty } \\
\text { DSD mode }\end{array}$ \\
\hline & & $\begin{array}{l}\text { 60-minute individual behavioural counselling } \\
\text { session then } 3 \text { consecutive weeks of group or } \\
\text { individual sessions where hearing tactics and } \\
\text { coping strategies were taught and practised }\end{array}$ & $\begin{array}{l}\text { No interven- } \\
\text { tion post-fit- } \\
\text { ting }\end{array}$ & $\begin{array}{l}\text { Activate - } \\
\text { psychoso- } \\
\text { cial }\end{array}$ & Face-to-face & Medium & $\begin{array}{l}\text { Group or In- } \\
\text { dividual }\end{array}$ & $\begin{array}{l}\text { SMS content } \\
\text { DSD format } \\
\text { DSD intensi- } \\
\text { ty } \\
\text { DSD mode }\end{array}$ \\
\hline & & $\begin{array}{l}\text { 60-minute individual behavioural counselling } \\
\text { session then } 4 \times 2 \text {-hour sessions including } \\
\text { video feedback on role play, applied relax- } \\
\text { ation, information and homework }\end{array}$ & $\begin{array}{l}\text { No interven- } \\
\text { tion }\end{array}$ & $\begin{array}{l}\text { Activate - } \\
\text { psychoso- } \\
\text { cial }\end{array}$ & Face-to-face & High & Individual & $\begin{array}{l}\text { SMS content } \\
\text { DSD format } \\
\text { DSD intensi- } \\
\text { ty }\end{array}$ \\
\hline & & $\begin{array}{l}\text { Self-help manual supplied with 1-hour face- } \\
\text { to-face training session including relaxation } \\
\text { training followed by telephone contact over } 4 \\
\text { consecutive weeks }\end{array}$ & $\begin{array}{l}\text { No interven- } \\
\text { tion }\end{array}$ & $\begin{array}{l}\text { Activate - } \\
\text { psychoso- } \\
\text { cial }\end{array}$ & Face-to-face & High & Individual & $\begin{array}{l}\text { SMS content } \\
\text { DSD intensi- } \\
\text { ty }\end{array}$ \\
\hline & & $\begin{array}{l}\text { 4-week communication course - information } \\
\text { and discussion regarding hearing loss, hear- } \\
\text { ing aids and communication }\end{array}$ & $\begin{array}{l}\text { No interven- } \\
\text { tion }\end{array}$ & Advise & Face-to-face & Medium & $\begin{array}{l}\text { Group ver- } \\
\text { sus individ- } \\
\text { ual }\end{array}$ & $\begin{array}{l}\text { SMS content } \\
\text { DSD intensi- } \\
\text { ty }\end{array}$ \\
\hline & & & & & & & & DSD mode \\
\hline & & $\begin{array}{l}\text { 4-week course AR - } 2 \text { hours per week with lec- } \\
\text { tures covering different aspects relating to } \\
\text { hearing loss and communication }\end{array}$ & $\begin{array}{l}\text { No interven- } \\
\text { tion }\end{array}$ & Advise & Face-to-face & Medium & $\begin{array}{l}\text { Group ver- } \\
\text { sus Individ- } \\
\text { ual }\end{array}$ & $\begin{array}{l}\text { SMS content } \\
\text { DSD intensi- } \\
\text { ty }\end{array}$ \\
\hline & & & & & & & & DSD mode \\
\hline & & $\begin{array}{l}5 \text { visits including fitting - structured guidance, } \\
\text { use of diary with specific homework tasks, re- } \\
\text { stricted HA use during first month }\end{array}$ & $\begin{array}{l}\text { Standard fit- } \\
\text { ting }\end{array}$ & $\begin{array}{l}\text { Activate - } \\
\text { psychoso- } \\
\text { cial }\end{array}$ & Face-to-face & High & Individual & $\begin{array}{l}\text { SMS content } \\
\text { DSD intensi- } \\
\text { ty }\end{array}$ \\
\hline
\end{tabular}




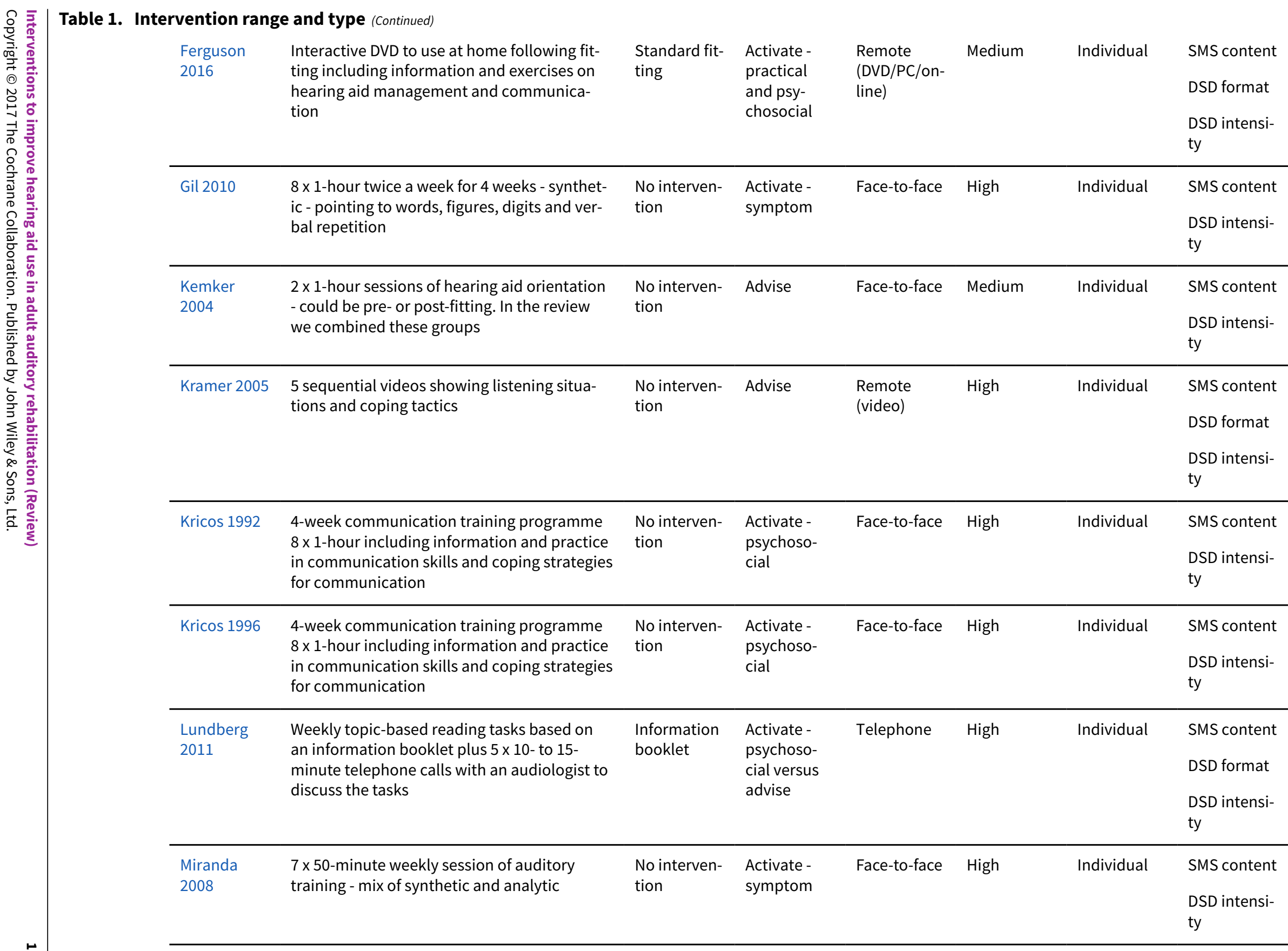


Table 1. Intervention range and type (Continued)

Oberg 2008 Pre-fitting sound awareness training. 3 visits with different listening exercises. 1 visit with out amplification and 2 with an experimental adjustable aid

Oberg 2009 Pre-fitting use of an experimental adjustable hearing aid - 3 clinic visits to adjust the aid a week apart and experience at home in between

Olson $201320 \times 30$-minute sessions at home over 4 weeks using interactive DVD delivering synthetic auditory tasks
No interven- Activate - Face-to-face Medium Individual SMS content tion symptom

DSD intensi-

ty

\begin{tabular}{llllll}
$\begin{array}{l}\text { No interven- } \\
\text { tion }\end{array}$ & $\begin{array}{l}\text { Activate - } \\
\text { symptom }\end{array}$ & Face-to-face & Medium & Individual & $\begin{array}{l}\text { SMS content } \\
\text { DSD intensi- } \\
\text { ty }\end{array}$ \\
\hline $\begin{array}{l}\text { No interven- } \\
\text { tion }\end{array}$ & $\begin{array}{l}\text { Activate - } \\
\text { symptom }\end{array}$ & $\begin{array}{l}\text { Remote } \\
\text { (DVD) }\end{array}$ & High & Individual & SMS content \\
& & & DSD format
\end{tabular}

DSD intensity

\begin{tabular}{|c|c|c|c|c|c|c|c|}
\hline $\begin{array}{l}\text { Preminger } \\
2008\end{array}$ & $\begin{array}{l}6 \times 1 \text {-hour speech training classes including } \\
\text { auditory and audiovisual analytic and syn- } \\
\text { thetic tasks }\end{array}$ & $\begin{array}{l}\text { No interven- } \\
\text { tion }\end{array}$ & $\begin{array}{l}\text { Activate - } \\
\text { symptom }\end{array}$ & Face-to-face & High & $\begin{array}{l}\text { Group ver- } \\
\text { sus None }\end{array}$ & $\begin{array}{l}\text { SMS content } \\
\text { DSD intensi- } \\
\text { ty } \\
\text { DSD mode }\end{array}$ \\
\hline $\begin{array}{l}\text { Preminger } \\
2010\end{array}$ & $\begin{array}{l}\text { Group AR plus separate group for SPs } 4 \times 90 \\
\text { minutes }\end{array}$ & $\begin{array}{l}\text { Group AR } \\
\text { without } \\
\text { group for } \\
\text { SPs }\end{array}$ & Advise & Face-to-face & Medium & Group & $\begin{array}{l}\text { SMS content } \\
\text { DSD intensi- } \\
\text { ty }\end{array}$ \\
\hline $\begin{array}{l}\text { Saunders } \\
2016\end{array}$ & $\begin{array}{l}10 \times 30 \text {-minute auditory training sessions de- } \\
\text { livered by DVD at home over a } 2 \text {-week period } \\
\text { OR } \\
20 \times 30 \text {-minute auditory training sessions de- } \\
\text { livered by PC at home over a 4-week period }\end{array}$ & $\begin{array}{l}\text { No interven- } \\
\text { tion }\end{array}$ & $\begin{array}{l}\text { Activate - } \\
\text { symptom }\end{array}$ & $\begin{array}{l}\text { Remote } \\
\text { (DVD or PC } \\
\text { based) }\end{array}$ & High & Individual & $\begin{array}{l}\text { SMS content } \\
\text { DSD intensi- } \\
\text { ty }\end{array}$ \\
\hline $\begin{array}{l}\text { Smaldino } \\
1988\end{array}$ & $\begin{array}{l}4 \text { sessions of rehabilitation including infor- } \\
\text { mation on hearing and hearing aids, practice } \\
\text { and problem-solving regarding communica- } \\
\text { tion and role play }\end{array}$ & $\begin{array}{l}\text { No interven- } \\
\text { tion }\end{array}$ & $\begin{array}{l}\text { Activate - } \\
\text { psychoso- } \\
\text { cial }\end{array}$ & $\begin{array}{l}\text { Remote (PC- } \\
\text { based) }\end{array}$ & Medium & Individual & $\begin{array}{l}\text { SMS content } \\
\text { DSD intensi- } \\
\text { ty }\end{array}$ \\
\hline $\begin{array}{l}\text { Sweetow } \\
2006\end{array}$ & $\begin{array}{l}30 \text { minutes } 5 \text { days a week for } 4 \text { weeks at home } \\
\text { analytic and synthetic auditory training, in- } \\
\text { formation on communication strategies }\end{array}$ & $\begin{array}{l}\text { No interven- } \\
\text { tion }\end{array}$ & $\begin{array}{l}\text { Activate - } \\
\text { symptom }\end{array}$ & $\begin{array}{l}\text { Remote (PC- } \\
\text { based) }\end{array}$ & High & Individual & $\begin{array}{l}\text { SMS content } \\
\text { DSD format }\end{array}$ \\
\hline
\end{tabular}


Table 1. Intervention range and type (Continued)

DSD intensi-

ty

\begin{tabular}{|c|c|c|c|c|c|c|c|}
\hline Thoren 2011 & $\begin{array}{l}\text { 5-week online education programme includ- } \\
\text { ing information, tasks assignments and pro- } \\
\text { fessional contact via email }\end{array}$ & $\begin{array}{l}\text { Online dis- } \\
\text { cussion fo- } \\
\text { rum with } 5 \\
\text { weekly top- } \\
\text { ics but no } \\
\text { task assign- } \\
\text { ments and } \\
\text { no profes- } \\
\text { sional guid- } \\
\text { ance }\end{array}$ & $\begin{array}{l}\text { Advise ver- } \\
\text { sus Activate } \\
\text { - psychoso- } \\
\text { cial }\end{array}$ & $\begin{array}{l}\text { Remote } \\
\text { (email fol- } \\
\text { low-up) }\end{array}$ & High & Individual & $\begin{array}{l}\text { SMS content } \\
\text { DSD format } \\
\text { DSD intensi- } \\
\text { ty }\end{array}$ \\
\hline Thoren 2014 & $\begin{array}{l}\text { 5-week online rehabilitation programme in- } \\
\text { cluding self-study, training and professional } \\
\text { coaching in hearing physiology, hearing aids, } \\
\text { and communication strategies as well as on- } \\
\text { line contact with peers }\end{array}$ & $\begin{array}{l}\text { No interven- } \\
\text { tion }\end{array}$ & $\begin{array}{l}\text { Activate - } \\
\text { psychoso- } \\
\text { cial }\end{array}$ & Remote & High & Individual & $\begin{array}{l}\text { SMS content } \\
\text { DSD format } \\
\text { DSD intensi- } \\
\text { ty }\end{array}$ \\
\hline Turbin 2006 & Single session of group AR - length not clear & $\begin{array}{l}\text { No interven- } \\
\text { tion }\end{array}$ & Advise & Face-to-face & Low & $\begin{array}{l}\text { Group ver- } \\
\text { sus Individ- } \\
\text { ual }\end{array}$ & $\begin{array}{l}\text { SMS content } \\
\text { DSD intensi- } \\
\text { ty } \\
\text { DSD mode }\end{array}$ \\
\hline $\begin{array}{l}\text { Vreeken } \\
2015\end{array}$ & $\begin{array}{l}\text { Weekly home visits for } 3 \text { to } 5 \text { weeks. Partici- } \\
\text { pants received a handbook with background } \\
\text { information and a checklist accompanied } \\
\text { with exercises covering: hearing aid use, } \\
\text { maintenance and handling; living environ- } \\
\text { ment; hearing assistive devices; communica- } \\
\text { tion strategies }\end{array}$ & $\begin{array}{l}\text { No interven- } \\
\text { tion }\end{array}$ & $\begin{array}{l}\text { Activate - } \\
\text { psychoso- } \\
\text { cial }\end{array}$ & $\begin{array}{l}\text { Face-to-face } \\
\text { plus booklet }\end{array}$ & High & Individual & $\begin{array}{l}\text { SMS content } \\
\text { DSD format } \\
\text { DSD intensi- } \\
\text { ty }\end{array}$ \\
\hline Ward 1978 & $\begin{array}{l}2 \text { treatment groups }-1 \text { received } 2 \times 2 \text {-hour AR } \\
\text { sessions, the other } 4 \times 2 \text {-hour sessions. Ses- } \\
\text { sions including physical practice with aids } \\
\text { and communication advice and practice. Also } \\
\text { psychosocial aspects }\end{array}$ & $\begin{array}{l}\text { No interven- } \\
\text { tion }\end{array}$ & $\begin{array}{l}\text { Activate - } \\
\text { psychoso- } \\
\text { cial }\end{array}$ & Face-to-face & Medium & Group & $\begin{array}{l}\text { SMS content } \\
\text { DSD intensi- } \\
\text { ty } \\
\text { DSD mode }\end{array}$ \\
\hline Ward 1981 & Self-help book on hearing tactics & $\begin{array}{l}\text { No interven- } \\
\text { tion }\end{array}$ & Advise & Booklet & Low & Individual & $\begin{array}{l}\text { SMS content } \\
\text { DSD format }\end{array}$ \\
\hline
\end{tabular}




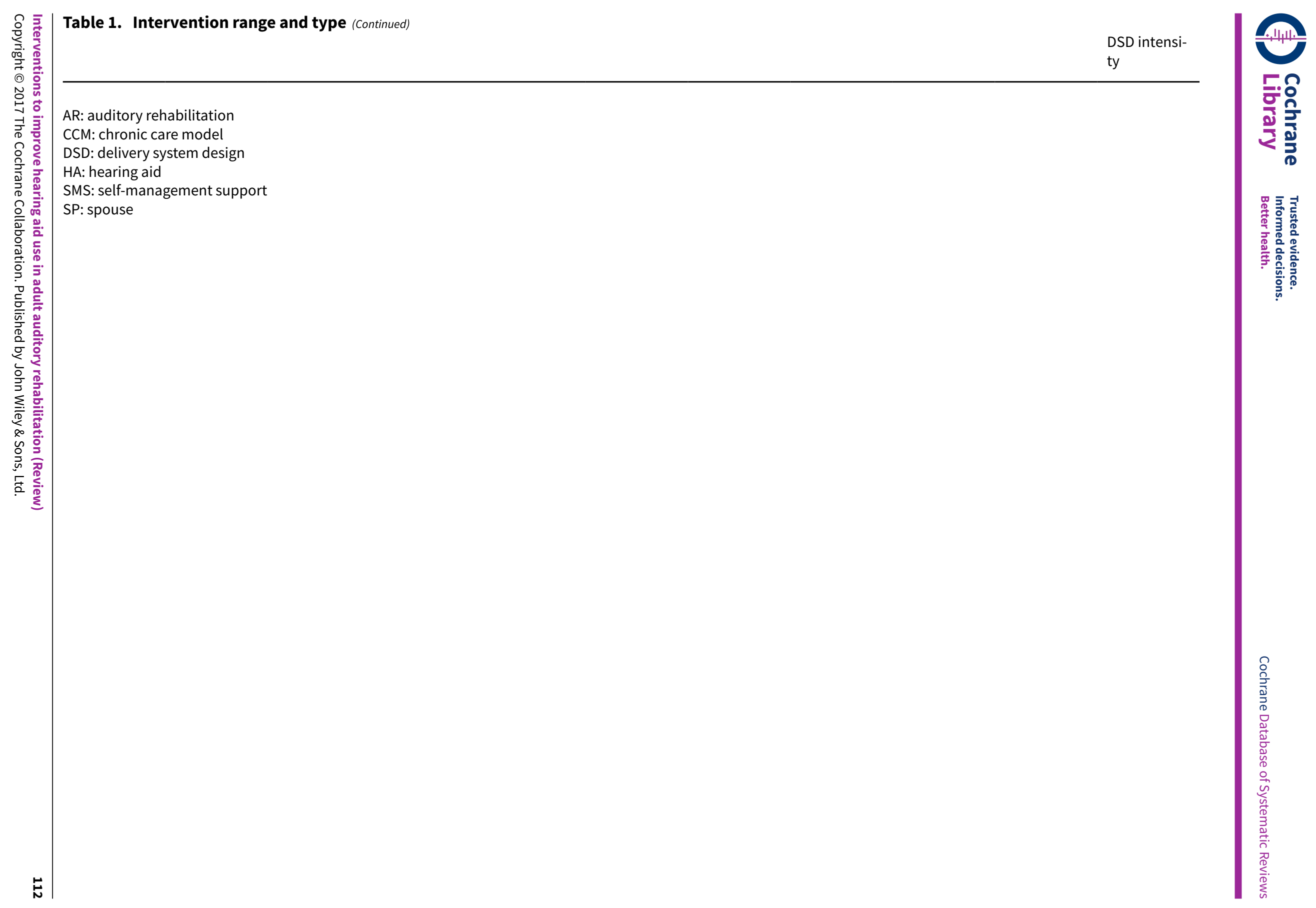




\section{AP PEN DICES}

\section{Appendix 1. Search strategy}

\begin{tabular}{|c|c|c|c|}
\hline CENTRAL & PubMed & EMBASE (Ovid) & CINAHL (EBSCO) \\
\hline \#1 MeSH descriptor: [Hearing Loss] ex- & \#1 Search "Hearing Loss"[Mesh] & 1. exp he & S1 (MH "Deaf- \\
\hline plode all trees & & ment/ & $\begin{array}{l}\text { ness+") OR (MH } \\
\text { "Hearing Loss, Par- }\end{array}$ \\
\hline \#2 MeSH descriptor: [Hearing Impaired & sons"[Mesh] & 2. (hearing adj (loss or im- & tial+") \\
\hline Persons] explode all trees & $\begin{array}{l}\text { \#3 Search ("hearing loss" OR "hear- } \\
\text { ing impair*") }\end{array}$ & pair* & $\begin{array}{l}\text { S2 TX "hearing } \\
\text { loss" or "hearing }\end{array}$ \\
\hline \#3 hearing near (loss or impair) & & $\begin{array}{l}\text { 3. (Hypoacusis or Hypoa- } \\
\text { cuses).tw. }\end{array}$ & $\begin{array}{l}\text { impair*" } \\
\text { S3 TX Hypoacusis }\end{array}$ \\
\hline \#4 Hypoacusis or Hypoacuses & $\begin{array}{l}\text { \#4 Search (Hypoacusis or Hypoacus- } \\
\text { es) }\end{array}$ & 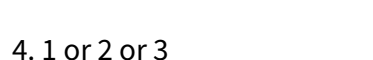 & or Hypoacuses \\
\hline$\# 5 \# 1$ or \#2 or \#3 or \#4 & & 4.16 & S4 S1 OR S2 OR S3 \\
\hline & \#5 Search (\#1 OR \#2 OR \#3 OR \#4) & 5. exp adult/ & S5 (MH "Adult+") \\
\hline trees & \#6 Search "Adult"[Mesh] & $\begin{array}{l}\text { 6. (older or elderly or aged } \\
\text { or aging or "middle age*" }\end{array}$ & $\begin{array}{l}\text { S6 TX older or el- } \\
\text { derly or aged or } \\
\text { aging or "middle }\end{array}$ \\
\hline $\begin{array}{l}\# 7 \text { older or elderly or aged or aging or } \\
\text { "middle age*" or "age related" or ac- } \\
\text { quir* or adult* }\end{array}$ & $\begin{array}{l}\text { \#7 Search (older or elderly or aged } \\
\text { or aging or "middle age*" or "age re- } \\
\text { lated" or acquir" or adult") }\end{array}$ & $\begin{array}{l}\text { or "age related" or acquir* } \\
\text { or adult*).tw. }\end{array}$ & $\begin{array}{l}\text { age*" or "age relat- } \\
\text { ed" or acquir* or } \\
\text { adult* }\end{array}$ \\
\hline \#8 \#6 or \#7 & \#8 Search (\#6 OR \#7) & 7.5 or 6 & S7 S5 OR S6 \\
\hline$\# 9$ \#5 and \#8 & \#9 Search (\#5 AND \#8) & 8.4 and 7 & $\begin{array}{l}\text { S8 S4 AND S7 } \\
\text { S9 (MH "Presbycu- }\end{array}$ \\
\hline \#10 MeSH descri & \#10 Search "Presbycusis"[Mesh] & 9. exp presbyacusis/ & sis") \\
\hline $\begin{array}{l}\text { plode all trees } \\
\text { \#11 Presbycusis or Presbycuses }\end{array}$ & $\begin{array}{l}\text { \#11 Search (Presbycusis or Presby- } \\
\text { cuses) }\end{array}$ & $\begin{array}{l}\text { 10. (Presbycusis or Presby- } \\
\text { cuses).tw. }\end{array}$ & $\begin{array}{l}\text { or Presbycuses } \\
\text { S11 S8 OR S9 OR } \\
\text { S10 }\end{array}$ \\
\hline$\# 12$ \#9 or \#10 or \#11 & \#12 (\#9 OR \#10 OR \#11) & 11.8 or 9 or 10 & $\begin{array}{l}\text { S12 (MH "Hearing } \\
\text { Aids") }\end{array}$ \\
\hline $\begin{array}{l}\text { \#13 MeSH descriptor: [Hearing Aids] this } \\
\text { term only }\end{array}$ & $\begin{array}{l}\text { \#13 Search "Hearing Aids"[Mesh:No- } \\
\text { Exp] }\end{array}$ & $\begin{array}{l}\text { 12. hearing aid/ } \\
\text { 13. exp prosthesis/ }\end{array}$ & $\begin{array}{l}\text { S13 (MH "Prosthet- } \\
\text { ic Fitting") } \\
\text { S14 TX "hear- }\end{array}$ \\
\hline $\begin{array}{l}\text { \#14 MeSH descriptor: [Prosthesis Fit- } \\
\text { ting] explode all trees }\end{array}$ & $\begin{array}{l}\text { \#14 Search "Prosthesis Fit- } \\
\text { ting"[Mesh] }\end{array}$ & 14. "hearing aid* ".tw. & $\begin{array}{l}\text { ing aid*" OR "ear } \\
\text { mold*" OR ear- }\end{array}$ \\
\hline \#15 "hearing aid*" & \#15 Search "hearing aid*" & $\begin{array}{l}\text { 15. ("hearing aid"*" or } \\
\text { "ear mold*" or earmold* } \\
\text { or "ear mould*" or ear- }\end{array}$ & $\begin{array}{l}\text { mold* OR "ear } \\
\text { mould*" OR ear- } \\
\text { mould* OR amplif* }\end{array}$ \\
\hline \#16 "ear mold*" or earmold* & $\begin{array}{l}\text { \#16 Search ("ear mold*" or ear- } \\
\text { mold* or "ear mould*" or earmould* }\end{array}$ & mould ${ }^{\star}$ or amplif*).tw. & $\begin{array}{l}\text { S15 S12 OR S13 OR } \\
\text { S14 }\end{array}$ \\
\hline \#17 "ear mould*" or earmould* & or amplif*) & 16. 12 or 13 or 14 or 15 & S16 S11 AND S15 \\
\hline \#18 amplif* & \#17 (\#13 OR \#14 OR \#15 OR \#16) & 17. 11 and 16 & $\begin{array}{l}\text { S17 (MH "Health } \\
\text { Behavior") }\end{array}$ \\
\hline $\begin{array}{l}\# 19 \# 13 \text { or \#14 or \#15 or \#16 or \#17 or } \\
\# 18\end{array}$ & $\# 18$ (\#12 AND \#17) & 18. patient compliance/ & $\begin{array}{l}\text { S18 (MH "Patient } \\
\text { Compliance") }\end{array}$ \\
\hline$\# 20 \# 12$ and \#19 & $\begin{array}{l}\text { \#19 Search "Health Behav- } \\
\text { ior"[Mesh:NoExp] }\end{array}$ & 19. health behavior/ & $\begin{array}{l}\text { S19 (MH "Treat- } \\
\text { ment Refusal+") }\end{array}$ \\
\hline \#21 MeSH descriptor: [Health Behavior] & \#20 Search "Patient Compli- & 20. exp treatment refusal/ & $\begin{array}{l}\text { S20 (MH "Counsel- } \\
\text { ing") }\end{array}$ \\
\hline & ance"[Mesh:NoExp] & 21. exp patient attitude/ & S21 (MH "Patient \\
\hline $\begin{array}{l}\text { \#22 MeSH descriptor: [Patient Compli- } \\
\text { ance] this term only }\end{array}$ & $\begin{array}{l}\text { \#21 Search "Treatment Re- } \\
\text { fusal"[Mesh] }\end{array}$ & 22. counseling/ & $\begin{array}{l}\text { Education+") } \\
\text { S22 (MH "Audiolo- }\end{array}$ \\
\hline $\begin{array}{l}\text { \#23 MeSH descriptor: [Treatment Re- } \\
\text { fusal] explode all trees }\end{array}$ & $\begin{array}{l}\text { \#22 Search "Patient Acceptance of } \\
\text { Health Care"[Mesh] }\end{array}$ & 23. exp patient education/ & $\begin{array}{l}\text { gy/MT") } \\
\text { S23 (MH "Behavior } \\
\text { Therapy") }\end{array}$ \\
\hline
\end{tabular}


(Continued)

\#24 MeSH descriptor: [Patient Accep-

tance of Health Care] explode all trees

\#25 MeSH descriptor: [Counseling] this term only

\#26 MeSH descriptor: [Patient Education as Topic] explode all trees

\#27 MeSH descriptor: [Audiology] explode all trees and with qualifiers:

[Methods - MT]

\#28 MeSH descriptor: [Choice Behavior] this term only

\#29 MeSH descriptor: [Behavior Therapy] this term only

\#30 MeSH descriptor: [Behavioral Medicine] explode all trees

\#31 MeSH descriptor: [Adaptation, Psychological] explode all trees

\#32 (patient* or healthcare or "health care") and (compliance or cooperat* or co-operat* or adherence or "non-compliance" or noncompliance or "non-adherence" or nonadherence or accept ${ }^{\star}$ or nonaccept ${ }^{\star}$ or behaviour or behavior)

\#33 Any MeSH descriptor with qualifier(s): [Psychology - PX, Rehabilitation $\mathrm{RH}$, Utilization - UT]

\#34 educat * or train* or counsel* or "self manag*" or "management plan*" or "care plan" or "support tool ${ }^{\star *}$ or "chronic care mode" or ccm or promot* or psycholog* or psychosocial or teach ${ }^{\star}$ or motivat* or prefitting or Postfitting or "fitting protocol" or ghabp or "hearing aid orientat*" or HAO or "pre-fitting" or "post-fitting" or ((audio* or aural or auditory) near rehab*) or "hearing tactic*" or "active fitting"

\#35 ("take up" or "take-up" or use or utilis* or utiliz* or "non-use") and \#19

\#36 \#21 or \#23 or \#22 or \#24 or \#25 or \#26 or \#27 or \#28 or \#29 or \#30 or \#31 or \#32 or \#33 or \#34 or \#35

\section{\#37 \#36 and \#20}

\#38 MeSH descriptor: [Hearing Aids] explode all trees and with qualifiers: [Utilization - UT, Therapy - TH, Psychology PX]

\#39 \#37 or \#38
\#23 Search "Counseling"[Mesh:NoExp]

\#24 Search "Patient Education as Topic"[Mesh]

\#25 Search "Audiology/methods"[Mesh]

\#26 Search "Choice Behavior"[Mesh:NoExp]

\#27 Search "Behavior Therapy"[Mesh:NoExp]

\#28 Search "Behavioral Medicine"[Mesh]

\#29 Search "Adaptation, Psychological"[Mesh]

\#30 Search ((patient* or healthcare or "health care") and (compliance or cooperat* or co-operat* or adherence or "non-compliance" or noncompliance or "non-adherence" or nonadherence or accept* or nonaccept* or behaviour or behavior))

\section{\#31 Search (PX OR RH OR UT[MeSH Subheading])}

\#32 Search (educat* or train* or counsel* or "self manag ${ }^{\star} "$ or "management plan*" or "care plan*" or "support tool*" or "chronic care mode" or ccm or promot* or psycholog* or psychosocial or teach * or motivat* or prefitting or Postfitting or "fitting protocol" or ghabp or "hearing aid orientat" or HAO or "pre-fitting" or "post-fitting" or "hearing tactic*" or "active fitting")

\#33 Search ("audio* rehab*" OR "aural rehab*" OR "auditory rehab*")

\#34 Search (("take up" or "take-up" or use or utilis* or utiliz* or "nonuse") AND \#26)

\#35 (\#19 OR \#20 OR \#21 OR \#22 OR \#23 OR \#24 OR \#25 OR \#26 OR \#28 OR \#29 OR \#30 OR \#31 OR \#32 OR \#33 OR \#34)

\section{\#36 (\#35 AND \#18)}

\#37 Search (("Hearing Aids/psychology"[Mesh] OR "Hearing Aids/utilization"[Mesh]))
25. exp behavioral medicine/

26. exp adaptive behavior/

27. ((patient ${ }^{\star}$ or healthcare or "health care") and (compliance or cooperat* or co-operat* or adherence or "non-compliance" or noncompliance or "non-adherence" or nonadherence or accept* or nonaccept ${ }^{\star}$ or behaviour or behavior)).tw.

28. (educat* or train* or counsel* or "self manag*" or "management plan*" or "care plan*" or "support tool*" or "chronic care mode" or ccm or promot $^{\star}$ or psycholog* or psychosocial or teach* or motivat* or prefitting or Postfitting or "fitting protocol" or ghabp or "hearing aid orientat*" or HAO or "prefitting" or "post-fitting" or ((audio* or aural or auditory) adj rehab*) or "hearing tactic*" or "active fitting").tw.

29. ("take up" or "take-up" or "use" or utilis* or utiliz* or "non-use").tw.

30.16 and 29

31.18 or 19 or 20 or 21 or 22 or 23 or 24 or 25 or 26 or 27 or 28 or 30

\section{17 and 31}

S24 (MH "Adaptation, Psychological+") S25 (MH "Patient Attitudes") S26 TX (patient* or healthcare or "health care") and (compliance or cooperat* $^{*}$ or co-operat* or adherence or "non-compliance" or noncompliance or "non-adherence" or nonadherence or accept ${ }^{\star}$ or nonaccept $^{\star}$ or behaviour or behavior) S27 TX educat* or train $^{\star}$ or counsel ${ }^{\star}$ or "self manag*" or "management plan*" or "care plan*" or "support tool ${ }^{*}$ or "chronic care mode" or ccm or promot ${ }^{\star}$ or psycholog* or psychosocial or teach* or motivat ${ }^{\star}$ or prefitting or Postfitting or "fitting protocol" or ghabp or "hearing aid orientat ${ }^{\star}$ or HAO or "pre-fitting" or "post-fitting" or "audio* rehab*" or "aural rehab*" or "auditory rehab*" or "hearing tactic*" or "active fitting" S28 TX ("take up" or "take-up" or use or utilis* or utiliz* or "non-use")

S29 S15 AND S28 S30 S17 OR S18 OR S19 OR S20 OR S21 OR S22 OR S23 OR S24 OR S25 OR S26 OR S27 OR S29 S31 S16 AND S30 


\section{CAB Abstracts (Ovid)}

\section{AMED (Ovid)}

\section{Web of Science (Web of Knowledge)}

Trial Registries

2. (hearing adj (loss or impair*)).tw.

3. (Hypoacusis or Hypoacuses).tw.

4. (Presbycusis or Presbycuses).tw.

5. 1 or 2 or 3 or 4

6. exp Hearing aids/

7. exp Prosthesis/

8. ("hearing aid*" or "ear mold*" or earmold" or "ear mould*" or earmould $^{\star}$ or amplif*).tw.

9. 6 or 7 or 8

10.5 and 9

11. exp Patient compliance/

12. exp Health behavior/

13. exp Treatment refusal/

13. ((patient ${ }^{\star}$ or healthcare or "health care") and (compliance or cooperat* or co-operat* or adherence or "non-compliance" or noncompliance or "non-adherence" or nonadherence or accept ${ }^{*}$ or nonaccept* or behaviour or behavior)).tw.

14. (educat ${ }^{\star}$ or train ${ }^{\star}$ or counsel ${ }^{\star}$ or "self manag*" or "management plan*" or "care plan*" or "support tool*" or "chronic care mode" or ccm or promot* or psycholog* or psychosocial or teach ${ }^{\star}$ or motivat ${ }^{\star}$ or prefitting or Postfitting or "fitting protocol" or ghabp or "hearing aid orientat*" or HAO or "pre-fitting" or "post-fitting" or ((audio* or aural or auditory) adj rehab*) or "hearing tactic*" or "active fitting").tw.

15. ("take up" or "take-up" or "use" or utilis* or utiliz* or "non-use").tw.

16. 7 and 15

17.9 or 10 or
\#1 TS=(hearing NEAR/6

(loss or impair $\left.{ }^{\star}\right)$ )

\section{\#2 TS=(Hypoacusis or Hy- poacuses) \\ "hearing aid" OR \\ "hearing aids" \\ ICTRP}

\#3 TS=(Presbycusis or Presbycuses)

Clinicaltrials.gov

hearing aid*

\section{\#4 \#3 OR \#2 OR \#1}

\#5 TS=("hearing aid*" OR "ear mold*" OR earmold* OR "ear mould*" OR ear-

\section{\#6 \#5 AND \#4}

\#7 TS=((patient* or healthcare or "health care") and (compliance or cooperat* or co-operat* or adance" or noncompliance or "non-adherence" or nonadherence or accept ${ }^{\star}$ or nonaccept* or behaviour or behavior))

\#8 TS=(educat ${ }^{\star}$ or train ${ }^{\star}$ or

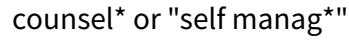
or "management plan*" or "care plan*" or "support tool ${ }^{\star}$ or "chronic care mode" or ccm or promot $^{\star}$ or psycholog* or psychosocial or teach ${ }^{\star}$ or motivat* or prefitting or Postfitting or "fitting protocol" orientat*" or HAO or "prefitting" or "post-fitting" or ((audio* or aural or auditory) NEAR/6 rehab*) or "hearing tactic*" or "active fitting")

\#9 TS=("take up" or "takeup" or use or utilis* or utiliz* or "non-use")

\#10 \#5 AND \#9

\#11 \#10 OR \#8 OR \#7

\#12 \#11 AND \#6 mould $^{\star}$ OR amplif*) herence or "non-complior ghabp or "hearing aid

\section{4. counseling/}

15. exp Patient education/

16. behavior therapy/

\section{7. exp Adaptation psychological/}

18. ((patient ${ }^{\star}$ or healthcare or "health care") and (compliance or cooperat* or co-operat* or adherence or "non-compliance" or noncompliance or "non-adherence" or nonadherence or accept ${ }^{*}$ or nonaccept ${ }^{\star}$ or behaviour or behavior)).tw.

19. (educat* or train* or counsel* or "self manag*" or "management plan*" or "care plan*" or "support tool ${ }^{\star}$ " or "chronic care mode" or ccm or promot* or psycholog* or psychosocial or teach ${ }^{\star}$ or motivat* or prefitting or Postfitting or "fitting protocol" or ghabp or "hearing aid orientat*" or HAO or "pre-fitting" or "post-fitting" or ((audio* or aural or auditory) adj rehab*) or "hearing tactic*" or "active fitting").tw.

20. ("take up" or "take-up" or "use" or utilis* or utiliz* or "non-use").tw. 


\section{FEE D B A C K}

\section{Dr Hashir Aazh, 3 August 2017}

\section{Summary}

"Page 85, Reasons for exclusion is not given correctly for Aazh 2016."

\section{Reply}

We have added extra text in the Characteristics of excluded studies table to clarify why this study was excluded. Although it was a randomised study with hearing aid use as an outcome, the participants were a selected group of non-users. We felt it inappropriate therefore to compare their outcomes with those of the other studies who had not selected in this way.

\section{Contributors}

Feedback: Dr Hashir Aazh. Reply: Dr Fiona Barker.

\section{WHAT'S NEW}

\begin{tabular}{lll}
\hline Date & Event & Description \\
\hline 9 August 2017 & Amended & $\begin{array}{l}\text { We clarified why a study had been excluded in response to feed- } \\
\text { back (Aazh 2016). } \\
\end{array}$ \\
& $\begin{array}{l}\text { We removed the data from one study from the meta-analysis be- } \\
\text { cause this had been entered in error (Beynon 1997). Values for } \\
\text { the mode and interquartile range had been entered instead of } \\
\text { mean and standard deviation. The overall estimate of effect was } \\
\text { unchanged as were the overall conclusions of the review. }\end{array}$ \\
\hline
\end{tabular}

\section{H I S T O R Y}

Protocol first published: Issue 2, 2013

Review first published: Issue 7, 2014

\begin{tabular}{|c|c|c|}
\hline Date & Event & Description \\
\hline 24 November 2016 & Amended & $\begin{array}{l}\text { We made corrections to the 'Risk of bias' assessment for one } \\
\text { study (Ferguson 2016). Following concerns highlighted by the } \\
\text { study authors, we noted errors in the transfer of the 'Risk of bias' } \\
\text { assessment from our paper records to RevMan. We have now as- } \\
\text { sessed this study as being at overall low risk of bias. The main } \\
\text { text of the review has been amended to reflect this. }\end{array}$ \\
\hline & & $\begin{array}{l}\text { We checked the data transfer for the other included studies and } \\
\text { found this to be correct. }\end{array}$ \\
\hline
\end{tabular}




\begin{tabular}{lll}
\hline Date Event Description &
\end{tabular}

We have included an additional systematic review of individual computer-based auditory training in the Discussion section.

The overall results and conclusions of the review are unchanged.

\section{July 2016}

New search has been performed

The review has been updated to include data from an updated
search (June 2016).

11 July 2016

New citation required but conclusions have not changed

\begin{abstract}
We included five new studies (Ferguson 2016; Lavie 2014; Saunders 2016; Thoren 2014; Vreeken 2015), and excluded a further four studies (Aazh 2016; Cardemil 2014; Kuk 2014; Lavie 2013).

We identified three new ongoing studies (ISRCTN77340339; NCT02233361; NCT02264314), and two studies are awaiting classification (Henshaw 2013; Malmberg 2015).

One new combined self-management support/delivery system design study showed a significant effect on adherence to hearing aid use in the short term. Otherwise the results and conclusions of the review are unchanged.
\end{abstract}

\section{CONTRIBUTIONS OF AUTHORS}

FB and SdeL conceived the review question. FB wrote the protocol, review and co-ordinated comments from the other authors.

EM and LE provided clinical advice, content relating to audiology and participated in study selection and data extraction.

SdeL and SJ provided general feedback on the protocol, review text and analyses.

\section{DECLARATIONS OF INTEREST}

Fiona Barker: none known Emma Mackenzie: none known

Lynette Elliott: none known

Simon Jones: none known

Simon de Lusignan: none known

\section{SOURCES OF SUPPORT}

\section{Internal sources}

- University of Surrey, PhD programme, UK.

This review is funded as part of the PhD programme of the first author.

\section{External sources}

- National Institute for Health Research, UK. Infrastructure funding for Cochrane ENT

- National Institute for Health Research, UK. NIHR-Cochrane Incentive Award 2015 (for the update of the review)

\section{DIFFERENCES BETWEEN PROTOCOL AND REVIEW}

We made some revisions to the method regarding definitions of intervention types to provide more theoretical support for our approach using the chronic care model. In particular, we provided additional evidence and rationale for subgroup analyses within the elements of self-management support and delivery system design.

Other changes to the methods included the following: 
We decided to use a random-effects model for all analyses and included our rationale in the full review text.

We had originally intended to enter skewed endpoint data from studies of fewer than 200 participants into additional tables rather than into the analyses. In fact there was a considerable quantity of potentially skewed data with high standard deviations relative to the means. We considered that the risk of not including these data and being able to draw only limited conclusions outweighed the statistical risk of including these data. Where there was a high risk of skew we noted this and downgraded the quality of the evidence if necessary. This allowed us to combine data that would otherwise have been excluded from the meta-analyses.

We revised the outcomes of interest. Originally we had intended to scope the range of outcomes addressed in adult hearing healthcare research. However, we were advised that this introduced additional complexity into an already complex review. We therefore redefined (post-protocol publication but pre-analysis) the primary and secondary outcomes we judged to be of most interest to patients, clinicians and policy-makers. Adherence remained our main primary outcome but we combined self-reported daily hours of hearing aid use and data-logged hearing aid use into a single outcome of daily hours of hearing aid use. Adverse effects were included in the original review protocol as a secondary outcome. During the peer review process we were advised to include this as a primary outcome. We then specified the secondary outcomes of interest.

Some situations anticipated in the protocol did not occur and so some types of analysis could not be performed (such as funnel plots).

\section{N DEX TERMS}

\section{Medical Subject Headings (MeSH)}

Communication; Hearing Aids [ ${ }^{\star}$ statistics \& numerical data]; Hearing Loss [ ${ }^{\star}$ rehabilitation]; Patient Compliance [statistics \& numerical data]; Quality of Life; Randomized Controlled Trials as Topic; Self Care [methods]; Time Factors

\section{MeSH check words}

Adult; Aged; Humans; Middle Aged 